Florida International University FIU Digital Commons

$11-6-2009$

\title{
Environment, Culture, and Medicinal Plant Knowledge in an Indigenous Amazonian Community
}

Christine Labriola

Florida International University, christinelabriola@yahoo.com

DOI: $10.25148 /$ etd.FI09121606

Follow this and additional works at: https://digitalcommons.fiu.edu/etd

\section{Recommended Citation}

Labriola, Christine, "Environment, Culture, and Medicinal Plant Knowledge in an Indigenous Amazonian Community" (2009). FIU Electronic Theses and Dissertations. 143.

https://digitalcommons.fiu.edu/etd/143 


\section{FLORIDA INTERNATIONAL UNIVERSITY}

Miami, Florida

ENVIRONMENT, CULTURE, AND MEDICINAL PLANT KNOWLEDGE IN AN INDIGENOUS AMAZONIAN COMMUNITY

A thesis submitted in partial fulfillment of the

requirements for the degree of

MASTER OF ARTS

in

COMPARATIVE SOCIOLOGY

by

Christine Labriola 


\section{To: Dean Kenneth Furton}

College of Arts and Sciences

This thesis, written by Christine Labriola, and entitled Environment, Culture, and Medicinal Plant Knowledge in an Indigenous Amazonian Community, having been approved in respect to style and intellectual content, is referred to you for judgment.

We have read this thesis and recommend that it be approved.

$\begin{array}{r}\hline \text { Laura Ogden } \\ \hline \text { William Vickers } \\ \hline \text { Dennis Wiedman, Major Professor }\end{array}$

Date of Defense: November 6, 2009

The thesis of Christine Labriola is approved.

$\begin{array}{r}\text { Dean Kenneth Furton } \\ \text { College of Arts and Sciences } \\ \hline \text { Dniversity Graduate School }\end{array}$

Florida International University, 2009 


\section{ACKNOWLEDGMENTS}

I would like to thank the members of my committee, Dr. Laura Ogden and Dr. William Vickers, and especially the chair, Dr. Dennis Wiedman, for their academic guidance, patience, and support. I would also like to thank many other professors in the Department of Global and Sociocultural Studies, the Department of Earth and Environment, and the Department of Biological Sciences for providing me with the background in the methodologies, theories, and literatures needed to conduct this study.

I would also like to thank the Tinker Foundation for awarding a research grant for the

fieldwork, and the Latin American and Caribbean Center for providing this funding opportunity. Thank you also to Project Amazonas for their important role in arranging fieldwork, and most of all I thank the community of Comandancia for their participation, generosity in sharing their knowledge, and inspiration. 


\title{
ABSTRACT OF THE THESIS \\ ENVIRONMENT, CULTURE, AND MEDICINAL PLANT KNOWLEDGE IN AN INDIGENOUS AMAZONIAN COMMUNITY
}

\author{
by \\ Christine Labriola \\ Florida International University, 2009 \\ Miami, Florida \\ Professor Dennis Wiedman, Major Professor
}

Diminishing cultural and biological diversity is a current global crisis. Tropical forests and indigenous peoples are adversely affected by social and environmental changes caused by global political and economic systems. The purpose of this thesis was to investigate environmental and livelihood challenges as well as medicinal plant knowledge in a Yagua village in the Peruvian Amazon. Indigenous peoples' relationships with the environment is an important topic in environmental anthropology, and traditional botanical knowledge is an integral component of ethnobotany. Political ecology provides a useful theoretical perspective for understanding the economic and political dimensions of environmental and social conditions. This research utilized a variety of ethnographic, ethnobotanical, and community-involved methods. Findings include data and analyses about the community's culture, subsistence and natural resource needs, organizations and institutions, and medicinal plant use. The conclusion discusses the case study in terms of the disciplinary framework and offers suggestions for research and application. 


\section{TABLE OF CONTENTS}

CHAPTER

PAGE

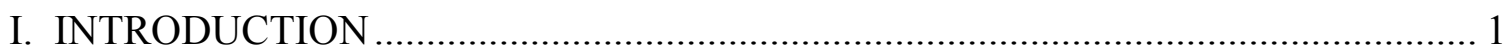

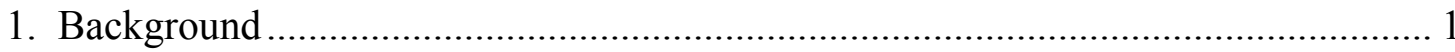

Tropical Forest Cultural and Biological Diversity .................................................... 1

Indigenous People and Environmental Knowledge .................................................. 2

2. The Study: Environment, Culture, and Medicinal Plant Knowledge ........................ 4

Overview and Research Questions .................................................................... 4

Case Study and Research Expectations ................................................................ 5

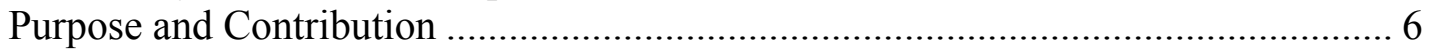

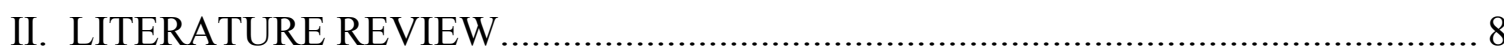

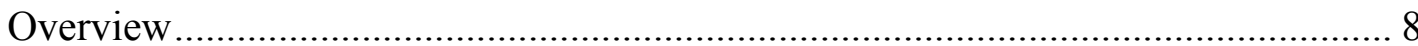

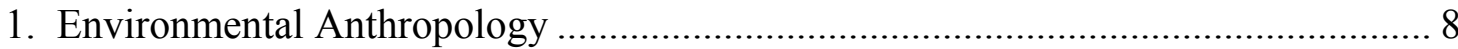

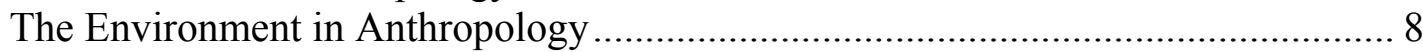

Indigenous People and Biodiversity Conservation ................................................. 10

From Local to Global: Indigenous Communities and Natural Resources ................. 17

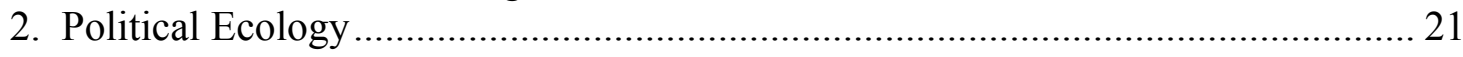

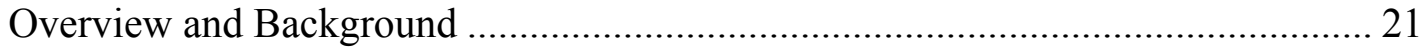

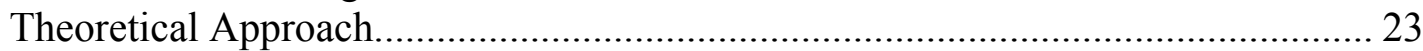

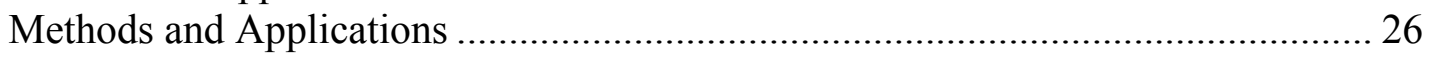

The Amazon Environment and Indigenous Knowledge ........................................... 29

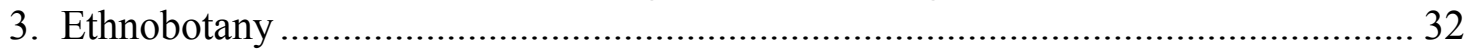

Background, Theory, and Methods................................................................. 32

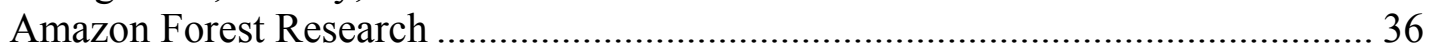

Traditional Botanical Knowledge and Biocultural Conservation............................. 39

Indigenous Medicinal Plant Knowledge ............................................................ 42

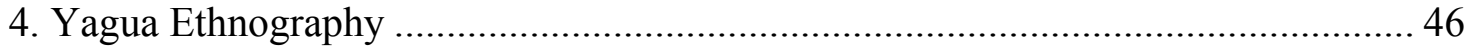

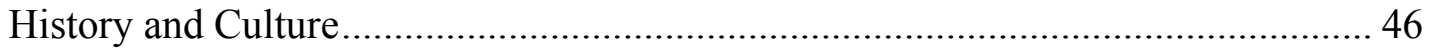

Shamanism, Leadership, and Health.................................................................. 49

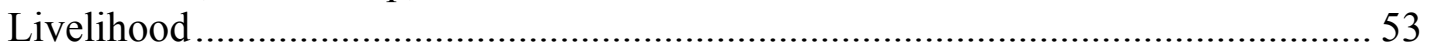

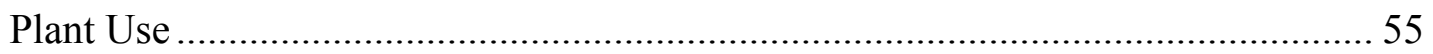

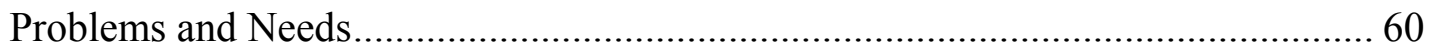

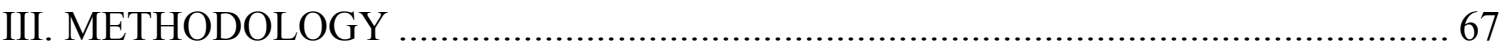

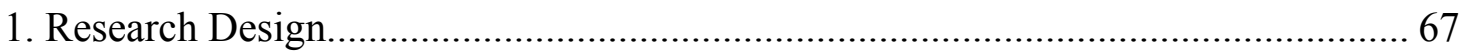

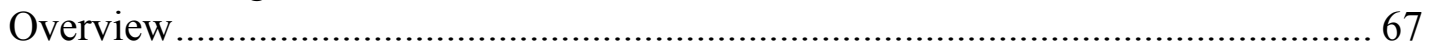

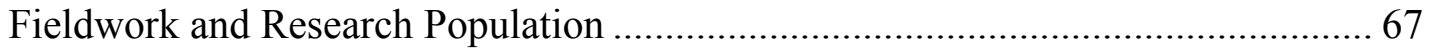

Confidentiality and Benefits to Participants .............................................................. 69

Community Participatory Approaches............................................................. 70

Limitations, Validity, and Reliability …………………..................................... 72

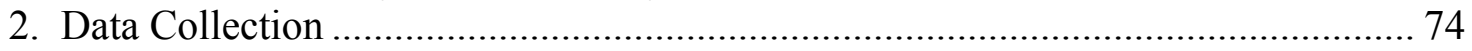

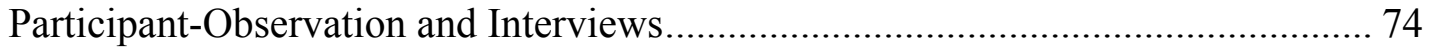


Focus Groups, Meetings, Workshops, and Photographs .................................. 76

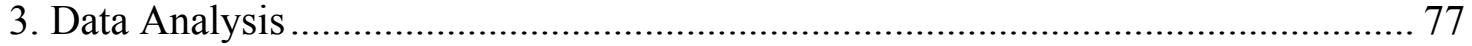

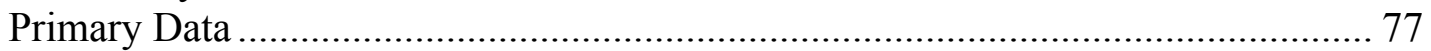

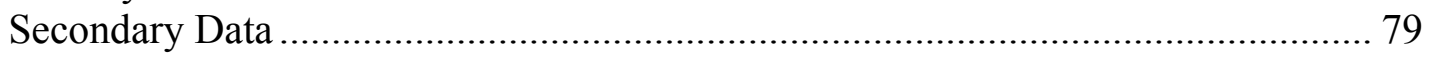

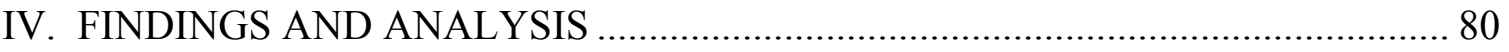

1. The Yagua Community of Comandancia: Social and Cultural Overview.............. 80

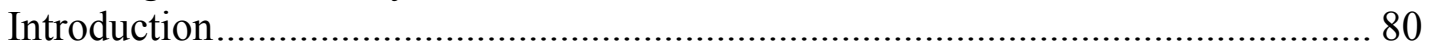

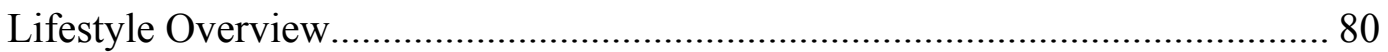

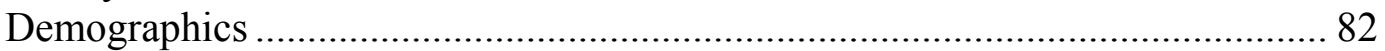

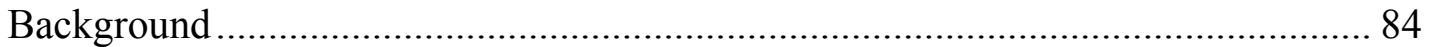

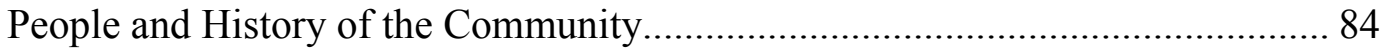

Past Yagua Communities: Culture and Food.................................................... 86

In the Past: Health and Environment .............................................................. 89

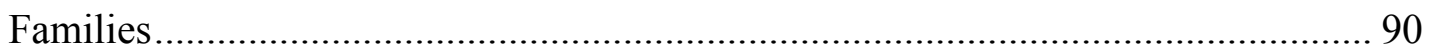

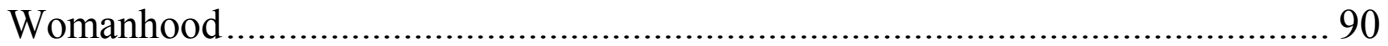

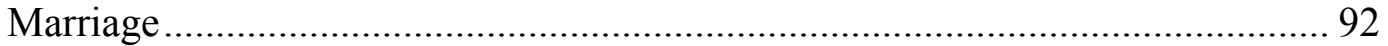

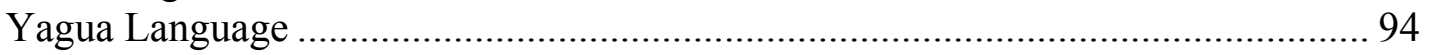

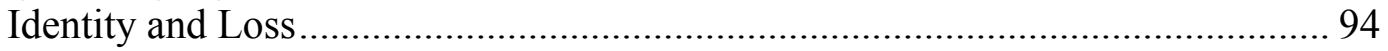

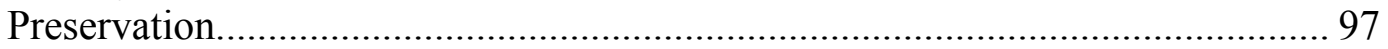

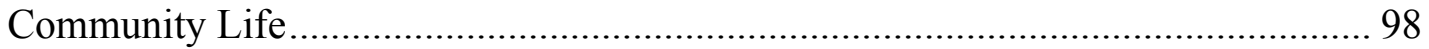

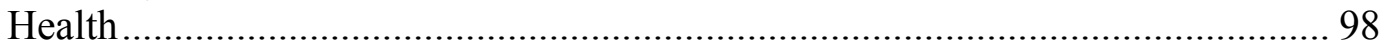

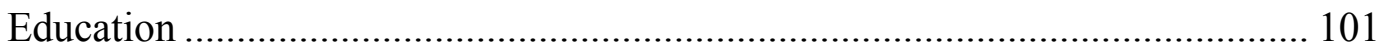

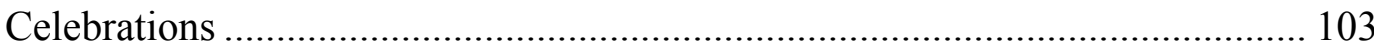

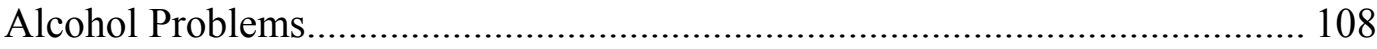

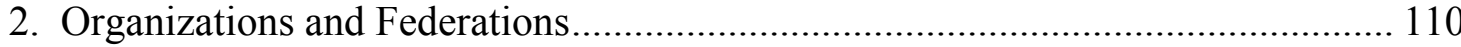

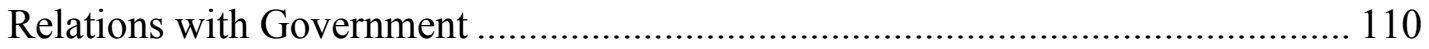

Leadership and Power Problems........................................................................ 112

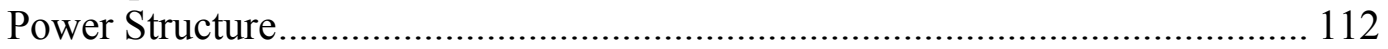

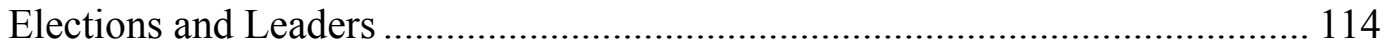

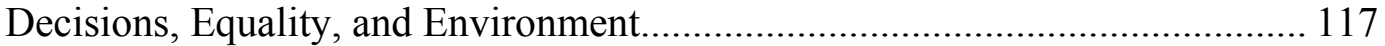

Participation and Communication Problems ........................................................ 119

Community Governance and Organizations ...................................................... 121

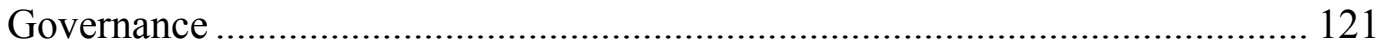

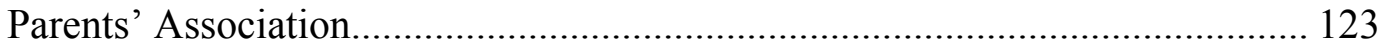

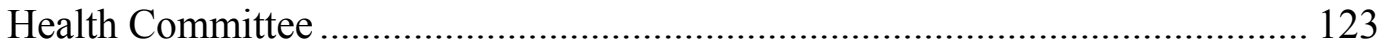

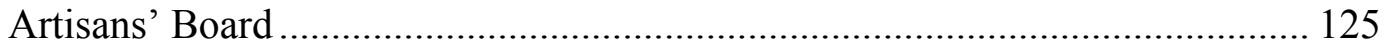

Glass of Milk Committee.......................................................................... 125

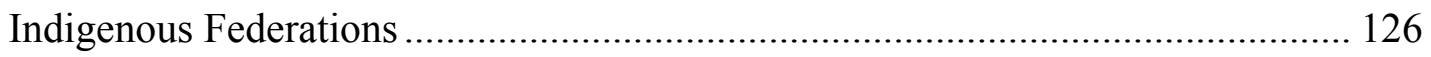

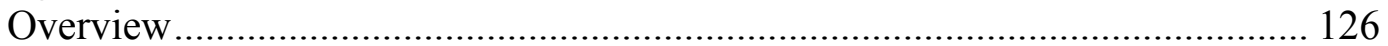

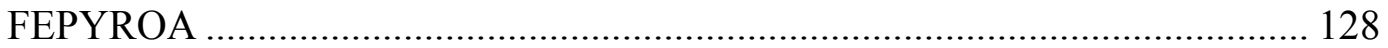

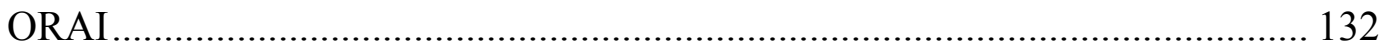

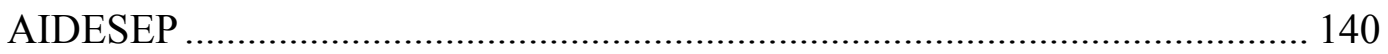

3. Environment and Livelihood ...................................................................... 142

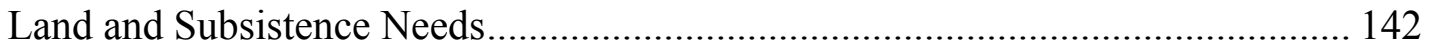




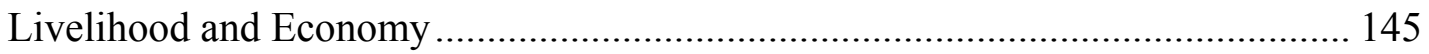

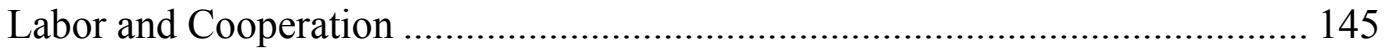

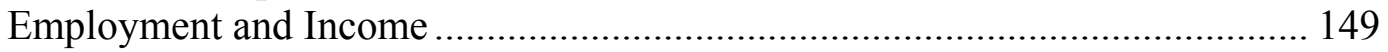

Extractive Activities and Natural Resource Problems.......................................... 152

Extractive Industries and Land Concessions ................................................... 152

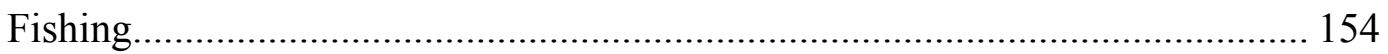

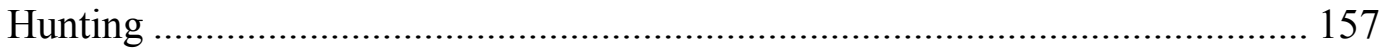

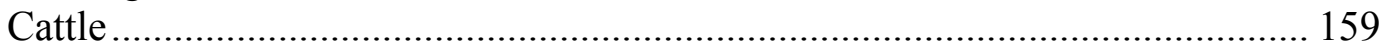

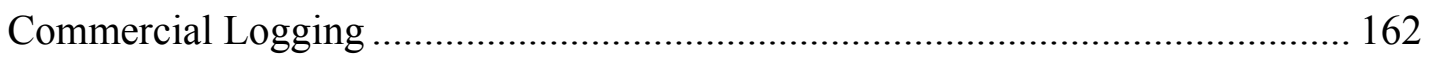

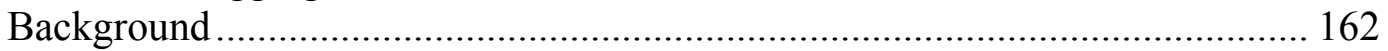

Forestry Policy and Indigenous Communities .................................................. 164

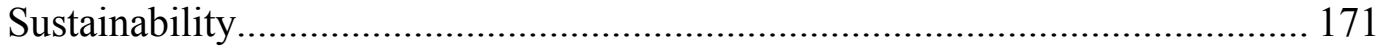

Economic and Livelihood Effects.................................................................. 174

Family and Community Issues....................................................................... 177

Challenges and Potential Solutions....................................................................... 180

4. Traditional Botanical Knowledge and Plant Resource Use .................................. 187

Subsistence and Other Useful Plants .................................................................. 187

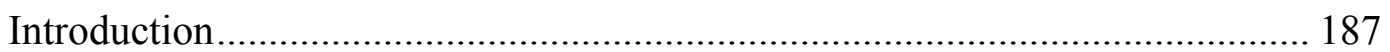

Agriculture, Fruits, Recipes, and Masato......................................................... 188

Handicrafts, Clothing, and Other Items .......................................................... 190

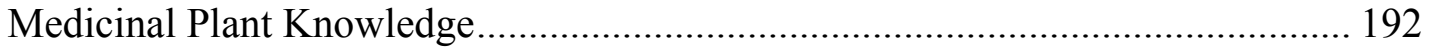

Knowledge and Health............................................................................... 192

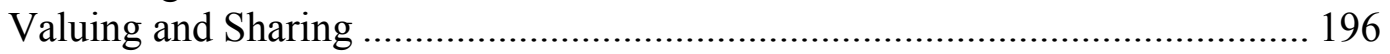

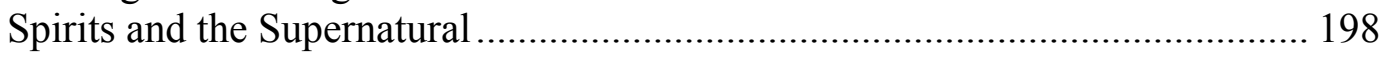

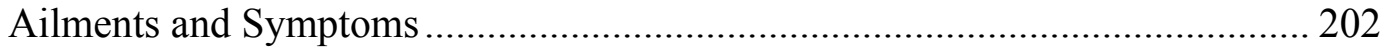

Top Ten Medicinal Plants ............................................................................. 206

Important Community Plants ......................................................................... 211

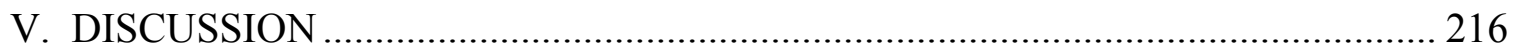

1. Disciplinary and Theoretical Framework ………….......................................... 216

Summary of Research Topics and Findings …………...................................... 216

Environmental Anthropology and Political Ecology ……………......................... 217

2. Culture and Environment from Local to Global: Research and Application.......... 224

Community Needs and Suggestions for Research ………………………............... 224

Environment and Sustainable Livelihood in the Amazon ..................................... 227

Suggestions for Cultural and Biodiversity Conservation........................................ 232

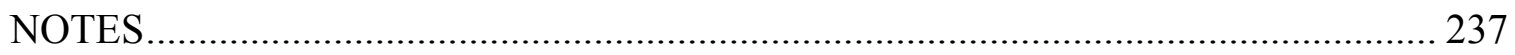

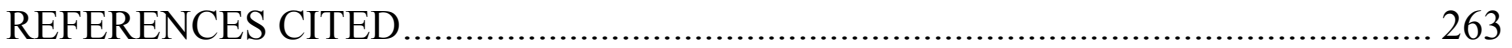




\section{LIST OF TABLES}

TABLE

PAGE

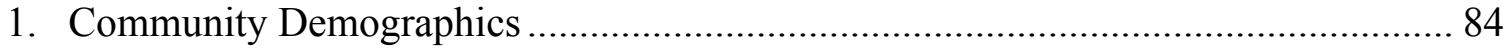

2. Organizations and Leadership........................................................................ 114

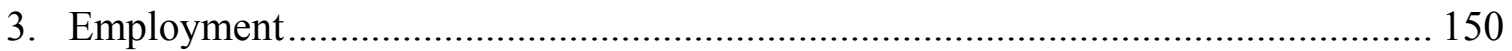

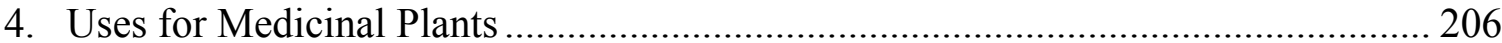

5. Consensus about Top Ten Medicinal Plants....................................................... 207

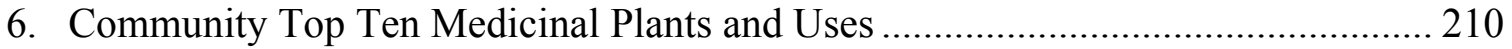

7. Community Top Ten Medicinal Plants Locations ............................................ 211

8. Medicinal Plants Important to Community.................................................... 215 


\section{LIST OF ACRONYMS}

AIDESEP Asociación Interétnica de Desarrollo de la Selva Peruana (Inter-Ethnic Association for the Development of the Peruvian Forest)

APAFA Asociación de Padres de Familia (Association of Parents of Families)

CIFOR .Center for International Forestry Research

COICA................Coordinadora de las Organizaciones Indígenas de la Cuenca Amazónica (Coordinator of the Indigenous Organizations of the Amazon Basin)

FENAMAD........Federación de Comúnidades Nativas del Río Madre de Dios y Afluentes (Federation of Native Communities of the Mother of God River and Tributaries)

FEPYROA ..Federación de Pueblos Yaguas Río Orosa Apayacu (Federation of Yagua Villages on the Orosa and Apayacu Rivers)

IBC. Instituto del Bien Común (Institiute of the Common Good)

ICBG .International Cooperative Biodiversity Group

IIAP ..Instituto de Investigaciones en la Amazonía Peruana (Institute of Peruvian Amazon Research)

INEI. .Instituto Nacional de Estadística y Informática (National Institute of Statistics and Computing)

INRENA. Instituto Nacional de Recursos Naturales (National Institute of Natural Resources)

NGO. .Non-Governmental Organization

NTFP Non-Timber Forest Products

ORAI ..Organización Regional AIDESEP Iquitos (Iquitos Regional AIDESEP Organization)

SICNA......Sistema de Información sobre Comunidades Nativas de la Amazonía Peruana (Information System on Native Communities of the Peruvian Amazon)

TBK Traditional Botanical Knowledge 


\section{INTRODUCTION}

\section{Background}

\section{$\underline{\text { Tropical Forest Cultural and Biological Diversity }}$}

The increasing global concern about loss of species, ecosystems, cultures, languages, and indigenous knowledge systems around the world has made biocultural diversity conservation an important focus in anthropology, ethnobiology, and environmental science. As V. M. Toledo et al. summarize, "The research accumulated in the three last decades by conservation biologists, linguists and anthropologists, ethnobiology and ethnoecology, has converged toward a shared principle: the world's biodiversity will be effectively preserved only by protecting the diversity of human cultures, and vice versa," (2002:561). Yet our globalized economic system, which exploits natural resources and drastically transforms landscapes, continues to contribute to the destruction of the earth's environment and indigenous cultures.

The Amazon, one of the tropical rain forests greatest in biological, cultural, and linguistic diversity, contains an enormous variety of indigenous peoples and incredibly species-rich ecosystems. In this vast, resource-filled area, extractive industries such as oil and logging, supported by state policies, continue to degrade the area's ecosystems and transform local cultures. Deforestation and land conversion to agriculture are also major contributors to global warming, and climate change further complicates both cultural and biological diversity conservation efforts.

The subsistence and health of indigenous peoples in the Amazon are integrally tied to environmental conditions since they depend directly on the plants and animals of their 
ecosystems for almost all of their basic needs. These communities are often in precarious positions, attempting to survive in a market economy while the natural resources that provide their livelihood are being diminished. Cultural and social transitions as well as environmental changes also lead to increasing dependence on the market economy and modern foods and medicines. When their basic subsistence and health needs are not met, higher needs such as education, preservation of cultural knowledge, and biodiversity conservation are difficult to pursue. Industrial development activities in tropical forests and also state governments have largely ignored indigenous communities, knowledge, and needs as well as the environment. Local and international organizations have brought attention to these issues in the last few decades, but much work remains to be done.

\section{Indigenous People and Environmental Knowledge}

Since indigenous Amazonian communities utilize plants, animals, and other natural resources to survive, they usually possess detailed knowledge about them. Most of the major food plants and many of the modern medicines utilized by the "developed world" originated in traditional cultures. Interest in indigenous peoples' knowledge about nature - traditional environmental or ecological knowledge - has increased in the last few decades, especially for tropical and high-diversity habitats. The study of indigenous natural resource use has also informed cultural and biodiversity conservation efforts. Indigenous environmental knowledge enables people to use their natural resources for food and medicine, but cultures and the natural world are increasingly transforming, a problem exacerbated by extractive industries. 
The concept of indigenous environmental knowledge has been categorized into a number of different terms, each with its own acronym. A focus of this study centers on Traditional Botanical Knowledge (TBK), defined in the field of ethnobotany by C. M. Cotton as:

the total botanical knowledge held by any non-industrial community and incorporates all utilitarian, ecological, and cognitive aspects of both plant use and vegetation management... encompasses all types of knowledge...including that concerned with the identification, processing and management of plants used in subsistence, material culture and medicine, while considering this knowledge within its original spiritual and sociological context. (Cotton 1996:60)

I find this treatment of knowledge as an entity with boundaries to be problematic, and I do not document the total knowledge of the community, so my use of this term does not strictly adhere to this definition.

Medicinal plant knowledge, a type of traditional botanical knowledge, is an important part of indigenous environmental knowledge. In tropical ecosystems, traditional health remedies consist of recipes that use medicinal plants, and billions of people worldwide use plant medicines when treating illnesses. Indigenous cultural knowledge about how to use these natural resources often declines with modernization and consequently disappears over time, a loss of centuries of experience and information. Communities' subsistence, health, and culture are dependent upon both their access to natural resources and the continuation of their knowledge about how to use them.

Indigenous livelihoods are now almost ubiquitously involved in some way with the market economy, and peoples' struggles for access to natural resources and for cultural rights have connected them with a number of economic, political and social actors. Investigating indigenous environmental knowledge requires not only researching 
local level information about plant uses, but also understanding how uses of forest products at a global level affect this knowledge. Studies with Amazonian indigenous communities affected by extractive and other industries have increased our understanding of indigenous knowledge and environmental change, but both research and application continue to be urgently needed. This thesis in applied environmental anthropology investigates the changing natural and social environment and also medicinal plant knowledge in a Yagua community in the Peruvian Amazon.

\section{The Study: Environment, Culture, and Medicinal Plant Knowledge}

\section{$\underline{\text { Overview and Research Questions }}$}

This research focuses on an indigenous Amazonian community's relationship with the environment at two levels: current livelihood, and traditional knowledge. First, it investigates their natural resource and social conditions as well as their subsistence, health, and other needs. To connect the local level to national and global influences, this study examines the roles of community and indigenous organizations as well as other stakeholders in local natural resource use. Second, since environmental and cultural changes threaten indigenous knowledge and since health is a community problem, this research also documents ethnobotanical knowledge about medicinal plants. Anthropological methods have been used to explore the community's perspective on these environmental, social, and cultural issues as well as to involve community members 
in the process of documenting medicinal plant knowledge and other aspects of Yagua culture.

The main research questions this study addresses are:

- What environmental, cultural, and social changes are affecting the community?

- What is some of the community's medicinal plant knowledge?

This research also explores:

- Subsistence, livelihood, and health needs

- Stakeholders and issues involved in land use and natural resource access

- The role of community organizations and indigenous federations

○ Community participatory methods to document cultural knowledge

\section{Case Study and Research Expectations}

The Yagua community of Comandancia in the Peruvian Amazon possesses several qualities that make it a good site for research on environmental and cultural change, community needs, and indigenous plant knowledge. Extractive industries have become more active in the region under new natural resource policies, including forestry laws granting concessions to logging companies. Men from the community now work for the logging industry, which may cause economic and social changes. Other extractive industries such as commercial fishing may also be challenging their access to natural resources.

This particular community is actively involved in indigenous organizations since their local Yagua indigenous federation is based there, and a community member also holds a leadership position in the regional indigenous federation headquartered in Iquitos. These 
organizations are involved in indigenous rights, livelihood, and cultures, and they are also working with NGOs to establish protected areas in the region. Comandancia has also participated in a number of projects through the NGO Project Amazonas, which also facilitated arranging this research, as described in the methodology section below. The Yagua of Comandancia also use their traditional medicinal plants to treat illnesses.

At the onset of this study, I expected that the activities of extractive industries would be detrimentally affecting the community, probably contributing to subsistence, livelihood, and health needs. I also expected the community's ethnobotanical knowledge would be similar to that of other Amazonian indigenous groups, and that this medicinal plant knowledge would cover a wide variety of plants for their most common ailments.

\section{Purpose and Contribution}

The purpose of this study is to explore the combination of elements affecting the community's natural environment and culture from their local perspective, and also to investigate and document their medicinal plant knowledge. Researching indigenous environmental knowledge contributes to the ethnosciences and environmental anthropology. Ethnographic research with the Yagua of the Peruvian Amazon is mostly dated, and in this particular community, no anthropological or ethnobotanical research has been conducted. This study provides current information about the community's needs and documents other aspects of Yagua culture as well.

Also investigated in this research are elements of the political ecology theoretical perspective in which power over natural resources is unequally distributed in the modern world economy, adversely affecting groups like indigenous peoples. The findings from 
this study provide an overview of the roles of community organizations, indigenous federations, policy, and industry in the way natural resources are controlled and accessed in this community. However, this research does not establish the precise relationships among all of the stakeholders in the local environment.

Community participatory methods were utilized to involve community members in documenting their own cultural and environmental knowledge, and in reflecting on their needs. Valuing, teaching, and utilizing medicinal plant knowledge can provide benefits to communities including: sharing this important cultural resource among themselves, transmitting it to future generations, improving the community's livelihood and health, providing incentives for natural resource conservation, and empowering community members. Findings from this research could also be applied to projects addressing community subsistence, health needs, traditional knowledge, or natural resources.

In the literature review that follows, I discuss environmental anthropology, political ecology, ethnobotany, and Yagua ethnography in relation to this study. In the methodology chapter, I describe the research design, data collection, and analysis. I discuss the community's lifestyle and culture, organizations and indigenous federations, livelihood and environmental issues, and traditional botanical knowledge in the findings chapter. In the final section, I analyze the data in terms of the disciplinary framework and provide suggestions for research and application. 


\section{LITERATURE REVIEW}

\section{$\underline{\text { Overview }}$}

Several disciplines that investigate human-environment relationships provide theories and methods useful for researching the environment and plant knowledge of an indigenous community. Four areas have informed this research, each contributing differently to the study. Environmental anthropology provides a broad disciplinary framework, so below I first explain recent approaches to and issues regarding indigenous people, knowledge, and conservation. Next, I outline political ecology as a theoretical approach for understanding environmental change's ties to the political and economic forces that influence Amazonian resource use. Ethnobotany is a focus of the study, so I then describe research in traditional botanical knowledge for biocultural diversity conservation and indigenous medicinal plant knowledge in the Amazon. Finally, I summarize from existing Yagua ethnographic research the cultural and plant use findings that are relevant to this study. The combination of these four topics provides background for understanding the community of Comandancia's environment, culture, and knowledge through the study's findings that follow.

\section{Environmental Anthropology}

\section{The Environment in Anthropology}

Investigating the natural environment and the relationships humans have with it has become an important subfield in anthropology. Recent environmental anthropology has largely focused on local to global understanding of and greater anthropological 
involvement in environmental issues and the communities affected. Peter Brosius (1999:280-281) describes environmental anthropology as investigating discourse, power, knowledge, resistance, development, cultural studies, and political ecology through transdisciplinary work, and he identifies three major current trends: a critique of essentialized images, an emphasis on contestation and consideration of stakeholders, and an interest in globalization.

Distinctions are sometimes made between "environmental" and "ecological" anthropology, a discussion beyond the scope of this thesis. Summarizing Brosius' (1999:278) contrast of them, he explains that environmental anthropology draws from poststructuralist theory, political economy, and globalization, and therefore pays more attention to issues of power and inequality. Conrad Kottak (1999) distinguishes between the "old" and "new" ecological anthropology, stating that the new approach links global to local systems, blends theoretical and applied research, focuses on political aspects, and recognizes culture as mediating in ecological processes rather than as merely an adaptive tool.

Increasing interest in environmentalism in recent years has shaped anthropology's role in analyzing these efforts. Brosius (1999:277) believes the goal is not simply to understand human impact on the environment, but also to investigate how the environment is constructed, represented, and contested, recognizing the power of discourse in creating reality, especially in the perpetuation of structures of domination. He discusses the recent growth of environmental NGOs, national agencies, and transnational institutions concerned with the environment as well as the resulting theoretical trends in anthropology that critique environmental movements, rhetoric, and 
representations of indigenous people. He also describes eco-politics, community-based conservation, and environmental racism as other current topics of interest in environmental anthropology.

Environmental anthropology has also investigated indigenous environmental or ecological knowledge, a topic this study focuses on, discussed more below from the ethnobotanical perspective. In reviewing the recent proliferation of anthropological interest in indigenous knowledge, Paul Sillitoe (1998) describes it as an important new anthropological method that involves collaboration with subjects, community participation, and cooperation between social and natural sciences. According to Benjamin Orlove and Stephen Brush (1996), anthropologists have advocated for human knowledge to be a component of plant genetic resources in folk classification studies in ethnobiology and behavioral research in cultural ecology, and recent intellectual property rights debates have also included anthropologists.

\section{Indigenous People and Biodiversity Conservation}

An important debate in environmental anthropology and the conservation sciences has centered on a discussion about how "conservation-oriented" indigenous people are. Amazonian examples have been frequently cited, and arguments have ranged from claiming an indigenous "conservation" ethic evident in resource management (Posey 1982) to denial of this (Parker 1993), with a number of other positions in between. Other

lines of research in environmental anthropology have also contributed to the rethinking of indigenous people's relationship with the environment. One of the most important paradigm shifts has been the discrediting of the pristine or virgin forest myth because of 
research showing the anthropogenic origin of many Amazonian ecosystems and their diversity (Balée 1989; Smith 1999). In many of the discussions that followed, indigenous knowledge of nature has sometimes been confused or conflated with indigenous protection of nature.

In response to the lack of success of some conservation interventions in indigenous communities, Kent Redford (1991) coined the term and articulated the idea of the "ecologically noble savage." He argues that the relationship that indigenous people have with nature is not innately conservationist, but instead pragmatic since they rely directly on their environment for all aspects of livelihood. Critiquing development as well as conservation efforts that operate using the noble savage model, (the idea that indigenous people are in "harmony" with nature), he points to numerous examples that show that indigenous people are not immune to being forced or convinced into accepting new methods, crops, and technologies. He emphasizes that there is no cultural mechanism that prevents Indians from improving their lives or feeding their families, even at the expense of natural resource sustainability, and he argues they should certainly not be blamed for partaking in the modern world. In summary, Redford concludes that: "To believe that when confronted with market pressures, higher population densities, and increased sedentism most indigenous peoples will maintain the integrity of their traditional methods is not only to argue against the available evidence, but worse, to fall into the ideological trap that produced the ecologically noble savage," (Redford 1991:48).

Manuela Carneiro da Cunha and Mauro de Almeida (2000), however, argue that some indigenous people might be cultural although not natural conservationists. They devise three categories of environmentalism: ideology without practices, practices and ideology, 
and practices without ideology, and they argue that many indigenous cultures fit within the latter two of these categories. Although this study of the community of Comandancia will not assess their resource use in terms of Western conservation goals, it is interesting to note that Carneiro da Cunha and de Almeida cite the Yagua as a classic example of a "conservationist" group in both ideology and practice:

Second is the case in which sustainable practices and cosmology are both present. Many Amazonian indigenous societies uphold a sort of Lavoisierian or zero-sum ideology in which all things, including life and souls, are recycled. Theirs is an ideology of limited exploitation of natural resources in which human beings are the sustainers of the equilibrium of the universe, nature and supernature included. Values, taboos on food and hunting, and institutional or supernatural sanctions provide the instruments for them to act according to this ideology. Such societies could easily fit into the category of cultural conservationists. The Peruvian Yagua example comes immediately to mind. (Carneiro da Cunha and de Almeida 2000:8)

Some studies have shown Amazonian examples of increased biodiversity as a result of indigenous resource management, but Allyn Stearman (1994) concludes that this occurs not because of a conscious "conservation" effort as in modern Western environmentalism, but rather as a result of producing for subsistence and livelihood needs. Having a stake in the land also influences traditional Amazonian people's use of low-impact techniques. However, most examples of sustainable indigenous ecosystem management are found only where there is low population density, abundant land, and little involvement with the global market economy, conditions which rarely exist today in the neotropics (Carneiro da Cunha and de Almeida 2000; Redford 1991).

These discussions have been important because indigenous peoples are a dimension of civil society that overlaps with global biodiversity conservation concerns. The previous exclusionary conservation model that portrayed Indians as obstacles to environmental efforts had been replaced by an approach that was more inclusive, but that 
was based largely on ecologically noble savage ideology. Contemporary anthropological investigations of indigenous and environmental movements have addressed the similarities and differences of these agendas. Redford and Stearman (1993:249-250) describe how in a 1989 declaration written to environmentalists, the Coordinadora de las Organizaciones Indigenas de la Cuenca Amazónica (Coordinator of the Indigenous Organizations of the Amazon Basin) (COICA) expressed indigenous peoples' concerns that environmentalists had not included them in plans for Amazonian preservation and that indigenous organizations had not been involved in the political process, even though they had never delegated power to environmentalists. The indigenous federation specifically asked for recognition of ownership rights, self-representation, partnerships, "debt for stewardship" efforts, a permanent dialogue, support, acceptance, and an alliance. Highlighting the problematic aspects of the differences between the conservation agenda and the indigenous agenda in the Amazon, Redford and Stearman discuss how indigenous sustainability ideologies and practices are both varied and also changing quickly through modernization. They argue that conservationists cannot demand that indigenous people limit technology or retain traditional resource use, concluding that supporting indigenous land rights is still the best hope for conservation.

Another critique centering on the treatment of indigenous people by international environmental actors in the Amazon is Beth Conklin and Laura Graham's (1995) examination of the implications of linking local indigenous struggles with global conservation efforts and organizations. They argue that environmental NGOs allied with indigenous leaders partially to legitimize their foreign involvement and partially based on unrealistic misconceptions about Indian society. Indigenous groups, in turn, utilized the 
international attention to advance their land and resource rights objectives. The authors explain that problems have arisen because the two agendas are very different and also because indigenous representatives do not always account for the interests of their usually egalitarian communities when making economic and other choices with outside stakeholders. They conclude that the environmental-Indian alliance is asymmetrical, and that support for indigenous causes should be based on realistic understandings of Indians. Calling for further anthropological work, they argue that the way indigenous people are understood and depicted is increasingly important since they are now connected to the outside world.

Delving further into the indigenous-environmental interplay in the Amazon, Conklin (2002) analyzes the strategic use of shamanism and indigenous knowledge to leverage political power. She describes how aligning with the environmental movement had supported indigenous people internationally, but had alienated them nationally. Therefore, native activists have since allied with the Brazilian State against the threat of biopiracy, using the opportunity to claim a national identity as citizens that guard environmental and indigenous knowledge. She explains that by emphasizing shamanic and other privileged, cultural knowledge more then indigenous environmental practices, indigenous identities negotiate between globalism and nationalism and between local indigenous struggles and the international environmental movement. As these examples illustrate, problematizing the "other" in anthropology has informed current understandings of indigenous people by challenging the ecologically noble savage myth and critiquing perceptions of them. 
Reviewing these recent anthropological treatments of the relationship between indigenous people's struggles and global conservation efforts, Jim Igoe (2005) summarizes the problems and disparities that have occurred. He argues that indigenous activists have had to utilize "strategic essentialism" in order to articulate their problems to distant audiences and have had to assert that their environmental values are consistent with Western conservation principles in order to compete for funding (Igoe 2005:283). He explains that these spiritual and environmental standards are impossible for indigenous people to achieve in practice, and their situation is confounded by the difficulty of being both traditional and also negotiating complex modern international bureaucracies. As a result, he says that many Western conservationists then deemed indigenous people unworthy of being "conservation partners" since they are not “ecologically noble."

In assessing the relationship between indigenous people and environmental sustainability, Orlove and Brush (1996) favor pragmatic solutions to coordinate local populations and conservationists in what may be the second best option for both sides. They argue that anthropologists have shown that customary resource extraction is usually compatible with conservation and that alliances can sometimes be made between these populations and conservationists, although they also warn about essentializing ecological nobility. Because of the problems of organizational and communicative incompatibilities, they contend that co-management and community-based conservation efforts have had mixed results.

Finally, it is important to note that many factors affect the sustainable use of natural resources. Research on communities and forests has shown that a variety of physical, 
socioeconomic, demographic, institutional, human incentives and behavior, and ecosystem factors influence a community's use of the forest (Gibson, et al. 2000). The case studies in Gibson et al. 2000, for example, analyze a range of products and user groups in a diversity of conditions and show that multiple processes are involved and vary in each individual case, demonstrating that national or even regional-level policies might not fit local circumstances. This work and similar studies have illustrated that in terms of governance and management of natural resources, local level institutions play a critical role. The authors conclude that user groups, property rights systems, types of forest commodities, and rule enforcement are the major non-biological factors that determine forest condition. Carneiro da Cunha and de Almeida (2000) also emphasize the importance of conservation rules, legitimate leadership and institutions, and alliances with NGOs, academics, and governmental institutions. Other research such as Rocheleau and Edmunds' (1997) work elucidates the additional variables of gender, customary norms, and other internal structures that affect access to natural resources.

Expanding on the attention to types of institutions, regulatory practices, and behavior, Arun Agrawal (2005) applies ideas from Foucault and postmodernism to the analysis of communities and environmental preservation. He offers an approach he calls "environmentality" that links together the ideas of power/knowledges, institutions, and subjectivities to understand how political relationships play out to regulate and protect the environment (Agrawal 2005:8). In the findings from this study of the Yagua community of Comandancia, I attempt to identify some of the social, economic, and institutional factors that may play a role in the their natural resource use. 


\section{From Local to Global: Indigenous Communities and Natural Resources}

Other recent anthropological critiques have focused on how outside environmental and conservation projects are implemented on indigenous lands, advocating the need for better understanding of local situations. Stearman (1994) argues that generalizing about indigenous practices has contributed to conservation and development policies that often disregard the specificities of site and human population characteristics. Margarita Serje (2003) discusses an example of an NGO that attempted to organize, manage, and plan projects for indigenous people in the Columbian Amazon according to a Western system of democracy and liberal market economy. She explains that the premise of the NGO as well as of the Columbian government that granted territorial management to indigenous communities was that the Indians would guarantee biodiversity preservation according to ecological Indian and virgin forest myths. Her analysis is that although the NGO idealized Indians, imagining they would prefer the traditional and spiritual instead of the material, the NGO simultaneously - and ironically - utilized modern planning and management techniques and democratic institutional ideas while claiming to attempt to strengthen indigenous identity. As a result, she concludes, indigenous knowledge was transformed into a resource for planning and development, and she argues that these types of projects do not address the asymmetries of capital and access to state decisionmaking.

Mac Chapin's (2004) analysis of the local effects of the largest international conservation organizations centers on how their programs that involved alliances with local communities were replaced by large-scale scientific conservation strategies, leading to the undermining of both community and conservation goals. He explains that 
integrated conservation and development projects have mostly been failures because few community partnerships were formed, indigenous people never designed or ran the projects, conservationists had little community experience, smaller, local NGOs were excluded, and biodiversity conservation and science were prioritized. He argues that: "As corporate and government money flows into the three big international organizations that dominate the world's conservation agenda, their programs have been marked by a growing conflict of interest - and by a disturbing neglect of the indigenous peoples whose land they are in business to protect," (Chapin 2004:1).

Chapin (2004) also addresses the political and financial factors that he suggests may play a greater role than science, in large part because conservation NGOs receive funding from multinational corporations that are involved in oil, pharmaceuticals, and mining. These partnerships exacerbate indigenous peoples' conflicts with national governments and corporations over natural resources. He also points to the issue that although the foundations that financially support these NGOs have been concerned about the exclusion or abuse of traditional peoples, conflicts of interest also include people who hold positions in both NGOs and the foundations that fund them. In conclusion, Chapin advocates cooperation among groups and a renewed effort to form local partnerships. Since conservationists are not accountable to anyone, he also calls for independent evaluations by the other sectors and continued discussions about protecting biological and human diversity. Since many critiques along these lines have increasingly appeared in the literature, it seems there is great room for improvement of conservation projects involving indigenous people in the Amazon and elsewhere. 
In assessing these developments in indigenous communities and conservation efforts, Igoe (2005) argues that successful biodiversity conservation requires approaches that are flexible enough to both adapt to the complexities of the specific local conditions of ecosystems and human communities and also account for the more universal forces and processes involved. "Supporting particular paradigms or policies by ignoring the realities for which they cannot effectively account may grease the wheels of bureaucratic machines, but it does not change the fact that effective conservation and indigenous liberation must ultimately occur in local circumstances," he asserts (Igoe 2005:386). Although solutions must be locally specific, he identifies the foundation for successful indigenous and conservation partnerships:

alliances between conservationists and indigenous communities are more likely where indigenous peoples have legal authority over natural resources; where they have been allowed to live inside protected areas; where indigenous leaders have good accountability to their constituency; and where indigenous peoples initiated the relationship with conservationists rather than vice versa. (Igoe 2005:386)

Many anthropologists believe that their work can help to bridge the objectives of these different stakeholders through research and policy analysis of environmental issues (Ervin 2005). Orlove and Brush (1996) describe how anthropological research has made positive contributions to biodiversity conservation by encouraging and advocating for the participation of local people in conservation projects. They argue that anthropology has been especially important for documenting local knowledge and practices, elucidating the different goals of local populations and international conservationists when local people participate in projects, and being involved in policy debates and advocacy through NGOs and other agencies. From isolated regions to multiple stakeholders, they explain, anthropological research has focused on management of common property resources, 
relations between states and locals, and the political organization of institutions involved in conservation. Brush (1993) also advocates increased anthropological attention to intellectual property rights of indigenous people for their traditional knowledge, conservation of biodiversity and indigenous knowledge, and ensuring economic benefits for indigenous communities.

A number of other multidisciplinary approaches have been addressing indigenous natural resource needs and environmental concerns, and best practices can be applied from the range of areas involved in biological and cultural diversity conservation. As Fikret Berkes (2004) describes, a number of emerging interdisciplinary fields focusing on common property, traditional ecological knowledge, environmental ethics, political ecology, and environmental history have been pursuing social-environmental interactions and informing current conservation strategies. He identifies paradigm shifts towards a systems view, inclusion of humans in the ecosystem, and participatory approaches to ecosystem management as the basis for community-based conservation.

Most importantly, indigenous people's natural resource and other needs must be addressed. In Indigenous Peoples and the Future of Amazonia: An Ecological Anthropology of an Endangered World, Leslie Sponsel (1995) calls for research that focuses on the needs of indigenous communities:

If we are to increase the relevance of anthropological research for these communities... then two themes deserve much more attention: [1.] indigenous adaptations to the challenges presented by the cultural and environmental impacts of Western society, and [2.] the immediate application of anthropological research to the needs, interests, priorities, and rights of indigenous societies, such as in providing information directly to them, recognizing their intellectual property rights, and promoting their self-determination. (Sponsel 1995:12) 
Also advocating an applied anthropological focus on indigenous communities and access to natural resources, Michael Painter explains:

Ultimately, we are talking about who wins and who loses in the struggle for the resources upon which many depend to produce and, through their production, to survive and prosper. Environmental destruction and economic underdevelopment are a consequence of relationships between people with diverse and conflicting economic interests. (Painter 1995:34)

In conclusion, one of the major themes of recent environmental anthropology has been connecting local level indigenous knowledge and needs with global level resource use and conservation efforts. The above theoretical perspectives and Amazonian research have informed my understanding of indigenous people's relationships with the environment, and this study of the Yagua community of Comandancia investigates a local level perspective on natural resource and other needs in a changing environment.

\section{Political Ecology}

\section{Overview and Background}

Political ecology, a field that has evolved over the last few decades, investigates the political and economic dimensions of environmental and social change. As a theoretical approach, it is utilized in fields such as geography, anthropology, sociology, environmental history, and development studies to study the influences of the state and the market on the environment. In environmental anthropology, increased attention to the social, political, and economic underpinnings of environmental change and its effects on local communities contributed to the development of political ecology. Recent ideas in environmental anthropology about human-environment relationships have therefore 
grown through the influence of political ecology's examination of power, institutions, and economy in explaining environmental change and social inequalities. Below I summarize the background and main theoretical framework of the field, and then I focus on research and ideas about Amazonian forests and people.

Paul Robbins defines political ecology as: "empirical, research-based explorations to explain linkages in the condition and change of social/environmental systems, with explicit consideration of relations of power" (2004:12). In deconstructing humanenvironment relationships, Arturo Escobar replaces the baggage-laden terms nature and society with biology and history, defining political ecology as "the study of the manifold articulations of history and biology and the cultural mediations through which such articulations are necessarily established" (1999:3).

Roderick Neumann (2005) describes how anthropologists and geographers conducting research in rural development and cultural ecology had been concerned about the relationship between poverty and environmental degradation, the role of Northern technologies in developing nations, and the supposed benefits of market relations. The main initial premise of political ecology was that "ecological problems were at their core social and political problems, not technical or managerial, and therefore demanded a theoretical foundation to analyze the complex social, economic, and political relations in which environmental change is embedded" (Neumann 2005:5).

The term "political ecology" was coined by Eric Wolf in 1972 (Neumann 2005), and Marxist political economy, critical development research, dependency theory, world systems theory, environmental history, and others provided theoretical influences on its development. Richard Peet and Michael Watts (1996) describe how the field began in 
the late 1970s when critical deconstruction was used by geographers, anthropologists, and historians to reject major features of ecological anthropology and cultural ecology. Robbins (2004) notes that aspects of cultural ecology that were retained by political ecology include the materialist focus on modes of production and the attention to local environmental knowledge and practices.

Robbins (2004:7-12) explains that political ecology also provides an alternative to a number of "apolitical ecologies," non-political explanations of environmental change. These include: ecoscarcity, which utilizes Malthusian population theory and is still applied in current population policy; modernization, which claims that management is inadequately implemented; forms of sustainable development, which combines economic growth and conservation; as well as diffusionist and other theories. He argues that not only do these ideas assume Western superiority, but by diverting attention away from political and economic causes, they are actually not "apolitical" because they support rather than question dominant political and market systems (2004). Raymond Bryant and Sinead Bailey (1997) discuss how political ecology is still considered a "radical" discipline since in contemporary policy, environmental crises are still seen as local demographic problems due to an overabundance of poor people or as underdevelopment problems requiring market and technology solutions from the West.

\section{Theoretical Approach}

Robbins (2004) describes the basis of political ecology theory as the premise that differential power and unequal distribution lead to social and environmental outcomes that favor some, exploit others, and degrade the environment. In political ecology, 
"environmental change and ecological conditions are the product of political process," he explains, so the costs and benefits associated with environmental change are distributed unequally among actors, reinforcing and causing their social, economic, and political inequalities (Robbins 2004:11).

Some scholars, such as Peet and Watts (1996), claim that political ecology has no cohesive theories, but Robbins (2004:127-202) disagrees, identifying four specific theoretical claims that correlate to four theses. He describes and provides examples of what he calls the dominant theses of political ecology: (1) degradation and marginalization, (2) environmental conflict, (3) conservation and control, and (4) environmental identity and social movement. Neumann (2005) defines the general questions that the field addresses as: how is the relationship between society and nature conceptualized, how is access to land and resources controlled, and how are environmental costs and benefits distributed?

Although political ecology originated in a materialist framework, much of the field's later theoretical development has been influenced by the paradigm of poststructuralism. In examining its manifestations in political ecology, Neumann (2005) discusses how the concepts of knowledge, power, truth, and cultural difference have been useful in critiquing development theory. He explains that political ecology's interest in cultural politics and symbolic meaning, the symbolic struggles at the core of material struggles, and new social movements based on socially constructed ideas of race, gender, and ethnicity can all be traced to poststructuralism. Peet and Watts (1996) focus on social movements in the third world, using the term "liberation ecology" to better reflect the relationship of the environment to new social movements. "Liberation ecology integrates 
critical approaches to political economy with notions derived from poststructural philosophy," Peet and Watts explain (1996:260).

According to Robbins (2004:113-118), political ecologists utilize the concept that nature is socially constructed. Neumann (2005:9), for example, labels his stance "critical realism" and argues that "the environment" outside of human perception and knowledge does exist, but that our knowledge is only a representation of reality, not reality itself. Arturo Escobar $(1996 ; 1999)$ discusses further the use of poststructural theory in political ecology, arguing that since nature is socially constructed, it must be analyzed discursively, not just materially. He articulates a theory of nature that includes the many forms in which it is culturally constructed and socially produced while still acknowledging its biophysical basis (Escobar 1999). Capitalism and modernity, not biology, are what depicted nature and people as separate, he argues, because nature is collective, discursive, and artificially produced. Most significantly in terms of political ecology theory, he asserts that the cultural and biological resources for collectively inventing natures and identities are unevenly distributed. He concludes that since political ecology attempts to understand the forces linking social change, the environment, and development, these politics of nature need to be articulated.

Critiques of political ecology have ranged from those claiming that it does not emphasize politics enough to those claiming it does not emphasize ecology enough; some have argued against the field's theoretical premises while others have argued that the field has no coherent theory. A significant and much-cited critique is that of Andrew Vayda and Bradley Walters (1999) who argue that political ecology is biased by its theory that political forces are the major explanatory factors in environmental change and 
as a result underemphasizes the complex range of variables actually involved in environmental change. Their critique centers on the idea that scientific fields or subfields should be distinguished by what is to be explained, (in this case, environmental change), and not on the basis of theories about what will do the explaining. Since political ecology is as much a theoretical approach as a discipline, it seems to me that focusing on political and economic factors that have been shown to be significant is useful for demonstrating how some types of environmental and social changes occur.

In discussing and assessing the range of critiques of political ecology, Peter Walker (2005:73) concludes that the critique that political ecology has become "politics without ecology" is as of now unfounded. Rather, he argues, political ecology questions the centrality of biophysical ecology, expanding the concept of environment to include knowledge about it. He advocates a modern political ecology that combines advances in understanding social and discursive struggles over resources with biophysical ecology.

\section{Methods and Applications}

Methodology in political ecology is diverse, and as Neumann (2005:6) outlines, it includes complex multiscaler, political-economic, historical, and discourse analyses as well as ethnographic and ecological field studies. He describes how studies of interactions between the state and the market and their influences on the environment are combined with historical analyses. Discourse analysis in political ecology critiques modern ideas about objectivity and rationality, examines the relationship between power and scientific knowledge, and identifies multiple, culturally constructed ideas about the environment, he explains. Also, he says, political ecology utilizes the non-equilibrium 
model of contemporary ecological theory, and ecological methodologies can be used to illuminate ecological change and its cause if they are employed critically. Since political ecology was shaped largely within anthropology, ethnography has been an important methodology to understand different perspectives on the environment among actors at local, regional, and global levels, especially in terms of symbolic meaning and control of natural resources.

Robbins (2004) summarizes the goal of political ecology as the attempt to make explicit the causal connections between capitalist growth and environmental outcomes and to demonstrate that poverty as the main cause of ecological deterioration has been created by dominant structures. He explains that in examining how human-environment interactions are influenced by and also affect local political processes, research in political ecology has also been applied to issues concerning social and ecological justice. Using the analogy of "the hatchet and the seed" to describe the dual purpose of political ecology, Robbins describes how the hatchet deconstructs, critiquing dominant systems and myths and "denaturalizing" social and environmental conditions to show they are contingent upon power and not inevitable, while the seed searches for more equitable and sustainable ways of managing natural resources such as researching traditional ways and local ecological knowledges (2004:12-13).

Escobar (1996) describes how political ecology's major critiques center on the managerial style of Western conservation and development efforts and the goals of Western science being imposed on other parts of the world. The discourse of "sustainable development," he argues, disguises the fact that economic development is inherently contradictory to conservation efforts and gives the impression that both goals 
can be fulfilled, which is not possible without major reform of the entire system (Escobar 1996:327-332). He asserts that even utilizing a postmodern conservationist paradigm, nature is still considered as capital. This is evident through discourse that: utilizes conquest of nature terminology such as "biodiversity reserves," essentializes indigenous people as "stewards of nature," and judges indigenous knowledge in terms of its utilitarian value to modern science (Escobar 1996:332-335). Bryant and Bailey (1997) argue that since the political ecology approach asserts that political and economic structures are at the root of environmental crises and social inequality, any application of this theory must address these forces as well as the environmental and social outcomes. They conclude that as is typical of a radical perspective, political ecologists have not actually developed a tenable alternative to the mainstream concept of sustainable development.

Robbins (2004) says that in exploring environmental and social changes, political ecology suggests that there are better, more just and sustainable ways of managing the planet, and he describes how research and ideas from the field have been applied to the work of NGOs and other agencies. Neumann (2005) explains how poststructural critiques of development including questioning the efficacy of territorially-based conservation strategies and the fortress conservation model (human exclusion) as well as examining the links between economic development, environmental conservation, and degradation have not led to easy answers or simple alternatives. He outlines potential alternatives to the fortress model of conservation in the form of nature-society hybrids such as extractive reserves, joint forest management, indigenous reserves, integrated conservation and development programs, and community-based natural resources 
management. However, he warns that there are many problems with these models, such as the conflicts of interest inherent in conservation efforts as well as indigenous issues being integrated into the world economy using Western concepts and goals, but he concedes that community participatory approaches are the best solutions to date. In terms of Robbins'analogy (2004:12-13), it seems that much of the hatchet's work has been done, but more seeds need to be planted.

\section{The Amazon Environment and Indigenous Knowledge}

The environment, development, and biodiversity conservation are central topics in political ecology, and indigenous people are at the intersection of local struggles and global strategies. The Amazon has been the center stage for environmental and indigenous issues, and political ecology research has revealed the complex events taking place. Robbins (2004:129-137) designates Amazonian deforestation as an emblematic example of his "degradation and marginalization" thesis, which argues that local production systems become unsustainable, degrading the land and marginalizing people, because of state intervention or market integration that leads to poverty. In analyzing the historic roots of resource exploitation, he discusses how the Amazon has been misunderstood since the first European colonists associated it with a pristine Eden, obscuring its true ecological processes and human subsistence practices. Ignoring the anthropogenic nature of ecosystems has served to justify control of land by eliminating indigenous people from history, and explanations of Amazonian degradation that usually blame the poor and disregard structural inequalities have been used. He explains that due in part to political ecology research on Amazonian deforestation, Malthusian arguments 
that blame overpopulation and the resulting "tragedy of the commons" are seldom heard academically anymore, but are still heard popularly.

Marianne Schmink and Charles Wood (1987), some of the first anthropologists to use political ecology, utilized the approach to investigate Amazonian deforestation and indigenous communities. Assessing the relationship between the natural environment and socioeconomic behavior, they identify contradictions and conflicts of interest. Their model incorporates surplus, sociopolitical organization, production and accumulation, markets, civil society, social class, the state, global interdependence, and ideology. Using a materialist interpretation of the socio-political system behind Amazonian deforestation, they focus on struggles between groups to control the forest rather than on individual loggers. The study's findings show that as indigenous groups and other local producers are brought into the market economy, ecosystem stability is disrupted and resources are overexploited. They conclude that conservation and sustainability are fundamentally at odds with expanded production and accumulation and suggest placing limits on extraction, organizing policies to enforce them, and ending market incentives.

Susanna Hecht and Alexander Cockburn (1989) also employed political ecology to investigate Amazonian deforestation. They used a mid-level instead of micro-level analysis, demonstrated the failure of existing frameworks, and focused on the political economy of Amazonian development. Their study found that the role of the state, Brazil, and its land strategies were a significant factor in deforestation since they provided incentives to develop the Amazon through cattle ranching, and they concluded that Schmink and Wood's "global capitalism" idea was oversimplistic. According to Robbins (2004:137), recent political ecology research on Amazonian deforestation tends to follow 
either the Schmink and Wood model, focusing on the land, labor, and market dynamics that drive tree-cutting at the local scale, or the Hecht and Cockburn model, addressing state strategies for hegemony. He notes that in recent years, logging has become a more significant cause of Amazonian land use and land cover change than cattle ranching, so new studies will need to address these changing conditions. This research on the community of Comandancia investigates the role of logging as one of the factors in the community's livelihood.

Investigating indigenous environmental knowledge and local practices is also important for understanding Amazonian environmental change. In Escobar's (1999:7-11) framework of the manifestations of nature, what he calls "organic nature" is the view from Third World rural communities. He argues that the political ecology of organic nature goes beyond production, politics, and commodities, so it is best studied through the anthropology of local knowledge. Neumann (2005) discusses how political ecology critiques of development have led to investigations of indigenous technical knowledge and other local knowledges as alternatives to development, but without outlining a role for Western science and state and international policies. He explains that other problems with this approach are that immersion into the global market has made indigenous systems impossible or unsustainable, and also that idealizing indigenous knowledge propagates romanticized views of indigenous people. In debates over property rights and stewardship, however, he cautions against the opposite problem of straying too far away from the ecologically noble savage model and therefore not including indigenous people in management plans at all. 
In conclusion, many concepts and theories from political ecology are relevant to this thesis research on social and environmental changes and plant knowledge in an indigenous Amazonian community. Since power relations, both between the state or market and local communities as well as within the community itself, play a key role in explaining changes in environmental and social systems, the findings from Comandancia below identify some of the major economic stakeholders and state incentives. Focusing on local knowledge and the community perspective, perceptions of environmental and livelihood changes were documented, and power relations were analyzed at the community level. Critical medical anthropology has also utilized a political ecology approach to analyze the larger political, social, and economic factors that influence illness and health (Singer and Baer 2007). This study of Comandancia also investigates medicinal plant use not only because of the importance of conserving cultural knowledge, but also because health is a crucial issue in indigenous communities, which, like subsistence, has been adversely affected by cultural and environmental changes.

\section{Ethnobotany}

\section{Background, Theory, and Methods}

In light of the now common knowledge that humans have always modified their environments and in spite of the fact that indigenous people may not inherently possess a conservation ethic, the consensus is, as Luisa Maffi describes, "that small local groups with a history of continued and unchallenged occupation of given territories will over time tend to develop and maintain detailed and accurate knowledge about their ecological 
niches, as well as about sustainable ways of extracting and managing natural resources" (2001b:11). This is the premise of ethnoecology and research in traditional environmental knowledge.

Ethnobotany started in the late $19^{\text {th }}$ century but became more popular in the 1960 s, especially because of research in shamanism and mind-altering plants as well as the search for plant species that might contain medicinal compounds. Richard Evans Schultes, considered to be the father of Amazonian ethnobotany, was the first major figure in Amazonian medicinal plant research, and several generations of important ethnobotanists were trained or influenced by him. As Michael Balick (1996) explains, the science has evolved from listing useful plants to a multidisciplinary attempt to understand the relationship between people and plants, and recent ethnobotanical work is also developing ties with government and other agencies. He describes how disciplines such as anthropology, botany, nutrition, ecology, conservation, economics, and pharmacology are involved in issues ranging from biodiversity conservation, food shortage, indigenous resource management, and ethno-directed pharmaceutical prospecting to cultural concerns such as the spiritual relationship between people and plants.

The premise of ethnobotany is that indigenous and other traditional communities have an in-depth, widely-distributed, and empirically-based knowledge of plants. Some research has found that more sedentary, horticultural people have greater ethnobotanical knowledge than foragers because plant knowledge is an insurance against crop failure, sedentary lifestyles encourage knowledge acquisition, and human disturbances increase biodiversity and therefore plants to learn about. Other research has shown that 
communities that lack access to modern health care have a greater reliance on medicinals, and variables that predict ethnobotanical knowledge loss over time in a population have also been identified. The community of Comandancia, the subject of this research, is sedentary, horticultural, and has little access to modern health care.

Important theoretical research in ethnobotany has been conducted on indigenous classification systems. The ethnosciences overlap with cognitive anthropology and ethnosemantics in their analysis of traditional systems of knowledge and communication. Harold Conklin studied systems of naming and color perceptions among different cultures, influencing Brent Berlin whose work centers on indigenous taxonomies: how people perceive, name, and classify plants and animals. Berlin (1992) has found that the organization of plants from broad categories to specific organisms has five levels in most cultures, including Western scientific classification. In general, however, ethnobotany does not have a strong theoretical framework and is more focused on descriptions and applications.

The characteristic methodology employed in ethnobotanical research is the comprehensive surveying of a community's plant use, such as in classic studies like the work of William Vickers and Timothy Plowman (1984) and Brian Boom (1987) that catalogue many of the plants known to and used by a group. Plants are often listed both by family and by type, resulting in categories such as food, fuel, construction and crafts, medicinal, poisonous, commercial, et cetera, with descriptions of use and preparation for each. Other ethnobotanical methods include plot surveys, plant use interviews, consensus analysis, interviewing about artifacts, and conducting an inventory and then interviewing about it. Balick (1996) reviews the use of other methods such as: the credibility rating 
scale for plant utilization analysis, germplasm conservation using a combination of ex situ and in situ methods, market studies which have led to increasing public botanical literacy, and increasingly since the 1980s, quantitative ethnobotany which employs rigorous methodology and statistical analyses to quantify forest value, indicating the need for conservation of certain plant families.

Community participatory research is particularly important in ethnobotany. Ticktin et al. (2002) have compiled guidelines for carrying out participatory ethnoecological conservation research. These guidelines suggest that researchers, comprised of interdisciplinary teams, should ensure that local people are fully integrated into the research team, some of the research is carried out by the community itself, the project offers the community short-term results, and alliances are created with local NGOs.

Bioprospecting for useful plants and the intellectual property rights of communities have been major points of contention in ethnobotany. Stephen Brush (2001) explains how bioprospecting links legal, political, and economic spheres as well as the state, so not just the local community is involved. He outlines the intellectual property concerns associated with bioprospecting for crop and medicinal plants and describes the positions of each the stakeholders involved. These include indigenous organizations, private users of biological resources, public users of biological resources, and the state. Because of the legal complexity of issues of ownership, Brush (2001) suggests finding new ways of compensation outside of the mold of possessive individualism such as enhancing other public goods, and he calls for the development of alternative frameworks.

Michael Brown (2003) details the history of ethnobotanical research and bioprospecting in terms of the nuances of cultural and intellectual property rights, 
knowledge, and ownership. As the search for medicinal plants led to bioprospecting, alliances among ethnobotanical researchers, transnational drug companies, indigenous communities, and national governments were formed. He traces the development of the International Cooperative Biodiversity Groups (ICBG) program, an attempted NorthSouth collaboration that paid explicit attention to the intellectual property interests of local communities through complex and difficult arrangements. Unfortunately, political events and the involvement of other organizations led to the failure of the ICBG Maya project, and now the conditions for bioprospecting are very difficult to meet because of the more stringent rules of national governments. He concludes that from the rubber boom to the recent interest in medicinals, the paradigm of outsiders invading to steal plants and knowledge has been difficult to replace. It seems that bioprospecting had the potential to be a positive collaboration between indigenous communities and drug companies, but it has not worked out well due to the difficulty of delineating benefits.

\section{$\underline{\text { Amazon Forest Research }}$}

Ethnobotanists have often focused on indigenous communities in tropical forests because of the abundance of both biological and cultural diversity and thus the sophistication of indigenous knowledge in these regions. Since the 1970s, environmentalists have been increasingly concerned about tropical forest destruction, and this global awareness of deforestation has increased ethnobotany's importance in these areas (Balick 1996; Bennett 1992). Methods employed in applied and development anthropology can also be useful in applying ethnobotanical data to contemporary development problems (Cotton 1996). 
Since the 1980s, ethnobotanical studies of indigenous resource management systems in the Amazon such as agroforestry systems and home gardens have been increasing as well. Darrell Posey's (1982) foundational research in agroforestry with the Kayapó in Brazil and other studies that followed have led to greater understanding of agriculture and forestry in the tropics. William Balée's (2001) work in historical ecology utilizes ethnobotanical data and linguistic methods to determine the history of modes of subsistence for a particular indigenous group. In an analysis of Sirionó plant names, he traces how languages change environments and environments change languages, concluding that the Amazonian landscapes resulting from these interactions are products of both ecology and history acting together.

Amazonian indigenous agroforestry systems are highly managed and complex systems, and ethnobotanical research has included mapping, descriptions, data comparison, and sustainability and economic analyses. Many studies have focused on the extraction of non-timber forest products (NTFP) as a conservation strategy that can also benefit forest peoples. Bradley Bennett (2002) reviews case studies of community conservation projects and sustainability assessments and argues that additional sociocultural factors should be considered in management plans to make them more effective.

Christine Padoch's (1988) market study in the Iquitos area focused on the economic importance and marketing of forest and fallow products. She analyzed many of the variables involved including the market for each product, the distance from communities to Iquitos, transport costs, difficulty of cultivation and harvest, local plant availability, tribe involved, and season, among others. Findings indicate that in the Iquitos region, extractive industries have not been the most important income generators since the 1950s, 
having been replaced by agriculture and livestock. However, the study found that forestbased activities are still important: in 1980, the most important minor forest products were rubber, ojé, palm heart, and barbasco. The percentage of household income varies among houses and communities, but selling forest products produces more than 50 percent of the household income for many, so it is an important economic activity for most households. Padoch concludes that her findings that the medicinal plant trade is significant also support what many economic botanists and other researchers have stressed: that the potential for export of medicinals from Amazonia is much greater than is now realized.

Tropical home gardens, a subdivision of agroforestry, have also been an important focus in ethnobotany. Studies have described garden composition through species and cultivar listings and have investigated the ecological sustainability of home gardens and the extent to which they emulate the natural environment (Budwoski 1990; Nair 2001; Wojtkowski 1993). E. C. M. Fernandes and P. K. R. Nair (1990 ) evaluate different garden types in terms of structure and function and find that they are usually diverse and multi-strata, all contain some food crops, and fruit trees predominate. V. E. Mendez et al. (2001) identify six different garden types, ten distinct management zones, nine main plant uses, and high biodiversity in general in Nicaragua home gardens, for example.

Christine Padoch and Wil de Jong's (1991) findings from the lowland Amazon basin also show high species diversity and large variability among gardens, reflecting family differences. Comparing gardens on the arid coast, in the Andean highlands, and in the Amazon in Peru, Vera Niñez (1990) finds that sweet potato is the most versatile garden crop and that bananas are found in all gardens, and she concludes that indigenous gardens 
are successful and ecologically stable management systems. Socioeconomically, home gardens also play an important role in people's subsistence by providing food (Niñez 1987; Wezel and Bender 2003). Findings from this thesis research in the Yagua community of Comandancia, described below, show which of their medicinal plants are cultivated in home gardens, located in their garden plots, and gathered from the forest.

\section{$\underline{\text { Traditional Botanical Knowledge and Biocultural Conservation }}$}

Ethnobotany has been used to investigate the links between biological and cultural diversity, especially through studying traditional botanical knowledge. Current unprecedented threats to biodiversity and indigenous cultures and languages have focused much of contemporary ethnobotanical research on conservation. Ethnobotany contributes to conserving both biological and cultural diversity by identifying native plant resources and learning about their uses and potential in order to preserve both the local knowledge and the plants that people use (Bennett 1992). The descriptive aspect of this thesis on the community of Comandancia is important since documentation is crucial in the face of drastic cultural and environmental changes in the Amazon.

Some studies have attempted to measure the loss of traditional knowledge over time or from one generation to the next in order to highlight this concern. Stanford Zent (2001) conducted a systematic, empirical, quantitative study of change in traditional environmental knowledge among the Piaroa of Venezuela. Using ethnobotanical plot surveys, structured interviews, informant consensus analysis, and linear regression analysis with time as the variable, his results show that age is the most significant social 
variable in determining ethnobotanical competence and he concludes that ethnobotanical knowledge is being lost.

Manuel Lizarralde (2001) also measured traditional ecological knowledge loss in the Barí of Venezuela. The study's variables include: time living in area, subsistence practices, bilingual ability, and level of formal education. He found significant loss of ethnobotanical information from one generation to the next and contends that this is indicative of what is happening all over the Amazon because of indigenous loss of land and changing lifestyles. Conducting document analysis to systematically measure and compare folk knowledge and traditional environmental knowledge through the historical use of certain biological terms, Phillip Wolff and Douglas Medin (2001) also conclude than biological knowledge is declining. They formed a devolution hypothesis centering on cultural support, arguing that the degree to which a society promotes a particular area of knowledge affects the survival of that knowledge, so biological knowledge has declined because of lack of cultural support.

Contemporary ethnobotanical research has also explored ways to preserve traditional botanical knowledge. Michael Warren (2001) argues that indigenous knowledge is cultural capital, and emphasizing the importance of cultural resource centers for preserving indigenous knowledge, he describes the current global organization of such centers. Based on their ethnobiological survey in Brazil, De Lima et al. (2002) make suggestions for preserving traditional knowledge such as: returning ethnobiological data to the community through courses, seminars, and presentations; compiling a notebook with descriptions of medicinal plants, uses, and a glossary; and creating a medicinal plant garden. They support projects that include conservation of native species through local, 
certified, controlled production of food or medicinal plants and a financial return from the products to the community in order to improve quality of life, maintain ethnobiological knowledge, and utilize plant products for health care.

Teaching children is also a crucial part of conserving traditional botanical knowledge. Rebecca Zarger (2002) researched the acquisition of traditional environmental knowledge by studying transmission to children and the process of implementing culturally and ecologically relevant environmental education programs. Investigating the transfer of traditional knowledge among the Warao of Venezuela, W. Wilbert (2002) advocates bilingual culture and environment-specific books to utilize in the classroom to support enculturative learning. Many others in this field also recommend teaching traditional ecological knowledge in schools using indigenous-focused books.

The 1992 Rio Earth Summit included emphasis on the vital role of indigenous knowledge in environmental management and development. There are numerous examples of ways that indigenous knowledge and traditional practices have maintained natural resources, so an important area of ethnobiology has been applying traditional knowledge to biological and cultural diversity conservation. The work of Gary Nabhan et al. (2002) on native American lands and biodiversity led them to recommend conserving biodiversity on native lands, utilizing traditional ecological knowledge in conservation, investing in conservation capacity-building for native Americans, and linking ecological restoration and linguistic revitalization. They conclude that conservationists should attempt to collaborate on community-based projects that foster the continued oral transmission of traditional ecological knowledge, the persistence of 
indigenous languages, traditional subsistence and ceremonial practices, and the generation of health benefits or income for community members.

Incorporating traditional knowledge into biodiversity conservation requires equitable partnerships and rights for indigenous peoples. Darrell Posey (2001) recommends that indigenous self-determination, territorial and land rights, the right to development, collective rights, community empowerment, prior informed consent and privacy, control of access, religious rights and religious freedom, and the right to a unique language be included in the framework of all conservation projects. He contends that the activities of anthropologists, environmentalists, linguists, and other researchers involved in biocultural conservation are always political in nature and require a collaborative approach for a greater chance of success. Luisa Maffi (2001a) argues that although Western scientific disciplines separate linguistic, cultural, and biological diversity and attempt to draw links between them, these concepts are already combined in indigenous views. In recent decades, international awareness of indigenous rights issues has increased, but she believes that indigenous languages have not received adequate attention. She concludes that "indigenous heritage" includes language, not just material culture, and she suggests utilizing a human rights framework for cultural conservation and for reformulating the intellectual property rights system.

\section{Indigenous Medicinal Plant Knowledge}

Ethnobotany's area of expertise and the focus of this study is indigenous medicinal plant knowledge in the Amazon. Thomas Carlson (2001) discusses the central role that medicinals, ethnomedicine, and traditional botanical knowledge play in tropical public 
health. He explains that most tropical rural populations do not have access to modern pharmaceuticals for their health care needs, and in many cases modern medicine is not viable because of cost, perishability, and lack of trained personnel. Traditional botanical medicine is cheap or free, however, and ethnomedically selected plants have yielded many modern medicines, so Carlson believes that ethnobotany can contribute positively to improving rural health. He calls for greater integration of traditional botanical knowledge in modern public health and medical programs by collaborating with local healers, recognizing the value of traditional ethnomedical systems, and using local medicinal plants for the ailments that they are able to treat.

In an anthropological study on medicinal plants in home gardens in the Andes, Ruthbeth Finerman and Ross Sackett (2003) find interesting gender, generational, health, and socioeconomic information reflected in garden composition. The home gardens have a "predictive value" since despite attempts at privacy through fencing, women assess their neighbors' health and economic status by the contents of their gardens. The gardens also affirm women's identity as health care providers for their families as well as play a role in their social status and relationships with other women. As these gardens are being threatened by land changes, the authors "fear that the loss of medicinal plants, reduced dietary breadth, and especially the erosion of household autonomy and control over family health... forfeitures in terms of ethnomedical knowledge, women's status, ethnic identity, cultural heritage, and biodiversity may well prove vast, irreversible, and tragic," (Finerman and Sackett 2003:479).

Recent ethnobotanical studies on medicinal plants in the Amazon include Shepard's (2002) work with the Matisgenka and Yora of Peru. Focusing on how botanical 
knowledge is learned and transmitted through sensory cues, he finds that Yora ethnomedicine has both homeopathic features and also elements that correspond with the "doctrine of signatures" medicinal plant premise found in other herbal traditions. (The "doctrine of signatures" is the belief that a plant's physical features provide information about which human body parts it can be used for.) Shepard recommends bilingual texts with medicinal plant information, intercultural curricula, and ethnobotanical garden plots in native schools to facilitate the transmission of ethnobiological knowledge in modern times. In a study on the loss of medicinal plant knowledge and acculturation, Marsha and Robert Quinlan (2007) analyze the variables associated with maintaining traditional ecological knowledge in rural Dominica. They conclude that modernization does not necessarily play a simple and straightforward role. Women and older people know more medicinal plants, findings which are consistent with many other studies, but in this case, commercial occupation and consumerism are also positively associated with herbal knowledge.

Contributing to the discussion about shamanism and medicinal plant use in indigenous communities in the Amazon, Serena Heckler's (2007) research addresses herbalism among the Wõthïhã of the Venezuelan Amazon. Her findings show that they rely on medicinal plants more now than in the past because of the decrease in shamanism which had previously provided for their health needs. She explains that Amazonian cultures that emphasize shamanism often utilize fewer herbal remedies, believing that they only relieve symptoms and do not treat the underlying cause of illness. As the influence of shamanism has diminished, largely due to Christianity, and since biomedicine is often not affordable or available, herbal remedies are increasingly 
incorporated. She concludes that researchers who come in search of medicinal plants may find a new emergence of female herbalists and identify them as traditional, yet they are actually the result of both recent outside forces and of fulfilling expectations of indigenous botanical knowledge.

Indigenous medicinal plant knowledge has also been the focus of projects where ethnobotany is applied to community needs. Balick (1996) describes a Belize ethnobotany project that included conducting a comprehensive plant inventory and utilizing innovative methodology such as a multiple use curve to determine sample size as well as valuation studies to determine the economic value of an area for protection and sustainable harvest. They are also working on the development of a forest-based traditional medicine industry and the establishment of an ethno-biomedical forest reserve.

Another example of applying ethnobotany to health care challenges is the Federación de Comúnidades Nativas del Río Madre de Dios y Afluentes' (Federation of Native Communities of the Mother of God River and Tributaries) (FENAMAD) program involving indigenous communities and natural medicine. Linking health with the cultural and ecological changes resulting from development, Miguel Alexiades and Didier Lacaze (1995) discuss how this federation of native communities in the Southern Peruvian Amazon began a project with medicinal plants that combines modern health care and traditional botanical knowledge. They explain that since the program's approach also considers the social, political, and environmental dimensions of health care, it provides community education and development as well as training in grass roots organizing, and it supports cultivating medicinal plants and creating a decentralized health care system. 
Many other projects using traditional medicinal plant knowledge have been implemented, so a number of case studies and best practices exist to inform future endeavors.

\section{Yagua Ethnography}

\section{History and Culture}

"Culturally speaking, Yagua society is disappearing," ${ }^{1}$ concludes Jean-Pierre Chaumeil, the leading Yagua expert who is well-known for outstanding studies of Amazonian ethnohistory, shamanism, and ritual (1981:11). Conducting extensive field work in the 1970s and 1980s, he covered much of their territory and later produced numerous publications, many describing aspects of Yagua shamanistic practices in their indigenous setting. His Yagua ethnography (Chaumeil 1987) written in 1979 is the most comprehensive since Paul Fejos' (1943) ethnography since publications between the two that mention the Yagua are limited in scope. Chaumeil covers a wide variety of topics including a large section on their "ethnographic past," but here I will summarize only a few of the findings that are most relevant to this research, mainly from the "ethnographic present" part of his work which is based on 1970s fieldwork. I also include pertinent data from some of his other publications. The descriptions here also serve as a comparison for the findings of this study in the Yagua community of Comandancia, analyzed in the findings section below.

The Yagua, "the blowpipe Indians," are a major indigenous group with a population estimated at 3,500 (in the 1970s) living in the northeastern Peruvian Amazon east of Iquitos. They comprised about 60 groups ranging from ten to 180 members, spread 
through a cultural mosaic of small societies from diverse linguistic families and increasingly, mestizo communities (Chaumeil 1998:53; 2001:84). Their territory totaled about 70,000 square kilometers in 1981 and is located on both sides of the Amazon, as far north as the Yaguas river (a tributary of the Putumayo on the border with Columbia) and as far south as the Yavari river (on the border with Brazil). Yaguas call themselves ñihamwo, la gente (the people), and the term Yagua was probably given to them by the first white invaders, or possibly before by Tupi-speaking groups (Chaumeil 1987:19).

The Yagua are considered some of the last speakers of the Peba-Yaguana linguistic family on the Macro-Caribe branch (Chaumeil 1981:9). Despite divergent linguistic origins, the Yagua share cultural similarities with the Mai Huna and the Ticuna with respect to kinship (patrilineal clans and a system of dual organization), patterns of warfare, and long-range trade relations. Three major Yagua cultural divisions along clanfamily lines each has its dialect: the Orosa River area, along the Putumayo River on the Colombian border, and around Pebas (Chaumeil 1987:20). The 15 or more tribal clans, each associated with an animal or plant name, were probably geographically separate in the past, but modern living arrangements have changed this as well as their patrilineal kinship system. It also appears that in the past there was no centralized political organization, but rather each local group formed its own independent political entity (Chaumeil 1981:10; 1998).

Chaumeil's (1981:9) research on Yagua migration patterns showed that before European contact, Yagua groups moved often, sometimes every year, as a result of frequent wars with other Yagua groups, hunting activities, shamanism, and the death of a person. Hunting and warfare caused their societies to be very mobile with low 
populations and wide-ranging habitats. Tracing Yagua migrations from European contact to the present and analyzing the factors involved in their settlement patterns, Chaumeil describes how rubber extraction, jute production, and later logging and other economic activities based on raw materials from the region affected Yagua settlement. In the final time period that he analyzed, from 1950 to 1976 , wars, rubber, and conflict with Columbia were no longer the dominant factors, but land ownership systems, epidemics, and obligatory military service continued to play a role in migrations. New factors that affected where the Yagua settled during that time period included: most significantly, mestizo commerce on the banks of the Amazon, the creation of "campesino groups" by the Ministry of Agriculture, the implementation of schools by the Ministry of Education, and to a lesser extent, the political-religious Santa Cruz movement and the creation of "native communities" with land titles by SINAMOS (a previous government agency) (Chaumeil 1981:88-117, 167-169).

By the 1970s, because of schools, designated native lands, and hunting limits, most Yagua lived in exclusively sedentary communities, which also had the effect of increasing their birth rate (Chaumeil 1981; 1987:65). These new population dynamics resulting from a sedentary lifestyle have caused structural changes in Yagua kinship and social organization (Chaumeil 1984; 1987). Also, after settling, Chaumeil found that they have had different relationships with the dead: no longer following ancient funerary rituals, they would move a short distance or simply burn the house of the deceased and continue living in the area. During fieldwork for this thesis, members of Comandancia told me that they now have a cemetery a distance away from the community where they bring their dead. 
According to Chaumeil, traditional migrations, which before had maintained balance among the groups, had nearly disappeared by the 1970s, and more than 90 percent of Yaguas were in debt to various private or state entities, so they could not move. $\mathrm{He}$ describes how the final stage of evolution of the Yagua habitat was in becoming the exact copy of a mestizo village with a soccer field in the middle. This village design was tied to the establishment of schools and was often created because of mestizo teachers. After settling, houses were often built more mestizo style as well, closed instead of open, and sometimes with walls and a door (Chaumeil 1981; 1987:67). They still celebrated several of their traditional celebrations centering on masato, an alcoholic drink made from sweet manioc, and these parties continued to play an important role in maintaining social relations (Chaumeil 1998:62). In the community of Comandancia where I conducted this research, there is a school and soccer field as he describes, and masato and traditional celebrations also continue to be an important part of their culture.

\section{Shamanism, Leadership, and Health}

Shamanism, a major focus of Chaumeil's research on the Yagua, has received much anthropological attention. Interpretations have evolved from deeming shamans to be mentally ill or psychotic to considering them to be psychoanalysts or professionals, and whether or not shamans can truly be possessed by spirits has been debated. More recently, the social function of shamanism has been emphasized. Chaumeil $(1998: 39,51)$ explains that for the Yagua, the complex phenomenon of shamanism is the totality of the social body, and he argues that it functions sociologically as a true institution that is both religious and social. He describes shamanism as pervasive throughout all aspects of 
Yagua life: hunting, sickness, death, and revenge are interpreted through shamanism, and it justifies hostile relationships between local groups.

According to Chaumeil (1998), in addition to its social and cultural dimensions, Yagua shamanism is a system of ideas and practices about the world and its reproduction, a system of representation, a world vision, and a reflection on the world. Seeing, knowing, and power are the key functions of a Yagua shaman, and knowledge and ability come from sight. Shamans can see the true reality beyond the tangible world, often through the use of hallucinogens to see the "mothers," or essential spirits, of these plants that give them knowledge. He explains that through these visions they learn how ancient people lived, how the earth was formed, and how things of this world are transformed. Although shamanism was not specifically investigated in this study of Comandancia, elements of these ideas were evident in people's discourse, especially about health and healing.

Chaumeil (1987:145-146) describes two important types of Yagua leaders: curacas and shamans, though not all communities have them, some communities have one of the two, and other communities have both. He explains that curacas are supposed to be chosen for being cooperative, good speakers, and effective negotiators, which are essential qualities since they have no real authority. In reality, however, the position is often filled by sons and grandsons of curacas. Chaumeil (1987) describes their primary function as ensuring the maintenance of peace and harmony: they play the role of regulator among people as the shaman does between the living and the dead. In addition, they are the main representatives of the group when dealing with outsiders, including for economic transactions. In acting as an intermediary between his own group and their 
neighbors, a curaca, who lives and works as a regular community member, negotiates to preserve the economic interests of his group.

In distinguishing between a curaca and a shaman, Chaumeil (1987:145-146) explains that a curaca is based on prestige and has a political-economic role as mediator among people through peaceful commerce with outsiders. In contrast, a shaman is based on power and has a political-religious role as mediator between the living and the dead as well as between men and spirits through aggressive witchcraft with the outside world. In the case of the community in this study, there is no shaman living in the village of Comandancia. The leadership position, although not called curaca, fits much of Chaumeil's description, including the hereditary aspect. In the findings chapter below, I explain how this system conflicts with modern democratic ideas in the community.

Shamanism is an integral component of traditional Yagua conceptions of sickness and health. Chaumeil (1987:146) shows that a Yagua shaman is also much more than simply a healer: his therapeutic activities play a key role in their society. He describes how illness affects not only the individual, but rather the whole community, since when a sick person cannot produce for his family, the whole group's health and sometimes food production is affected. Furthermore, pathological phenomena cannot be defined in and of themselves, but only in relationship to the totality of social activities. Chaumeil (1987:146-147) explains that the shaman is the only one who can see the disease and make sense of the symptoms present in the sick person, which the shaman then interprets in terms understandable in his society. Yagua do not distinguish between somatic and mental illnesses: all sicknesses affect the total person, body and mind. Yagua believe that as with all living things, each illness has a "mother," the essence of the illness, and it 
indicates to the healer the process of formation and the components of each case. $\mathrm{He}$ describes that the shaman sees the diseases during a ritual or in his dreams, but this vision of the diseases does not have any curative power because the "mothers" by themselves did not produce the diseases.

Chaumeil (1987:147) explains that as in many other Amazonian societies, the Yagua have two theories of illness: the presence of an outside body in the organism that has to be extracted, or the lack of some vital being that has to be reintroduced into the body. $\mathrm{He}$ describes how during an exorcism, the shaman massages, blows tobacco smoke on the body and afflicted area, and then suctions out the foreign object. During an adorcism, the shaman sends helpers to distant worlds to find the lost spirits which are then reincorporated through massage and blowing. Pathogens are always exogenous and supernatural, he states.

Chaumeil (1987:147) details how those who are truly responsible for the sickness, the "blowers of illness," are divided into two major categories of diseases: illness from witchcraft and illness from the creator. Most illnesses are witchcraft, caused by other shamans or forest spirits and are curable. Illnesses inflicted by the creator, however, as a consequence of some rule-breaking such as incest, uncontrolled sexual activity, crime, and theft are incurable. Nothing tangible separates the symptoms in these two categories, and only the shaman can discover the cause during the curing ceremony. He explains that once the arrow or other projectile is removed, the shaman must determine its sender to discover the type of illness and whether it can be cured. As described in the findings chapter below, Yagua in the community of Comandancia also still consider some 
illnesses to be caused by exogenous, supernatural forces, and people mentioned healers dreaming to determine causes of illness.

\section{$\underline{\text { Livelihood }}$}

Although shifting horticulture has provided most of their diet both in weight and in calories since they have settled in communities, according to Chaumeil (1998:58-59), the Yagua still consider themselves to be hunters and define themselves in relation to hunting, now more symbolic value than productive activity. When they do hunt and gather in their tropical forest habitat, these activities are always tied together and often take place at aguajales, areas with groups of aguaje (Mauritia flexuosa) palm trees that produce protein-rich fruits. He explains that aguajales are central places in Yagua economy as hunting areas since mammals use the habitat, such as monkeys at night, and products to be gathered are found in greater concentrations there. Depending on the time of year, gathering frog, turtle, and bird eggs is done by both sexes, but honey and pijuayo (Bactris gasipaes) palm fruit collection are men's jobs. Palm larvae, especially from the aguaje or the shapaja (Scheelea brachyclada) are collected, and the larvae are either toasted in a patarashca in leaves, cooked in a masamorra with grated llantenes, or eaten raw (Chaumeil 1987:80-81). Many of these foods and activities were mentioned by the people of Comandancia during this thesis research, also as a smaller portion of their diet than agricultural products.

As the Yagua have moved closer to the Amazon river over time, fish, which before comprised only about 10 percent of their diets, has surpassed hunted animals in dietary importance since there were fewer animals along major rivers (Chaumeil 1987). 
Chaumeil reports that some Yagua have recently started raising animals like chickens, birds, ducks, and sometimes pigs, but this production was only rarely a part of their diet because the meat was usually sold for mestizo products. Despite missionary attempts, Yagua did not have cattle yet, he said (Chaumeil 1987:97). Findings from this study of Comandancia, described below, also show a fish-based diet for the community and some animal raising, but a change from the time of Chaumeil's fieldwork in that cattle are now present.

Chaumeil (1987:127-130) states that most Yagua had moved near the mestizo populations of missionary centers. They hunted and gathered and then sold skins, meat, and wild fruit as well as worked in logging, harvesting rice in some areas, cultivating jute (Urena lobata), and making items such as baskets and hammocks. He explained that since the land they were given was not always adequate for cultivation, many Yagua worked on mestizo-owned land in situations ranging from near slavery to wage labor for private companies, national factories, or an agrarian bank jute production project. Chaumeil observes (1987) that they would work hard for a boss for months just to earn some clothing or other item. This patron-client system still exists in a more modern form, and the findings chapter below describes the men of Comandancia's current labor in logging.

The Yagua had abandoned old techniques such as pottery and plant clothing, Chaumeil (1987:127) describes, and they were now dependent on mestizo society for batteries, kerosene, guns, and other material goods. The main products that had been introduced included salt, sugar, rice, alcohol, soap, cloth, blankets, and synthetic dyes, and the consequences of these included alcoholism and abandoning traditional dress, bark 
blankets, and vegetable dyes. In general, the Yagua had changed from more of a collective society to more of an individual one as people have acquired and owned individually these items, he explains (Chaumeil 1987). Based on the data from this study in Comandancia, these trends have continued, and nowadays the Yagua are even more connected to mestizo society.

\section{Plant Use}

According to Chaumeil's data from his 1970s fieldwork (1981:11), more than 50 percent of the total Yagua diet, 80 percent in weight, came from cultivated plants, and gathered fruits and honey made up about five to ten percent. Each family usually had several plots in various stages of cultivation and succession. Ideally, he explains, Yagua would start a new field every year and "abandon" it after two consecutive sweet manioc harvests, although the "abandoned" fields continued producing a number of items such as fruit trees even after the secondary forest had grown back. He says that when choosing new plots to cultivate, Yagua tended to select monte suave, secondary forest, instead of monte duro, primary forest, which has large, hard trees with deep roots that are difficult to burn and less favorable soil for agriculture. They planted during full moons in areas near their homes that would not flood, and each crop was planted in a particular place and in a different way to optimize production, resulting in plots that looked like "cultivated forest." Plant growth fertility rituals were not directed to a general earth spirit, but instead each plant has a "mother," a vital beginning that makes the plant germinate, flower, grow, and die. The Yagua tried to influence the "mothers" in each plant to favor the plant's growth and protect it against parasites and plagues (Chaumeil 1987:87-97; 
1998:59-62). In the community of Comandancia, I observed that shifting agriculture still provides the majority of their diet.

Chaumeil (1987:87-97; 1998:61) describes that manioc and plantains were quantitatively their most important crops, comprising about 80-90 percent of cultivated plants, and manioc was transplanted each time it was harvested to ensure continuous production. Among their basic cultigens were: at least six varieties of manioc (Manihot esculenta), at least sixteen varieties of plantains (Musa paradisiaca), two varieties of sachapapa (Dioscorea), two varieties of camote (Ipomea batatas), witino (Colocasia), two types of potatoes, dale-dale (Calathea), two varieties of pijuayo (Bactris gasipaes), two varieties of corn (Zea mays), two varieties of sugar cane (Saccharum officianarum), and they also cultivate nineteen different kinds of fruit trees and seven spices. In my fieldwork in Comandancia, I also observed that manioc and plantains are still the main staples, and many of these other plant foods are produced in this community.

In describing yearly fruit harvests, Chaumeil (1987:67-69) says that February was the first "time of the pijuayo," an important fruit in the Yagua diet. Pijuayo is rich in minerals, protein, and vitamin $\mathrm{C}$, and was eaten daily cooked whole or made into masato, an alcoholic beverage. Afterward, the "time of the fruits" began and lasted until April or May during which time guaba, umari, uva, zapote (Quararibe), cacao (Theobroma), aguaje and other fruits were ripe. "Time of the chonta" was in March, and "time of the caimito" (Moutabea) began in May. In July began the second "time of the fruits" and in August the second "time of pijuayo." When rains begin in September, the trees flowered and it was "time of the flowers" until December. Chambira huallo could be found during this time and guayaba (Psidium) in December. Chaumeil (1987:80) notes that fruits were 
rarely eaten raw, and he lists forty seven of their most commonly collected fruits. Many of these fruits were also mentioned by community members during fieldwork for this study in Comandancia.

Medicinal plants were usually planted in gardens next to their houses to have them on hand, Chaumeil (1987:148) explains. In the findings chapter below, the data from this study also show that most medicinals are located in home gardens. He says that after an agricultural plot was abandoned, secondary growth set in, including fruit trees and medicinal bushes such as cocona (Solanum), bijao (Heliconia), mullaca, guabilla, and others. Chaumeil's (1987:149-152) findings include a list of the names and uses of 71 medicinal plants, 17 of which are cultivated, and some have several varieties. His list is analyzed below and compared to this study's findings. He explains that Yagua shamans do not use any medicinal substances during curing sessions, and medicinal plants only complement and follow a shamanic cure. Instead, medicinal plant knowledge is public information. "The knowledge and use of medicinal plants is in the dominion of collective knowledge. All Yagua (men or women) know them more or less and can use them," ${ }^{2}$ he explains (Chaumeil 1987:148). This study in Comandancia also found medicinal plant knowledge widespread among the people of the community.

According to Chaumeil (1987), masato, the fermented drink made from manioc that women prepare, was as important as meat. I also found that masato is still integral to the Yagua diet. Chaumeil describes that in addition to intoxicants such as fermented drinks and sugar cane alcohol, Yagua were familiar with and used for therapeutic and psychedelic purposes hallucinogens such as ayahuasca (Banisteriopis) and toé (Brugmansia) as well as stimulants such as tobacco (Nicotiana tabacum), whose effects 
are often comparable to true hallucinogens. He states that it is quite likely that the Yagua chewed coca (Erythroxylon coca) leaves in the past as well. Taking hallucinogens was tied to the practice and teaching of shamanism with preparation strictly for males, and plants were ingested according to the purpose. He explains that the Yagua believed these plants possess "powers" or "mothers" that become visible to those who ingest the plant, so these plants have contributed to a large part of Yagua cosmological and medical knowledge. Chaumeil (1987:106-107) lists eight main hallucinogens and stimulants used by the Yagua. In the community of Comandancia, many of these plants were mentioned although not often used since there is no shaman. There were also mentions of women using hallucinogens, so perhaps this has changed since the time of Chaumeil's fieldwork.

Chaumeil (1987:94) describes that piripiri (Cyperus) appeared to be a ritual plant since it was used in various crop fertility ceremonies including burning agricultural plots, making plants grow, making the sun shine, and making the wind blow, rituals that were more effective when a shaman intervened. Piripiri was also the first plant used for initiation into shamanism. His data show that the one Spanish translation piripiri has many different Yagua words, and he notes that there were over 50 varieties with different uses. Another ritual plant that he mentions is a variety of garlic (Allium sativum) whose "mother" took care of the crops; after preparing and burning a new plot and before planting, it was planted in the middle of the field (Chaumeil 1987:92). In the findings from this study of Comandancia, described below, piripiri was mentioned for several ritual and supernatural purposes.

As with many other aspects of Yagua livelihood, Chaumeil (1987:90-92) found gender divisions in plant activities. Women's plants included manioc, sachapapa, 
potatos, witina, camote, pijuayo, hot peppers, guaba, and some varieties of piripiri. Men's plants included plantains, corn, sugarcane, papayas, pineapples, mangos, sweet peppers, tobacco, hallucinogens, and some varieties of piripiri. He said that planting was normally done by women, including plants in the men's category, except for tobacco and hallucinogens. Women harvested root vegetables like manioc, camote, sachapapa, and witina, and men were in charge of plantains and fruits, especially if they had to climb or cut down a tree.

Chaumeil (2001) describes how Yagua religious philosophy abounds with references to palms and palm derivatives such as blowpipes and flutes, all associated with longlasting qualities and integral bonds with past generations. As anthropologists have analyzed using similar artifacts in other Amazonian societies, he explains that these tubeshaped objects transform energy from wild to socialized as air passes through them, just as a shaman's breath transforms energy through his body. He describes how in Yagua botanical nomenclature, palms form a separate class, within which different palm species are thought to be related through sibling or cousin ties, somewhat like clan members. Pijuayo (Bactris gasipaes) and aguaje (Maurita flexuosa) are related, for example, and are the most important palms of the Yagua cultural universe, both possessing a more powerful spirit than all of the other palms. Traditional Yagua clothes are made from aguaje palm fiber, and pijuayo trees represent memory of the dead and chronological time is measured by their fruiting seasons (Chaumeil 2001:93-97). 


\section{$\underline{\text { Problems and Needs }}$}

The final chapter of Chaumeil's Yagua ethnography (1987:169-178) is titled "Ethnographic Future" and discusses the most pressing concerns and problems that he observed among the Yagua: health, land rights, education, lack of a native federation, the influence of other religions and cultures, commercialization of Amazonian products, discrimination of indigenous people, and tourism. Since over thirty years have passed since his fieldwork, here I summarize his descriptions of these issues from that era and comment on their current status in the community of Comandancia. Below in the findings chapter, I will discuss many of these in greater depth.

In Chaumeil's (1987:171-172) view, health care was one of the Yagua's greatest needs, and he provides detailed data showing that rates of sickness and death and frequency of infections had risen, especially in children. He says that the role of one particular type of shaman, the healer, had become more important due to this increase in diseases. Although it was difficult to calculate if their traditional pharmacopeia had increased or decreased over time, he concluded that regardless of the number of medicinal plants, healers' actions were ineffective against new illnesses. He believes that medicinal plants were not enough to combat new diseases, and so the Yagua were in need of outside help which was nonexistent in most communities and available only in some missionary centers. A greater problem he observed was that the Yagua completely distrusted Western medicine and its administrators, and as of 1978, Western medicine had almost never been used among the Yagua. He states that they did go to curanderos, or healers, but only to a doctor as a last resort after having tried everything else. 
Preventive medicine was therefore problematic, and he denounces the Ministry of Health for having conducted systematic vaccinations without medical examinations.

Chaumeil (1987:171-172) reports that native health posts had been planned and training for health promoters began in 1973, but disappointingly, by 1977 only one ended up being permanent. Nevertheless, he considers health posts to be a good idea that should be developed, and he supports building more local hospital centers, stocking them with low-priced essential items, conducting more discriminate vaccinations, developing native health promoters, improving emergency transport services, and improving hygiene in areas near mestizo populations. On the basis of the findings of this study of

Comandancia, health is still a primary concern, although the circumstances have changed. People in the community do not seem to fear but rather seek access to Western medicine, which is still very lacking as Chaumeil described.

Land rights was the Yagua's second most important need, according to Chaumeil (1987:173). He argues that it was vital that Yagua obtain property titles to guarantee their traditional territory since these titles are the only effective partial defense against the invasion of their lands. At the time of his writing, 14 communities had obtained land titles, and many others were waiting to resolve the slow process. He advocated accelerating the process of concession of legal property titles and ensuring that the assigned territory could meet all of the residents' needs. In the years that have since passed, many more indigenous communities in the Peruvian Amazon have received land titles, although many now need to seek amplifications since the territories were insufficient for their needs. However, as I will explain below, the lands surrounding 
these territories have already been conceded to commercial interests, and also indigenous communities do not have subsoil rights.

The third most significant problem for the future of the Yagua, in Chaumeil's (1987:174-175) opinion, was the education system, and he criticizes how it was implemented in native communities. Until 1970, the education of native populations had been provided mostly by Catholic or Protestant missions, focusing on religious teachings and Western culture. He explains that the state took over education by the late 1970s, but the teachers were mestizos, not well-qualified, and did not know Yagua culture or language. The system did not preserve Yagua language and culture, and instead systematically devalued and disintegrated it, a process that Chaumeil deems to be ethnocide. The presence of schools and mestizo teachers living in their communities made the Yagua more sedentary and removed them from conducting and learning about subsistence activities and rituals. He believes that a bilingual education system should be implemented that would be taught by native teachers and in their language, focus on natives, take into account their culture, not impose outside value systems, respect their lifestyle, utilize textbooks that include native history and culture, and adapt the school calendar to their agricultural activities. Although nowadays some bilingual education is being implemented in native communities, it falls far short of the ambitious goals Chaumeil describes.

Another problem in Chaumeil's view at the time of his writing was that there was no native federation or Yagua organization beyond individual communities, leaving them unarmed and vulnerable against Peruvian society (1987:176). Since they were comprised of about 60 communities over a vast territory, he believed that an organization and later 
an intertribal federation would make them stronger and assert their rights. In 1984, a federation of communities of the lower Napo and Amazon that included Yagua was indeed formed, and a Yagua-Ticuna federation started around the same time. Chaumeil notes in his 1986 introduction that eight years had passed since the fieldwork for his ethnography, and that significant socio-political changes had taken place with the Yagua since then as a result of these newly formed organizations. Their impact and political weight had already grown, he describes, transforming not only the perspectives of the native groups, but also their inter-ethnic relationships with the state, and he emphasizes the need for updated research. In the last 20 years, indigenous federations have continued to strengthen, and intertribal organizations now exist as well. This research in Comandancia investigated the current role of the local Yagua and other levels of indigenous federations which are described more below.

Chaumeil (1987:176) also believed that the influence of missionaries and the introduction of outside religion and culture was a threat to the Yagua's future. For example, missionaries had made them move from their traditional collective houses to individual homes and wear western suits and clothes. However, he concedes that at the missions they did receive medical care and some economic aid. The community of Comandancia does not currently have a priest or church, but nearby communities do.

Commercialization of forest products is another problem that Chaumeil (1987:176177) anticipated would have adverse effects on the Yagua. Few economic benefits had reached the Yagua, and those that did were usually received by individuals, not the community as a whole. He believed that selling crops and forest fruit was ultimately not sustainable or dependable, and he predicted that hunted animal and fish supplies would 
decrease. With other jobs such as logging, the Yagua worked for and were dependent on mestizo bosses, and jute cultivation had transport issues. In Chaumeil's opinion, selling native handicrafts to tourists changes the social function of these items and would ultimately destroy their traditional role. He suggests implementing native support institutions that could reduce middle men and assist with making investments and forming infrastructure such as transportation, storage, machines, contracts, and accounting. Animal and fish supplies have indeed diminished over the years, and the men of Comandancia are currently dependent on outside employers, discussed in the livelihood findings below.

Chaumeil (1987:177-178) thought that the attitude of mestizos towards natives was also a threat to the future of Yagua culture since they did not respect indigenous peoples. He reports that sometimes mestizo men convinced young Yagua girls to leave with them, and they often never returned to their communities and ended up being exploited. Tourism was the final threat to the Yagua's future that Chaumeil identified, and he felt it was necessary to protect them against it. He concludes that the problem was not that the Yagua would disappear completely, but rather that they would lose their culture and identity due to these pressures. For Yagua and other native communities, relationships with mestizos remain problematic, and tourism has greatly increased since then.

In discussing the issues that all Peruvian indigenous communities currently face and the struggle for their rights, Andrew Gray (1997) traces the progress and challenges that indigenous movements have had in terms of human rights. He argues that native communities in the Peruvian Amazon have suffered from resource exploitation, and that there is a clash between indigenous identity and Peruvian citizenship due to the actions of 
the Peruvian government and the history of state claims over indigenous rights. The growing development of indigenous rights internationally, however, has led to indigenous peoples' awareness of their rights, territories, and resources.

Gray (1997) discusses the UN Working Group on Indigenous Populations that has been meeting in Geneva since 1982 and their recent project that investigated indigenous rights and development as seen through their understanding of key concepts. Findings from this project included that territory, people, cultural identity, government, development, and self-determination are always discussed in a non-indigenous framework that contrasts with the indigenous worldview. He says that indigenous notions of territoriality, identity, and culture need to be investigated, and indigenous governance in Amazonia has rarely been studied. The 2007 UN Declaration of the Rights of Indigenous Peoples has helped self-determination, and their federations from community to international levels are also strengthening their positions, but Gray argues that ensuring indigenous rights is a process that is far from over and that is still lacking the indigenous perspective. His solution to development problems involving indigenous communities is self-development as an alternative form of development and as opposed to no development.

To conclude this literature review, indigenous people and the environment have been examined through several disciplines. In the last few decades, environmental anthropology and ethnobiology have focused on environmental sustainability and indigenous knowledge. Political ecology has informed analyses of the forces driving the social and ecological changes that threaten cultural and biological diversity as well as jeopardize the well-being of indigenous groups. This study of the community of 
Comandancia combines elements of ethnobotany, environmental anthropology, and political ecology research to provide a holistic understanding needed for addressing indigenous livelihood, health, and cultural issues as well as natural resource and biodiversity concerns. It also updates Yagua ethnographic research by investigating the current condition resulting from the dramatic social and territorial changes of recent years and can perhaps inform conservation or humanitarian initiatives in the Yagua region.

Below I describe the methods that were utilized to document livelihood, culture, traditional botanical knowledge, community needs, and the local perspective in the midst of social and environmental change in the community of Comandancia. 


\section{METHODOLOGY}

\section{Research Design}

\section{Overview}

A multimethods, holistic approach was utilized to investigate the environment, culture, and traditional botanical knowledge in the Yagua community of Comandancia. This exploratory, ethnographic and ethnobotanical research consisted of a synchronic case study of one Amazonian indigenous community, emphasizing community participatory methods. Data elicited include a combination of descriptive, historical, and other qualitative data, and some quantitative data. (See Appendix 1 for the complete list of data collected.) Analyses are mostly qualitative. Secondary research of Amazonian, ethnobotanical, and other relevant anthropological literature was also conducted, some of which is summarized above.

Anthropological fieldwork methods as described by Alexander Ervin (2005) for applied research were employed, such as a more defined and practical focus to delimit participant observation. To acquire a preliminary, qualitative understanding of the situation, I worked with local participants, focused on an emic perspective, and triangulated data collection as James Beebe (1995) recommends for rapid projects.

\section{Fieldwork and Research Population}

Fieldwork arrangements were facilitated by Project Amazonas, an international humanitarian, conservation, and education NGO that has been providing medical care and implementing environmental and other projects for many remote communities in the 
Loreto region of the Peruvian Amazon for over ten years. The president of Project Amazonas presented my research proposal to the community leadership who endorsed the project with a signed letter granting permission. Project Amazonas also provided a base for fieldwork at their biological research station a few kilometers downriver from the community as well as local river transportation. Most importantly, the first step in developing rapport with community members was enabled by the NGO's longstanding relationship, favorable reputation, and earned trust with local communities. Florida International University's Institutional Review Board also approved this project for research with human subjects (IRB approval number 062305-02).

The research population for this study was the community of Comandancia, which consists of about 220 individuals living in 32 households along the Orosa River in the upper Amazon River region in the department of Loreto in Peru. Most are Yagua Indians, but a few community members married in from other neighboring tribes. Between July 4, 2005 and August 11, 2005, I spent several hours or more per day in the community. Upon arrival, I orally presented to the leaders and community members the purposes of the study, and as Ervin (2005) suggests, I gave them a one-page written project summary in lay language that was posted on the school door, not knowing at the time that most people are illiterate.

After introductions to the community leaders and other members, the beginning of fieldwork included developing rapport, gaining familiarity with the area and culture, and conducting participant-observation and informal and unstructured interviews. I identified key participants to collaborate with; in this case, the teacher, his wife, and to some extent the leaders and a few other interested community members. (Throughout this thesis 
when I use the term "the teacher," I am referring to the older teacher who is the director of the school.) Later, I designed, tested, revised, and administered structured interview questionnaires and conducted semi-structured interviews and focus groups about plant use, community organization, needs, and other cultural and environmental topics. Both community members and Project Amazonas' staff assisted me in involving the community, conducting research, understanding the culture, and interpreting findings. All interviews and other methods were conducted in Spanish.

In investigating the broader social context of the community and its environment, I spoke with representatives of several relevant NGOs and indigenous federations. Researchers and board members of Project Amazonas provided information about local environmental change, experiences with the indigenous communities, and other regional and cultural information. In Comandancia, I interviewed leaders of the local Yagua federation, the Federación de Pueblos Yaguas Rio Orosa Apayacu (Federation of Yagua Villages on the Orosa and Apayacu Rivers) (FEPYROA). The Peruvian NGO Instituto del Bien Común (Common Good Institute) (IBC) ${ }^{3}$ is working with local communities, including FEPYROA, to create a communal reserve. Semi-structured interviews with representatives of the IBC and the regional indigenous federation, the Organización Regional AIDESEP Iquitos (Regional AIDESEP Organization Iquitos) (ORAI), were conducted in Iquitos, Peru on August 12, 2005.

\section{Confidentiality and Benefits to Participants}

Confidentiality and anonymity were informally discussed with each individual when oral consent was obtained before interviewing and conducting focus groups. Names of 
participants have not been used, and notebooks and data have been kept secure throughout the process. With open houses and children, family, and neighbors coming and going, individual interviews were never really private, however. Since people can be identified by their roles and positions in such a small community, I attempted to be sensitive to contentious issues in the findings below.

Benefits to participants and the community as a whole included the documentation of their culture, needs, and plant knowledge. Community participatory methods also involved adults, adolescents, and children in a number of research activities, resulting in not only sharing information but also acquiring skills they can use to continue to record their knowledge. I gave them copies of the lists of plants in the community that they had created, and after completion of fieldwork, I sent back copies of tape recordings of interviews, focus groups, and the Yagua celebration as well as all the photographs of them in their community that they had taken.

\section{Community Participatory Approaches}

Many community participatory methods worked very successfully, and I consciously tried to empower people and encourage collaboration throughout the process. First, I asked the leaders, their families, and other community members about their needs and what cultural information they wanted to document. I showed them a medicinal plant book I had created with an indigenous community in Mexico to see if they were interested in botanical knowledge documentation. I also read to them information from the IBC's SICNA ${ }^{4}$ project that explains that collecting family and community data is useful for both voicing concerns to the government and also for looking for solutions to 
problems. The leaders and others decided that they wanted to collect medicinal plant data, hold a medicinal plant workshop, and document other aspects of Yagua culture as well as their natural resource needs.

I recruited any adults who were interested to participate in some aspect of the project, and I talked to both the leaders as well as those who oppose the leadership. A number of community members acted as research collaborators, playing key roles in organizing people, talking about problems, and documenting cultural knowledge. Several literate adults worked together to write about useage and preparation of medicinal plants in Spanish and Yagua, consulting other community members about the information. Other people spoke about medicinal plants, Yagua culture, and other topics in Spanish and Yagua. The teacher also conducted meetings where he interviewed people. After the plant list was generated by community members, they labeled plants on the list according to their uses. They used my tape recorder to record meetings, songs in Yagua, and other events. Some people photographed families, houses, and community areas with a camera I lent them for a few weeks. I periodically consulted the key participants about methods and ideas.

Since the teacher is very interested in preserving the Yagua language, plant use, and other cultural knowledge through teaching the children, I organized part of the project around these goals. At his suggestion, many children and adolescents became actively involved in the research process. Although working with them was time-consuming, they learned both research skills and about their own cultural knowledge from the adults they interviewed, and they facilitated access to people, ensured accuracy of data, and taught me the cultural norms. They compiled plant lists with local names, participated in the 
medicinal plant workshop, and helped to create a map of the community with household locations and family names, later used for systematic sampling for structured interviews. I tried to give them control whenever possible, so they wrote in my notebook, used the tape recorder, and several of the older, more literate children administered many of the structured interviews. After working each day, I lent them watercolor paints, brushes, and colored pencils, and they painted and drew. These techniques built initial rapport for later interviewing, actively involved people in the project, and produced data to answer the research questions.

\section{Limitations, Validity, and Reliability}

This study is neither a comprehensive ethnobotanical inventory, nor an extensive ethnography, nor a multiscaler stakeholder analysis (as Neuman (2005) recommends utilizing in political ecology research), but rather an exploratory project combining aspects of all of these. Anthropological methods were utilized to obtain community and cultural information, and interviews with representatives of NGOs and indigenous federations were conducted, but this research is not a complete ethnographic or political ecology study. Data on common medicinal plant use were elicited using several methods, although the entire scope of the community's traditional botanical knowledge was not recorded. The botanical method of voucher specimen collection (plant samples) was not used since time-consuming permits would have been required, but photos were taken of most plants. 
Since the primary purpose was to understand the people's knowledge and perspective, ecological methods such as species frequencies and distributions and detailed land use assessment were beyond the scope of this study. The community's perceived needs were documented, but formal needs assessment techniques as Ervin (2005) describes were not employed. Also, this was not community-determined research, although it utilized some community-participatory and -directed methodologies. Finally, fieldwork was conducted for only about five weeks during the dry season, and my gender and age may have influenced people's communication with me.

Regarding validity and reliability, one of the strengths of this research design is that the triangulation of methods produced reliable data. A range of different interviews and focus groups elicited information about plant uses, people's needs, and other aspects of their culture that were compiled and compared. Daily participant observation, as conducted in this study, also increases the validity of data derived from interviews and focus groups according to Bernard (2002) since it reduces subjects' reactivity and increases the researcher's understanding of the culture. Although this study focused on documenting the knowledge and situation of this particular community as a case study and is most valid at this level, many of the findings may be generalizable to other indigenous Amazonian communities. 


\section{Data Collection}

\section{$\underline{\text { Participant-Observation and Interviews }}$}

I spent several hours per day during the fieldwork period in the community conducting participant-observation, continuously taking notes, and informally interviewing. Daily activities, family and social structures, culture, and all forms of plant use and preparation were noted. I attended meetings and parties, visited areas in and near the community, observed interactions among community members and with outsiders, and documented references to the environment, other social actors, and natural resource and health needs. Participant-observation also informed me about the community's language, terminology, priorities, and lifestyle to better modify questionnaires for later interviewing. According to Neuman (2005), observing indigenous sociopolitical systems and resource management practices is integral to a local level understanding in a political ecology approach, so I also focused on community organizations and livelihood.

Unstructured, semi-structured, and structured interviews were all conducted. Since this was an exploratory study of a small, culturally similar research population, I conducted unstructured interviews using volunteer, snowball, and convenience sampling to elicit data about livelihood, Yagua culture, and plant use. I asked and noted what people said about changes in the environment and their subsistence and health, their personal histories, community and indigenous organizations, and logging companies. Data from these unstructured interviews provided general community information and were used to formulate the questionnaires for semi-structured and structured interviews. 
Ethnographic research requires cultural more than individual data as Bernard describes (2002), so non-probability sampling techniques were used to choose several key informants for semi-structured interviews. Purposively-sampled key informants, both individuals and couples, included people with leadership roles, knowledgeable about plant use, and better able to understand and articulate their culture for the purposes of this study. Semi-structured interviews such as plant and checklist interviews are a major part of ethnobotanical research and were used in this study to collect different types of plant use data (Alexiades 1996). Other semi-structured interviews focused on Yagua culture, community governance and organizations, indigenous federations, logging and commercial fishing industries, perceived needs, and natural resource problems. Semistructured interviews were also conducted with NGOs and indigenous federations as described above.

Structured interviews about household members, medicinal plant use and preparation, involvement in community governance, organizations, and indigenous federations, employment, and language use were conducted with the head or heads of household with about one-third of the households (13 interviews out of a total of 32 houses) using systematic random sampling. (See Appendix 2 for the structured interview questionnaire.) First, with the help of participants, I drew a map of all the houses in the community, which are in one row along the river. Starting from one side, I marked every three houses as a household to interview. If after several weeks of almost daily attempts no one was home, willing, or able at one of the designated houses, one of the houses next door was attempted; this happened for two of the interviews. Restricted free listing of 
medicinal and other important plants was included in the questions to elicit comparable and quantifiable data about this cultural domain as Cotton (1996) describes.

\section{Focus Groups, Meetings, Workshops, and Photographs}

I conducted several focus groups using mainly purposive and also volunteer samples. For this study, focus group is defined as three or more people; groups ranged from four to more than a dozen. Focus groups incited interaction and dialogue among people, triangulated data from individual interviews, and lead to interesting discussions of research topics. Groups included a women's group at their request and one comprised of community leaders, and issues discussed included community problems, Yagua culture, stories from the past, use and preparation of medicinal plants, and NGOs and protected areas, among others. I also utilized focus groups to clarify concepts such as illnesses that I did not understand, determining cultural consensus of their explanations. People were shy to speak in meetings, in large groups, and when leaders were present, but smaller groups without leaders elicited more conversation.

Meetings and workshops consisted of largely volunteer and convenience samples, and the number of participants varied. Ideas that surfaced in key informant interviews and observations lead to the topics for these group events. The medicinal plant workshop, where people brought in plants and explained usage to the children and other community members, was very successful. During meetings I showed slide shows of the community photos I had taken.

I photographed about 1,300 digital images of people, plants, cultural artifacts, places in and near the community, and special events. As mentioned, I lent a camera to the 
community as well for them to take photos when I was not present. These visual data provide a more in-depth analysis than textual data alone since many details were difficult to document in written form, and photos aided in plant identifications.

\section{Data Analysis}

\section{$\underline{\text { Primary Data }}$}

The above methods for primary data collection produced mainly qualitative, textual data and some quantitative data. In terms of analysis, inductive and in vivo coding techniques were utilized (Bernard 2002), so topics and themes were organized using participants' words and ideas. Tape-recorded interviews, focus groups, and meetings were transcribed and then compiled by topic, and field notes from participant observation were also organized by topic. All medicinal plant use and preparation data from all methods were compiled into a database. Natural resource issues, cultural, historical, and other information from all methods was grouped into categories and then compared and assessed. Many of the findings were verified through triangulation.

For the data from the structured interviews, an entity-relationship model was created. (See Appendix 3 for the entity-relationship model.) This method combined variables into logical groups and determined their relationships to each other. Then, an Access database based on that model was built, and the data were entered and analyzed. Using this database, queries were executed to compare two or more variables and their components at a time. 
A complete plant list with all of the plants mentioned through all of the methods was created (Appendix 4), and scientific names for each were located. Scientific names were identified using only the Spanish common names given by the community and photographs for many of them: with no voucher specimens, many of the identifications may be approximations. I identified plants using Duke and Vasquez's Amazonian Ethnobotanical Dictionary (1994), a Peruvian Amazon medicinal plant book (Desmarchelier and Witting Schaus 2000), a dissertation on plant resource use and management in a nearby Peruvian Amazon community (Lamont 1999), and the Foster et al. identification guides (Foster, et al.). When there was a discrepancy, I went with Duke and Vasquez. When more than one species was a possibility, I gave only the genus. The list includes cultivars and varieties as well as species when separate common names were used, and in some cases, the same common name is used for more than one plant. Abuta, motelo sanago, piñon (rojo and blanco), and trompetero sacha are examples of these problems. I always retained the community's words and distinctions, treating each common name as a plant on the list, and I tried to be as accurate as possible. A Project Amazonas biologist who is very knowledgeable about flora in the region edited my final list.

As Cotton (1996) describes, free listing of important plants can elicit comparable and quantifiable data about this cultural domain, and the data can be used to analyze similarities and differences at household levels, to assess cultural consensus of important plants, and to verify findings through triangulation. For this study, the structured interviews included free listing of important medicinal plants. A community top ten medicinal plant list was generated using Anthropac software (Borgatti 1996) ${ }^{5}$ which 
creates a saliency index by compiling all of the respondents' top ten lists, calculating both the plants' rankings on the lists as well as the number of mentions across all lists.

\section{Secondary Data}

Since the social and environmental context of the community is integral to this study, a review of several areas of literature, summarized in the literature review above and also in the discussion below, contributed to the analysis. Cultural data from this study were compared to previous Yagua ethnographies, and plant use data from the community were compared with findings from other Amazonian ethnobotanical studies. To better interpret and analyze the case study and to consider implications for cultural and biodiversity conservation and natural resource management, I also researched state policies, development and conservation activities, and other relevant issues that are affecting local indigenous peoples and the environment. Analyzing all of the above data types together, I assessed the community's cultural and environmental circumstances, needs, and traditional botanical knowledge. 


\section{FINDINGS AND ANALYSIS}

\section{The Yagua Community of Comandancia: Social and}

\section{Cultural Overview}

\section{Introduction}

\section{Lifestyle Overview}

The Yagua community of Comandancia is located on the south bank of the Orosa River, a southern tributary of the Amazon River, in northeastern Peru about 150 river kilometers east of Iquitos. The Orosa is a black water river except for the seasonal white water influence from the Amazon. The várzea and igapó forests along the Orosa are seasonally flooded, and on the other side of the river from the community are seasonally flooded swamp forest and floodplain lakes.

The community subsists on swidden-fallow agriculture, fishing, and some hunting and forest extraction. Sweet manioc, plantains, corn, and sweet potatoes are their agricultural staples. Fish are their primary source of protein, and they fish in the river or in a nearby cocha (oxbow lake). After hunting and gathering, they return from the forest with a backpack made of palm leaves filled with animals caught and fruits gathered. Some families have a few domestic animals such as chickens, ducks, and local fauna such as the matamata turtle. A few children have pets including parrots, spider monkeys, and pichico monkeys. Access to modern health care is limited, and many people use medicinal plants. They make small boats and canoes for their river transportation, some motorized and some with paddles, periodically resealing the cracks with tar. There are no 
radio communications or electricity, but music is occasionally played with a battery-run tape player, and a TV and stereo powered by a generator are rented for parties.

Greeting people while walking past or approaching their homes every day, I would ask "How are you?" and their reply was not "fine," but invariably: "Here we are." The 32 houses are widely spaced in a row along the river, so everyone has direct access to both the river and the forest with garden plots in the land behind the houses. Twenty three of the houses are part of upper Comandancia, with the school between houses 13 and 14. Lower Comandancia, accessible by river or a trail through the forest, contains seven more homes of related families. The leader said that they will build houses in the main part of the community for the families who live on the lower side, including the community vice president. (When I use the term "the leader" throughout these findings, I am referring to the patriarch of the most prominent family who holds and has held the most leadership positions, detailed in the organizations section below.) Currently homes are constructed with wooden planks raised off the ground and a thatched palm roof, mostly without doors or outside walls, and furnished with woven hammocks and wooden benches. Children and adults often enter other people's houses without permission whether or not they are home.

Playing soccer is the main recreational activity and provides excitement and joy for the community. Many of the men play in the field behind the school in the late afternoon while women and babies sit on the ledge watching and nursing, and children run about. Women who are usually quiet in their kitchens and at meetings cheer and shout commands to the players, their sons and family members. The women also play soccer in the smaller field in front of the school or after the men's game has ended. Project 
Amazonas' staff sometimes comes to play with the men, and soccer tournaments are also arranged with other communities.

\section{Demographics}

In the enormous Peruvian department of Loreto that covers Iquitos and much of the northeast of the country, the province of Maynas contains the district of Las Amazonas, an area of 6,592.27 square kilometers. The community of Comandancia is a part of this district that had a total of 10,331 people as of the 2007 national census. Children 14 and under make up 44.7 percent of this district total, adults between 15 and 64 are 51.3 percent, and people 65 and over are just four percent (INEI 2007). This study's data from the household census portion of the structured interviews below also confirm these population demographics at the community level, most notably that around half of the population is under 15 and that there are very few people over 65 .

According to the IBC's SICNA database, the Yagua community of Comandancia had a population of 212 with 37 families as of their last census (Instituto del Bien Comun 2008). The leader told me in an interview that there are currently 245 people in Comandancia with 47 total families, 22 of which have children in school. However, over the course of the fieldwork, I discovered that some people had difficulty with numbers and remembering birth dates, so some of the self-reported data below from the structured interviews may not be entirely accurate.

Findings from the 13 structured household interviews are described in several of the sections below such as the organizations and medicinal plant knowledge sections. (See Appendix 2 for structured interview questionnaire.) These 13 interviews were conducted 
with 20 interviewees because many were couple interviews with both the male and female heads of household. The 20 interviewees ranged from 22 to 58 years old. A census of each of the 13 households resulted in data from 22 families totaling 108 individuals. Out of the 108 people covered in the census, 76 of them, about 70 percent, were born in Comandancia. Fifty six of the 108 are 15 years old or older: voting adults and often married and with children. Forty eight percent of this sample is under 15 years old. Table 1 below summarizes these data.

The average number of living children per woman for all of the families covered in the census is 5.4. For women over 40 years old, the average number of living children is ten, presumably closer to the total number of children in a lifetime. Since a few of the women over 40 years old included in these interviews had unusually low numbers of children, the total number of children in a lifetime for many women in the community is even higher than these averages. Removing these outliers, nine out of the 13 women over 40 years old have 11 or more living children.

All of these numbers, however, are for living children, and since miscarriages and deaths were often mentioned, the number of pregnancies and childbirths in a lifetime is higher. When asked, "How many children do you have?" " a typical response was as one woman replied: "I have had 12, but of 12 only eight are living. Six women and two men." According to Project Amazonas literature, life expectancy in the Orosa River area of which Comandancia is a part is 52 years, and infant and child mortality occur at rates of about ten percent. Previously, infant and child mortality rates were around 20 percent, and life expectancy was lower (Project Amazonas 2000). 


\section{Table 1: Community Demographics}

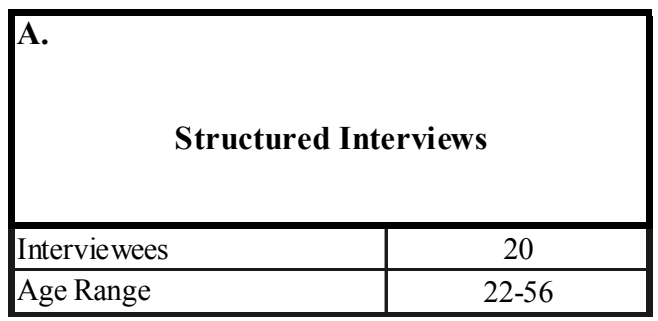

\begin{tabular}{|c|c|}
\hline Women in Census & $\begin{array}{c}\text { Average Number } \\
\text { of Living } \\
\text { Children per } \\
\text { Family }\end{array}$ \\
\hline All Women & 5.4 \\
\hline Women 40 and Over & 10 \\
\hline
\end{tabular}

\begin{tabular}{|l|c|}
\hline \multicolumn{2}{|l|}{ Beople Included in Household Census } \\
\hline Total & 108 \\
\hline Born in Comandancia & $76(70 \%)$ \\
\hline 15 and Over & 56 \\
\hline 18 and Over & 51 \\
\hline
\end{tabular}

\begin{tabular}{|l|l|}
\hline Women over 40 & $\begin{array}{c}\text { Number of } \\
\text { Children }\end{array}$ \\
\hline 9 out of 13 & 11 or more \\
\hline
\end{tabular}

Table 1: A. The structured interviews were conducted with male and female heads of household participants spanning this age range. B. In the household census conducted with these interviewees, birth place and birth date data about 108 people were collected. C. Separating the women aged 40 or over gives a better indication of average number of children in a lifetime. D. Since a few of the female interviewees over 40 had unusually low numbers of children, the total number of children in a lifetime for many women was even higher.

\section{Background}

\section{People and History of the Community}

A middle-aged woman told me about her past and how the community used to be.

She said she was born in Comandancia, which consisted of about five or six houses at that time, and her parents had been born there as well. They used to live further inland and moved to the river when the school was built. Originally, the only families were the Panos, the Cahuamaris, and the Santanas, she said. Different Yagua clans are still retained in the community members' last names, such as the Cahuachi clan to which most of the leaders belong and the Cahuamari clan. Almost everyone is extended family of the original inhabitants or the few families that arrived later. Not everyone currently 
living in the community is of Yagua descent, however: I encountered one Inca, one Bora, and an Ecuadorian Quichua who had married into the community. Some of the Yagua families came from other communities and even other countries. The leader said he was born in Columbia and moved to this area in 1973. A mestizo man who had grown up on the same river- "I am naturally from here, from this Orosa," ${ }^{10}$ he said- incidentally ended up settling here. "Here is all a mix- mestizos, Yaguas," ${ }^{11}$ he explained, although Yaguas clearly comprise most of the community. When I asked the wife of the Quichua man if Yagua culture has changed, she said, "The culture is different. Now they come from different races, they are not pure- there is change." ${ }^{12}$

After the 1974 Native Communities Law was implemented, communities in Loreto and elsewhere began to receive land titles. The size of the titled plots was too small in many cases and does not cover all of the forest and river areas used by the indigenous communities for subsistence and market activities, so many are now seeking to expand their legal holdings. The leader told me that Comandancia was formed in 1982 and was named after a commander. He had asked a church to help him build a school here since there was none before. In 1984, the government demarcated the village boundaries, and later Comandancia was titled, he said. He said that they cannot sell their land, but they can do whatever they want with it. According to IBC's SICNA database, Comandancia was registered in 1986, and their land title was registered in 1989 for 1,814 hectares, although they use 3,437 more (Instituto del Bien Comun 2008).

The first mestizo couple to join the community described in an interview what they encountered when they first moved to Comandancia 14 years prior, around 1990. They left their house and farm in Yarina, a nearby village, and came with their children and 
chickens, ducks, flour, and food. But when they arrived, there was no more land, no more plots. "My daughters, Christina, how they cried," she described, "because you couldn't see anything." 13 "My daughters cried, they said 'Let's go, mom, let's go back. What are we going to do here?' They said, 'The wild Indians are going to finish us off!' they said."14 Finally they received a piece of land, she said, but "It was totally overgrown, Christina, my God." "It was jungle!"16 her husband interjected. They set up a little shelter, and "We and my daughters began to clear with machetes," ${ }^{17}$ she recalled. For a time, the only area cleared was "just the paths to the doors," 18 and "this path they made too so the children could go to school."19 They made a larger shelter, and later a regular house. After a while, it has "all been cleared. We've cleared all of it already. Lots of manioc has been grown here," 20 she said. "We've planted all of it, this was manioc." "Plantains,"22 her husband adds. Why they can no longer grow these crops near their house is explained in the environmental section below. Their daughters married over the years and built their houses nearby because "my daughters didn't want to leave me." 23 "And that is how I came to live here," she concluded her story: "Those are the things that have happened before." 24

\section{Past Yagua Communities: Culture and Food}

While interviewing some of his older family members, the school teacher, a key participant in this study, explained: "We want a history, a history of memory, how they had lived before, how they lived previously... We want to know about the formation of

our people, how we formed." 25 The leader also expressed similar desires in an interview: "We want to talk about history, of the past, of our ancestors, so that our children, for 
those who want to later, will have this memory: the history that the Yagua people lived together."26 The leader told me stories he had learned about how the Yagua people had suffered during the rubber boom and how badly the patrones (owners or employers) had treated them. These participants and many others valued documenting stories about the past and Yagua knowledge, especially in the Yagua language.

People talked about their past, usually with great fondness and rhetoric of abundance and joy. Livelihood and food, including masato, a Yagua nutritious alcoholic manioc beverage, as well as family relationships were discussed. In one focus group, a man described his past: "Before, my grandma and my grandfather, my grandma made her masato. And my grandfather went to the forest and brought back [animals] and gave it to the woman here in the kitchen, and she cooked. And after cooking... visitors, masatowell, they drink, there they were together."27 They had their little house, and they drank water from and fished in the creek. A creek would not provide enough fish for a community, rivers have more fish, he explained.

In the past, he said, houses were far from each other, between an hour and an hour and a half walking from one to the other. They used drums and instruments to communicate. When they were going to meet, they had to go far from one house to another to inform people. "They don't lack anything- they eat, they drink, ${ }^{, 28}$ he concluded. "Dancing, eating, drinking- they don't lack anything,",29 a woman echoed. Another woman in the group agreed:

Well, truly that's how it was before. When my uncle existed, my brother-in-law's dad. When he came to invite my dad, truly that's how it was, that story. That my uncle never invited us for no reason- there was masato, there was smoked meat, there was baked beetle larvae, aguaje [fruit]- and truly he invited us to eat. They didn't use before these plates from here- they had their earthen [pottery]. In truth, then, like 
that, my uncle invited us before, and you ate well, you drank well, and then you returned well-fed. And that's truly how it was before. And so, as my brother says, then, we lived like that before... There we go, children, with my mom to eat. Truly it was like that before, then. You ate well, you drank- not hungry like now. ${ }^{30}$

She laughed. "And there are no ancient people anymore also. They are all dead already,"31 the other woman lamented.

In another focus group, people discussed other aspects of Yagua history and culture.

An older man shared his memories: "Previously, my grandmothers- I'm going to tell a story about how it was before. She told us how to do dances, from where and to where we go. By the sun, and by the moon. She told us: when the moon is born, soon the moon ages and is lost- it is a month, there are 30 days." ${ }^{32}$ A woman commented, "How she had her experience! She didn't know, but-" ${ }^{, 33}$ The man continued:

The sun does not have that like the moon, the sun comes out every day. They realized, my people, what time it is. Now it's late, now when the sun is over here. And my people said in Yagua language, "Now it's three in the afternoon." They would go to some creeks, and they looked at the sun to see what time they are going to go back. And they went back to make food in their houses. With all of their children, their elders, they waited... They gave food to their children and grandchildren, and that's it.

Previously, they did not sleep in a bed. In a hammock. Just like here. Ancient people. Previously, it's making me remember, that previously, there was an earthen plate, charcoal is put there, and it's put underneath to scare away mosquitoes. It's put there, there it is smoking, warming. It's put under the hammock, and it doesn't burn you. ${ }^{34}$

Cultural change is another important theme in their discourse, and some of these changes are further discussed in the sections below. In an interview, the leader summarizes the cultural transitions he has seen in his lifetime:

The changes that we have seen in this life, that during our life we have seen, are that we don't wear our [traditional] clothing anymore- it's all clothes. We don't speak our language anymore. We don't do the dances at every party that we have anymore. So it has changed a lot. We don't use our typical songs anymore. Stereos are used that do not agree with our reality anymore, and it is changing quite a bit. It seems that the 
year 1955 had changed and continues changing until now. Already many are forgetting the customs. The older people themselves do not want to show the children the culture anymore, they don't want to sing anymore, many don't want to speak their language anymore.

So, for us it has been a change, and from then until today; for that reason we thought again to write and value our own culture. Our very own selves have to say yes: what we still talk about today is conversing with the children, is making the children understand that Yagua is a country in Peru, is a language in Peru because Yagua exists in the Loreto region, not in all parts of the country. One part in Brazil, and another part in Bolivia. They are the places where our indigenous Yagua populations can be found. ${ }^{35}$

\section{In the Past: Health and Environment}

Yagua culture and society, people's health, and environmental location were all inextricably linked to each other in Yagua history and were profoundly affected by exposure to mestizo society. This is one of the major themes that emerged when people

talked about their history. In an interview, the teacher provides an overview:

People lived far from the river, they lived in the forest, and few used medicine... what they had was just the flu. Whooping cough, as they say, they were afraid of that, earlier people. But as the time arrived, they had to get to know about, let's say, the river, didn't they? Make their villages. Previously, then, it was a community, wasn't it? Where they had made a community, where only [Yaguas] live. But since now, well, it's not like before anymore. Before they lived alone, just one family was a community. But now not anymore, today the community is comprised of several last names, isn't it? Well, there are different ones. And so, I, I think that also because of that, there is change in the ideas that are used- they are different. ${ }^{36}$

This topic was also discussed in focus groups. In one of them, a man also highlighted the disease-avoidance of his ancestors:

I would like to tell you the story of my father, he who came before, you know? So before, just as our friend is saying, they didn't know about anything, did they? They lived in the forest. They did not want to live here on the riverbank. Because here they say are diseases- the flu... measles... And they didn't want to drink water from here. They preferred to drink water from the creeks, not from the rivers. And when a boat passed, my people before preferred- [they said] "there is disease." Then little by little, we have lived more civilized. ${ }^{37}$ 
In another focus group, similar histories emerged. A woman began by saying that "previous people did not live not even close to the rivers. Before, they lived out there, in the forest, along the little creeks." ${ }^{38}$ A man explained further:

Miss, in the past they were scared of the mestizos. In other words, they had never known mestizos... "They are coming!"- that's what ancient people said... They don't want to see people from here, from the Amazon. Furthermore, from here diseases are carried, for example, flu. And, well, so they didn't want to come near... But now, we already know how to speak Spanish. And so we are near the bank of the big river already. It's not like before, we didn't talk, we didn't even understand Spanish. ${ }^{39}$

"It's not like now when the kids know how to swim in the river. Who's going to know how to swim in little creeks?!" the woman added. "They were scared of diseases," ${ }^{40}$ she agreed. "Sometimes a mestizo has measles, whooping cough, that's it- that's why they were afraid," ${ }^{41}$ the man reiterated. They avoided all contact "because they were scared of the mestizos" ${ }^{\prime 42}$ and their diseases. He summarized: "Since we didn't know Spanishnothing, nothing, not even a few words- Yagua language is spoken... But more than anything it's because of diseases that they did not want to get near the mestizos." ${ }^{\text {,3 }}$

\section{Families}

\section{Womanhood}

Perhaps because I am female, the women told me about the personal and family aspects of Yagua culture such as menstruation rituals and taboos, courtship, and marriage. In a focus group, a middle-aged woman said that she wanted to tell the story of her first menstrual period, and she spoke in Yagua, and the other women laughed. Then she explained: 
Miss, when we get our period for the first time, we can tell our mom. When we get our first period. We did not let my dad and my brothers who are men see us. We hid. Then, when my little brother looked for me, he tells my mom, that I just got my period. And so my mom told my dad to make my hut. A little hut. A little house, this small... So my dad made my little hut where I'm going to be alone then. When he finished making my hut, and my dad came back from there, my mom knows where I am.

So my mom left me there. For a week... There I made a little fire... With food there. We [women] ate certain food, not any food. Without salt... It was going to be four days that I was there in my little hut, and since I wasn't used to there, so, I say to my mom, "mommy, I want to leave already, I'm bored here."

"Who are you going to talk to? And she was scared of the tunchi [evil spirit]!

Sleeping all alone!" ${ }^{45}$ another woman commented. The woman continued.

I told my mom, and she told my grandpa. "Dad," she said to him, "you have to go to virotear [perform a ritual on] my daughter," she said to him. Well, he brought a blowgun, then, since it was early. So with a carapa of huacrapona [plants], not a little, big like this, he warmed it on the fire. There are three that are covered. And so my grandpa performed the ritual on me. And like that, all of it, to be with people again. He made piripiri for me to drink, he put piripiri on me, all that then so that nothing would happen to my brothers and my dad...

But mestizos are different. They have taken pills so that a lot of blood doesn't come down from them. And we also have then our remedies, like medicinals. I have that piripiri that I have for women over there. ${ }^{46}$

Female puberty and menstruation rituals such as the isolation of menstruating girls is common in Amazonian societies. The women of Comandancia claimed that the Yaguas in the community, not the mesizos, still follow the tradition of putting girls in huts, but I did not actually observe this. In another focus group, the teacher said that he knows very well that their ancestors lived before, but nowadays they do not know everything about the past and how the ancestors lived. For example, he said, ancestors had their plant fiber clothing, and he remembered that his grandfather had told him that they had something to support "the lower part" when going to the forest. He wondered how menstruating women took care of themselves when they were naked in the past. 


\section{Marriage}

In the women's focus group, I asked how Yagua family arrangements had changed from the past. They said that in the past, the man would go live in the woman's village. A middle-aged woman said that her brothers were not under her father's power, they were under her uncle's power. She said she would explain how women were given to their husbands in the past. First, she spoke in Yagua, and the other women laughed during her story. Then she said:

So like it was before... the husband was big and the girl cried. She didn't want to have a husband. So we forced her into being given away. "This is your husband." Then, well, she was given away to the man. So, once she was given, her mother, of the girl, made her big hammock to put her son-in-law there, to give away the girl, her daughter. And so she said, "well, this is your woman, you're going to take her away now, then, it is your woman." So, she cries because she didn't want to have a husband, then. A young girl that doesn't know anything yet, what a man is. And so, the girl cried. ${ }^{47}$

She told the story of her sister who at the age of 13 was given to a man who was over 20 years old.

And so I myself have seen my sister. When they gave her away, my sister to her husband, they forced her because they never fell in love. And so I cried too, then, for pity for my sister. I didn't know what a man is. And my sister was given away. And my mom, tied up a hammock, I remember. To put my sister next to her husband. So my sister cried, "I don't want to have a husband, mommy," like that. "Why? This is your husband already, he is for you;" that's how it was before. When she said then your husband is for you, she was given away. And so I cried, for pity for my sister. He's going to take her away, who is going to wash my clothes? ${ }^{48}$

Another women told the story of when she was 13 and was almost given to a 25 year old man. Her grandmother had told her what was being planned, so she did not go with her parents. “They've talked parents with parents, but to the young person, they never told anything. I saw him, but I never talked... And I didn't know anything about them 
going to give me away... There they didn't tell me anything. My clothes were in a bag with my mom, ${ }^{49}$ she explained. The man said to her dad, you did not keep your end of the deal, and later when they were intoxicated, they fought, she recalled, and then repeated the story in Yagua.

A woman who does not speak Spanish told the story of her and her husband in Yagua. Another woman translated for her: "When she had met with her husband, that her mom and dad didn't like him. Because he says he was an 'Indian,' and 'no, why have you met up with that Indian, he's going to eat us,' he said. That's what her dad said." ${ }^{50}$ I asked why "Indian" and if he is from another group. She said yes, another group; they are Quichuas. She continued the story:

And so, her dad and her mom say they didn't like him. "When you are going to have a child, we are going to throw your child in the water so the paña [fish] eat him," her mom said like that... And she, she wanted, then, her husband, she didn't want to leave him then, you know, when you already have two, three children. How are you going to want to separate from your husband?... And so, her dad said... and he wanted to throw her children in the water, so the fish eat them.

So she said to her dad, she loves her husband, because "you aren't going to buy my clothes, you're not going to buy my underwear."... A father, well, sometimes does not have the possibility to buy for you, you know... And so, well, she didn't want to leave her husband, then, she was used to him. Because he bought her clothes, because, her husband, to serve, then, her... And so, then, until today, she has continued living with her husband, she very well, they live peacefully, with their children. Now that her dad doesn't exist anymore, he died. ${ }^{51}$

The other women laughed, and she encouraged more women to tell their stories, but many were shy or embarrassed.

Nowadays, they say, things have changed a lot. Young people become boyfriends and girlfriends and talk to each other about getting married. One woman explained: "Well, many times the young man has to present before the father, before the mother. As we say, the common word, is 'ask for her hand.'... Yes, now they talk among themselves. 
It was different, today they talk more." ${ }^{, 52}$ Another woman added, "Today the dad can't give away the girl like that anymore; now they know how to fall in love, then." ${ }^{, 5}$ The other woman said that after asking for the woman's hand, they go to unite that night or in a week. She explains that not everyone in the community is married, most are just living together. In another focus group, the teacher said: "I think that previously, a very disadvantageous situation... But now they are saying frankly, now yes, truthfully we have to see our daughters, what they should want, and clearly our daughters have to present that truthfully they want to have a husband."54

\section{Yagua Language}

\section{Identity and Loss}

The Yagua language is a major source of cultural pride and identity for this community. Middle-aged and older people's faces would light up as they switched from Spanish into Yagua with enthusiasm in their voices. Many older adults were much more comfortable talking in idioma (language), how they refer to the Yagua language, and a few in the community do not speak Spanish at all. Middle-aged adults had spoken Yagua at home growing up with their parents and siblings and still speak Yagua when talking to parents, siblings, and other adult family members. At silent meetings where only a leader was speaking, when someone would begin speaking in Yagua, older people would start talking, and lively conversations would ensue.

In focus groups, middle-aged and older people relaxed and opened up by talking in Yagua, laughing as they told stories. After several hours I once asked if they were tired or wanted to continue recording, and a woman responded enthusiastically, "Continue 
on!" ${ }^{55}$ People really liked speaking in Yagua and told more stories and expressed themselves more this way, and then (presumably) repeated in Spanish. Stories shared in focus groups often began as one woman said: "I'm going to tell it in Yagua first.",56 Their enthusiasm during story-telling, laughing, and commenting in Yagua was not the same in Spanish, but they were very gracious in translating and explaining things to me.

Unfortunately, one of the main themes that emerged as a major need for the community that the adults expressed deep concern about is the Yagua language being lost. Loss of indigenous languages and diminishing numbers of speakers is a problem for cultures across the globe. Here in the Las Amazonas district of Loreto, only 0.8 percent or 66 individuals over five years old learned an indigenous language as their native language, and 99.1 percent of people five years old or over learned Spanish as their native language, as of the 2007 census (INEI 2007). The trend that most adults described happening in Comandancia is that they spoke Yagua growing up, but their children do not speak it now. As one woman summarized in a focus group:

In truth, before, we- my dad, my mom- we didn't speak Spanish, just Yagua. For, such as, for food, we called it- everything was in Yagua, and my grandparents spoke in Yagua. For us there was no Spanish. Everything was just Yagua. That's how we were before. Now, well, we three siblings talk, then, but my children, very little, now they don't know it. ${ }^{57}$

People brought up the subject of the language being lost in nearly all of the focus groups and individual interviews that included questions about Yagua culture or problems in the community. They usually blamed themselves, as exemplified by a woman's opinion:

Well, I am also going to tell that like when my parents and I were young, we never spoke Spanish... My parents still spoke Yagua to us before... I never spoke in Spanish with my parents... Now we ourselves are to blame. As a mother, with my 
children, we don't speak in Yagua. We are to blame. Knowing how to speak Yagua, and not teaching the children. My children say to me, 'Mom, why don't you teach me Yagua?... We have to speak Yagua with our children... We are to blame. We shouldn't blame others, then. ${ }^{58}$

In another focus group, a man responded to my question about cultural changes:

"Different. Now I see that- for me it's a different thing that we cannot speak with my people in our own language."59 "We cannot speak because we don't know. Before everyone knew. We don't know how to speak our language,"60 a woman lamented. The man continued: "Why are we Yaguas but the children don't know anything? Who is to blame? The fathers and mothers. For not teaching. Even I have two sons. They don't know. They understand, but they can’t speak."61 Another problem that people mentioned is that for the mixed couples where one is Yagua and the other is from another tribe, they speak in Spanish to each other and so their children cannot learn the native languages.

The leader's discourse on the subject of language considered the greater historical, cultural, and political players and institutions that have caused them to speak Spanish. He said that although most adults speak Yagua, parents do not want to speak to their children because they think Spanish is better now. Not everything about their new education system has been positive, he said, such as this language loss as part of the civilization process:

The children very little, they don't know how to speak their own languages or tongues anymore for the reason that the mestizos have transformed us into the Spanish language. For the reason that they always said to us that when you speak your language, 'You are not Indians anymore, you are civilized now.' But that for us, talking about the Yagua language and other nationalities, other languages- they are the same as us in that they have also valued their cultures like the Yagua people are valuing. ${ }^{62}$ 
He gave the following message to young people: "Brothers, I also want to leave this message. Never stop speaking your own language, our own tongue. Because we cannot lose our great Yagua stories... We want to face, saying that we are Yagua, with our language, recognizing that we are Yagua." ${ }^{\text {63 }}$

\section{Preservation}

One of the most important values that the adults of the community expressed, then, was preserving their language. The teacher and his wife dedicate time and effort to maintaining the language through Yagua books and teaching children. She said that a few times in the past, foreign students have come to document the Yagua language, and one wanted to send her to Puerto Rico to work on the project, but she could not go because of her children. She and the teacher work on making detailed corrections of the grammar and diction in the few Yagua books they have. They have marked the mistakes in the grammatical explanation in the beginning of the Yagua-Spanish dictionary and other bilingual books. They said they want to send these changes to the editors, but these books are no longer being published. One of the bilingual books teaches how to prepare to give birth, and the other teaches about hygiene, both for forest communities.

The teacher is a true educator and plays a positive role in not only teaching the children, but also in educating and awakening the community about passing on their culture and language. He told me that he teaches the sounds of the Yagua letters to the children to distinguish them from Spanish and also five Yagua words a day, but that they really only learn about two a week. He sometimes showed the bilingual books to community members, trying to engage them in conversation about the errors and 
stimulate their interest in maintaining the language. From an interview, here are some of his thoughts about the loss of the Yagua language being one of the most significant changes in their culture:

Another thing, a change from previously, we all spoke in the mother language, and now it is being lost... So, the linguistic institute has always been a little concerned about looking for a bilingual teacher, and now we are working on this, but not much, no, it's not enough. Here, then, what is happening is that parents of children are stopping speaking with the same language to their children...

And there is change, in the case of the mother language, and now some know it, some don't speak. For example, I myself, I realize about myself. I am a teacher, right? My children don't know how to speak, none of it... and it seems to me that there it is- we are to blame, the parents that don't, don't seek to teach their children. Now I realize that my children- because you can't get there if sometime they want to be some professional- but they have to first speak the mother language. That is the bilingual education law now. That is what I am seeing the changes in, then, Christina. ${ }^{64}$

Clearly the Yagua language diminishing is a major concern for the community, and these efforts to teach and maintain it should be strengthened. It seems that people could also benefit from a better understanding of the social and cultural forces that have resulted in their current educational and political circumstances rather than individuals just blaming themselves.

\section{Community Life}

\section{Health}

"Health is primordial,", ${ }^{65}$ said the leader at a meeting. Without it, "you can’t work,

you can't do anything, ${ }^{, 66}$ he emphasized during a discussion about passing on medicinal plant knowledge. Commandancia does not have a clinic; the nearest health center is several kilometers away in Yanashi, and transportation is an expense. They do have a person designated as the village health worker, described more in the organizations 
section below, but lack of supplies and medical knowledge remain major problems.

Project Amazonas organizes and provides health care services and medicine, but they serve many communities across a large area with limited resources.

Women usually give birth in their homes with their husband and a midwife or their mother, I was told. Sometimes the midwife does not arrive in time if the baby comes quickly and so the husband is alone. One woman said that she had one of her children in a boat with only her husband there because they had no house during that time. No medicines are used, just soap and water and an herbal tea afterwards. After giving birth, a woman rests for about eight days while someone else cooks and takes care of the other children. Apparently they can give birth in the clinic in Yanashi for free, but only if they had been going throughout the pregnancy for check-ups, and they never did that because it was too far and difficult to travel. One woman told me about a friend of hers who went to the clinic the year before to give birth and died in the process.

During Chaumeil's fieldwork in the 1970's, he found health to be a major problem among Yagua communities. According to his findings, at that time the most frequent illnesses were: whooping cough, influenza, fever, diarrhea, intestinal parasites, measles, malaria and similarly transmitted illnesses, tuberculosis, geophagy, bad air, filariasis, insanity, and skin infections (Chaumeil 1987:171). In an interview with the teacher about health in the community, I asked him which types of illnesses were problematic in the community, and he listed the most common ones:

Here what there is most, as always, what they most suffer from, is diarrhea, vomiting, colic, sometimes there is cough, dry cough, and then there is diarrhea with blood, what they call 'pujo.' That is what the population here most suffers from... Sometimes we get bronchitis, and sight, vision. A lot of people are suffering from that, from sight. They lose their vision. It is- I don't know what the cause of this 
could be, Christina, I also do not know. Children sometimes do not see well. Here two or three people have sight like this. Children, even, sometimes lose their sight. ${ }^{67}$

He also said that these illnesses did not exist in the past and began more recently.

When I asked why he though the frequency of the symptoms and ailments he described were increasing, he identified the possible causes:

Well, I think that maybe because of change in climate- sometimes there is a high river level, a high level, the water, or it could be the heat. So that's why... [Before] it was hot, just like it always is, but it's as if, it has changed... and we don't know what the problem is, what's happening. Well, a lot of eye pain, as I was saying... Because of the sun. It seems like the sun is giving a lot of heat, Christina...

And the water, you bathe in the water, the water contains a lot of dirtiness. And maybe since we, we don't take care of our sight, right? You go into the water- the worst is that the kids get dirty with the mud, and the sickness originates from there. I think that it's because of the water, and because of the heat. That's the problem. The diarrhea also comes from the water. Here the population is not used to drinking boiled water, just pure, like before, you know? We're just used to getting water... and drinking... I don't know what could be the change in the- maybe because of change in, in climate, I repeat again. ${ }^{68}$

Several factors have caused health changes in the Yagua, but his idea about changes in climate is an interesting observation.

During my time in the community, I observed a few health problems and the accompanying concerns about accessing care and medicine and would likely have learned about more had I inquired directly. There were a few feverish babies, such as one that had been crying and sick for two days. The health worker gave her antibiotics and said if she did not get better soon, they would take her to Yanashi. The following day the baby's fever was higher, and someone suggested garlic and oil, but no one had any. Later that day, they did go, and when I inquired the next day, they said she was better after an injection at the clinic. One man hurt his knee while hunting at night, and it was swollen and painful. A child cut her finger with a machete, and motor oil was applied to 
the wound. Several people also had eye infections while I was in the village. Symptoms and illnesses are analyzed more systematically in the medicinal plants section below.

\section{Education}

For many Amazonian indigenous communities, schools unite villagers and are often at the literal center of the community, and such is the case in Comandancia. Killick's (2008) research in the Peruvian Amazon showed that for some Ashéninka communities, the desire to obtain land titles had actually been tied more to educational than territorial goals. He found that although families had lived widely dispersed and self-sufficiently under traditional arrangements, their value of education brought them together (Killick 2008). In Comandancia, in an interview a couple said that the most significant change to the community had been establishing the school, which had led them and many others to settle there, moving closer to a major river. The first school was a thatched-roof wooden structure like their homes, another couple told me, but now it is a large cement building that is also used for meetings and parties. The school includes six primary grades but no secondary ones. Students in these six grades share one classroom, split between two teachers on opposite sides of the room. The classroom is very spartan with desks, benches, old chalkboards, and a few posters.

The teachers and leaders talked about the value of education in a changing world. In an interview, the leader said that education in Yagua communities has advanced considerably. The teacher said that in the past, there were animals and wood to sell, but now there are not, so he tells his own children to study so they can look for other jobs. In a meeting, the community president said that they must educate their children to be 
professionals and obtain salaried employment so they will not continue to suffer from unmet needs. The teacher who is the director of the school has been an educator for over 20 years and is very dedicated to bilingual education, teaching the Yagua language and other cultural knowledge, such as medicinal plant uses. He engaged the students with questions before the medicinal plant workshop, and after returning to class, he followed up by asking about plant uses they had learned.

One of the major problems for education in the community is the lack of food, an issue that I describe more in the environmental section below. The community president said during a meeting that the children cannot progress in their studies because of a lack of food. The teacher told me that many times children come to school without breakfast, and often when they are too hungry to stay any longer, children leave the classroom to go fishing. Mestizo teachers in other nearby communities described the same situation: many children have to work and do not even attend school, and those who do are unfed and sometimes faint in class. "That is our reality," ${ }^{69}$ a teacher from another community told me.

Tied to this subsistence problem is the issue of attendance and participation, another difficulty in education that the teacher discussed at a community meeting. The children from lower Comandancia are further from the school and attend irregularly, he said. $\mathrm{He}$ called on parents to take care of their children and encourage their education. This issue is a challenge in many communities because children's labor is needed for family subsistence and because education may not seem relevant to everyday needs. Lack of school supplies is also a difficulty for community education. "The problem that we have. Why can't we have more education? Not everyone has money sometimes to buy the 
necessities, ${ }^{, 70}$ the teacher explained. They sometimes receive donations from people associated with Project Amazonas and infrequently government support, but in general, notebooks, pencils, and other necessary items are lacking. There are a few very used books and not much else in the classroom.

The final issue in education for this particular community is the tension between the administrators of the school and the local leaders, despite their public rhetoric supporting education in theory. This local situation seemed to adversely affect both teaching and learning and morale in general. For example, I was told that one of the sons of the leadership family wanted to be a teacher, but had never worked in the school and had caused some record-keeping problems. Apparently he had taken the students' files to Iquitos, so the teacher did not know which students were in which grades. There was an incident where an intoxicated leader threatened the teachers' jobs, and in general, their treatment of the teachers was unpleasant and diminished much-needed support for education. Despite these resource, attendance, and other challenges, the teacher is genuinely interested in educating the children and preserving the Yagua language and culture, working towards these goals every day.

\section{Celebrations}

People spoke with fondness about Yagua celebrations of the past. In a focus group, an older man described these:

We had parties... We invited our people. We had the custom, little drums, and [each] one with his music. And from there the people, the older women prepared their food in big pots. What is the pot made out of? Of earth. And from there, then, we finished the party, then all of the people, each one returned to his house then and 
carried their little drums over here, over there, others. Without any fight for any reason with anyone... That's how my people were before. ${ }^{71}$

A woman told me in an interview that in the past, once or twice a year, depending on how much manioc they had in their fields, they would have a big Yagua party. They would play drums and other instruments while dancing in the big round communal house, drinking and eating hunted meat, she said. They do not continue this tradition now, she said, because "the old people do not live anymore."72 "That was our joy,",73 she reminisced.

In another focus group, other people talked in Yagua and then Spanish about the parties of the past. A woman said, "Before, my grandparents, my dad, and my mom drank, they danced... They danced around in the house and... I was little, I watched how my mom danced. We [women] continue that history... We drank with little drums, and we danced....”74 In a women's focus group, someone mentioned past celebrations and rituals that women did not participate in. She said that they heard the men's shouts, but could not see them.

Another older woman explained the traditional roles for different generations: "When a mom danced, the daughters did not dance. And if the daughters already danced, a mom did not dance anymore." ${ }^{75}$ She continued:

That's how it was at that time when I was little and my siblings too... only my parents went, just old people at the party... And when they became women, only then did they start to participate in parties... they danced, they drank, but with respect in my dad's house. They don't arrive drunk. That's how it was, miss, before. But now it's not like that. Now, miss, you go to the party, the daughters dance... We have never drank, just a drink with my dad, and we have never smoked cigarettes. Young people at parties with adults, drinking, smoking, they don't respect sometimes their mom, their dad... Sometimes it hurts one's heart. ${ }^{76}$ 
The others agreed that parties had changed in this way. The woman said that she does not go to parties anymore because her children are now young adults and dancing, and she wants to set an example for her grandchildren. She said that it is also wrong to drink and work with children and their spouses. Her husband, on the other hand, said that he likes to go to parties and does not see drinking with his daughters and sons-in-law as disrespectful.

Peruvian Independence Day on July 28 came and went without being mentioned by anyone in the community. While in the field, I was invited to a large, elaborate birthday party in the community for a woman's $47^{\text {th }}$ birthday. They rented lights, a stereo, and a television, and first the children watched music videos, then popular Latin music was played all night while people danced. People were dressed in their best clothes, drinking and talking, and some sold candy and cigarettes. Hammocks were strung around the edges of the room for sleeping children. For food, they had a roasted pig and large pots with noodles and manioc. There were huge barrels of masato, and people also drank mixtures of milk, sugar, egg, vanilla, and aguardiente, or straight aguardiente. Some people gave bottles of liquor as gifts, and one of the sons of the leadership family took the opportunity to give a speech. He spoke in Yagua, and also said, "We are not mestizos, we are Yaguas." 77

I was fortunate to be in the community during the annual Yagua culture and language celebration that began on August $8^{\text {th }}$ and continued for several days. Women began making masato days before, and an older man in a focus group proudly described what they would do: "Hopefully you are going to be here for the party that we have. We are going to demonstrate a little bit of the past. The party is going to be the $8^{\text {th }}$. There's 
going to be a presentation. So you are going to see a part of us, the songs, what it was before. Five people are named, and five women to dance.",78

The communities of Santa Ursula and Santa Rosa were invited, and in the afternoon, they had a soccer match together. In the evening, the events began with speeches by the community president, the leader, the teacher, and a priest from Yanashi, who then led everyone in singing the national anthem. The leader spoke in Yagua, and then talked about celebrating indigenous cultures.

We as part of this world indigenous organization, we have to celebrate it, reminding ourselves of the great history of our Amazonian indigenous peoples at the level of Peru and at the world level. So, the pride of we the Yagua peoples, we are celebrating the day of our language, Yagua, of indigenous peoples of the country as also at the world level. So we have concerned ourselves a lot with valuing, writing, so that our peoples, the youth, and those that come after us remember our great history. What was the clothing of my grandparents? What was the custom of my grandparents? What was the song of my grandparents?... Not only the Yagua indigenous peoples, but also at the level of the Loreto region, at the world level, exist indigenous peoples of different languages on our earth. ${ }^{79}$

The speeches were followed by a few traditional Yagua songs and dances with beautiful music of drums and flutes. The dancers wore traditional Yagua garments of fiber skirts and other fiber accessories. "The Yagua still exist in the world," said the leader.

Some of the older people took great pride in these traditional songs and dances, but most younger people were more interested in the party in the school that followed, much like the birthday party described above. In the classroom, popular music played and people danced, and women and children sat along the walls. An entire room was filled with barrels of masato, and everyone drank out of the same bowl, as is also done in homes. The leader said that people are drunk, but tomorrow everything will be the same, so they should drink, dance, and enjoy. Late into the night, he asked me to tape record an 
elderly man from another community singing in Yagua. The man said that he sang better in his youth, but he is 80 years old now. He sang all the Yagua songs he could remember, including one about being rejected by a girl.

In the days after the night of the party, people continued drinking and celebrating in their homes with the relatives who had come from other communities. With the entire community intoxicated and relaxing, these days were not good for interviewing, but they were great for observing and recording people singing traditional Yagua songs and dancing traditional Yagua dances with their family members in their home. The teacher's wife's elderly relatives were visiting, and in her brothers' house, they told stories in Yagua and sang traditional songs, playing drums and dancing while the children watched. The teacher encouraged them, interviewing each relative and asking them to sing. "We want to know the traditional songs of our people... I know that you know the traditional songs of the past, ${ }^{, 80}$ he said.

They sang Yagua songs, each of which was used for a different communication purpose. The teacher translated songs that lovers used to sing at each others' houses, that men used to sing to make a woman fall in love, that a woman would sing to a man when she wanted his love, and the song that the man would use to respond. One woman said that if someone did not return feelings of love, they would use the piripiri plant since it is strong. Other songs included those they sang when they were inviting people to drink masato, and songs that young single people sang. In conclusion, drinking masato and other alcohol during these days of celebration with family and Yaguas from other communities encouraged talking and singing in Yagua, dancing, and a more overt cultural pride that is not as expressed in daily life. 


\section{Alcohol Problems}

Traditionally and currently, Yaguas and other communities drink masato while working in the fields and for parties and events, as described above, and these forms of drinking foster community solidarity and cultural pride. However, excessive alcohol consumption in daily life, mostly of hard liquor, by some community members and the resulting domestic and other forms of violence are major problems for this community. On a daily basis, I observed very intoxicated men and women drinking in their homes, congregating in groups outside, stumbling along, or passed out across the path through the community. "You from over there have capacity. Here what we have is masato," man told me. Self-deprecating comments like these seemed to reflect both low selfesteem and a sense of hopelessness that, augmented by alcohol, seemed to fuel many people's apathy.

People seemed to be used to and not very bothered by intoxicated family members and other individuals. Women would tell each other about who was intoxicated and being violent. One woman told her cousin about a man who was intoxicated and fighting with his equally intoxicated sons. Another woman told me that a young wife who was hit by her husband took him to court in Yanashi and he was jailed for 48 hours. Once when I was interviewing in the house next door to hers, she was hiding there with her baby since he was intoxicated and trying to hit and cut her. I inquired about a burned kitchen at the house of a couple that always drinks and fights, and she said that her husband had burned it down while intoxicated. One day one of the children who participated in this project could not go home in the evening because her father was intoxicated and hitting her mother. 
In a focus group, women discussed the alcohol problems in the community. First I asked what they thought about the increase in consumption that they described. "Well, for us it's bad. Fighting among family, ${ }^{, 82}$ one woman responded. Large amounts of alcohol is brought into the community, and some people are "not even one day sober," they are "drunk every single day," ${ }^{, 3}$ she said. "It's ok that they drink, if they don’t fight, $" 84$ commented another woman.

The women then shared the difficulties they have had with their sons who drink. "My sons started to drink at 15 years old, 15 years they already drink their masatos, ${ }^{, 85}$ a woman began. She told a story about her son who was drunk one night and fighting with his brother and on the verge of striking his father. She did not say anything to him that night, but the following morning she was very stern with him and told him he was never to fight with his siblings or threaten his father like that again. She told him that he does not see her and her siblings acting like that, and he promised he would not do it again.

And from then on, miss Christina, he never again confronted his dad. He gets drunk, gets dizzy. He comes to rest, and he sleeps. And he says to me, "Mommy, is there food to eat? I am dizzy," and he rests. "A good drunk sings, cries- that's a good drunk," I tell him... He drinks peacefully and he sleeps. That's a good drunk... My son shaped up already... He sleeps peacefully when he's dizzy. ${ }^{86}$

"Well, mine are like that too. My son is a drunk. That one is a crazy one," ${ }^{87}$ said another woman. "When he's drunk, you can't say anything to him. You talk, he doesn't answer anything," ${ }^{\prime 88}$ she said. She tries to teach him to follow her example, but "that one is a crazy one, then. He's a bad drunk, I won't say he isn't. A bad drunk." ${ }^{89}$ Her other son is better: when he comes home intoxicated, he sleeps, and sometimes she gives him her bed. "He asks me if there is food. There is food, sometimes I give it to him. And when there isn't any, where are you going to give it to him from?"90 
People's intoxication was also the main barrier to research. Each day, the young people who worked with me would point out which people were intoxicated and thus could not be interviewed that day. Some houses were never able to be interviewed, and eventually some interviews had to take place with partially intoxicated people to maintain the sampling method.

\section{Organizations and Federations}

\section{$\underline{\text { Relations with Government }}$}

In Peru, the legal framework regarding indigenous communities consists of three laws: the Political Constitution of the State, the Civil Code, and the Law of Indigenous Communities and Agrarian Development in the Lowland and Andean Forest (Pitman, et al. 2004). Indigenous communities are considered legal entities in the public interest, and they have autonomy over their internal organization, administrative and economic management, and use of their lands and natural resources. However, most of the current day conflicts between indigenous communities and the state center on economic and environmental policies that result in extractive industries operating on or near indigenous lands. Investigating indigenous communities' various relationships with different government agencies is beyond the scope of this study, but I noted when Comandancia community members mentioned the government or linked a particular natural resource problem to the state.

In an interview, the leader of Comandancia summarized the history between the Yagua and the state: "Before, the Yagua did not know how to read and write, but 
nonetheless, they had their stories, their pasts, where they could live peacefully on their land with their natural resources. And they never bothered the state, they didn't bother the authorities like now during these years that we are suffering." ${ }^{91}$ He said that the government does not care about them, they have to fend for themselves, and there is very little help with obtaining agricultural loans. During a focus group discussing community problems, the teacher also commented that the municipal authorities do not come to see them or support them in any way.

As occurs with communities in many places, local and national politicians make promises to the community in the political campaign season before an election that are rarely fulfilled. One result of their experiences with the different sectors is that people expressed more hope in international NGOs than in the government to help with their needs. As the leader described the situation:

What's going on, Christina, is that some organizations have their own funds, they have their own projects, that have already been working for like ten years, some federations, with their own resources. And FEPYROA does not have any. It has absolutely nothing. We sometimes have to bother other NGOs for them to give us even 100 soles, 200 soles to be able to do administration for the communities that belong to our organization...

That's why it is very important that we insist on recognition from many of the regional leaders, that they do some projects for us, to try out in a meeting in the communities. In order for this- well, I don't know if they could do it at the international level, at the national level. Because at the government level of Peru it is difficult, difficult. They have not wanted to recognize our projects, but then during campaign season, they all want the indigenous votes because there are so many millions that exist, and the votes of the indigenous communities to elect the government. $^{92}$

State policy and extractive industries have led to natural resource problems for the community, as is discussed in the next section. In meetings and focus groups discussing community needs and potential natural resource projects, the discourse of the leaders 
centered on the role of the government and industry. In a focus group, after describing land and livelihood problems, one of the leaders said: "Who is to blame?...The government, that is what sends all of those businessmen out here, because it is receiving money for wood, for territory, whatever they are selling. The Peruvian government is very bad. Why? Because it doesn't think about us as indigenous people... On the contrary, they want to kill us from hunger." 93 These commentaries seemed to contribute to attitudes of apathy and hopelessness in other community members and did not encourage discussion and collaboration to try to improve their situation. It also seemed that the leaders sometimes adopted the rhetoric of a united community working against the government as a shared outside threat in part to deflect criticism about their leadership or an inequality or injustice at the community level. The speech ended with this commentary: “... and we are all family, I could not discriminate against anyone. We all feel the same pain, we all feel the same hunger... we all have the same problems." 94

\section{$\underline{\text { Leadership and Power Problems }}$}

\section{Power Structure}

The structured interview included questions about past and present membership and leadership positions in community governance, community organizations, and indigenous federations, and the resulting data is presented in Table 2 and discussed below. The ratio between total leadership positions mentioned and the number of individuals occupying them appears to be a fair distribution of power: out of the 51 adults in the interviewed households, 18 different individuals have held or hold 40 total leadership positions. Ten 
different individuals currently hold the 17 leadership positions that were mentioned (Table 2B).

However, separating the data about these 17 current leadership positions and focusing on the nine highest leadership positions reveals the major power structure problem in the community. (Highest leadership positions were defined as: positions with FEPYROA, community president or vice president, health promoter or vice promoter, and presidents of the Family and Artisan associations.) Eight out of the nine highest leadership positions mentioned are held by the same immediate family (Table 2C). Out of these eight positions, four are held by one person, three are held by his son, and one by his wife. The man with four current highest leadership positions is president of the Parents' Association, president of the Artisans' Association, the Health Promoter, and the asesor (advisor) of FEPYROA, as well as being previous president of the community. One of his sons is the current community president, the vice president of the Health Committee, and an advisor in FEPYROA. His wife is the leader of indigenous women for FEPYROA. Another son, not included in the structured interview sample, is the president of FEPYROA and the vice president of ORAI.

Data from interviews and observations also support that power and decision-making are largely controlled by one man and his immediate family. The concentration of power in one family alone is perhaps not necessarily problematic, but many community members complained about the lack of democratic process and voiced their grievances about the current system, some of which are described below. I discuss the cultural context of their political system in the FEPYROA section below. 
Table 2: Organizations and Leadership

\begin{tabular}{|c|c|c|}
\hline \multicolumn{3}{|c|}{ Current Leaders and Members } \\
\hline $\begin{array}{c}\text { Organization/ } \\
\text { Institution }\end{array}$ & $\begin{array}{c}\text { Leadership } \\
\text { Positions }\end{array}$ & Other Members \\
\hline Community Governance & 4 & All Community \\
\hline $\begin{array}{c}\text { Local Yagua Federation } \\
\text { (FEPYROA) }\end{array}$ & $\begin{array}{c}3 \\
\text { (all same family) }\end{array}$ & All Community \\
\hline Health & $\begin{array}{c}2 \\
\text { (all same family) }\end{array}$ & All Community \\
\hline Parents & 5 & 2 \\
\hline Artisans & 2 & 11 \\
\hline Cup of Milk & 1 & 5 \\
\hline
\end{tabular}

\begin{tabular}{|l|c|c|}
\hline B. & Leadership Positions \\
\hline & Total Positions & $\begin{array}{c}\text { Number of } \\
\text { Different } \\
\text { Individuals }\end{array}$ \\
\hline Past and Present & 40 & 18 \\
\hline Present & 17 & 10 \\
\hline
\end{tabular}

\begin{tabular}{|c|c|c|}
\hline C. Distribution of Leadership Positions \\
\hline & Total Positions & $\begin{array}{c}\text { Same Immediate } \\
\text { Family }\end{array}$ \\
\hline Present Highest Leadership Positions & 9 & 8 \\
\hline
\end{tabular}

Table 2: A. This table summarizes the results of the structured interview (13 households) organizational involvement questions about positions and memberships currently held. The low number of members of the Parents' Association may be due to participants without leadership positions inadvertently not mentioning their membership. B. Of all the past and present leadership positions mentioned in the structured interviews, about half of them are held by different individuals. C. After separating the highest current leadership positions by family, the community power structure is more evident.

\section{Elections and Leaders}

Men and women aged 15 and over vote for candidates to fill leadership positions in community governance, community organizations, and FEPYROA - at least in theory. I 
asked a woman who is actively involved and who was even the community president in the past about how often they vote, and she said she was not sure. Another woman told me that they do not really vote, that the leader just puts his children's names on the papers and arranges things in Iquitos. A man agreed that voting has not happened fairly. Since interviews were never really private with children from interconnected families running about, this topic was difficult to investigate.

An interview with a couple revealed the same findings. When I asked if there were elections and if they voted for the current community president, the man responded, "No. They appoint themselves. There are no elections. They have their meetings-" "95 "They appoint themselves, Christina," his wife explained. "They ask who is going to be the community president, and the people have said that it's going to be [so-and-so]. They choose among themselves. They say who it is, and that's it. And the rest-""96 "Among themselves, only among themselves," ${ }^{97}$ he emphasized. Then I asked when they will vote again, and he replied, "That we do not know, Christina." "We "We don't know," repeated. "Possibly, at any time, the people are soon going to work at changing him,",100 he said.

In an interview with the leader, I asked him if there are records of the organizations and their leadership positions. He said, "They are not in order right now. Sometimes there are in some notebooks, the records, where the names are, but now they are not in order." 101 I asked if there is any written record of previously held positions, and he said only "by memory. It is not known" 102 who they were. A key participant later told me that the community does have a record book that it is Iquitos, and the community 
president is supposed to have a copy. "I have seen the statute, and there is the whole family, ${ }^{103}$ he said.

The houses of the family of leaders, one of which serves as the base of FEPYROA, are located in the middle of upper Comandancia next to the school, and they have established relationships with the organizations and groups that come to the school to trade or donate. The leaders also have close family ties to lower Comandancia, and there are tensions between the families in the two parts of the village, I am told.

The leaders possess the oratory skills that Chaumeil (1987) describes as essential in traditional leadership positions. I observed that meetings and celebrations are often dominated by their monologues and speeches, usually a typical political rhetoric that is more lengthy and grandiose than substantive. The younger sons also speak loudly, clearly, and well, although they sometimes do not seem to know what to say. People in the community complained to me about the leaders not letting them speak at meetings and celebrations. A woman told me that the leader speaks in Yagua at events and does not allow them to even though many of them know how to.

People in the community told me about several problems they had with the family in leadership, the most important being that their cattle eat other people's plants, which is discussed in the next section about natural resource problems. Community members were not warm towards their leaders and would sometimes comment to me privately such as when one man said, "He has two faces." ${ }^{104}$ In an interview, another man said, "He is the only one now, there is nobody who can say anything anymore."105 Following are several of the other problems resulting from this power structure in the community. 


\section{Decisions, Equality, and Environment}

One problem that people brought up a few times was that the leaders do not inform them about news or decisions. There were several examples of this lack of communication, including about my coming to the community. One man described the lack of dialogue about issues:

That is what sometimes happens here in our community. A letter is sent, without knowing, without having any meeting, without the people's knowledge... It seems to me that that's bad, Christina. They want to do a report, first they have to consult with everyone, to see who are in favor and who are against. But here the authorities are used to reporting without knowing. In other words, the people, they don't know, they don't have knowledge of it. That is a problem that we have here in the community.

That family that is always- we know, don't we? Always against the teachers. And they never want to talk face to face- it's one of the problems, isn't it? Because if I have a problem, I can present it: "I have this problem with you," but they never... It seems to me that now you are already recognizing that that family- Without letting people know- it's a problem that there is... That's it, we don't know how to solve it, because they always go against you. That is what is always happening. ${ }^{106}$

Community members also said that donations and gifts were many times not

distributed throughout the community since people were not informed when they arrived, and they described several incidences when this occurred. Although most people are Yagua and were born in Comandancia, a woman told me that one of the leaders had said that the other community members are mestizos and that only his family is Yagua. They said this because "They don't want to notify us" ${ }^{107}$ when things arrive, she explained. Her opinion was that things should be distributed equally to everyone and all of the houses should be informed with something arrives.

People also expressed that the leaders are not taking enough action on their natural resource-related subsistence problems. When discussing extractive industries depleting their food resources during a focus group, I asked if it would be difficult to stop the 
freezer boats that overfish their waters. "I say that it wouldn't be difficult, miss, when the community president decides to put his mind to it. Stop playing around," ${ }^{108}$ one woman responded. Another woman agreed about the importance of leadership and said that the previous president did little, and:

Now this one also is just the same. That's what we suffer from now, then. It can't be difficult, it depends on the authority, that's all. We also can join with when people from outside come, we can go with to say, "Well, you're not going to pass by here because it's prohibited." They are finishing off the fish, and the grandchildren, what are they going to eat? That is what the authority should do, then, what is the community's. But since he doesn't tell us anything, how are we going to join with to support? ${ }^{109}$

When I asked how some of these problems might be solved, a woman said in an interview, "I say, well, talking, if they want to, then- if not, well, what can be done?"110 Her husband gave his opinion:

For me, Christina, these problems could be solved, maybe changing the leadership. Maybe that's how it can be fixed. I think that if it's another leader. Because there is just family- there can be no solution. Because just them- it's them. What they say, and it dies there. And so, well, there is no solution. That's why I think that maybe changing the leadership. If it were others... So that's how it can be fixed because day by day the situation is getting worse. ${ }^{111}$

In summary, then, it seems that the power structure of this community is that much of the leadership and decision-making is concentrated in one family. Community members complained about the lack of democratic process, access to information about and distribution of resources, action on natural resource threats, and other problems. I cannot assess the validity of all of these claims, but people's words reflect their understanding of and feelings about what is certainly a very real situation that includes all of these components. 


\section{$\underline{\text { Participation and Communication Problems }}$}

Social interactions among families and neighbors are crucial in a small forest community like this one not just for the sake of good relations, but because everyone has a direct shared stake in the water, crops, animals, and other components of livelihood, and there is little outside recourse for addressing conflicts. Presented here is what people said about apathy and lack of communication as well as other deterrents to community organization. After a meeting where I observed people silently listening to monologues, I asked the community president how meetings are conducted to discuss things. He said that people are not used to being asked questions about problems, livelihood, and projects. When an agreement is made, people are asked if they agree or not, and they say yes or no, he explained. They do have many problems, he said, but they are not used to talking about them in a group.

The teacher also talked to me about participation, and said he would like to have meetings more often to keep people engaged. He said in an interview that he considers the lack of civic engagement of young people to be a change in the community and a serious problem.

And young people. Here in Comandancia, I'm going to tell you very clearly, that young people care little about... they are invited to a meeting and they don't go... They would have been better off attending the meetings so that they can learn about all of the agreements that one makes, so that they are learning. Because sometime we will die before, let's say, won't we? We are going to disappear, and who is going to remain as authority? Who is going to be able to work, let's say, at the center of the community, be an example? There is no one. This is a problem that there is here in the community...

And caring little about the community developing, right? Or to have good, good discipline... so that they are knowing, so that they are waking up... There is a meeting- only old people go, not young people, do they?... Someday the authorities are not going to live anymore as authority... They also have to learn, so that 
sometime they also become responsible as authority. That is what there is a change here I am seeing, Christina. ${ }^{112}$

The leader also commented on this issue during a focus group:

And that's it that around here, many get confused about jobs, the laws that the government makes. If we don't study it, if we don't know it, if we don't practice it, if we don't have meetings just like we are right now, many of the young people don't know, they don't know. So, why wouldn't they be here if there is a meeting here? Because they don't care about knowing, they don't care about learning. Because they think that with time, they are going to live just like they are right now. There's going to be everything. ${ }^{113}$

In an interview, a couple described a range of related problems that adversely affect organization, productivity, and community well-being. First the woman voiced her complaints:

You know, Christina, that when one speaks, the rest don't want to speak... Sometimes one complains- our right, isn't it?... So, I say that a meeting is for debating things... They stay quiet, Christina; the majority don't want to say anything... If they are all family, then, what can be done? If you talk, they remain. That is what happens here.

Instead of fixing itself up, it gets worse. Because doing it like that, then, it can organize itself, like they say, do something for the people to be ok, but no- instead of fixing itself up, the village looks just the same. ${ }^{114}$

“Even worse, worse. Don't you realize? When there is a meeting, people don't show up, ${ }^{115}$ her husband added. Only a few people show up at meetings, she agreed. She said that they go with their kids at the agreed-upon time, and sometimes they wait, no one arrives, and the meeting does not happen. She continued:

But the alcohol talking, that yes. Or if there's going to be a donation of anything, there, yes, the people go, Christina, it's totally full. But for a meeting- they don't show up. Have you realized?... That's what one wants: that the village improves... So I'm telling you again, when there is some donation- sometimes the mayor says, "I'm going to send such-and-such thing to the village"- that day you see people. It's totally full. But for a meeting, two, three, four at most show up. They don't care, I think, Christina, because they don't want to come to meetings. ${ }^{116}$ 
When I asked if people complained about problems they had described like the cattle eating their plants, she said:

But that, 1 repeat, Christina, when they are drunk, well, there yes, they have a mouth, but when they are sober, they don't say anything. Sometimes I say something about me. When I have something to complain about, right?, I have to talk to that person, I go to talk to him. But not them. When drunk they insult each other, they shout at each other, whatever, then... That is not the way to talk... That's what we suffer from here. ${ }^{117}$

Other people in the community also told me about the problem of people talking while intoxicated but not at meetings. One man emphasized to me that it is important to sit and talk face-to-face to resolve an issue, and that it is not good to say bad things to someone while intoxicated as many people do. It seems, then, that alcohol plays the truth serum role that it does in many cultures, but the more community-oriented people in this village view this behavior as unacceptable and not helpful in creating social change. In summary, then, the community has a number of communication and participation challenges that appear to be detrimental to organizing to resolve problems.

\section{Community Governance and Organizations}

\section{Governance}

Community governance consists of a president, vice-president, secretary, and treasurer, and they also have a municipal agent, police, fiscal agents and vocales (representatives). Out of the 51 adults that were included in the household census portion of the structured interviews, four of them reported having current community governance leadership positions. Community meetings are on the same date each month, except when they are moved for soccer tournaments, parties, or other events. 
As explained above, the previous community president, the father of the current community president, continues to play a major leadership role. Interviewing him about community leadership positions was difficult, however, because he could not recall who currently holds some of the community positions and did not seem willing to talk about this subject. "Right now I don't remember, but it's written in the record," 118 he said. Regarding the responsibilities of the community president, his response was vague: "Well, the president- to invite people to a meeting, to coordinate their activities that they have within their organization in the community." to write down all of the work plans discussed during meetings and to keep records, though I never observed this. The roles of vice-president, treasurer, and municipal agent for the district are as their titles suggest. "The community police currently are the representatives," ${ }^{120}$ he said. He explained: "As the community president, he has his board, his representatives, which are the police that inform about meetings, they inform which day we can have a meeting- that is their function." ${ }^{121}$ It seems that many of these roles are just official and in name only, having no bearing on actual decision-making in the community.

I asked about elections, and he responded: "Well, the statute says that every five years community president. Municipal agent, each time that the mayor is changed. And that is for three years." ${ }^{122}$ As described above, other community members did not respond the same way to the election question. In a focus group, he said that he would like to create statutes for the community, but "they charge us 150 soles to prepare a community statute. And you have to know the history of the community, of its internal laws. So all of those things cost." ${ }^{123}$ 


\section{Parents'Association}

The Asociación de Padres de Familia (APAFA) (Parents' Association), an organization recognized by the Ministry of Education, includes all of the parents of the children in school. Out of the 51 adults that were included in the structured interviews, there were five mentions of current APAFA leadership positions and two mentions of membership. This low membership number may be due to participants without leadership positions inadvertently not mentioning their membership.

In an interview with the leader who is also the president of APAFA, I asked him about the organization. He said that APAFA began when the school opened in 1982 and includes the 22 parents of schoolchildren as well as the teachers. The organization also has a vice president, secretary, treasurer, and representatives, and he named the people who fill some of these positions, but did not remember some of them.

The teacher was often trying to plan meetings to discuss education-related issues and mainly to encourage community support for education. One mechanism that I observed the teacher utilizing to try to improve education was to adhere to APAFA's meeting schedule even when the president of the organization was out of town. He suggested that he was better able to resolve issues this way, and he covered a lengthy agenda at these three or four hour meetings.

\section{Health Committee}

This organization is associated with the Ministry of Health which provides basic training to representatives from communities and some medicine. Two leadership positions were mentioned out of the 51 adults that were included in the structured 
interviews. The leader who is also the Promotor de salud (community health worker), or as it is called, the president of the Comité de Salud (Health Committee), said in an interview that this organization began in about 2000 and serves the whole community. There are six people with leadership positions: president, vice-president, secretary, treasurer, representative, and fiscal agent, he said. Besides himself being president and his son, the community president, being vice-president, he remembered who held one of the other positions and could not recall the rest.

In terms of duties, he said: "Well, as the Health Committee, its responsibility is to look after people and some sicknesses, in so much as, when there are medicines, of service to the people, if there is medicine." ${ }^{124}$ He showed me the medicines that he sells, and he said that problems include that people do not follow medication instructions, that medicine is too expensive for them, and also that now people rely on them instead of on plants.

Regarding the literacy of the community health worker, a literate man said in an interview, "He doesn't know how, he doesn't know how." ${ }^{125}$ He suggested that in addition to the issue of illiteracy, there are problems with the administration and distribution of medicine. "Well, the greatest need here is that we have... for example, sometimes they give us medicines, right? We don't have someone who can administer all of them. They are given to a person that doesn't know how to administer... So, the community suffers from sicknesses more than anything..." ${ }^{126}$ he explained. He also said: "There are remedies, sometimes there were. I remember about one... of medicine that we received, a donation, and now it is not known what it is that they do."127 


\section{Artisans' Board}

The Directiva de Artesanias (Artisans' Board) includes all of the people who make handicrafts to trade with tourists, and many women are involved in this group. Two leadership and 11 membership current positions were mentioned out of the 51 adults covered in the structured interviews. In an interview, the leader who is also the president of this organization, said that the group started six years prior and has 35 craft-makers as members. He named the secretary and said there is no vice-president, and he did not remember the names of the treasurer and representatives. In response to my question about the purpose of the group, he explained:

Well, mostly, when I am here, I am the one who summons everyone, at what time the trade is going to be, how they have to sell their crafts. So, and more than anything, each person put in order their things that they have to sell, their crafts. And also before that, explain to them to not touch the travelers' backpacks... rather, take care of them, not be wanting to grab their things. ${ }^{128}$

\section{Glass of Milk Committee}

The Comité de Vaso de Leche (Glass of Milk Committee) implements a National Program of Food Support (PRONAA) service that sends food to communities. Out of the 51 adults that were included in the structured interviews, one woman currently has a leadership position and five others are members. The leader said in an interview that Glass of Milk began about ten years prior and exists mainly for the municipality to send food to distribute to mothers, pregnant women, nursing women, and children. The leadership positions are all women, and he named the president or coordinator. There is also a secretary, treasurer, and representatives, women in a focus group told me, explaining that the government gives them powdered milk. A woman with young 
children who is in the organization said in an interview that all women with children up to eight years old are included. Twenty two women are currently part of the group, and she named the representatives. After a drop-off, I observed women walking back to their homes with bags of powered milk on their heads.

The above information about all of these groups with their members, missions, and leaders suggests a level of community organization and communication that is not fully implemented according to my observations. What I observed was the participation and communication as well as the leadership and power issues described in the sections above, so the system of organizations outlined here appears to serve to authenticate the power structure in the community. Nevertheless, these organizations could be strengthened and utilized for community projects.

\section{$\underline{\text { Indigenous Federations }}$}

\section{Overview}

Recent anthropological literature, some of which is discussed in the earlier literature review, has focused on issues of indigenous organization and representation, problematizing the concepts of consensus within communities and cultural identities. Indigenous communities in the Peruvian Amazon began organizing into federations in the 1980s to address territorial problems such as lack of land titles and diminishing natural resources because of outside hunters and fishermen. The Pitman et al. 2004 report describes the difficulties that federations had in the past in managing funds for development projects that were incompatible with indigenous culture. Dialogue and relationships with the national government have also been a struggle, they state, and 
among their recommendations they include strengthening federations by providing training to the leaders (Pitman, et al. 2004).

In an interview, the leader of Comandancia described the reasons for the development of indigenous federations.

We didn't have representatives. Now we have representatives and organizations. We have organizations at the district level, at the community level, at the provincial level, at the level of the Peruvian nation, at the international level where we are organized now to defend our own cultures and the right that our indigenous people have: more than anything, to territory, to life, and the lives of indigenous people... We have to organize ourselves why? Because before we didn't need to organize ourselves because there was enough to live. ${ }^{129}$

The community's local Yagua indigenous federation, the Federación de Pueblos Yaguas Rio Orosa Apayacu (Federation of Yagua Villages on the Orosa and Apayacu Rivers) (FEPYROA) is based in Comandancia. Prior to the FEPYROA, the community had been part of another federation, the FEPYBABAN, which regrouped geographically into separate federations, the leader explained. As shown above in this section, members of a family here hold the FEPYROA leadership positions in addition to current and past community governance positions.

The son who is the president of the FEPYROA is also the vice president of the regional indigenous federation headquartered in Iquitos, the Organización Regional AIDESEP Iquitos (Regional AIDESEP Organization Iquitos) (ORAI). The ORAI is the Iquitos section of the Asociación Interétnica de Desarrollo de la Selva Peruana (InterEthnic Association for Development of the Peruvian Forest) (AIDESEP), the umbrella organization for all indigenous peoples of the Peruvian Amazon. The AIDESEP is part of the Amazon-wide federation, the Coordinadora de las Organizaciones Indigenas de la 
Cuenca Amazónica (Coordinator of the Indigenous Organizations of the Amazon Basin)

(COICA). Figure 1 provides an overview of these relationships.

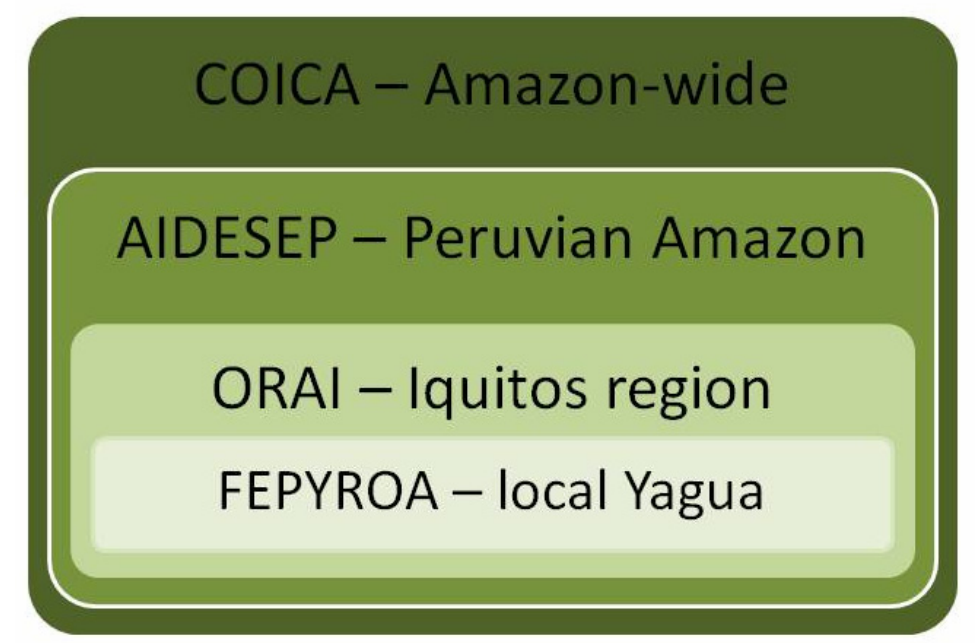

Figure 1: Levels of Indigenous Federations

Comandancia is the base of the FEPYROA, a federation representing 12 communities on three rivers. The FEPYROA is one of the 14 federations in the Iquitos region that forms the ORAI.

\section{FEPYROA}

The FEPYROA is based in Comandancia and represents communities on the Orosa, Apayacu, and Napo rivers. Out of the 51 adults that were included in the household census portion of the structured interviews, three of them, all in the same immediate family, have positions in the FEPYROA. Another son who was not included in the sample is the president of this indigenous federation. In an interview with the president of the FEPYROA, he said that the federation consists of 12 communities and that they would be having elections for all positions in September.

His father, the asesor (advisor) to the federation, said in an interview that the FEPYROA was founded in 1996. They hold elections every three years, he said, and 
positions include president, vice president, secretary, representatives, and fiscal agent.

He explained that the board of directors deals with the problems in each of the communities relating to territory, land titles, and territory amplifications as well as administrative problems in Iquitos, complaints to authorities, and coordinating with the regional federation to work with lawyers. His wife described her position: "Leader of women in the federation. Every time we [women] go to meetings in Iquitos, we spread the word to the communities." ${ }^{130}$ As an advisor, he said, he has knowledge about the customs of the Yagua people, how to organize the federation, and how to have meetings.

In an interview with another leader of the ORAI who is not part of the leadership family of Comandancia, he discussed a range of issues concerning the federation that are detailed below. A very lengthy explanation to my simple question about the name of the advisor position in the FEPYROA illuminated a tension between traditional and modern political systems. Here is some of what he said:

It's a self-designation because... he is the founder of this organization, of the Yagua people. And so, like in indigenous villages, there were no elections, it was hereditary, right? Power was transferred... Much in advance it was known who was going to be the next chief once one was dead, right? So, in the same way, they continue thinking, some brothers, generally older ones, that they should continue being in the organization.

But, this new democratic system came, didn't it? We also adapted to the system. So, these changes, it's as if the founder or the depository of indigenous knowledge felt a little outside of the organization already. And also the treatment that the new directors gave the elders, right? So here we have thought that nobody should be excluded, right?

In other words, one is a position that changes, that we call the directors, and others are the leaders. And the leaders are those that have given us knowledge of the ancestors and they have a very important role in the organization as counselors during difficult moments in the organization... In some communities, there is the council of elders. In some federations, right in the councils of elders are those brothers that come directly... from the children with direct relatives of those who were chiefs, thereby inheriting and transferring knowledge, transferring power... I would say that 
instead of being called advisor, he should call himself, then, it should be like counselor, like chief. ${ }^{131}$

This depiction of coexistence of two functioning systems does not quite seem to coincide with people's descriptions of the power structure in the community as detailed above. His rhetoric also suggests that this issue is unresolved and a source of contention. As shown above, the lack of democratic process is not acceptable to community members and has affected community level governance and organizations. It appears that this same type of power distribution occurs in these federations. None of my data indicate any support from community members for the hereditary system. More importantly, people articulated their opinions not about two simultaneous systems, but rather one unsatisfactory system. Centralizing community power and decision-making into one family appears to follow the model of the hereditary system. However, instead of being indicated as such, it seems to have been integrated into the structure of a democratic system, though unsuccessfully, based on community commentary.

Assessing the legitimacy and effectiveness of these political configurations is beyond the scope of this study, but these data do suggest that the tensions between democratic and hereditary systems are not resolved. The situation merits further research because of the impact of power, politics, and leadership on the environment and livelihood, described in the next section. The democratic system being superimposed on the hereditary one without the corresponding political processes not only affects social capital ${ }^{132}$ within the community, it also further complicates representation when dealing with the state, NGOs, extractive industries, and other stakeholders. 
One of the most significant land and natural resource projects that the FEPYROA has been participating in was creating a large communal reserve with 28 communities from nine different indigenous cultures. The reserve does not include Comandancia territory, but community members with leadership roles in the FEPYROA were involved in the lengthy process, representing the Yagua communities on the Apayacu River. Two other indigenous federations, also part of the ORAI, are partners in this project. The Instituto del Bien Común (Common Good Institute) (IBC) worked with local communities to map resource and land use in the area and to create the proposal, and other NGOS, institutions, and foundations also contributed to the proposal and research for the project.

As explained in the rapid assessment report for the proposal (Pitman, et al. 2004), in the early 1990s, the Communal Reserve concept was incorporated into the national park system by the INRENA, the ministry of agriculture. This conservation area in the Ampiyacu, Apayacu, and Putumayo area combines a national park, communal reserves, and expanded native community boundaries. Goals for the reserve include joint management between the communities and the INRENA and development of sustainable use programs (Pitman, et al. 2004).

Researchers at the IBC in Iquitos described to me in an interview the process they had undergone working with the communities and the federations, conducting field research, and obtaining government approval. The new forestry laws were implemented and logging concessions began being granted in the midst of their planning, a significant complication since logging is the most important economic activity for communities in the area. In discussing the challenges they have had coordinating with the communities, one researcher said that the boards of directors often change frequently in the indigenous 
federations. The other said that the federations had opposed the national park model, and despite years of working with the communities on this project, many people still do not understand the natural resource management plan.

In the community of Comandancia, the leaders talked about the reserve in a focus group. The advisor of the FEPYROA said that they support the reserve because communities will be able to use resources and there will be enforcement to keep outside loggers away. He said, "Around the Apayacu, we have some communal reserves and a reserve like a park of indigenous peoples." ${ }^{„ 133}$ His son, the community president, corrected him:

It's not going to be a park: it's been agreed as an indigenous territoriality... Because a national park also doesn't benefit us, because it's also managed by the state... But we in meetings that we've had in Lima, we have also debated about this of territoriality, and which is what they accepted from us that is going to remain as an indigenous territoriality... It's not going to be a park, because they were wanting to give it to us as a park, a national park, or a reserve, a reserved zone, or mosaics, but none of those three proposals benefits us, then... When we talk about indigenous territories, we are not only talking about territory anymore, what's above, but also we're talking about below, to have the right to complain against petroleum, other minerals that they also get. ${ }^{134}$

In 2007, the regional government of Loreto finally approved part of the proposal for this conservation area, so the challenges of communicating and coordinating among all of the stakeholders involved to implement natural resource management are just beginning a new phase.

\section{ORAI}

The vice president of the ORAI is the president of the FEPYROA and a son in the leadership family in Comandancia. In an interview, he said that the ORAI, founded in 
1997, consists of 13 federations that include a total of 371 communities. There are five positions on the board of directors, and he had just begun his position several months prior. Community directors always come to them with proposals for support for projects, he explained, but they have limited resources. They communicate by radios and in some places by phone, he said, and the nearest to Comandancia is in Yanashi. They also hold meetings and events, and the representatives from each community report back to their constituents, he said. In an interview with the leader, he explained that prior to the ORAI, federations were directly part of the AIDESEP, and he said that they hold elections every three years.

Besides the members of the leadership family, other people in the community rarely mentioned and did not seem to know about the workings of their indigenous federations. In a focus group, I asked some of the people who are involved in community organizations about what the ORAI does. One woman said that she did not know. She thought that they must be working on documents to stop the loggers, but that it is too late because there is no wood anymore. Another woman said they are not informed about what the leaders are doing, and suggested that there had been comments about the leadership's activities. From governance to community organizations to indigenous federations, then, it seems that communication and sharing of information could be improved.

The ORAI has had to contend with serious problems with extractive industries and contamination in their communities in Loreto. Prompted by a May 2006 Ministry of Health report that showed high levels of cadmium and lead in hundreds of Achuar people due to contaminated water, they issued statements in June and July of 2006 (ORAI 
2006a; ORAI 2006b). Denouncing the oil companies involved and any future extractive activities, they called upon the state to defend their lives and culture and to annul petroleum concessions, and they also began a lawsuit against the companies. They participated in a symposium focusing on petroleum activities and indigenous people in voluntary isolation in July of 2006 and in an indigenous assembly in August of that year.

The ORAI has been involved with international organizations such as the Amazon Alliance, which formed after a 1990 meeting in Iquitos between international environmental NGOs and the COICA. The Amazon Alliance's 2004 annual meeting was held in Iquitos where the ORAI and other indigenous organizations and NGOs participated to coordinate strategies for dealing with extractive industries. The resulting recommendations included increasing women's involvement; establishing regional meetings about logging; working at regional, national and international levels to promote the economic rights of indigenous people; and strengthening networks for exchange, commerce, education, and capacity building. The ORAI partners with the IBC for their proposed communal reserve, and they work with several other NGOs as well on women's and territorial issues.

An interview with a representative of the ORAI, not a member of the leadership family in Comandancia, provided much information about the federation. He has provided apoyo técnico (technical support) to the federation in an administrative position since its establishment. He said that they help the board of directors with analyzing and interpreting documents and going to meetings, and they also have an anthropologist who specializes in geographic information and evaluating maps. First he explained the political structure of the organization. From 1985 until 1996, they operated as a regional 
office to serve the Loreto communities, but they were under the AIDESEP national policy. In 1997, he said, they wanted political and administrative autonomy, and the decentralization process began. The AIDESEP now serves as a national coordinator of its 6 regional organizations which meet to make decisions and to alternate leadership positions, he said. In December they would be voting for a new AIDESEP board after three years, so the ORAI would be sending one representative from each of their federations.

Regarding the functional part of the organization, he said that they created a Plan for Life in 2000 designed to last through 2020. This plan focuses on four areas: territory, natural resources, and the environment; education and culture; communication; and indigenous organizations, citizenship, and rights. They develop workshops, activities, and some other projects and programs under these themes, some successfully and some limited by funding, he said.

The indigenous federations' first goal was territory related: obtaining land titles, amplifications, and establishing native communities, but territory issues continue to be a primary concern. Without territory, they cannot live, he said, and they realize that they must defend these rights to maintain their source of food and medicine. The state, their opponent in this struggle, has been mistreating them since the republic was formed over 100 years ago, he said, and the government had failed to recognize that there are peoples that have existed since before the state who have natural rights. They had to fight for constitutional reforms and recognition of indigenous peoples, but since the beginning of the process in the 1970s, almost 12 million hectares of community territory have now been titled to them, he said. He stressed the role that international organizations had 
played in helping them to obtain territorial rights, not only in terms of financial and technical support, but more importantly in terms of political pressure.

"So, when we are overcoming these territorial problems from 35 years ago, other bigger problems arrive, which is oil exploration," ${ }^{135}$ he said. Oil exploration began in the region 35 years ago, he said, and the expectation of the peoples at that time was that this industry would bring prosperity and development. The petroleum companies had told the communities that they would build schools and health centers, provide transportation, and install electricity in their homes, but the result has been serious problems: extensive contamination, illnesses, and destruction of natural resources, he explained. He said that if at that time they had understood the consequences, if they had known, perhaps they would not have let the petroleum companies enter or would have required environmental standards and cleaner, more costly technology. It is another unresolved problem, he said, but there is greater consciousness now among communities about contamination and rejecting petroleum activities. "Now we are in other times, and we are demanding more," ${ }^{136}$ he said.

Another major challenge that they face, he said, is the problems caused by forest concessions. He explained that communities had been given a maximum of 5,000 hectares, depending on their population, but ancestral territory is much larger, and the territories that have not been titled are still ancestral territories. Since the state considered these spaces to be free, it concessioned them. Because the territories were concessioned, indigenous communities cannot amplify their territories, he said, and they have had to put that process on hold until they can stop the forest concessions in Loreto. 
They need to continue amplifying community territories and obtain titles for additional communities, and they are proposing the creation of reserves for large spaces, he said.

He provided an interesting analysis of the issue of indigenous communities and logging companies. "It's very complicated, the conduct of indigenous brothers, if we refer to the individual level. At the collective level, those indigenous communities that maintain unity are those that have demonstrated perseverance in the struggle in the defense of indigenous peoples, ${ }^{, 137}$ he said. This suggests that community cohesion and social capital play a role in addressing livelihood needs, a situation I observed in Comandancia. Unfortunately, in some cases there have been confrontations with illegal extractors, but they do avoid violence, he emphasized, "even though indigenous peoples had interethnic wars and mainly for the defense of our territories, and that warrior spirit of indigenous peoples is still maintained." 138

Rather than defending the land, however, many community members now work for logging companies, he said. “But nevertheless, we can't deny that we have weaknesses. And weaknesses do not respond to a question of heritage, right?, but rather, they respond to a question of need," ${ }^{139}$ he explained. He continued:

If they had put into practice the heritage of our ancestors, no logger would have entered. So we evaluate that as an effect of all the processes... cultural fragmentation... not just physical, but also at the level of self-esteem, and the relationship of indigenous peoples with the market, right? Because the market is where they have to buy, through a means of exchange, which is money. So, not finding money... to buy other needs that we have, and since there is no government plan to utilize in a sustainable way... There is the problem: dependence. The market generates a series of weaknesses in our communities. ${ }^{140}$

He said that when they go to communities to talk about how to ensure future resources, the people understand, but they also complain and ask for economic initiatives. 
The do not have resources for this, so the state needs to include in government-level plans what to do with indigenous peoples as well as other river and rural peoples also in economic need, he said. He concluded: "I would say that we are progressing, we are progressing. There is a greater tone of consciousness, increasingly greater, and there is greater responsibility to protect our resources for future generations; we think in that way." 141

Regarding the ORAI's efforts in education, culture, and languages, he described how market forces have caused cultural as well as economic problems for indigenous peoples.

There is a series of external factors- cultural, economic, social, gastronomical- from other places, and since we do not have the resources to be acquiring for ourselves the new models, the new habits, we fall into need, and that is what is happening in the communities... We have weakened our food security in wanting to copy, you could say, the customs, that involuntarily we are assimilated with these processes. So, there is also the problem of identity, the cultural problem, and the educational problem. ${ }^{142}$

The challenge, he said, is that the government implements an educational curriculum that is taught in Spanish, devaluing the languages of all of the communities. As a result, he explained, the ORAI has been working on training young people from native communities to become bilingual teachers as one means to maintaining their identities.

In terms of the ORAI's communications goal, he said that they want to communicate their worldview to "civil society." He explained that "communication is another theme that we are implementing. Communication in the sense that, despite that they've lived many years here in the Amazon, many people do not know, not even those that live within the country, know about the cultural value, the value and the traditional knowledge of indigenous peoples." 143 Those that come from outside the country, he said, imagine them as "handicrafts, and nude bodies of indigenous people, thereby 
generalizing that we only know how to dance, make some crafts, and walk around nude. But the truth, indigenous knowledge, no." ${ }^{144}$ The ORAI wishes to dispel these myths that cause devaluing of indigenous peoples by outsiders, he said, and hopes "that they go discovering the true value of indigenous peoples. And the historic role that we have fulfilled for the balance of the ecosystem and also for cultural balance."

When the previous first lady, Eliane Karp-Toldeo, an anthropologist, had shown interest in indigenous peoples, he said that she had given them high hopes and expectations that all of their environmental and cultural problems would be solved. Instead, a government agency was formed to deal with indigenous issues, and there were so many problems with it that the indigenous federations had to request that it be annulled, he said. Relationships with the state have since worsened with the current administration.

Finally, I asked him what he wanted the international community to know about the ORAI and the indigenous peoples that it represents. He replied that they are looking for sincere and transparent cooperation that is not involved with the politics of the government in order to help them to achieve their objectives. Also, their communities and issues are not very well-known, he said, and they hope "that they discuss the problems of indigenous peoples in other countries, on other continents, so that, in other words, they can follow the politics of the government, because the government also depends a lot on global politics, on the world politics of other large institutions, right?"146 He said that they are going to need support from many people in the future "because we are at a global level, there are a series of unbalances on the planet, right?... a series of problems among loggers, transnational businessmen, and indigenous peoples.”147 
In summary, his thoughtful responses illustrate the history and complexity of the problems faced by Amazonian indigenous peoples regarding their land and other rights. It seems that development has been a double-edged sword for these communities, adversely affecting them both economically and culturally. Since the state plays a major role in land and livelihood concerns as well, his emphasis on political pressure from the international community is an important message.

\section{AIDESEP}

The AIDESEP is a Peruvian Amazon umbrella organization that joins 57 indigenous federations under six regional indigenous units, representing a total of 1,350 indigenous communities. In an interview with the community leader, he said that the AIDESEP was celebrating its $25^{\text {th }}$ anniversary. He said that at the national level, the AIDESEP coordinates the presidents of the federations of each region. They go to Lima to evaluate the funds that they obtain for the communities of all the regions and to receive information about what is being done at the national level, what is happening in other regions, and what they will work on during that year, he explained. The AIDESEP is part of the COICA, he said, which began in 1984 and organizes country-level meetings with its Amazonian members as well as coordinates with foreign countries.

The AIDESEP has a website with information about its history, programs, documents, collaborating anthropologists, and other activities (http://www.aidesep.org.pe/). Concerned with all aspects of indigenous needs, its programs are divided into: territory and natural resources, economy and alternative development, health, rights, education and culture, women, and communication. They 
provide access to microfinance projects, and their bilingual education program is a crucial component of their culture and education goals. Through cooperation among the ministry of education and the Loreto regional department of education, their school for the training of bilingual teachers aims to create new generations that will exercise their rights and defend their land.

Oil extraction and contamination problems are unresolved not only for the communities of the ORAI, but also for many of the federations in the AIDESEP. Indigenous communities had protested in the Bagua region in August 2008 against proposed forest legislation, and after the AIDESEP's battle in Congress, these contested laws were annulled, a success for the organization and the communities involved (Rénique 2009). A recent violent manifestation of the struggle between indigenous land rights and extractive industries supported by the state took place in the same area in May and June 2009 when government and industry actions led to deaths. The AIDESEP and the communities involved have received national and international support by organizations also critical of the natural resource privatization model and the international trade agreements with the U.S. that contribute to these conflicts. The AIDESEP formed a special commission in September 2009 to investigate the events that transpired (AIDESEP 2009). 


\section{Environment and Livelihood}

\section{Land and Subsistence Needs}

This section presents data from the community about their livelihood and subsistence difficulties, such as lack of fish and animals, and the role of commercial logging and fishing industries and cattle. Community-generated potential solutions to these natural resource problems follow. The most significant problem in the community and a major theme of many discussions was not having enough food: specifically, protein sources. With such a basic need not fully met and demanding their attention every day, it is very difficult to discuss projects, plan for the future, focus on cultural and language preservation, etc. In the final chapter of Chaumeil's Yagua ethnography (1987:169-178), he provides a long and detailed list of all the problems that he anticipated for the future. One of the most striking differences between the issues that most concerned Chaumeil 30 years ago and the problems expressed by the people of Comandancia today is that lack of food is not on his list, yet was consistently mentioned by community members as the most important problem now. This suggests a disturbing trend in their access to natural resources for subsistence.

Descriptions of the past always used the rhetoric of food abundance. This excerpt from a woman at a focus group reflects the sentiments that people often expressed when considering their younger years:

And it's not like before anymore. Before, in truth, there was sufficient fish caimitano, paca, sunga- it's not the same. You ate, and plenty appeared in the trap right away. Well, the time was not [houses] here when my dad existed- that's it, you lived like three, four houses... I'm going to tell this story, that of my dad when he existed. At that time there were sufficient animals, Christina. There were, truly. There were birds, there were huanganas, collared peccaries, deer, fish, and big 
sungas, of this size could be seen. But right now at this time, well, we have grown up, we are mothers- my sisters, we have brothers too, they have sons- and animals can't been seen anymore. You see a lot of freezer boats that have come, taking away all of our animals. And so, then, they suffer now, this time. They don't eat like before anymore, we ate well. That is what we suffer from at this time. ${ }^{148}$

The present day lack of sufficient food was mentioned in almost every interview and focus group. "For example, we suffer, sometimes about food, plus the forest animals, and the fish,"149 a man summarized in an interview. In a focus group, a woman emphasized a mother's perspective:

Sometimes, truly, we don't eat every day. When you search, also there isn't in quantity; sometimes there is at night, for a breakfast, and for midday, there isn't anymore. In the afternoon there is nothing anymore, then. And so, the children aren't interested in studying- you know, sometimes in the morning, there is nothing for breakfast. They go to drink their [drink], it's not enough for them to study. And so the children also get bored in school: 'I'm hungry.' Sometimes at recess several of them take off already, they feel it in their stomach, they are hungry. And so, the children don't learn how to read- they don't want to get their notebooks, they get their little traps and they go to the lake to look for something to eat... so the children suffer here, that need.

And that's why, well, even my children... sometimes don't eat. 'Mommy, I'm hungry,' - it's not enough a banana that we have. We have plantains, they drink their [drinks]: it's not like eating a fish every day or three times a day. That is what the children suffer from here, then. They aren't interested in studying. Sometimes the very teacher has not eaten anything. Certainly, since he also is going to teach, he has to eat well. When we have money, well, a little, you go to buy in the shop to make a breakfast, but just one. And then there isn't anything, it's gone. ${ }^{150}$

I asked if the other women agreed, and one replied, “That's how it is, miss, there isn't any."151 "The children eat and nothing for me sometimes. Because I give food to the children," 152 another woman says.

In an interview with a couple, they reflected on changes in their economy and cost of living and its significance for the future. He shared his thoughts:

Life at that time for me was good because there was, at that time- everything was easy. There was everything to eat, nothing cost. Now at this time, things cost, things are expensive... That's why I tell my little grandchildren, 'Look at these things, the 
situation that we are suffering right now, and you should put into practice, and study... Before was cheapness. Now we suffer from necessity. Things are expensive.' Sometimes I say that, miss. That's why I, analyzing things well, sometimes talking with my wife, how things are- things are really expensive. But trying, oneself, to analyze the situation well, things- it's something to think about. ${ }^{153}$

Nowadays, if you do not have money, you cannot buy necessities, she explains.

"Sometimes you sell a banana [branch]; they pay you four soles, three soles. It's not enough, miss."154 "Things have risen a lot," he reiterates. "But life before, it was a gifted life... my parents not even one day in school... That's why I tell my grandchildren to aspire to something for themselves." 155

As the area around Iquitos has become over-exploited in the past few decades, hunters, fishermen, loggers, and other extractors have expanded further into indigenous areas. People in the community talked about their subsistence problems in the context of these diminishing natural resources such as fish, animals, and wood. At a recorded community meeting where I was not present, the teacher addressed these issues:

Our natural resources are already being lost, parents of families and villagers. We are seeing little by little that they are decreasing, they are running out, that someday they aren't going to have any, not even for our canoe. That is what is happening in our community. Not only here, but in all of the area of our groups. We must be careful of this. Previously, if we had had the knowledge, perhaps they would not have taken advantage of us. Since larger companies have entered, the companies operate, the logging companies - they come with money, they do what they want. ${ }^{156}$

In a focus group, the leader explained that the Peruvian laws that give indigenous communities autonomy have been positive for them, but natural resource laws have not been, such as: "Where it says some resources are for the use of the community, but other resources- the subsoil, oil, gold, everything that is mineral- we have nothing. It's a problem... So the law is not favoring us. Like I said, one part favors us, another part also 
betrays us." ${ }^{157}$ In another focus group, a leader expressed her concerns about subsistence and resources for future generations:

I'm going to talk only about the territory first. Well, we suffer here in Comandancia because of territory. The businessmen want to leave us without territory now... Because of them, we also don't have food anymore because the businessmen did away with our animals, the animals from here from our territory.

We don't have where to find our food from anymore... There is nothing anymore. It's not like before, before we didn't suffer from hunger... We ate, we didn't need any mestizo things. Our food was at hand, at our hands... What are we going to eat? The children now, the grandchildren now are not going to know the animals anymore. And the wood trees... Our grandchildren aren't going to know anything. ${ }^{158}$

\section{Livelihood and Economy}

\section{Labor and Cooperation}

Working in gardens, especially planting, harvesting, and other subsistence activities have since settlement been done in groups. This communal work party or work group is called a minga, and they get together to do a job ranging from a few hours to days. I was told that community members working in a minga are given masato to drink all day and food by whichever family has organized the minga, and workdays are rotated through all of the families' plots, In a focus group, a woman told me that the word minga is not used anymore; mecánica is the new word for minga. I observed several mingas, ranging from about eight to nearly 50 children and adults, taking place in the community during my time in field.

Mingas are less utilized than they used to be, however, and the community has major cooperation challenges that hinder group work and projects. In a focus group, while discussing potential projects to ameliorate the community's current livelihood situation, 
one of the leaders explained that people are now used to working for the outside market

economy:

Now, about the farm animals too, it can't be done because sometimes here we ourselves don't organize ourselves... and a person doesn't get paid his day of work, no one wants to help. And you know that to pay people, well, they want money, food, to make people work. And so, since one doesn't have any, then it can't be done. But, like I said, organizing ourselves too, yes, it can be done.

But here, mostly, well, brothers from here are not used to working like that, organized... Mainly the people are already used to working for money. Mainly they're used to patrons... Patrons are men who help people from the community so that they go to work in logging as monthly laborers, workers. And also they help with hunting, hunting animals, and they are called patrons. In other words, they help them, they give them things, and they go to work so that they help them. And that is the problem then now, that we can't organize ourselves... and no one wants to work, no one wants to help you like that, for no reason. That is a little lack of organization. ${ }^{159}$

People also talked about working together, livelihood, and the issue of mingas and group cooperation based on their experiences at the family and community level. One woman said that her children and grandchildren are examples of good collaborators.

Even her young grandchildren are responsible, and they know how to make crafts and masato and work in the fields. By the time they are 15 , they will already be used to working and collaborating, she said.

Because here it is required, Christina, that young men and young women work starting at $15 \ldots$ when they got to the age of 15 , they had told me that they should now be in the record book recognized for jobs. And my daughters started working. They requested collaborators, and they were equal with collaborating. But Christina, here I see it's very different. From me, my children collaborate. But I see other mothers whose children don't collaborate. ${ }^{160}$

Another woman described the difficulties of getting her son to do communal labor:

Now he goes. At first, he didn't go. Here too, his aunt invited him; she invited him, he didn't go. "For what am I going to go, mom," he says to me, "it's not my field to work." "But it's not like that, my son, you have to help, because we also are going to need to do a job." He didn't want to go, then. How am I going to make him if he 
doesn't want to go? He didn't go... But now he is 16 already, now he goes to the work group, he drinks a little masato. ${ }^{161}$

These issues of work and cooperation were sometimes discussed. During a focus group, a woman explained why group work and projects are difficult to organize:

But before, they worked organized, Christina... For example, I have my field, they're going to work today- everyone goes there... Why have we stopped working in a big group? Because sometimes we don't all go: one stays, or two stay, and the rest say, "Well, you don't want to work in my field, so I am also not going to your field." We don't organize ourselves, then. We don't work together. ${ }^{162}$

In an interview, a couple emphasized the role of community-level leadership and enforcement. They said that previously, things had been going well in the community, and they had tried to organize people. Regarding people working together, she said: "If there is a job, some come, and the rest don't come. And according to what he says, well, there the authority, he says, leave a part for those who didn't show up to do. But you don't see when those who didn't show will fulfill this. We ourselves are going to do the work. That's how it is here."163 Her husband said that he does not know why some people do not want to collaborate, and "that's why the authority there says which people have to comply, and until now it has never been seen. No compliance from the authority is seen." 164

I asked them if other nearby communities have the same problems or if they are more organized. They said that in other communities such as Yanashi, Santo Tomas, and Israel, people work collectively more successfully. As an example of the accomplishments that can result from community organization, she described a project they participated in while previously living in another community. Ten families joined together to request a teacher for their community, working together to build a school and 
a house for the teacher and to create a community field to grow things to sell for money

for school supplies and celebrations. She contrasts communities that successfully

manage a communal work system with those that do not:

In other communities they are more organized... If there is a work group, if it's going to clear a field- let's say, the community field- then one works, all together, and it's nice, Christina. Here, one works, the rest don't come. It's not nice. When you're in a group, then, with everyone it can be done... When there are two or three, you don't finish the job... ${ }^{165}$

Her husband also notes the differences among the communities:

There you're going to do a job- all together. So they are organized... Because a work invitation, and everyone is there. There isn't anyone who is missing, no one. Everyone is there- that is their group. Why not here? What could it be? How can I say: they are negligent about work. I don't know what it could be. You invite them to a job, required, and you go to inform them, and they aren't there. They're in another group, have gone fishing, have gone hunting. What?- Why did he go hunting when that day was planned for him to work? And when they work, it's not all day, it's for two hours, not more... In other communities it's not like this. In other communities there is compliance. A person is missing, doesn't do the work, the police come to find him. ${ }^{166}$

Several other people also reported that other communities are more fair, organized, and productive, and some suggested that insufficient enforcement of work rules is playing a key role. The woman being interviewed explained how the system is supposed to work:

There was a public job, and some parents don't want to come. They go to his woman or his children: "Where is so-and-so?" "He's sick." And the leader, then, "Where is my police?" And he goes to see if he is sick in his house. "Where's your dad?" "He's in a work group, in such-and-such place." So he's not sick, and, "What do you think about that?" His fine is ten soles. ${ }^{167}$

Her husband commented on this community's current system: "Here the fine is five soles, but until now it's never been enforced. I don't see any of that. Why don't they want to? 
What could it be? Some of us talk about organizing ourselves- it's like, it bothers them. It bothers them, they don't want to organize themselves." 168

His wife added that women need to work together also, and not collaborating in making masato for a party should have the same fine as a job, ten soles. In summary, then, it seems that both employment in the market economy as well as lack of local enforcement of the communal work system are significant challenges to organizing communal work. This is concerning for the community since, as described further below, communal projects are among the few potential solutions for future sustainable sources of the natural resources needed for subsistence.

\section{Employment and Income}

Community members expressed that one of the biggest problems for them is lack of jobs and lack of money to buy basic necessities. The structured interviews included questions about past and present employment of household members. Out of the 28 total men over the age of 18 included in these households, 12 of them have worked in logging at some point, and seven of them currently work in logging, according to the head/s of household interviewees' responses (Table 3). These totals are likely higher since some adult sons may not have been mentioned, and the question about current employment may have been misleading since many would leave in September, a month after field work.

The only other current job is the two school teachers, one of whom was included in these interviews. No households reported females ever having any employment. In a focus group, a woman talked about voluntarily accompanying and cooking for her 
husband and the other men in a logging group, but not being paid for it. Occasionally

selling forest products is nowadays a minor, unreliable source of income for the

community. Several people noted that employment in logging is ultimately an

unsustainable source of income for the community. As the teacher summarized the

community's economic situation:

And some people don't have money... that is the main problem. You know that here in the community [finding] work is a little difficult. Since the only work there is here is just logging. There is no wood, and it's disappearing like that, and the time is going to come when you're not going to have work and there isn't going to be money anymore. ${ }^{169}$

The community's experiences with the logging industry are discussed in a section below.

Table 3: Employment

\begin{tabular}{|l|c|}
\hline \multicolumn{2}{|c|}{ Employment } \\
\hline & Total \\
\hline Men Over 18 Included in Census & 28 \\
\hline Ever Worked in Logging & 12 \\
\hline Currently Working in Logging & 7 \\
\hline Other Jobs (Teacher) & 1 \\
\hline $\begin{array}{l}\text { Table 3: The logging industry is virtually the only source of } \\
\text { employment for the community. }\end{array}$ \\
\hline
\end{tabular}

A few houses make money by selling alcohol and food to the rest of the community. According to women in a focus group, these little shops contribute to alcohol abuse and violence in the community. One woman said, "It's ok that they still sell things to eatrice, noodles, milk, sugar. But the liquor causes a lot of problems." ${ }^{\prime 10}$ Another woman agreed that these little shops are to blame for the daily intoxication of some community members.

Hitting among family- I don't like those things, not even a little bit. I have said I'm going to open my [shop], I'm not going to sell alcohol. Because alcohol- for me it's not ok, not even a little. I don't like that they are fighting. Maybe my two brothers 
are fighting because I sold the alcohol- who is to blame? I myself. I don't like liquor. Sell other things- soft drinks, things to eat, rice, food, for people to buy. But mostly there is that liquor. ${ }^{171}$

“That isn't lacking, even in the forest there is. Let's see, ask, 'Is there rice?'- There isn't any. Let's see, ask, 'Alcohol?'- There is. That's not lacking," ${ }^{172}$ the other woman added.

Many community members, especially women, trade or sell different homemade handicrafts made from plant and animal parts to tourists and other foreigners for clothing and household items. People spend time weaving bags and baskets and creating other crafts, and everyone takes their wares to the ledge outside the school for display when the foreigners come. I observed the women sitting in anticipation, handicrafts in bags until the tourists arrived, then discussing what might be in the tourists' suitcases. Tourists bring tee shirts, household items, and a number of other things for trade as well as gifts like candy and toys. These foreigners come to the community usually through an ecotour company associated with Project Amazonas. The leader told me that since they wanted foreign travelers to come, they had given Project Amazonas permission to build a field station on part of community territory in 1994, and indeed, this organization has provided numerous school, household, and medical donations over the years. Children from the community sometimes bring animals and insects to show the tourists and researchers at the nearby station, hoping for a gift or a tip. In conclusion, other than working in logging, minor sources of income, and trade and donations, the community does not have a sufficient, permanent source of income or access to a market. 


\section{Extractive Activities and Natural Resource Problems}

\section{Extractive Industries and Land Concessions}

In the area around the community of Comandancia, logging, fishing, and hunting by outsiders has increased in recent years, challenging the community's access to sufficient natural resources for subsistence. The rapid assessment report for the nearby AmpiyacuApayacu reserve also describes unregulated resource extraction in the area and community complaints that logging, hunting, and fishing by outsiders take place near and sometimes inside community territories (Pitman, et al. 2004). It explains that unmanaged logging intensifies erosion and impoverishes aquatic habitats, fishing is done without regard for minimum sizes or harvest limits, and use of fish poisons toxifies the water. Some of these activities have been due to extractive industries operating within natural resource laws, and some have been illegal.

Development in the Amazon increased in the 1990s, and recently the Peruvian government has been granting companies more exploratory and development concessions for logging, oil, and mining. Conflicts between the state and Amazonian indigenous communities over territory and natural resources continue to occur, with communities opposed to these concessions on their lands. International indigenous rights, humanitarian, and environmental organizations have been involved, especially after recent concessions for oil and gas exploration on the land of uncontacted tribes. Now in 2009, tensions have escalated into violence with the Bagua incidents.

In a focus group, the leader gave his opinion about these concessions and the government's treatment of local indigenous communities: 
But what happens in the concessions, Christina? The lands sold in the concessions for one sol fifty per meter- the State has done that to negotiate with other businessmen. Rather, the government gets the money, not us... The law says that indigenous people have large territories, but they don't work them... the government has already said. Those people- the indigenous communities, the river people- but they don't work it, what do we do? Bargain it. To those that have money, for the funds of the country. That's how mainly it has favored people that have money...

So, the Peruvian government, the very Peruvian country, that's the way its politics is. They never arrive at an understanding of the realities, how indigenous people can sustain their necessities... No, what happens is the government has done it only with their congressmen, not with the regional authorities. But when have they come to consult us here?... They have never come... They have not consulted first if their decision is going to harm us- there is the problem. And all of the sale is for another country, not for us. And still they are taking more land from us. They are taking our resources. Because the law facilitates taking out wood. Then, what can we do? But, organized, the community can defend its resources, it can defend its territory. ${ }^{173}$

Since the designated indigenous territories do not include subsoil rights and since many other Amazonian communities have been contaminated by oil extraction, people in the community are worried that petroleum companies will enter their area. Land that has been designated as lots for oil extraction has been superimposed on community territory (Instituto del Bien Comun 2008), but I am told none has been found in the area.

Community members did talk about their concerns during focus groups, however. The womens' leader said:

Here in Santa Ursula there is a petroleum well, it won't be much longer until the oil company comes... That means that the government doesn't want to see us alive anymore... What water will we drink? Nothing, we will die of thirst. We will die of hunger... Plants can't grow, manioc rots, plantains die. All of the earth turns black with oil... We don't want to accept that, we as indigenous people. They with their money, we with our right, we as indigenous people... ${ }^{174}$

Another woman confirmed that she had seen that oil had been discovered in Santa Ursula. The womens' leader said, "We should fight so that that company doesn't enter." 175 
The community president discussed the issue in another focus group. He explained that at a meeting in Lima he had been informed about the proposed activities of a petroleum company in the area, and they had been asked if they would agree to be paid for extraction. The money is not worth the consequences of contaminated water, land, and air, he said. He said that government authorities had told them that since they had been given their territories, they would be responsible for taking care of them and that the government would not provide enforcement. The only way to keep the companies out, he concluded, is to unite all of the communities of the Orosa River basin to not let the outsiders enter along the river. Petroleum and other mineral extraction have not yet affected this community, but as discussed below, commercial fishing and hunting have depleted the supply of fish and animals, and the presence of cattle in the community creates other environmental problems. Since logging plays a major role in their livelihood and has significant social and environmental effects, it is discussed separately in the next section.

\section{Fishing}

In the community, people spend time fixing their boats and repairing their fishing nets that hang outside their houses when not in use. There are not enough fish to meet their subsistence needs, people said. One of the most important issues that almost everyone talked about was the abundance of fish in the past and the current scarcity, especially during certain times of the year. In a focus group, a woman said, "Well, when I was young with my mom, there were plenty of fish."176 A leader compared the past to the present in another focus group: 
I remember about myself, that when I was still a boy, I still went fishing with a hook. I went in my canoe going along the edge of the river fishing with a hook, with my arrow... That, then, is a change, it's a change for us. Now the only hope is a trap. If it's not a trap, you don't eat... But now, as time goes by, not even with a trap are you going to be able to fish. ${ }^{177}$

In an interview, the teacher said: "Freezer boats have entered the river, the lake, and change is happening. It was not like this before, Christina- if you went to get some with your hook, if you went to the creek, you get so that you can eat, but now not anymore... If you want to fish, there isn't any, there isn't any. We are suffering from a great, great need."178

Commercial fishermen use freezer boats to extract large quantities of fish from rivers and lakes in the area. They are given permits since legally, bodies of water inside of communities are open resources, but some communities have organized themselves to prevent freezer boats from entering their territories. "Well, fish, we don't have in large amounts anymore. The fish are being finished off already," ${ }^{179}$ said the community president. The women's leader described the issue in the women's focus group. Because of the freezer boats, they do not have fish, she said, and the children do not eat breakfast. She said that the commercial fishermen tell the community that if they want to fish, they should go to Iquitos and buy traps, even though they are fishing in the river and lakes on community territory.

In another focus group, several people discuss this problem. One woman explained, "The fish go in the freezer boats, then. They come and they take them." "180 "They take off with the fish," 181 a man added. Some do not even take all of them, they leave the small fish to die, she said. "And so, there are few fish," the man continued. "The freezer boats take them to Iquitos. They're all gone." 182 Another woman explained, "They have 
a lot of traps, Christina. They bring a large amount of traps. They're from outside." ${ }^{183}$ These outsiders also poison the water to get the fish, the man added. There are dead, swollen fish, and they have to drink that poisoned water when it rains and comes downstream, she said. "That's why many children, and adults, have diarrhea- because of drinking rotten water, water with poison...The fish are already rotting that river. How are we going to drink that water?... We are never going to solve, I think, these things," ${ }^{184}$ she lamented. Another woman in the group agreed: "I worry about the fish: that there aren't any, then... Sometimes you go, miss, with a hook, with your trap and there you don't get anything... There isn't enough to eat three times a day."185

The leaders explained some of the other issues involved during a focus group. Since commercial fishermen have permits to fish on the rivers, community members do not understand these documents and do not know how to express themselves to claim their rights and to tell them to leave, the leader said. The community president described the broader scope of challenges involved and potential solutions.

We as members of the community, we are owners of our land. We are owners of our rivers... The ministry of fishing also gives them a permit, a document so that they can fish along the river. And that's the problem sometimes that we also can't block their passage.

As you see, you yourself, here in the community, sometimes people are not capable of going and saying that it's prohibited to fish here in our lake because it's community territory, titled, and the majority, well, don't want to say anything, they just wait for the authorities. But seeing the reality, because the service of the fish is for everyone, and everyone should take care of them, and the forest, the wood, for example...

Well, at this time, fishermen aren't seen here because I don't often let them... because before, they came to fish all of this zone. In the lakes entered freezer boats. In one day, two days, there were no fish to eat anymore. But now, at least it's been avoided a little now. But now, like I said, then, it's not that it can't be taken care of, everything depends on us. Yes also, the law permits us to defend our titled territories. ${ }^{186}$ 
In another focus group, people talked about previous attempts at organization with other communities to keep outside extractors away. One woman described how their community along with the three others in their zone- Santa Ursula, Santa Rosa, and Turimori- had created an agreement at a meeting to require payment from outsiders to pass through. Nothing came of it, another woman said. The other woman said that there have even been meetings in Iquitos, "and the same thing: a meeting is held, it had that agreement, but I don't see what that agreement does. And the people just pass and pass, the loggers, and they don't say anything... They pass by with a bunch of traps. And every day, five, six freezer boats pass by." ${ }^{187}$ They also said, however, that it is still possible to organize the communities against the extractive industries.

\section{Hunting}

The teacher described during an interview how traditional Yagua hunting with blowguns had been done in the past.

For example, before, then, we used for killing animals, we didn't use a shotgun; it was a weapon that we call blowgun. It had its dart, and they go to the forest, they blew it and they killed then with poison. That's nice, isn't it? This was their tradition, they lived like that... abuta macha, that is the poison. And they scraped it and they prepared it with various things, didn't they? Then the poison comes from there... and they put it on the dart, as it's called, isn't it? ${ }^{188}$

A woman in a focus group said that shotguns make a lot of noise and scare the animals away, but the blowguns of the past were silent. A man with a tigrillo (ocelot) skin hanging on the wall said that in the past, there were many ocelots that would kill and eat people, so the Yagua did not eat them. Now there are few of them and they are scared, so it is easier for people to kill them to eat them, he said. They used to sell the skins in 
Iquitos, but not anymore since it is illegal now, he explained, so now they just kill them for the meat and keep the skins for themselves.

Many community members said that lack of wild animals to hunt is another major subsistence problem for them. A woman in a focus group contrasted the present with the past: "Miss, today is very different...Everything was close. You had your weapon, you went to kill anything. It was close, they didn't walk far to look for something to eat. Now, well, it's not like that. Now there isn't any, not even birds, miss." 189 She said she used to go to get manioc at night and kill animals right there. Interestingly, ancient people had predicted their current situation, she said.

They said, at that time, "You see birds, you see all the animals, everything is close, but in time you're not going to see anymore. You are growing." They said to the young people, "Raise animals," they said, "chickens, pigs, to have something to eat. Because in time the animals are going to be gone." They knew, and that is what happened... Because they are from ancient times, they had experience. ${ }^{190}$

Overhunting in the region has been a serious concern, increasingly since the 1990s. The only regional market has been for game meat, and the market value of agricultural products like manioc, plantains, corn, and rice has been low. Extractive industries like logging further exacerbate the problem since their employees also hunt for subsistence and their activities drive wildlife away. In the Iquitos and Loreto region, overhunting and overfishing are also the biggest conservation issues, more so than agriculture and cattle ranching in this particular area of the Amazon.

In the community, the leader said that ribereños (river peoples) and loggers had depleted their supply of animals. People in a focus group agreed, explaining why there are few animals now. "Because, miss, before, people didn't come in," ${ }^{191}$ a woman said. "Before, well, there were no loggers," 192 another woman said, but since then many 
loggers with shotguns have finished off the animals both within and around community territory. "There aren't anymore. Few animals," 193 a man concluded. The community president alluded to the Yagua past and anticipated future challenges. "Also in hunting in the forest...They still kill birds, some monkeys. It is also a custom, a life for us. And before there was more... But now there isn't any anymore, there is very little. And in a while, there isn't going to be anything."194

\section{Cattle}

One of the biggest problems that people complained about was an entirely local one: the cattle that roam freely through the community that have eaten the medicinal and subsistence plants around their houses. There is tension between the leadership family that owns the cows and all of the other community members, and this was the most sensitive topic I encountered. In an interview with a couple, they described the problems with the cattle and the politics involved. The woman said that no one knew that the leader was going to put cattle in the community when he began doing so about five or six years prior. Her husband explained that the cattle are not actually the leader's, they belong to his nephew, and the leader is in charge of raising them. But they are supposed to be enclosed, he said, "Because everyone had their manioc next to their yard... Everyone had plantains next to them. Now you don't see anything... Because of the animals, the cows. They destroy the plants." 195 "They ate all of the plants," ${ }^{, 196}$ she emphasized, so now everyone has to plant their fields far away. "Sometimes it rains, you can't go to the field, it's far. When it's close, you take it, then, from there," 197 she said. 
They continued to voice their complaints about the cattle. He will not listen to us, she said, and the teacher has also been telling him because the cattle sleep and defecate in front of the school. Her husband said: "He doesn't want to enclose the animals. Everyone has already told him that they want them enclosed. In front of the school, like a barn of animals; at the school, cow urine, shit that there is, and the children are in that. For him it's nothing. He doesn't want to enclose the animals. He cannot be understood." 198 The woman added that this is a health concern. "The children sometimes have a wound from some thorn, or they cut themselves- it lasts, Christina. It takes a long time to heal."199

The man continued: "He has his area that is fenced in, but he doesn't want to put them there. I don't know what that man's problem might be."200 "He says that he is the owner of the land. Of everything," she said. "But I, Christina, I've let it go already-"201 "To avoid problems," he added. "We have said it, of course, yes, we have gone to charge, that they pay us for the damages. He didn't want to acknowledge it. And since I don't like to have problems with him, so, we let it go, right?"202 All of the community members have complained, he said, but the owner does not listen. "It's not fair, then," she said, and concluded: "But like I said, I don't like to be fighting among neighbors. That's why I've left this land. I've made it the same somewhere else. I have a field there, then."203 They are annoyed with us because we always complain and they and all of their family do not like that, he said. "They want what they say and that's it," said, but, "Everyone has the right."205

In another interview, a woman also said that the cattle had been brought in about five years prior. She explained that people had tried to build fences, but they are not well- 
built or are rotting away, so the cattle can pass through. They ate all of her sister's manioc at one point, she said, and lamented that the leadership family is the owner of the cattle so there is nothing they can do. A couple at the far end of the community said that they had put up a fence, but the cows pass through the river, eat all of their plants, and defecate everywhere. A man told me that there are currently about ten cows, about ten have already been sold in Iquitos, and many community members are angry about the cattle and have been complaining about it for a while. People used to have nice plots next to their homes, and now there are fewer plants, more mud, and more bugs, he explained, and the cows also ate trees that were planted for reforestation. Community members have asked the leader to confine the cattle to a field, and some families even eventually moved to Yanashi, he said.

The cattle do not have access to lower Comandancia where the houses are surrounded with fields and plants instead of the dirt and mud around the homes in upper Comandancia. This same contrast can be seen in other communities. In Santo Tomas and Nuevo Israel, two adjoining communities a short distance down the Orosa River, there are no cattle. The landscape is green and lush, fields surround the houses, grasses cover the ground instead of mud, and there are fewer biting insects. The above complaints and commentaries were given in interviews, but people usually avoided direct confrontation with the leadership family about the cattle. While discussing natural resource problems and solutions in a focus group with the leaders, one time the teacher broached the topic:

To raise, we have to have, for example, pigs. We have to plant manioc in large amounts, and here we can't plant manioc close because the large animal can dominate, because they don't let- There are places far away, but to carry it from there 
to feed the animals is difficult... Because a pig is... it can go, you don't know where it goes- you have to raise it enclosed. Same for the large animals- they should be enclosed, and it seems to me that that would be good management, right? That's the management of an animal. Because if we let them go loose, it bothers the neighbors. ${ }^{206}$

Based on this information, it seems that there are a number of livelihood, health, and environmental implications to having cattle in the community. People have not been able to use the fields around their homes for subsistence, and they may have had to clear additional forest plots. Cattle could be adversely affecting their ability to engage in animal raising and other economic activities. Hygiene may also be an issue, and as described in the next section, many medicinal plants are located in the fields around people's houses. Perhaps even more problematic is that the cattle are not a shared community investment, but rather belong to the leadership family even though the cows consume both community and individual resources. It appears that the power structure in the community provides these economic benefits to the leadership family to the detriment of other community members' livelihoods and natural resources.

\section{Commercial Logging}

\section{Background}

The logging industry, increasingly active in recent years due to land concessions, has become an influential stakeholder in the region, and the men's employment with logging companies has had important social and economic effects on the community of Comandancia. This industry is the primary source of income for the community, and there are almost no economic alternatives, a problem exacerbated by depleted natural resources. 
In an interview, a man told me that logging companies have been in the area for over 20 years. "Quite a bit of time. Over 20 years because I, when I came here for the first time to Comandancia in '86, there were already loggers. They were already here. But not yet in the community, in other places, ${ }^{, 207}$ he said. Since then, logging has escalated, and all of the big trees within Comandancia's territory have already been sold, he said.

When I asked his opinion about that, he responded:

Well, the agreements of the authorities. Well, Christina, the situation has happened, in a conversation, in a meeting, we came to agreement, the community members, that each member has to take 30 logs, no more than 30 logs. And we are informed after that, 30 logs anymore. And even the very, let's say, the very governance, works in logging. And there is no one who watches over. That is the problem that there was, then. And now, well, there's no wood, is there? Well, what can be done, right? Perhaps in the beginning, there was enough wood; there is not any anymore. That is what sometimes is happening in the community, Christina. ${ }^{208}$

Another man also told me that he first heard about logging companies in the area about 15 years prior. A woman said that Comandancia's men have been working in logging for about eight years, and prior to that, they hunted and sold meat for income.

A biology researcher told me in an interview her observations from working in the area over a long period. She has seen a large increase in the number of logs being extracted in the last four years. A few years ago, she said, logs floated by once in a while, and now full rafts come down the Orosa every day, meaning more logging upriver where the headwaters area is zoned for logging and there are several concessions. Illegal logging is also a conservation and safety problem in the Iquitos area, and she told me about a forester hired to assess the number of viable trees on a concessioner's land. When they arrived, they saw that illegal loggers had been there and logs had been cut, so 
when shots were fired, they left since their safety was threatened, she said. It is wellknown among researchers and local people that local law enforcement is nonexistent.

During my short time on the Orosa River, much of the time logs were tied and floating in the river, ready to be picked up. Several logging boats with dozens of men passed, docking for days in front of the community. In a focus group a female leader gave her opinion about some of the problematic aspects of logging for the community:

Because all of the people work in logging- working, working, then, all, all of it they want to finish off. In a little while, there's not going to be that wood that is tall anymore, and what are they going to work in when the wood is gone?... Right here, around our fallows, they are taking and they are selling it... Our territory must be respected. ${ }^{209}$

\section{Forestry Policy and Indigenous Communities}

A thorough analysis of the effects of Peruvian forestry policy and the logging industry on indigenous communities is beyond the scope of this thesis. However, since logging is both the primary source of income for the community and an environmental concern, a brief overview is warranted. New forestry laws were enacted in 2000 and 2001, and the creation of permanent production forests in the department of Loreto was approved in 2002. NGOs worked with medium and large sized Peruvian and international logging companies to create the technical and economic proposals that were required by the state. A point system was used to evaluate proposals, and 40-year logging concessions were granted for as little as one sol and 50 cents (about US\$.50) per hectare to a number of companies that are supposed to manage the forests they have concessions to. Over 60 percent of the permanent production forests now in Peru under these new laws are in Loreto. 
Research assessing the national level economic effects of logging concessions under the new forestry laws was conducted through El Consorcio de Investigación Económica y Social (The Consortium of Economic and Social Research) (CIES) in Peru (Galarza and La Serna 2005a; 2005b). This study by Galarza and La Serna provides a detailed analysis of the benefits and outcomes to date of the current forestry policy, and they believe that the logging sector has great potential for development, but its production is too low. They explain that the 2000 forestry law, resulting from international pressure to sustainably manage forests, modernizes the previous 1975 regime by promoting a competitive market through forest concessions that incorporate small and medium extractors and sustainably manage forest resources. The authors also attempt to demonstrate, citing the INRENA statistics in an uneven comparison of livelihood and industry, that the logging industry contributes little to deforestation compared to rural community wood use for energy and cooking and clearing for agriculture. Logging is the main source of livelihood for about 250,000 people in the Peruvian Amazon, yet the logging industry has not brought wealth to production areas and most of the populations are poor. They also state that prior to the new law there had been meetings for small extractors to participate in, but there was strong opposition from these groups. Although environmental NGOs participated in this process and the law requires a general management plan and annual operations plans, they report that few concessioners had actually presented these to the IRENA (Galarza and La Serna 2005a).

In the article that followed the report (Galarza and La Serna 2005b), they mention another problem: that some of the concessioners found that their forests had already been "invaded" by agriculturalists and native communities, and logs had already been 
extracted illegally. They recommend that the new laws could be better implemented if the agricultural threat to forest conservation is addressed, sanctions for illegal logging are enforced, and improvements are made to infrastructure and administration to increase production. The results of the study lead Galarza and La Serna to conclude that current challenges are a result of introducing a new, complex, concession system to a sector that had been abandoned for decades by the state. According to both their analysis as well as the stakeholders involved, the new regime is better than the old, they claim (Galarza and La Serna 2005b). In these publications, their framing of the dynamics of the system is problematic, some of their assertions are arguable, and most significantly, they make almost no mention of indigenous communities.

In the last few years, many indigenous rights and environmental groups have been addressing the issue of logging concessions, and there has been some press coverage about forestry policy. Little research about the effects on indigenous communities has been conducted thus far, however. The available information is summarized in this section. The 2004 United Nations Forestry Forum (UNFF) report entitled Forest Privatization and Indigenous Rights and Knowledge in Peru (Espinoza Llanos 2004) provides a detailed examination of the cultural and livelihood implications of each aspect of the new forestry laws and logging concessions. Referencing laws, government reports, and interviews with and proposals by indigenous organizations, this document analyzes a government-submitted report on its forestry policy and critiques the state model and its application by agencies. First, the report describes the national context of implementing the country's largest privatization project that covers one third of the national forests 
although simultaneously, national indigenous organization is at its highest and autonomy and consultation legislation is very progressive.

In assessing the legislative status of indigenous peoples and forests, the Espinoza Llanos report critiques many details of the government report, analyzes the legal language being used about indigenous organizations, and identifies progress that has been made as well as shortfalls. The author describes that one problem is that although there are well-developed national indigenous federations, the government has maintained their own agencies for indigenous affairs that have limited indigenous participation. According to the report, indigenous consultation has been minimal, and their participation has been insignificant, ineffective, and completely lacking when decisions are implemented, mainly by means of partnerships between the state and large corporations. It states that consultations on consent regarding traditional forest-related knowledge have been neither "prior," nor "free," nor "informed," have taken place during or after activities, and have been fraught with misinformation.

Regarding forestry practices, the report states that hasty and mass privatization under the new forestry model with renewable 40 year leases of up to 50,000 hectares has resulted in the concession of $24,586,458$ hectares of permanent production forests in ten Amazon departments including Loreto. "It has taken the Amazon OPI [Organization of Indigenous Peoples] 30 years to obtain the deeds of 11 million ha of land, while major logging capital has obtained 25 million ha in just a few years," the author notes (Espinoza Llanos 2004:4). The report references an AIDESEP report that concludes that the concessions granted are illegal, conflict with indigenous peoples' ancestral right of possession, and in the case of Loreto, do not consider the proposals for the communal 
reserves. This overlapping between the forestry use units and indigenous areas with pending land tenure arrangements is a serious problem especially in Loreto. The report concludes that privatization under the national forest strategy has negatively impacted indigenous rights and traditional knowledge.

In terms of state action and policies and traditional forest-related knowledge, some parts of the law are acceptable in theory, but as the report dissects, there are many references to utilization of indigenous knowledge that do not coincide with the reality on the ground. One questionable aspect of these laws is that cultural knowledge needs to be registered ahead of claims, and the report concludes that the state continues to be complacent or complicit in cases of biopiracy of indigenous knowledge and genetic resources such as has happened with several forest medicinal species.

Espinoza Llanos' recommendations are based on the indigenous federation's 2003 proposals and his own analysis. Included are constitutional reforms regarding indigenous rights over natural resources and traditional knowledge, indigenous land reclamation prior to implementation of the present forestry model, rectification of the forestry use units overlapping with indigenous territory, joint cooperation between the state and indigenous peoples' organizations for social and environmental "in situ" monitoring of forestry concessions, modification of laws about collective knowledge, and creation of a public institution for indigenous affairs.

An article by Tom Griffiths (2004) of the Forest Peoples Programme outlines the background to and summarizes the main findings from regional indigenous workshops on forest policy and indigenous peoples' rights that were held in Peru in 2004. He explains that the current forest law has been a point of contention between the government and 
indigenous peoples since its hasty adoption in 2000. According to the author, indigenous organizations had warned the government about land conflicts and had requested resolution of land rights issues first. The concession system was implemented in 2001 and 2002 without respect for indigenous rights, he states, except for in Madre de Dios because of intense advocacy by indigenous leaders there.

Griffiths describes how during the three indigenous workshops, people discussed and compiled their observations and experiences. The main findings were that illegal and supposedly legal commercial logging is creating increasing social, cultural and environmental crises in their communities in the Peruvian Amazon. People agreed that both legal and illegal logging has been destructive, and illegal loggers continue to invade indigenous territories without sanction. The workshops concluded that the forest law benefits commercial timber companies as well as lawyers, forestry consultancy firms, and environmental NGOs contracted to create management and operational plans, but it does not benefit indigenous communities. They discussed how the forest law and government agencies like INRENA are not geared towards supporting small-scale timber extraction and provide no support for native communities. As the author explains: "Procedures for complying with the forest law are highly technical and prohibitively expensive for Native Communities who either cannot obtain permits, or have to rely on abusive timber companies to secure official permission and to carry out timber extraction," (Griffiths 2004:2).

The social and cultural section of the rapid assessment report for the proposed reserve involving Yagua federations including FEPYROA (Pitman, et al. 2004) also discusses some of the problems with logging concessions on or near indigenous lands. The report 
states that the indigenous populations in the area consider the logging concessions to be an obstacle because they impede their access to forest resources and adversely affect families. Indigenous communities would need outside assistance to bid for concessions since the process is very complicated and they lack the technical assistance and capital necessary to participate in the auctions. Instead, concession owners are outsiders who have acquired exclusive rights to extract timber from the area and who prohibit indigenous people's access to the land where they currently extract resources for subsistence, the report concludes.

The above reports and articles demonstrate the problems with forestry policy for indigenous communities in the Peruvian Amazon. For these peoples, the struggle for land and resources is far from over. Communities in southern Peru have been more vocally opposed to how concessions were granted than the communities in the northern Amazon, as exemplified by the protests that escalated into riots in Puerto Maldonado in 2002 because of the new forest laws. In the northern Amazon, not only have native peoples been more exploited historically, but also communities generally have greater organizational challenges such as distance and isolation, lack of roads, lack of communication, and fewer economic resources. Future research and action involving communities and natural resources in the Amazon should pay careful attention to these economic and environmental policies and their effects on livelihood and culture.

Several researchers I spoke with lamented the fact that indigenous communities had been left out of the logging concessions, and they suggested that it would have been better if an NGO could have loaned, funded, or managed some sort of logging cooperative with indigenous communities. In an interview with IBC researchers, they 
discussed the local government's involvement in the logging industry and the impracticality of the new logging laws. One of them who had worked on the concessions process explained that neither the State, the regional government, the INRENA, nor the

NGOs had thought to include indigenous communities in the logging concessions.

But that is one of the big mistakes... Because the communities, the indigenous populations are the base of timber production. In other words, it is them who take out 80 percent of the logs... In other words, it is them who work for middlemen and for loggers, as patrons. But it is them who take out the wood... They never thought about the small producers, and they never thought about working with, much less thought about organizations like community ones, or some type of community organization that they would have been able to finance so that they could present in the competition... They were missing a map, something to see things, all of the components of this system and to try to work with all of them... The base, in other words, the people that work, the people that extract the logs here were not included in this process. ${ }^{210}$

She said that based on her experience with the concessions, she is sure that the communities would have been able to fulfill the requirements, submit the technical paperwork, and earn the necessary points if they would have had assistance like the medium and large companies did.

\section{Sustainability}

In the community of Comandancia, people's rhetoric about logging focused on the economic and employment aspects for them, but I also asked about environmental issues. In a focus group, I asked a couple who worked in logging if they planted seeds after cutting trees, and she said that they were "doing reforestation." 211 "Yes, that's how it's done," 212 her husband said, adding that he has worked "with several" ${ }^{213}$ different companies. I asked which ones had done reforestation, and he responded, "In the beginning, all of them... because it makes everyone, that law that you have to 
reforest." 214 In an interview, a man who worked in logging told me that they cut "just cedar. Nothing else." ${ }^{215}$ Regarding reforesting, he said: "Well, not yet for that sowing. Not yet- when the contract for that wood ends, then they are going to plant again. Then they go, along all of the roads that they have made, there they go planting. On all of the roads they go planting so that it's never lacking." ${ }^{216}$

The community president described a less optimistic picture of the situation in a focus group:

And the same way for natural resources, and everything that is timber, it is also running out. And it is a problem for us. And we don't see a way to solve it because the companies continue coming in, continue taking everything that is wood... It's a big, big problem for us. And furthermore, for our children, for our grandchildren who are going to come, well for them there isn't going to be anymore- because the only job here is just logging. ${ }^{217}$

I asked him if they plant seeds after cutting trees, and he said, "They don't plant them." 218 "It's because mainly, people that work in logging, well only, they are only interested in their pocket. Not for the future. They just want to destroy and not to build, ${ }^{, 19}$ he explained. As to whether logging is being done inside or outside of the community's territory, he said: "Well, at the moment, they are taking it also inside of Comandancia, and outside. They are taking it, but reforestation isn't done." ${ }^{220}$ Finally I asked if they could require reforestation on their territory, and he replied, "That's right. It can be done." ${ }^{221}$ Information from the community members was somewhat mixed, then, but it is well-known among researchers working in the area that despite the agreements that accompany the logging concessions, the companies rarely if ever reforest.

The environmental sustainability of logging is determined by the circumstances of management and regulation. For example, selective logging under a management plan 
can be a sustainable income-generating activity as it is for some communities, with profit benefitting the people who also have long-term interest in the land. An IBC researcher told me that some more organized Peruvian communities manage logging very successfully. However, since indigenous communities are required to obtain logging permits to cut trees but often lack the economic resources and technical skills for this process, they sometimes make agreements with outside loggers (Pitman, et al. 2004). In any case, under the new privatized land tenure regime, the circumstances are very different from community forestry models, so sustainability is questionable and reforestation activities appear to be dubious at this point.

The Ampiyacu-Apayacu assessment report (Pitman, et al. 2004) describes encountering ten meter by 50 meter cleared areas to drag cut wood to the water, and their seedling surveys of these clearings found they were dominated by weedy species. The authors also note that few timber species regenerate without active reforestation, which some communities are doing (Pitman, et al. 2004). The IBC researcher said that since logging is rarely done more than 30 meters from a stream or river, deeper forest is left intact and there is little overall impact. The selective logging of mahogany and now cedar, lupuna, and cumala is not as destructive as clearcutting or conversion to pasture or agriculture, and it is not as contaminating as oil and other mineral extraction. However, as loggers have progressed from high quality species to mid-grade timber for plywood, there is cause for concern about what the intensity of the damage might be over the 40 years of the concessions. Illegal logging also continues to be a problem. 


\section{Economic and Livelihood Effects}

The logging industry has had a number of livelihood and economic effects on the community of Comandancia. Logging activities contribute to diminishing fish and animal supplies because of hunting and fishing by these outside loggers, and also because logging scares away animals and erodes soil into rivers, affecting fish. In a report for another proposed reserve that would protect the headwaters of the Orosa River, the authors describe how this region that functions as a key breeding habitat for mammals and large fish is slated for logging concessions, which could potentially exacerbate the community's subsistence and economic problems (Pitman, et al. 2003).

As shown above, logging is the most important source of income in Comandancia, and the men speak with pride about their jobs. Many of the men work at the nearest concession, about 40 kilometers upriver and covering 30,000 ha, but some of them get sent away to work on different rivers. People said they get paid less than minimum wage, live in difficult conditions, and rarely get compensated for injuries, yet based on the price of logs and the cost of concessions, the logging companies must be making enormous profit.

The leader explained that men used to hunt and sell meat for money, but there are few animals now and agricultural prices for crops are too low, so most of the men must work in logging. Working in logging is easier for the men because they do not have to think about what they will eat and their needs are provided for, he said. However, he also said that they are paid very little, taken advantage of, and gone for months at a time, often to be underpaid or even unpaid at the end. He said that he would like for younger men to know about these issues before they make decisions to work for these companies or 
middlemen. Other people suggested that those in leadership themselves had been involved in logging on community land in the past.

Different members of the community have had a variety of experiences with logging, and in this section I summarize their opinions. Some people reported positive experiences working in logging. In an interview, a man told me that he works as a caretaker for the provisions and supplies for a logging team. They take the supplies deep into the forest and set up a base. The logging team goes about seven hours deeper, and they come back to the base about once a week to get more food. I asked if the other men in the community work for the same bosses and he said no, they each worked for different ones. Regarding the work, he said: "Well, for me, of course, I like it because they pay us. It's somewhat difficult because there is loneliness, one all alone... I don't have anyone to talk to, all alone, then... sometimes six months..."222 I asked which company he worked for, and he said, "It's not a company. Let's say, it's a trained man who manages people." ${ }^{223}$ He also said: "He treats us well. Everyone appreciates him because he works in logging and pays money."224

In a focus group, a couple talked about how they went together to work in logging. "I cooked for them to eat, but I didn't earn. That was my free will, that I supported them, but I also ate from there. That's how I went about," ${ }^{225}$ she said. Regarding how they were treated, he responded: "Well. I have worked since '74, the year 1974, and well, working in logging I've arrived here, and until now I continue working because they treat me well. For me there is no problem with the work. They pay, they give me work, like that... I am 51 years old, but I continue working with wood.",26 She added, "We don’t want to be millionaires, simply to raise our children. Even though not well-paid, but at 
least.",227 I asked if they had had any problems, and he said: "Well, in my job, no.

Everything has gone well. Well, I always work as a monthly employee. Sure, there are responsibilities at work." 228

Negative experiences with working in logging were expressed by another man in the same focus group: “Look, miss, excuse me: I have worked in logging in Montawai, I've worked with 12 people... He owed me three thousand soles to pay my people. The boss has not paid me. I also have not been able to pay my people... That is logging... They want to kill me because I don't pay them, that's why I want to complain about my boss."229 The woman explained that "not all loggers pay them well- sometimes it goes wrong, sometimes they don't pay them well, pay is delayed," ${ }^{230}$ I asked another man if he worked in logging, and he gave his reasons: "No. Field, agriculture, corn, like that. I never got involved in logging. I don't like it. Because we know that they are bad payers, the bosses. I never got involved in logging." ${ }^{231}$ During a party, a man from another community told me that a logging boss has not paid him for earned wages. "That man does not want to pay me for my work. I want to make a complaint about him. He owes me more than a thousand soles, ${ }^{, 232}$ he said.

In a women's focus group, they discussed illegal logging on community land. I asked if loggers have to get permission to work there, and one woman said: "Well, they go to take it too, not even coming to the authority, that community one. They don't present themselves, then, when they want to take wood on our territory. They go to take it just like that, without asking anyone's permission."233 Another woman added: "We agreethat they support us, then, right? That they pay us, at least the price that they sell, that 
they leave us with something, funds for the community... But those that work don't come to present themselves to the community, we don't know who is working."234

Finally, one of the most significant issues regarding logging and labor is a very important point that a woman in another focus group made about the availability of male labor for subsistence activities and community projects.

I also want to give my word, Christina, about that, what they are saying. The truth is you can't work just like the community woman is saying, because most of our sons go off logging... They go for months there, four months, sometimes five months they go... And so, we can't have enough of a field. We can't raise animals here because chickens cannot be raised like bananas- you have to plant corn, you have to plant rice. And so we can't raise chickens. We raise, sometimes, two, three chickens, but it's not enough.

What can we [women] do? I, as a mother all alone, I have very little young children, what am I going to do with them? They can't work, it doesn't work. And the older ones, well, they go to the jungle to work with bosses, and so we can't work on our job, and all of the young people here, they all go to the forest... That's why we don't raise animals, it's not enough, because a [woman] all alone can't work in the fields. We [women] can't if the men do not help us. So that is my word. ${ }^{235}$

An analysis of the true costs and benefits of earning income from logging vs. from community natural resource production projects would be interesting. Factors to assess would need to include quality of subsistence, money spent on alcohol or not paid, and also social and cultural elements, such as the family and community concerns that follow.

\section{Family and Community Issues}

Logging has had effects on families and the community besides the livelihood and economic issues described above. The biggest problem with logging that people talked about was the family difficulties that result from the men being gone for months at a time. A man explained to me that a major problem for many communities is that while men are gone working in logging, their wives sometimes find new men in other villages. 
Sometimes the women leave their children and go off with a new husband to his village, and sometimes they take their children, and the new husband beats them, he said. Many times a man returns from logging to find his house is empty and his wife, children, and all possessions are gone, he said. He also said that at the logging company, there is one woman who works there for all the men to share, but since they go back to their wives afterwards, he thought that it is not problematic like the women's behavior. The leader also mentioned the problems with women and families when the men work in logging. While addressing the community, he said that women have difficulties when their husbands are gone for months at a time, and sometimes they have someone else. Later someone told me the leader's own wife had left with another at one point, but he got her back.

The teacher also explained to me the link between employment in logging and alcohol problems in the community.

Plus it's the drunkenness... Before it wasn't like that, Christina. About like five years ago, that, since logging began... They give to a, let's say, a worker, a salary of 300,400 soles. Because they have money, they go to the shop and they drink. Since they have money, they have to sell, then, alcohol. And they drink. That, there was plenty of change in that, five years ago. ${ }^{236}$

In summary, family and community problems related to the men working in logging center on their absence, including from subsistence activities, and the alcohol consumed with their income.

A unique example of a positive family experience with logging merits mention, although it took place in the past. For one couple, working in logging before settling in the village had been a less stressful, healthier lifestyle, and their depiction of the village as the source of illness parallels with the stories of Yagua ancestors avoiding settlements 
and rivers. In a focus group, she said: "In logging we went about quite content- eating, drinking, the same. We didn't have problems. Sometimes I say to him- here we are in our house with problems, before you went everywhere, you didn't have problems. You had no problems about anything, you went about happy.",237 "In the middle of the forest you make your camp," he explained. "And when I was there, my first son that was born in Tamsheco... and then when he was a month old-" 238 "Three months," ${ }^{, 239}$ his wife corrected him. "Three months," he continued, "we had taken him to the middle of the forest to work in logging...From the start, then, he grew up in the forest." 240 "But miss, I'm telling you," she emphasized, "we never got sick. They didn't get sick. Here they have diseases, I have even lost two children." ${ }^{241}$ He agreed and said they ate everything in the forest. "There was no sickness. But then once we left for the village, there was the flu. And mostly my kids grew up in the forest, without shots, nothing." ${ }^{242}$ This couple also said that they learned much of their medicinal plant knowledge from being in the forest working for logging, which suggests a relationship between plant knowledge and settlement vs. forest activities. This is not a common present day family situation, however, since most men currently in the community must leave their wives and children behind when they go to work in logging.

There are other social problems resulting from outsiders logging that are on a broader scale than the community and family level. The ORAI representative mentioned incidents of violence between loggers and indigenous people and some deaths. An IBC researcher also told me that there are enormous social problems with both legal and illegal logging and there had been conflicts and murders. Timber has been stolen from indigenous territories, and many have been mistreated, she said. 


\section{Challenges and Potential Solutions}

This community has a number of livelihood and natural resource problems that need to be resolved. Tied in part to extractive industries, these challenges to subsistence and to producing income are also exacerbated by lack of cooperation and the local power structure. The ideas and potential solutions that follow were all generated by Comandancia community members based on their experiences and what they believe to be feasible. Regarding the impending natural resource issues, the community president said in a focus group: "In about ten years from now, five more years, things are not going to be the same that they are now. Everything is going to change."243

The main problem with most of these solutions, however, is that they would be difficult to implement without male labor. As described above, most of the men are absent for much of the time working in logging. In a focus group, the leader discussed the issue of labor and cooperation.

But what happens is that people don't know, they don't want to organize themselves. Because of the patrons they go outside of their communities, very dispersed. So, they come after half a year, six, seven months, and with these people we can't work to get what we're talking about here right now... because they are not going to learn anything. They only learn, well, I want to work with a patron, I want to go to logging, fishing, hunting, but they never are going to talk about... how to value my traditions, my customs. ${ }^{244}$

The community president expressed that he believes it would be better to involve only interested people in potential resource management projects rather than the whole community.

Speaking of projects and speaking of the problems of the community of Comandancia. Regarding the jobs that sometimes one wants to carry out, and trying to do a project- you know that to prepare a project, responsible people, and well, I think that it's not so much about putting it, as we say, in the community's name, all of the community members. It's difficult. I thought that instead, we could do it, maybe, 
a group of some people who want to do this job, to do a project, to raise animals or other jobs, to be able to do it like that, to have just one agreement. Because there are many people that don't want to: sometimes they have other jobs, and... sometimes they don't agree. ${ }^{245}$

This idea deviates from their collective model of labor and cooperation, but may be more appropriate under current conditions.

Women discussed their concerns about the future of their children in a focus group, and one woman emphasized teaching them farming to be self-sufficient.

Well, we, as mothers, we worry about teaching them, then, young people. Someday we'll die, they have to work too for their children. They have to make a field and buy their materials- hatchet, machete- that's why we work. And they have to follow the example that we have... I tell my children too... "you have to work, you are young men already, what are we going to eat?" If you don't have a field, what are you going to eat for breakfast, then? ${ }^{246}$

Subsistence farming can be a sustainable agroforestry system, and many indigenous fields contain a diversity of species. If the trend towards wage labor in logging continues, traditional botanical knowledge about cultivated crops may also diminish. A man in a focus group suggested mechanized farming to have large fields like those in other regions of the country in order to produce large quantities. He thought it would be good if the government or some NGO could support such a project. Since large scale agriculture is one of the principal causes of Amazonian deforestation, hopefully the community will find more environmentally sustainable economic solutions.

In a focus group discussing solutions to natural resource problems, the president said that fish farming and raising animals are the best solutions. "What would be as number one, well, it would be mainly raising animals. Fish ponds and raising animals now, because they are the two things that are useful to us every day for food... There is no fish pond... ${ }^{247}$ he said. He said that they would need a number of materials to build one, but 
they do not have money to buy them. In a focus group, a woman said that making a fish pond is easy, and that her family already has a large hole ready next to a stream. They need to fix it up to put fish there, and they will organize themselves when her brother is in better health, she said. Since commercial fishing has reduced the local fish supply, clearly the community will need to produce their own fish in the future like many other communities currently do, and selling fish can also provide a source of income.

Some people in the community have a few domestic animals, but many community members said that increasing animal husbandry could also provide both food and income. In a focus group, a woman said:

That's why now I say, when you have children- I also have my children, and I say to them, to the young people, so that they have something to eat, the animals. Not just a woman raises, a man also raises so that they have something to eat. Because if not, what are you going to eat? You realize that now there aren't fish like before... Ancient people said that, didn't they? It's not like before anymore. Everything changes. ${ }^{248}$

The other participants agreed with her. In an interview, the teacher outlined the possibilities for and constraints on raising animals.

Well, what is also the problem? Maybe, little raising of animals here, of trying to live an okay life, right? Raising chickens you can have money, right? Raising pigs to have money. But here, well, nobody, they don't raise, then, in quantity...

It seems to me that they also find it, they see it as very difficult. Because, let's say, a pig, a pig eats regularly, a pig eats. You have a little field, and it's finished off, and there isn't anything for the animals to eat. It's that a chicken, no- a chicken, yes, you can raise. As long as you have your corn, you raise them.

But here I think that sometimes also, the little, little interest. That is to say: I earn more going to work in the forest, right? But it's not like that. It seems to me that raising... Working here you can have money... Because there are some people that have done very well. They work, and they have enough to drink, they have enough to eat. They live well, there is no problem... because they concern themselves with raising... Here no one raises, then, thinks about chickens... That is what there is, that is the big problem that there is here. ${ }^{249}$ 
The president described in a focus group the impossibility of implementing an animal raising project without outside support, presumably in the form of some sort of grant or loan. In order to raise animals, he said, people have to constantly be producing food in the fields for the animals to eat. To be able to work in the fields, people need food, and therefore much time is spent attempting to fish and hunt with few results, he continued. He said that he realizes that what they need is a little support in supplying daily food to be able to work. Once the animal raising progresses, they could be self-sufficient, he thought. Other obstacles, he said, are that some families do not have the means to buy even a few chickens and a rooster, and also community members work for employers instead of raising animals, leaving women alone to work. He concluded that if there was a project that could help them start, later the animals would provide income for salt, kerosene, and other household items. Whether through individual families or as a group, whether starting small or implementing a project through an organization, it appears that the community will likely have to increase raising domestic animals in order to meet their subsistence needs and perhaps generate income.

In the midst of present day subsistence and livelihood problems, the issue of reforestation of wood, food, and other useful or valuable species was not expressed as a concern by community members. In a focus group, women laughed at the idea of reforestation, and one said that trees do not grow that fast. "It would be useful for grandchildren, then!" ${ }^{250}$ said another. Project Amazonas has done some reforestation projects in the community, especially with the children, as the leaders explained in a focus group. It seems that community members should continue these efforts, but the 
leader said that they need technical help and said that they should be paid for

reforestation projects. He described what he believed they would need:

So, right here, the technique: we also are technicians according to our knowledge here. Now, in another way, if we want to plant in order, it's another technique, isn't it? How we can plant each tree, a tree here, of another type, over there of another type... That's why we can, we need engineers that can give us knowledge, how we can reforest... an engineer of agriculture, of reforestation- that would be useful to us.

... according to the amount of trees that you plant. Maybe by person, the state gives money for their maintenance... So there people and money are needed... In other words, the very product gives a guarantee, so that there is backing, that with time, it's going to be useful to us to make logs. ${ }^{251}$

These comments suggest that even with technical assistance, they may be unlikely to carry out activities that do not provide an immediate subsistence or economic benefit.

Considering all of their unmet needs described above as well as findings in the literature on other communities, conservation and environmental efforts in the Amazon have to attend to these challenging local livelihood issues.

For all of these types of natural resource projects, the leaders and other community members emphasized the need for outside support. In a focus group, the community president described their condition: "The government does not support us. It does not give us any ability to work. We do not have, and we do not work with any project. We do not do any project- no institutions, NGOs, support us so we can work and have economic resources. We do not have any support." ${ }^{252}$ The leader also explained what he thinks the community needs:

What is the difficulty? Because there isn't anyone to prepare a project for us, to carry out a project. We know that there are, there are to get, many things. For fishponds, for animal raising, for reforestation... There is all that. In other places, they raise... they are raising everything. But it's not the people, of the indigenous people, they are foreign people, they have come to prepare, and they buy everything, and it is a project. This type of project is very necessary that we could have... projects about 
three things: reforestation, fishponds, all that is animal raising... because this is the only hope that we can have. ${ }^{253}$

Their discourse about needing support from organizations focused on economic resources and also technical assistance, often expressing a valuing of outside knowledge, even about managing their own natural resources.

The leaders of the community who are involved in indigenous federations expressed that their natural resource problems also needed to be addressed at the political and policy levels. The leader said in a focus group that recently when they were in Lima, they had consulted with the government. They had created a document about not giving concessions and permits in and around community territories, and they had also brought to their attention the fish supply problems, demanding the stopping of permits to enter indigenous territories, he said. Besides community natural resource projects and in addition to working at policy change, people also talked about what could be done at the community level to keep extractive industries out. Regarding the freezer boats of the commercial fishing industry, people in a focus group discussed keeping them out. "It could be done. Organize with all of the communities,",254 a man said.

Finally, policies and market forces affecting agricultural prices were mentioned by the leaders. In a focus group, the women's leader described the problem.

When their things cost, and our products don't cost- it's the worst. Still only theirs, they want to raise, and ours never rise. And another thing: we want to sell an animala chicken, a duck, a pig. Instead of us deciding the price, they decide the price... What they say- "I'm going to pay this much," and that's it. The producer, nothing. Despite that we suffer to raise an animal... What you have spent can't be recuperated, what it ate... That's the bad that the government does... What is it worth, what they pay there- a bunch of bananas, three sols, three fifty the biggest ones. $^{255}$ 
The leader said that he would like to create statutes for the community about selling prices and that he wants people to learn how to sell things and to create competitive prices. The teacher explained the additional problem of transportation and access to a market.

What there is not is where to sell products, there isn't anyone to buy. If they buy from you, they buy little from you... Then if there was a, let's say, a place to sell in quantity, yes. The production of manioc, for example, of plantains, the production of other products, corn- very little, they buy very little... On the Amazon, very well, right? On the Amazon, yes. They live there, they plant their plantains, they take 50, 30 bunches, they take them to Iquitos. Here, difficult to take to Iquitos. Where, then, to take them? It can't be carried. ${ }^{256}$

In summary, continued subsistence agriculture, fish farming, and animal raising could be used to meet livelihood needs, and reforestation could help replenish timber supplies for the future. As described above, however, the need for outside support as well as the additional challenges of male labor being diverted into the wage economy, cattle and other injustices resulting from the local power structure, low social capital, and alcohol issues all problematize meeting these goals. In addition, addressing natural resource policies relating to agricultural pricing, extractive industries, and other relevant concerns is needed for more systemic change. Indigenous federations perhaps with NGOs would need to put forth efforts at this level, but individual communities like Comandancia could then work locally to protect their lands.

A researcher from the IBC said in an interview that community organization is the limiting factor to implementing natural resource projects in native territories. She explained that for historical, social, cultural, and economic reasons, communities in Loreto are at very low levels of organization and their institutions have become very fragile. Other Peruvian communities in the South and other areas provide good examples 
of community organization, she said. She described communities in other places consisting of united families joined together in organizations that are not stateimplemented but rather traditional systems with good structure, activities that interest them, and solid, secure work. Here in Comandancia, strengthening the capacity of community organizations and governance as well as increasing communication and coordination with the indigenous federations is needed to help build the institutional support needed to undertake these problems from the community to the regional level. Indigenous environmental knowledge is also an important component of natural resource management, and the next section describes the traditional botanical knowledge of this community.

\section{Traditional Botanical Knowledge and Plant Resource Use}

\section{Subsistence and Other Useful Plants}

\section{Introduction}

The common description in ethnobotanical literature of the forest as a "storehouse" for indigenous people is an accurate portrayal of Comandancia's utility-based relationship with its habitat. Almost every plant that people pointed out and named has some use. Walking through the forest, they identified plants that are sources of food, wood, or medicine, and the children ran about, climbing trees and collecting fruits to eat, also constantly commenting about their uses or status.

In documenting the community's traditional botanical knowledge, I compiled a list of all the names of useful plants located in the community that were mentioned in 
interviews, focus groups, and walking around. These were mostly medicinals, food, and other useful plants. This community plant list, presented in Appendix 4, is not comprehensive, but it contains the names of all the plants that were elicited through all of the methods employed during my fieldwork. (The process for obtaining scientific names is detailed in the methodology chapter above.) Still, with 458 species and varieties, the list is testimony to the extensive use of plants by the community.

Many of the edible, medicinal, and other plants known and used by the community are found in the major Amazonian field guides and other ethnobotancial literature from the region, although as the teacher noted, "The name sometimes changes." ${ }^{257}$ A recent ethnobotanical dissertation (Lamont 1999) based on research conducted in several Yagua communities near Comandancia also includes plant lists and other plant use data. Most of the plants that Lamont documented are used by the people of Comandancia as well. Sacha is a native word for "wild," and a plant is distinguished between if "it is planted, or it grows as it wishes, ${ }^{, 258}$ the teacher described. Below is an overview of food and other plants used by the community, and then medicinal plants are discussed in detail.

\section{Agriculture, Fruits, Recipes, and Masato}

Cultivated plants in the community include manioc, corn, plantains, sugarcane, sweet potatoes, and fruit trees. "Swidden gardens is our thing, agriculture. We must have our field to live," 259 explained a man in an interview. His wife said that when she was young, she would work in the field every day, then cook, wash dishes, and rest at night. She said that she still has all the plants her mother cultivated. Corn is available all year, and is used to make food, drinks, and to feed chickens. Only sweet (non-poisonous) 
manioc is eaten here, and plants such as manioc, plantains, and rice come in several varieties (see Appendix 4).

The leader told me that each family is given a plot. After five years, they move to a new plot, but continue to use the land for fruit trees, and then after eight years, they go back there to plant again, he said. A woman said that plots are of varying sizes because some people work more and clear more land than others, such as those who make a lot of masato, since manioc takes up a lot of space. She said they go further and further away as they create new plots, but there is plenty of land. Forests with a mosaic of fields at varying stages of growth surround the community.

People consume a wide variety of forest fruits which are eaten raw, cooked, and made into drinks and other recipes. The mostly native fruit trees found here enrich soils and fix nitrogen, and some of the fruits are also commercially valuable (Pitman, et al. 2004). Fruit trees that community members pointed out and described during fieldwork include: almendra, anona, bacaba, binuayo, camote, cashew, caimito, guava, huito or jagua, uvilla and umari. Aguaje is one of their most important palms with edible fruit and also fiber for making clothes, and the huazay palm produces a purple fruit that they make a drink out of. Pijuayo fruits from a local palm tree are delicious, dark orange with a rich consistency, and served with a sauce made from lemon juice, onions, hot peppers, and salt.

The community subsists almost entirely on what they produce, catch, and collect, but they buy non-local foods when they can, such as for parties. As one woman explained: "Well, we... the truth is, when we have a little money, rice is bought [and other foods] to be able to improve breakfast a little too. But, most of the time we eat pangito, chiricano, 
masamora. ${ }^{260}$ In focus groups, people shared their traditional recipes such as: inguiri (plantains boiled with water and salt), pango (manioc on the bottom and fish on top), and chiricano (fish cooked with water, coriander, garlic, and onion). To make masamora, they grate plantains, break them up, mix them with water and cook, then afterwards add the fish, one woman described. For chirume, chop and wash raw manioc and cook it with meat from an animal, bird, or fish, explained another.

Masato, their traditional alcoholic beverage, plays a central role in the lives of the Yagua and was ever-present and often discussed. Mostly it is consumed throughout the workday as a source of subsistence when working in the fields. It is also used for intoxication at parties and celebrations. Since the fermentation process takes a several days, women make large batches in their kitchens a few days before a group workday is planned. To make masato, women mash boiled manioc in large wooden troughs and add sugar cane juice. Camote, a variety of sweet potato, is chewed and spit into the manioc mixture to begin the fermentation process.

\section{Handicrafts, Clothing, and Other Items}

People create beautiful and useful household items and crafts out of plant fibers, seeds, beans, and other local plant parts. Mostly women weave and sew hammocks, bags, necklaces, bracelets, straps, and other items using their traditional fiber from the chambira palm. They make fans and weave baskets and hard bags with other plants such as the fiber peeled from the branches of the huiririma tree. The jewelry has animal teeth and colorful red and black seeds as well as the purple seeds of rosario that grow with holes already in them. People also carve wooden animals, utensils, instruments, and 
masks as well as cups and decorative objects made of hard fruit shells. They decorate all the crafts and objects with a range of colors from plant dyes, using some of these items themselves and trading others with tourists. Further market potential as a source of income for the community is probably hindered by transportation and organizational barriers.

Traditional Yagua clothing is made from fibers from the aguaje and chambira palms. When the aguaje is young, they extract the fibers, separate them, hang them in the sun until they yellow, and then use them to make clothing. In several of the focus groups and interviews, people described this clothing. Men used to wear a champa de aguaje, a fiber skirt, and fiber bands on their calves, and women wore that plus a pampanilla, a fiber shirt. One man spoke in Yagua, then said, "I was saying, Christina, that before, my grandparents had aguaje for their champas. That was their pants before. They didn't wear like we do... They used agauje and chambira... That was their clothing.,"261

The leader viewed clothing as yet another need they can no longer meet selfsufficiently and now must buy: "We didn't get clothing in the city, we got clothing right in the forest. From there came... the champas, from there came all the clothing- we never bought clothes. But now it is necessary to buy, and there are no jobs, there is no help from the state... So, that has been a change between good and bad." ${ }^{262}$ He also said that many people are embarrassed about traditional clothing. However, some people wore these plant fiber clothes when dancing and playing music at the Yagua celebration, and some of the older men were proud to put it on for photos.

Many other plants are used by the community, such as different woods for house and other construction and palms for thatched roofs. The jute plant is soaked for 20 days to 
extract the fiber that used to be cultivated and sold through an agrarian bank loan project, I was told. A man said that their ancestors used to sew with cotton fibers, and now they use it for the wicks of their oil-burning lamps. Fish poisons from the crumpled leaves of huaca and barbasco are mentioned, but people say they avoid using them to not contaminate their water. Aji macusario is also cooked to make poison, and catawa is used for wood and for fishing as well as medicinally, people mentioned.

Achiote was mixed with leche caspi and used to paint wood in the past, and now is used as a colorant (for food or body paint) in addition to medicinally, a man described. Huito can also be used as paint, I was told. In a focus group, a man told me, "This herb is to greet."263 A woman explained: "This is albaca macho, perfume of the Yaguas. It's perfume of Yaguas, they say.",264 "That perfume is native," ${ }^{, 265}$ he said.

\section{Medicinal Plant Knowledge}

\section{Knowledge and Health}

In the midst of so many environmental challenges to livelihood and subsistence as well as the social and political issues described above, people in the community wanted to talk about their cultural knowledge of local plant medicines. As the teacher explained, medicines and foods are not distinct categories: "There are many more plants that you wouldn't believe, that it is an edible plant, but also the medicine works." 266 "We have a lot here in the forest, plants for medicines, ${ }^{, 267}$ he said. "For example, on the list that

there is, there is still not even half of what we know." ${ }^{268}$ Lack of a health care facility in the community combined with lack of sufficient economic resources may contribute to the community's use of and breadth of knowledge about medicinal plants. 
According to older people, this knowledge is relatively recent for the Yagua. Several people talked about the history of Yagua medicinal plant knowledge, explaining that their ancestors did not know how to prepare medicinal plants like they do now. In a focus group, a man described past practices for sickness and death:

Ancient people, sometimes, leave their children with bronchitis, flu, and don't know what they're going to cure with. They don't know how to prepare, just like we're talking about plants from the forest. They are dying, and they don't know how to prepare it for sick people.

And so, ancient people- I have a sick person, and I don't care at all. He's going to die, and they leave him all alone in his house to die, and they go somewhere else, make their houses and a new field, manioc, everything- and they don't care, they make a new house somewhere else. ${ }^{269}$

In another focus group, a man shared his opinion about using medicinal plants from

the forest, priding himself on knowing and using natural remedies that his ancestors did not:

A plant is, when someone gets sick here, miss, it's a remedy. Before, they didn't know what thing they're going to prepare. Here are remedies, plenty of herbs. Here people don't die like they died before. They didn't know what plant to prepare...

Plenty of remedies here, but if you don't know anything... But yes, now we know a little... Before ancient people died next to remedies, they didn't know how to prepare them. But now they don't die, every single person knows those remedies... Remocaspi is black, it is bitter, just the same as a pill...

I don't go to the store. I don't go to Iquitos. Here there are remedies. Before, when our people died, no one knew which remedy... There are plenty of remedies. They didn't know anything. There are remedies right now, like I'm talking to you... ${ }^{270}$

It is unclear what time period they are referring to and where their knowledge came from.

Within the context of their community and everyday lives, medicinal plant knowledge is valued not so much as an intellectual or cultural contribution, but very practically as necessary information for health and life. In a focus group, a woman said, "When someone doesn't know the plant, sometimes they die because of not knowing. Not 
everyone knows medicinal plants. ${ }^{271}$ The teacher also discussed in an interview the ties between traditional knowledge, Western medicine, and the community's economic condition:

Now for the remedies, then... we have that here at hand: plants, knowledge about how to prepare and how to use them. If everyone knew how to use them - such-andsuch plant, such-and-such plant, right? Then, if I know, let's say, I have learned, then I have to give the example now...

You wouldn't need any remedy, then, Christina, we knowing the remedies, and we don't want to do it. For example, bronchitis... some with bronchitis go to the health post- right here there is! Chicken's egg is good for bronquitis. Whenever you have your mix, they do it, and it goes away. Without getting shots, nothing, and it seems to me this is good, right? To learn and to not spend a lot... and there isn't money. I know very well that there might be remedies, right?, for bronchitis, but there is not money sometimes. And knowing what could be good, knowing how to prepare, they prepare it. ${ }^{272}$

The leaders are aware of the issue of intellectual property rights pertaining to ethnobotanical research and traditional knowledge. In a focus group, the leader commented at length about companies taking and using traditional medicine such as has happened with uña de gato (cat's claw). "Respect, I say, if some foreigners, some come to do studies, therefore, then, we should be paid. Paid, because this is the best lung in Peru, where the most plants exist that can exist in all of Peru, ${ }^{273}$ he said. Pharmaceutical companies have gone to collect plants from other communities that did not know their rights, he said. More significantly, this type of research leads to indigenous dependence on Western medicine, he explains:

But what happens, that with time, those that are here, we don't use our plants anymore because we don't want to prepare them anymore. Because pills come with the same thing... In other words, we stop using our medicine in waiting for support, in waiting for a capsule, in waiting for a syrup, of the same plant that they have taken. So we, instead of us benefitting, we instead have to buy from them. ${ }^{274}$ 
Variation in medicinal plant knowledge and use within a community is often related to age, gender, and location, among other variables. Although these variables were not systematically investigated in this study, people sometimes commented that women have more experience with medicinal plants because of curing their many sick children. Both men and women participated in talking about medicinal plant uses and preparations, and some individuals were more interested in teaching and documenting herbal remedies than others were. In general, older people knew more about plants and were more confident about and willing to share their knowledge.

The main source of variation in medicinal plant knowledge that people in the community themselves mentioned is between people who are familiar with the forest versus people who stay in the village. At a medicinal plant meeting, a woman said that she does not know forest plants because, “I don't know the forest, I just live in my house." ${ }^{275}$ In a focus group, regarding medicinal plants, another woman said: "I don’t know from the jungle, because I have never been to the jungle." ${ }^{276}$ The couple that worked in logging, on the other hand, said that they know a lot about medicinal plants because of their eight years in the forest. "Experience teaches you,"277 he said. A man in a focus group also talked about using forest plants while logging:

Here there is remocaspi. Remocaspi and huanzamana for malaria. I cure with that. That grows in the jungle. Its leaf. When there is a sick person, I cook it. I know how to prepare to cure my people when I work. I work in logging. I cure my people with that. I am a plant doctor. I am a true doctor because I know how to prepare remedies. ${ }^{278}$

The women who "do not know the forest" do grow and use certain medicinal plants, but people more familiar with the forest may know different species or a greater variety. Whether they actually obtain and use these forest plants would be an entirely different 
variable to measure. These comments by community members suggest that future ethnobotanical research on variation in medicinal plant knowledge and use could benefit from examining the factor of people's forest activities versus village life experiences.

\section{Valuing and Sharing}

Many people in the community were very interested in the idea of documenting medicinal plant knowledge, and it seemed that the research project also inspired them to value their culture. The teacher of the community played a key role in planning, organizing, and documenting, which also served to link the generations of older people with children, a crucial element in the goal of passing on traditional knowledge. In an interview, he said that the experience made him think more about documenting their culture, knowledge, and language as well as sharing these with other native communities. His rhetoric also suggested a privileging of Western knowledge, however, when he said several times that outsiders like students and researchers know the names of and everything about medicinal plants. This valuing of outside knowledge was also alluded to in the discourse of other community members regarding natural resource management and outside agencies and organizations. The effects of Western education, language, economy, and other cultural and social elements on their lives have produced a complex identity, probably further complicated by outsiders now encouraging them to value their traditional knowledge.

The leader said at a meeting, "As long as we take care of our territory we are always going to have medicinal plants. Land isn't useful just for logging, it's also useful for curing life, and medicinal plants are the most important." ${ }^{279}$ Some people were 
particularly knowledgeable about and interested in medicinal plants. One woman, for example, showed me the preparations she described: slicing bark off a tree, crumpling leaves in a bowl, and constantly running to get samples- all of which took place with her many children watching. She even included a medicinal plant in a photo of her family. Focus groups were a very successful method because people enjoyed talking and sharing their knowledge. People were enthusiastic to talk about uses and preparations of medicinal plants, especially in Yagua as well as Spanish, and both the knowledge and the language seemed to be strong sources of pride. They discussed and compared uses, and as a woman commented about one plant: "One person knows about a preparation, maybe another knows about another way, from the same plant. We knew about only for refreshing... Now I am also learning from her." ${ }^{280}$

Many adults talked about the importance of teaching children about medicinal plants, and community members actively participated in plant knowledge sharing and documentation. The leader said during a meeting that the community should "value our own medicine" because "the children are who are going to need these plants." ${ }^{281}$ He said that recordings and books can teach them how to use medicinal plants in the future. The teachers organized a medicinal plant workshop for the children, a successful example of a way to share this knowledge. Community members were invited to bring in a medicinal plant and then present to all of the students what it is used for and how to prepare it. The teachers lined the 13 plants on a table under the chalkboard and wrote the names above. Mostly women participated, and everyone was enthusiastic to talk about medicinal plants. Table 8 below presents these 13 plants compared with other medicinal plants important to the community. 
Community members expressed interest in joining with other communities for workshops and activities. The leader said during the workshop that other Yagua communities have also held similar events, and he wanted to compile the knowledge of various communities. The teacher agreed that a forum would be a good idea: "That each community comes... join them to give better knowledge. I think that it would be nice."282 He said, "There are other communities that know more, they know another way to prepare medicine."283

\section{Spirits and the Supernatural}

Their spirit world was not investigated directly in this study, but I learned a few basics when clarifying responses given to questions about medicinal plant use. Remedies were mentioned for ailments such as choque de mal aire (bad air shock) that result from encounters with tunchis (spirits) or bijuntos (ghosts). In a focus group, I asked some women to explain this phenomenon to me, and they laughed through the whole conversation. One was incredulous that a foreigner would be ignorant, finally realizing, "They do not know, then, what are spirits, what are ghosts- they do not know!",284 A woman began the attempt: "In the cemetery it lives, but the spirit hangs around here."285 "In my house!",286 another joked. "One's spirit, when you die,"287 the first woman continued. "It's not like when you're alive anymore... since there is no temperature,",288 the other added, presumably to ensure I understood the concept of death.

I probed about the connection to these illnesses, so the first woman patiently explained that not everyone is good, some people are bad, and some spirits are bad, those of people who are not nice. These bad spirits can grab a child, take his spirit, and the 
child dies. For example, she said that a while back her nephew got scared seeing his grandpa's spirit as a tunchi, and he died- "It was the tunchi, then." 289 There is a large cemetery far back where they bury their dead, they said, and since they go in a big group of adults, the tunchi does not go near them. They do not bring children who could get bad air shock, and they bathe in the river before returning to their house and making contact with children. Once a year they give food, masato, and liquor to the dead, saying their name and a prayer so they will not come back as a tunchi. If they do not do this, the tunchi, which smells like watermelon, will come looking for them, they explained, laughing.

Incidentally, the land that the community allowed Project Amazonas to build its field station on is supposedly an old cemetery and has a creek called Tunchi Cano running through it. I asked the women about the area, and one said, "Well, it is said that there are dead people there. ${ }^{290}$ I mentioned the stories of visitors with nightmares, and another woman confirms: "That is the tunchi, then, miss,",291 and sympathizes, "She sleeps all alone there!" ${ }^{292}$ When I asked if it is alright for us to be there with them, she said, "Well, since they are already used to it, already then, visitors arrive, and they don't know what the tunchi is, none of that, well, the tunchi also gets used to the people." 293 The women say that mucura, rosasisa, huingo, and achiote leaves are used to ward off these bad spirits.

In the categories listed in Table 4 below, "supernatural causes" and "belief" are not elements of the Yagua medical system; they are my distinctions in the attempt to understand their ideas. All of the data in these categories came from the responses to the question about the top ten most important medicinal plants. Included in my tenuous 
"supernatural causes" category are ailments such as choque de mal aire (bad air shock), since it has a supernatural cause, an encounter with a walking ghost, as described above, that produces physical symptoms of sudden vomiting and diarrhea. Therefore, to retain the community's distinction between what they label as a choque de aire (air shock) and when they use the words vómito (vomiting) or diarrea (diarrhea), for example, these responses were listed here instead of in the gastrointestinal category. In the belief category, I separated out non-physical problems such as plants used to botar la saladera (get rid of bad luck) if a person hunting cannot find food, and plants used to ver los ladrones (see thieves), identify in a dream who has stolen something.

Several other "supernatural causes" and "belief" types of plants were mentioned in other interviews and focus groups. People in the community talked about piripiri as a plant with special powers. Women in a focus group told about using piripiri during a girl's first menstruation as previously discussed. One woman described her grandfather performing a ritual where she drank and applied piripiri after her first period so that she could return to her family and look at her father and brothers again without anything happening to them. "That's what I'm saying that piripiri is for... So that the shadow, it's called, doesn't enter from the woman to the man... That's why we drink that piripiri then, ${ }^{294}$ she said. I asked what would happen, and another woman said, "He dies."295 "His stomach swells. He can't breathe anymore... That's why we use that piripiri...We [women] drink that so that nothing happens to the [men], ${ }^{, 296}$ the other woman explained. The day after the Yagua celebrations, some older people gathered to sing traditional Yagua songs which were used for a variety of purposes including courtship. One of them, translated into Spanish, mentioned using piripiri to make someone fall in love 
because it is powerful. Chaumeil (1987) describes a number of physical and spiritual uses for the more than 50 varieties of this plant.

There are no shamans in Comandancia, but several people mentioned common hallucinogens like ayahuasca and toé as well as tobacco which are also used in healing rituals. When the teacher interviewed his older family members, these are some of first that are mentioned. "Uncle, I know that you are a healer and you know the tradition of our language, ${ }^{297}$ he said, asking about medicinal plants and Yagua culture. The other man responded: "There are many. There is the medicinal plant ayahuasca first. Then there is the plant toé. There is plenty of medicine. There are many ajo sacha plants."298 Ayahuasca was mentioned in a meeting to "make you dizzy" and "to learn medicine." In a focus group, a man said: "Toé. The doctor drinks that, so that he learns, so that he kills people."299 "The curious ones,"300 a woman explained. Medicinal plant uses and preparations written by the community include tobacco to drink in order "to learn occult science."301

At one point, a baby was sick with diarrhea and antibiotics were not working, so the parents took her to a vegetalista (shaman) in a nearby community who sang, chanted, and blew smoke, the father told me. After the ceremony, the curandero (healer) slept and dreamt about which animal spirit had infected the child and which plants should be given to her. The next day the father said that it had been a fish spirit, and the baby improved after the treatment. The leader said that there are few curanderos nowadays who use tobacco and ayahuasca, so it is especially important to share their knowledge so the children learn about these plants. His commentary about tobacco at the medicinal plant 
workshop reveals a conflict between traditional Yagua and modern Western knowledge in which their major shamanic tool is ironically now considered problematic behavior.

And as you just explained, this tobacco also is a medicine. Our grandfathers cured with that. There were the beliefs, the plant doctors, some drink it to concentrate on the illness, what the child has. First the dizziness, they cured themselves with that medicine. In other words, it's also a medicine, it is not just a vice. It has also been support for us as medicine. It is not bad either. ${ }^{302}$

\section{Ailments and Symptoms}

Community members talked about a variety of ailments and symptoms for which medicinal plants are used. ${ }^{303}$ In my medicinal plant database, I compiled mentions of uses and preparations for all of the plants. Following are some of the most mentioned. Altahina and salvia were said to be used for fevers, and llanten is for both fevers and bronquitis. Barbasco and chiric sanago are used for colds, and catawa is used for colds and also for fertility. Doctor caspi, guayaba, and puma caspi are used for diarrhea, yahuar piripiri is used for pujo (stool or diarrhea with blood), and azucar huayo is used for diarrhea and colds. Ungurave was mentioned for bronquitis and capinuri for bronquitis and for tooth pain. Cetico is for respiratory problems, to make the phlegm come out, and chuchuasha is for lung problems and internal wounds. Cañagre was mentioned for flu and cough, and lime was mentioned for coughs and as a multipurpose medicine.

Andiroba, mullaca, and cumala, which grows wild in the forest, are used for cuts and wounds. Arcosacha is used for wounds and tumors, and uvo is used for cuts, wounds, and diarrhea. Basil and trompetero were mentioned for eye pain and eye infections, achiote for eye pain and for flus, and cashew leaves for eye pain and for diarrhea. Piñon 
rojo is used for white and red sores in the mouth as well as colds, and coriander for ear pain. The orange roots of turmeric are used for hepatitis, and cacao leaves for urination problems. Using the young leaves of caimito to increase breast milk was mentioned in several methods, and jergon sacha is for snakebites. Swollen stomachs in children were among the gastrointestinal illnesses: "We don't eat like in the city,"304 a woman explained. In focus groups, plants for menstrual and other pain, toothache, itchy wounds that enlarge, eye infections and parasites in domestic animals were mentioned. During the medicinal plant workshop, the leader said that a fever is a sign of another illness and is not a sickness itself, and the plants they use are for both symptoms and cause.

Malaria was often discussed in focus groups, although as with all of the other conditions they named, it is not possible to know if they are referring to that illness or to similar symptoms. In a focus group, women discussed who had been cured with which plants and who had gone to the health center. One mentioned yarina huayo, and another said she had used requia. In another focus group, a man talked about using remocaspi and huamanzamana. Using abuta for malaria was also written about by community members. In a recent ethnobotanical study of medicinal plants for malaria conducted in the Peruvian Amazon (Pérez 2002), findings indicate that most participants mentioned verbena, remocaspi, guisador, cedro, abuta, and mullaca as cures for malaria, and results also show that most of these contain active properties and chemical compounds. Many of the plants on their list were also mentioned by people in the community of Comandancia.

Community members described using a variety of plant parts that are mashed, grated, scraped, or crushed and made into a number of preparations. One of the most common for fevers and flues is to make a fresco (cool drink and wash) using certain plants to 
refresh the body. Serenar (to cool water with mist) is also done with many plants by leaving crushed leaves in water outside overnight with a cloth on top to catch the mist to later drink and bathe with. Ligar con vapor (to join with vapor) or ligadura (steaming) is done with plants like ajo sacha to steam the body and sweat to alleviate colds and influenza. A patarashca is made by grating bark or another plant part into a leaf that is baked, and then the cooked part is applied. Resins are applied to sores, and infusions in water are dripped into eyes and ears. Some people make infusions of various roots steeped in alcohol in glass bottles, and some plants are mixed with urine and then drunken. Through triangulation of data from interviews, focus groups, and other methods, for many of the medicinal plants, responses are the same or very similar about the type of illness or ailment they are used for, the plant part used, and the preparation.

People's descriptions of uses for medicinal plants contain a mixture of words referring to treatments, ailments, symptoms, and other related information. Determining what all the illnesses and diseases that were mentioned actually are and separating causes and symptoms is beyond the scope of this thesis, so I created categories using the interviewees' exact responses that I clarified the meanings of in a separate focus group. My coding system is detailed in Appendix 7 where the exact Spanish words and phrases from the interviews are listed with their English translations under the categories to which I assigned them.

The uses for all 59 of the top ten medicinal plants mentioned in the structured interviews are summarized in Table 4 . These data show all of the types of symptoms, ailments, diseases, medical, and other problems that they use their top ten most important medicinal plants for. The highest category is "fever/influenza" followed by 
"gastrointestinal" and "respiratory," so these may represent the most common types of health problems in the community, or they may be the types of conditions for which medicinal plants can be used. It appears there is not a lot of consensus about which specific plants to use for these ailments since most mentions of a use refer to a distinct plant. The "fever/influenza" category has fewer distinct plants mentioned in proportion to total mentions; still, 22 different plants were mentioned in only 13 interviews. The lower-numbered categories may occur less frequently or may have fewer known medicinal plants.

Appendix 6 breaks these data down by all of the individual plants and symptom categories to provide more information about which plants are used for which ailments. For example, ajo sacha received the most mentions overall, 18 of them across six different symptom category groups. In fact, the ten mentions of ajo sacha in the fever/influenza category out of 13 total interviews is the greatest community consensus out of all of the medicinal plants and uses data. A close second is lancetilla, with nine mentions out of 13 for the fever/flu category. Mucura has seven mentions for the fever/flu category, and most of the other numbers are lower. Again, low numbers may represent less frequency, or they may indicate a problem for which there are few options. In summary, then, a wide variety of plants are used for the ailments in these symptom categories, and there is not a great deal of consensus about which specific plants to use to treat these symptoms. There is a strong consensus, however, about the top three plants, mucura, ajo sacha, and lancetilla, which are frequently mentioned in the fever/influenza category. 
Table 4: Uses for Medicinal Plants

\begin{tabular}{|c|c|c|}
\hline Symptom Categories & Number of Mentions & $\begin{array}{c}\text { Number of Distinct Plants } \\
\text { Mentioned }\end{array}$ \\
\hline Fever/Flu & 57 & 22 \\
\hline Gastrointestinal & 32 & 20 \\
\hline Respiratory & 24 & 14 \\
\hline Pain/Body & 18 & 15 \\
\hline Skin & 11 & 8 \\
\hline Headache & 9 & 4 \\
\hline Mouth & 7 & 5 \\
\hline Belief & 5 & 4 \\
\hline Supernatural Causes & 5 & 3 \\
\hline Pregnancy/Child birth & 4 & 3 \\
\hline Eye & 3 & 2 \\
\hline Urinary & 3 & 3 \\
\hline General & 2 & 2 \\
\hline Malaria & 2 & 2 \\
\hline Ear & 1 & 1 \\
\hline Snake bite & 1 & 1 \\
\hline Measles & 1 & 1 \\
\hline Grand Total & 185 & 110 \\
\hline
\end{tabular}

\section{Top Ten Medicinal Plants}

In the 13 structured interviews, the participants gave free-listed responses about the ten most important medicinal plants for them and their families and also the use, part, preparation, and location information about each plant. Data from these interviews show a low degree of consensus among the community about which medicinal plants they consider to be the top ten. There is wide variety and little repetition in the plants mentioned as the top ten: out of the 13 interviews that elicited a total of 129 top ten medicinal plants, 59 distinct medicinal plants were mentioned, so most plants were mentioned only about twice across all lists. 
This variety is seen at a number of levels: in the 13 interviews, nine distinct plants were ranked as the number one medicinal, so there was little consensus about the top plant. Out of the 58 distinct medicinal plants, only nine plants were mentioned four or more times, and only four plants were mentioned five or more times across all 13 lists. There is, then, a wide variety of species of medicinal plants that the community considers important. This low degree of cultural consensus about the most important medicinal plants may indicate the breadth of traditional knowledge or perhaps variation among household medical needs. Table 5 presents an overview of these data.

\section{Table 5: Consensus about Top Ten Medicinal Plants}

\begin{tabular}{|l|l|c|}
\hline A. & \multicolumn{1}{|c|}{ Medicinal Top 10 Lists from Structured Interviews } & Total \\
\hline \multirow{4}{*}{} & Houses in Community & 33 \\
\cline { 2 - 3 } & Household Interviews & 13 \\
\cline { 2 - 3 } & Distinct Medicinal Plants Ranked as \# 1 & 9 \\
\hline
\end{tabular}

\begin{tabular}{|l|l|c|}
\hline B. & \multicolumn{1}{|c|}{ In All Top 10 Lists Combined } & Total \\
\hline \multirow{4}{*}{} & All Mentions & 129 \\
\cline { 2 - 3 } & Distinct Medicinal Plants Mentioned & 59 \\
\cline { 2 - 3 } & Distinct Medicinal Plants Mentioned 4 or More Times & 9 \\
\cline { 2 - 3 } & Distinct Medicinal Plants Mentioned 5 or More Times & 4 \\
\hline
\end{tabular}

Table 5: A. There is very little overlap in responses to the question about the most important medicinal plant. B. This wide variety of distinct plants mentioned is also seen throughout the top ten lists: most plants mentioned are repeated only once, and very few are repeated more than a few times.

All of the 13 household interview lists of top ten most important medicinal plants were compiled to create a ranked community list of all of the 59 total medicinal plants that were mentioned. This community ranking was generated using Anthropac software which compiles all of the respondents' top ten lists, calculating both the plants' rankings on the lists as well as the number of mentions across all lists (as described in the 
methodology chapter above). The complete ranked community medicinal plant list is presented in Appendix 5. I compared each of the 59 medicinal plants that were mentioned to the list of medicinal plants that Chaumeil (1987) includes in his Yagua ethnography, and the X's in the right column indicate which plants are on his list. Thirteen out of the 59 plants mentioned by this community are on his list of medicinals, and there are also plants on his list that were not mentioned by this community.

Table 6 compiles data about the top ten medicinal plants for the community, which are the first ten of the complete compiled ranked list described above. Scientific names were derived by comparison of the community's common Spanish names and photos, with various publications and identification guides (as described in the methodology chapter). Uses and plant parts are also compiled from the responses to the top ten plant questions in the structured interviews. These are translations of the participants' exact words in Spanish, and included are all given responses listed in no particular order. These top medicinal plants are used to treat fever, influenza, headache, stomachache, and a range of other ailments.

The two columns next to the Usage column in Table 6 compare this community's uses for these top ten medicinal plants with the uses described from other research in the area. I assessed the usages described for each of these plants in both Chaumeil's ethnography on the Yagua (Chaumeil 1987) and Duke and Vasquez's Amazonian Ethnobotanical Dictionary (1994) to determine if the ailments mentioned by the community were the same or different. Many of the community's uses for these top ten plants are the same as uses in other communities in the greater Amazon region as described by Duke and Vasquez. Most are not included in or not the same use as 
Chaumeil indicated, and only one is the same. Details about the locations of these top ten plants are discussed below.

In spite of the wide variety of medicinal plants mentioned, there is, however, a high degree of cultural consensus about the top three of the top ten medicinal plants. These top three were mentioned in most of the 13 top ten lists: mucura, the highest ranked on a number of measures, was mentioned ten times, ajo sacha nine times, and lancetilla eight times. Mucura, ajo sacha, and lancetilla were also the most often listed within the top five most important medicinal plants across all interviews. Data about these ten plants obtained from other methods follow below. 
Table 6: Community Top Ten Medicinal Plants and Uses

\begin{tabular}{|c|c|c|c|c|c|c|c|}
\hline Rank & $\begin{array}{l}\text { Spanish } \\
\text { Name }\end{array}$ & $\begin{array}{l}\text { English } \\
\text { Name }\end{array}$ & $\begin{array}{l}\text { Scientific } \\
\text { Name }\end{array}$ & Usage & $\begin{array}{c}\text { Chaumeil } \\
\text { Usage } \\
\text { Same } \\
\end{array}$ & $\begin{array}{c}\text { Duke and } \\
\text { Vasquez } \\
\text { Usage Same }\end{array}$ & Part Used \\
\hline 1 & Mucura & & $\begin{array}{l}\text { Petiveria alliacea } \\
\text { Phytolaccaceae }\end{array}$ & $\begin{array}{l}\text { to keep ghosts and bad } \\
\text { spirits away, diarrhea, } \\
\text { "bad air", flu, fever, } \\
\text { headache, to } \\
\text { refresh/cool, infection }\end{array}$ & No & Yes & $\begin{array}{l}\text { leaf, } \\
\text { new leaves }\end{array}$ \\
\hline 2 & $\begin{array}{l}\text { Ajo sacha, } \\
\text { Sacha ajos }\end{array}$ & $\begin{array}{l}\text { "Wild } \\
\text { Garlic" }\end{array}$ & $\begin{array}{l}\text { Mansoa alliaceae } \\
\text { Bignoniaceae }\end{array}$ & $\begin{array}{l}\text { fever, headache, get } \\
\text { rid of bad luck, to } \\
\text { refresh/cool, flu, } \\
\text { diarrhea, childbirth, } \\
\text { pain, colds }\end{array}$ & Yes & Yes & $\begin{array}{l}\text { leaf, } \\
\text { root, } \\
\text { heart } \\
\text { (developing } \\
\text { leaves) }\end{array}$ \\
\hline 3 & Lancetilla & & $\begin{array}{l}\text { Peperomia rubea } \\
\text { Piperaceae }\end{array}$ & $\begin{array}{l}\text { fever, headache, bad } \\
\text { headache, to } \\
\text { refresh/cool, cough }\end{array}$ & No & Yes & leaf \\
\hline 4 & Algodón & Cotton & $\begin{array}{l}\text { Gossypium sp. } \\
\text { Malvaceae }\end{array}$ & $\begin{array}{l}\text { stomacheache, colds, } \\
\text { giving birth }\end{array}$ & $\mathrm{n} / \mathrm{a}$ & Yes & leaf \\
\hline 5 & Huito & & $\begin{array}{l}\text { Genipa americana } \\
\text { Rubaiceae }\end{array}$ & bronchitis & $\mathrm{n} / \mathrm{a}$ & Yes & $\begin{array}{l}\text { heart, } \\
\text { leaf }\end{array}$ \\
\hline 6 & Rosasisa & $\begin{array}{l}\text { Mexican } \\
\text { Marigold }\end{array}$ & $\begin{array}{l}\text { Tagetes erecta } \\
\text { Asteraceae }\end{array}$ & $\begin{array}{l}\text { "bad air," vomiting, } \\
\text { diarrhea, to } \\
\text { resfresh/cool }\end{array}$ & $\mathrm{n} / \mathrm{a}$ & $\mathrm{n} / \mathrm{a}$ & leaf \\
\hline 7 & Malva & & $\begin{array}{l}\text { Malachra sp. } \\
\text { Malvaceae }\end{array}$ & $\begin{array}{l}\text { kidneys, to } \\
\text { refresh/cool, swollen } \\
\text { stomach, irritation }\end{array}$ & No & Yes & root \\
\hline 8 & Toronja & Grapefruit & $\begin{array}{l}\text { Citrus paradise } \\
\text { Rutaceae }\end{array}$ & $\begin{array}{l}\text { flu, cough, to } \\
\text { refresh/cool }\end{array}$ & $\mathrm{n} / \mathrm{a}$ & No & $\begin{array}{l}\text { fruit, } \\
\text { leaf }\end{array}$ \\
\hline 9 & \begin{tabular}{|l|} 
Ajengibre, \\
Jengibre
\end{tabular} & Ginger & \begin{tabular}{|l} 
Zingber officinale \\
Zingiberaceae
\end{tabular} & diarrhea, colds, pain & $\mathrm{n} / \mathrm{a}$ & Yes & root \\
\hline 10 & Orégano & Oregano & $\begin{array}{l}\text { Origanum vulgare? } \\
\text { Lamiaceae }\end{array}$ & $\begin{array}{l}\text { stomachache, } \\
\text { flatulence (air in the } \\
\text { stomach) }\end{array}$ & $\mathrm{n} / \mathrm{a}$ & $\mathrm{n} / \mathrm{a}$ & leaf \\
\hline $\begin{array}{l}\text { Table } \\
\text { and pa } \\
\text { compa } \\
\text { and Va }\end{array}$ & $\begin{array}{l}\text { This table } \\
\text { used are a } \\
\text { sons refer t } \\
\text { quez' Amaz }\end{array}$ & $\begin{array}{l}\text { presents th } \\
\text { o compile } \\
\text { the medici } \\
\text { nian Ethn }\end{array}$ & $\begin{array}{l}\text { nked community to } \\
\text { om the responses to } \\
\text { plant usages descri } \\
\text { tanical Dictionary }\end{array}$ & $\begin{array}{l}\text { list which is compiled } \\
\text { structured interviews } \\
\text { n Chaumeil's ethnogr } \\
\text { and Vasquez' 1994). }\end{array}$ & $\begin{array}{l}\mathrm{m} \text { the ind } \\
\text { are listed } \\
\text { on the } \mathrm{Y}\end{array}$ & $\begin{array}{l}\text { l top } 10 \text { lists. } \\
\text { particular ord } \\
\text { (Chaumeil } 19\end{array}$ & $\begin{array}{l}\text { The usages } \\
\text { er. Usage } \\
\text { 87) and Duke }\end{array}$ \\
\hline
\end{tabular}

Information about the locations of the most important community medicinals is useful for assessing people's access to them, the plants' ecological status, and other aspects of resource management. For each top ten medicinal plant mentioned, interviewees were asked where they obtain that plant: in the garden around their house, in their outlying garden plot or a family member's plot, in the forest, or given as a gift from someone else. 
Table 7 breaks these data down by location for the community's top ten medicinal plants. The home garden is the location where the majority of the community's most important medicinal plants are reported to be acquired. This data combined with people reporting that the cattle eat the plants in their home gardens suggests that this major source of their most important medicinals could be threatened. Ajo sacha, number two, is found predominantly in the forest, so its status may need to be assessed.

Table 7: Community Top Ten Medicinal Plants Locations

\begin{tabular}{|c|l|c|c|c|c|}
\hline Rank & \multicolumn{1}{|c|}{ Plant } & $\begin{array}{c}\text { Home } \\
\text { Garden }\end{array}$ & $\begin{array}{c}\text { Outlying } \\
\text { Garden }\end{array}$ & Forest & $\begin{array}{c}\text { Gift or } \\
\text { Bought }\end{array}$ \\
\hline $\mathbf{1}$ & Mucura & 9 & 1 & & 1 \\
\hline $\mathbf{2}$ & $\begin{array}{l}\text { Ajo sacha, } \\
\text { Sacha ajos }\end{array}$ & 3 & & 7 & \\
\hline $\mathbf{3}$ & Lancetilla & 7 & & & 1 \\
\hline $\mathbf{4}$ & Algodón & 4 & 1 & & \\
\hline $\mathbf{5}$ & Huito & 2 & & 2 & \\
\hline $\mathbf{6}$ & Rosasisa & 4 & & & \\
\hline $\mathbf{7}$ & Malva & 2 & & & 1 \\
\hline $\mathbf{8}$ & Toronja & 3 & 2 & & 1 \\
\hline $\mathbf{9}$ & $\begin{array}{l}\text { Ajengibre, } \\
\text { Jengibre }\end{array}$ & 4 & 2 & & \\
\hline $\mathbf{1 0}$ & Orégano & 3 & & & \\
\hline \multicolumn{5}{|l|}{$\begin{array}{l}\text { Table 7: This table breaks down by location the community's top } 10 \\
\text { medicinal plants. }\end{array}$} \\
\hline
\end{tabular}

\section{Important Community Plants}

All of the top ten plants were also mentioned using other methods during fieldwork, so in addition to the uses listed in Table 6 above, other data about uses for these plants follow. Mucura, ajo sacha, and lancetilla were the top ten mentioned and are some of the most important plants for the community, and data about the other seven follows. 
Mucura, number one on the compiled community top ten medicinal plant list, is used for physical ailments as well as some spiritual and supernatural ones. Using mucura for fevers was mentioned across five different methods besides the structured interviews, and using for coughs was also mentioned. The strong-smelling leaves of this bush with small, white flowers are used to make a cool drink and also to apply to the body and head of a feverish person. Mucura was also mentioned for keeping bad spirits away by preparing with water and applying to bodies and homes. These triangulated data suggest strong cultural consensus about the importance and use of this plant. For the top ten plants mentioned in the structured interviews, I asked about each plant why it is one of the most important medicinal plants. For mucura, someone said: "It is a plant that has a strong smell, and that gets rid of the illness." ${ }^{305}$ One man said in a focus group: "mucura: to refresh, for the flu, for everything." ${ }^{\circledR 306}$ Chaumeil (1987:150) lists mucura as a remedy for itching. Duke and Vasquez (1994) describe a variety of medicinal and spiritual uses for mucura in a number of different Amazonian tribes. Desmarchelier and Witting Schaus (2000) also detail its ethnomedical uses throughout the Americas as well as the bioactivity of this plant.

Using ajo sacha for influenza and fevers was mentioned across four different methods in addition to being number two on the community top ten list, so this triangulated data suggests strong cultural consensus about the importance and use of this plant. Headache, diarrhea, and childbirth were also mentioned. It is a forest plant, and leaves and roots are used. In a focus group, a man said: "When you have a sickness, I have to get ajo sacha for a cool drink against flu and fever... You yourself can cure with that too, with ajo sacha. If you have a high fever, grate the root, and drink it."307 
Regarding why it is one of the top ten, responses for ajo sacha included: "It is the best against fever," "With that you heal, it's a good medicine," and "It is for every illness."308 Ajo sacha contains a number of active compounds and is also used for physical and spiritual problems in several Amazonian tribes according to Duke and Gentry (1994).

Preparing lancetilla leaves for headaches and fevers was mentioned in four other methods, a strong consensus about the importance and use of this number three plant on the list. "I have lancetilla that is over there; it's used for a cool drink for a fever," woman said in a focus group. It is ground and taken three times a day, someone else said. Chaumeil (1987:150) lists lancetilla being used by the Yagua for influenza. Duke and Vasquez (1994) also mention use for fevers as well as for earaches and inflammation.

The cotton tree was mentioned for treating stomachache and vomiting in two other methods and for childbirth by three different methods. Huito was also mentioned for bronchitis through two other methods, and someone who included it on their top ten list said: "We have confidence in this plant because it has cured us. After giving it to a child, he doesn't have this illness anymore. He heals completely." ${ }^{\prime 310}$ Rosasisa was mentioned for treating vomiting, bad air shock and to refresh. Interviewees who included it on their top ten list for use against bad air shock said they did so "because that heals children," and "because I did the test when my son had bad air shock and it worked."311 Malva was mentioned for fevers through two other methods, and an interviewee said it was one of the top ten because "it heals people" $" 312$ with kidney problems.

Grapefruit is included in one of the top ten lists for cough "because we have tested it and it is good," and in another list to refresh "because it is better than [medicine] from the pharmacy."313 Ginger was said to be used for colds, stomach pain, and diarrhea. Finally, 
oregano was mentioned for stomachaches and vomiting through three other methods and is prepared by boiling leaves with rice or plantains and milk, or with water as a tea.

Clearly there are many plants that are important to the community besides these ten, but the results of the compiled top ten lists combined with these data from other methods provide a basic understanding of some of their health issues and traditional botanical knowledge.

Table 8 triangulates medicinal plant data from three different methods to present an overview of the medicinal plants that are important to the community. This table includes 19 important medicinal plants: the community compiled top ten medicinal plant list from the structured interviews, 13 plants that were presented by community members at a workshop, and 16 plants that were documented by community members in written form. For the workshop, people were told to bring a medicinal plant to talk about, but not specified as the most important one. Likewise for the community-written medicinal plants and uses: community members chose to document these medicinal plants and their uses and preparations in Spanish and Yagua. Assuming that the plants brought to the workshop and documented in written form are important to the community, this table summarizes some of the most important medicinal plants for this community. Six plants were mentioned through two of these methods, and seven were mentioned in all three of these methods. The plants appearing in more than one column may be more important, more often used, better known, and/or easier to obtain. 
Table 8: Medicinal Plants Important to Community

\begin{tabular}{|c|c|c|c|}
\hline Plant Name & $\begin{array}{l}\text { Community } \\
\text { Presented at } \\
\text { Workshop }\end{array}$ & Community Wrote & $\begin{array}{l}\text { Community } \\
\text { Top } 10 \text { List }\end{array}$ \\
\hline Abuta & & $\mathrm{x}$ & \\
\hline Achote, Achiote & $\mathrm{x}$ & $\mathrm{x}$ & \\
\hline Ajengibre, Jengibre & $\mathrm{x}$ & $\mathrm{x}$ & $\mathrm{x}$ \\
\hline Ajo sacha, Sacha ajo & $\mathrm{x}$ & $\mathrm{x}$ & $\mathrm{x}$ \\
\hline Algodón & $\mathrm{x}$ & $\mathrm{x}$ & $\mathrm{x}$ \\
\hline Caimito & $\mathrm{x}$ & $\mathrm{x}$ & \\
\hline Casho & & $\mathrm{x}$ & \\
\hline Huito & $\mathrm{x}$ & $\mathrm{x}$ & $\mathrm{x}$ \\
\hline Lancetilla & $\mathrm{x}$ & $\mathrm{x}$ & $\mathrm{x}$ \\
\hline Malva & & & $\bar{x}$ \\
\hline Mucura & $\bar{x}$ & $\bar{x}$ & $\bar{x}$ \\
\hline Orégano & $\mathrm{x}$ & $\mathrm{x}$ & $\mathrm{x}$ \\
\hline Piñon rojo & $\mathrm{x}$ & $\mathrm{x}$ & \\
\hline Puma caspi & & $\mathrm{x}$ & \\
\hline Rosasisa & $\mathrm{x}$ & & $\mathrm{x}$ \\
\hline Salvia & & $\mathrm{x}$ & \\
\hline Tabaco & $\mathrm{x}$ & $\mathrm{x}$ & \\
\hline Toronja & & & $\mathrm{x}$ \\
\hline Yahuar Piripiri & $\mathrm{x}$ & $\bar{x}$ & \\
\hline
\end{tabular}

Table 8: This table triangulates the same data from three methods: the community compiled top ten medicinal plant list from the structured interviews, 13 plants that were presented by community members at a workshop, and 16 plants that were documented by community members in written form.

In conclusion, this Yagua community has a rich culture and extensive traditional botanical knowledge. This knowledge about food, medicinal, and other plants ties cultural identity to both human health and environmental management. As with the Yagua language, their indigenous botanical knowledge needs to be documented and transmitted to future generations, especially in the midst of social, cultural, and environmental changes. 


\section{DISCUSSION}

\section{Disciplinary and Theoretical Framework}

\section{Summary of Research Topics and Findings}

To investigate the research questions of this study, I have utilized an ethnographic approach to analyze the environmental, cultural, and social changes that are affecting the community as well as their medicinal plant knowledge. The study's findings describe subsistence, livelihood, health, and other needs, and also plant knowledge and other aspects of Yagua culture in the community of Comandancia in the Peruvian Amazon. I have also provided an overview of the institutional context and power relations involved in land use and natural resource access, examining the function of community organizations and indigenous federations as well as the role of the state and extractive industries.

The main findings can be summarized as follows: The community's relationship with the environment is based on utility and livelihood. People reported that natural resources were more abundant in the past, but now there are unmet subsistence needs: lack of enough food in general, and insufficient fish and animals specifically because of extraction by outsiders. Many men are employed in logging and are absent from their families and from subsistence activities in the community for extended periods of time. Health and access to health care are also primary concerns for the community, and other challenges include cooperation, communication, and alcohol.

There are a number of community organizations, and the community is involved in indigenous federations, but the highest leadership positions are held by members of one 
family. One resulting problem is that the leadership family's cattle live in the community despite complaints by other community members. The community possesses deep botanical knowledge, and they use a wide variety of medicinal plants. They also take pride in and are interested in maintaining their Yagua culture and language. Here I discuss some of these findings in terms of the disciplinary perspectives employed in this study.

\section{Environmental Anthropology and Political Ecology}

The descriptions and analyses in Chapter 4 above contribute to environmental anthropology by demonstrating some of the connections between the cultural, social, and environmental transformations the community of Comandancia is undergoing. The circumstances of this case study also appear to fit well within a political ecology framework: a number of environmental problems as well as community natural resource needs are connected to larger economic and political forces, and power dynamics affect resource access at several levels. Critiques of political ecology include the need to distinguish between real versus perceived environmental change and between environmental change versus environmental destruction. Since this study of Comandancia was largely ethnographic, it focuses on community perceptions and information from literature and other sources, but does not include data that measure actual environmental change. This study does outline some of the stakeholders, issues, and relationships that should be further investigated.

The role of power relations in changes in environmental and social systems is emphasized in political ecology, and in this case study of Comandancia, power and 
control over natural resources operates at state, global market, and local community levels. Extractive industries are altering Amazonian ecosystems, and they are supported by state natural resource policies that provide incentives for market activities and concessions that have transformed the land tenure regime. New forestry laws and logging concessions have increased logging activity in the region, a system through which valuable resources are removed by outsiders. The community's subsistence difficulties have been exacerbated by other extractive industries. Commercial fishing and commercial hunting have depleted the local supply of fish and animals, so community members can no longer rely upon these activities for livelihood or even subsistence needs.

With few economic alternatives and many unmet needs, men in the community work for low wages in the logging industry to survive within a cash economy. Since agriculture and other subsistence activities are more neglected because of lack of male labor, the net benefits of this type of integration into the market economy are questionable. Men are separated from their families, and other cultural and social changes and community issues such as cooperation and alcohol are linked to these external economic activities. In these ways, the culture and environment of this community are being transformed through market and political processes that result in livelihood, subsistence, and health difficulties for the community. The influence of these economic, social, and political forces on this community is largely tied to the drastic inequalities in power and economic resources between indigenous peoples and the state and industry. 
At the local level, the community power structure concentrates decision-making largely within one immediate family. The leadership family's free-ranging cattle consuming other community members' plants is a literal manifestation of the effects of this power structure on the community and environment. This local political arrangement leads to inequality in access to natural resources since the cattle consume subsistence and other home garden plants, and they may also adversely affect community health. Other community members complained about the lack of democratic process, and these local politics may also contribute to the lack of social capital, lack of participation, and apathy in the community. In these ways, local and outside market dynamics interact and exert changes on the social and natural environment of the community. Also, as in many other examples in the anthropological literature about indigenous communities, this power structure also problematizes the concept of "community" because in interactions with outside stakeholders, the leaders do not necessarily represent the rest of the community.

Institutions and systems are central subjects of analysis in environmental anthropology and political ecology. In Comandancia, traditional systems are transforming into and operating alongside modern systems at a number of levels. From communal work to wage labor and from forest subsistence to the market economy, current circumstances are changing people's relationship to natural resources, yet certain aspects of Yagua culture and knowledge are maintained. New institutions have also developed, providing an infrastructure to interact with other stakeholders. Community level organizations focus more on livelihood issues, but their strength is largely inhibited by local politics. Indigenous federations, on the other hand, focus on issues of cultural identity and land rights, and they are gaining power with unity among different groups, 
though their struggles are far from over. These organizations and federations are one of the most significant changes in Yagua relationships with the outside world since the time of Chaumeil's fieldwork 30 years ago when there was no social organization beyond the community level (1987).

There is a tension between old and new political systems. As described above, the ORAI representative explained the difference between the traditional inheritance system and the modern democratic one, yet community members complained about the lack of elections and political justice. This study of Comandancia did not investigate this situation in detail, but it seems that interplay and negotiation between hereditary and democratic systems has not been resolved. There are probably examples of harmonious integration of both systems, but in this case it appears that the hereditary system is causing stagnation and corruption more than cultural vitality.

My data and analyses also suggest that the local political climate plays a crucial role in community organization and participation, necessary components of natural resource projects that the community will increasingly need. Organizations and agencies working with indigenous communities should be aware of these representation and participation issues, perhaps including both democratic processes and also traditional consultant roles in projects. Since the indigenous organizations that have been developing over the last few decades in the Amazon are integral to the land and cultural rights of their peoples, an analysis of the interplay between traditional and modern political systems would provide a better understanding of these cultural transitions.

Other topics that have been important in environmental anthropology include indigenous peoples' relationships with the environment, identity, and perceptions of 
outsiders, which I discuss here. In all of their dialogue, community members certainly never talked about "the environment," and not surprisingly, Western notions of conservation and sustainability were not part of their discourse. People did, however, talk about natural resources, and especially about food. Since much of the day revolves around trying to obtain food, it is a more time-consuming activity than in more developed places.

The Western conservation worldview of the natural environment is usually held by those whose own relationships with the natural world are abstract and far-removed, distanced from witnessing their own use of natural resources and largely dependent on long supply chains for their livelihood. Indigenous worldviews are held by people, such as those in Comandancia, who have direct relationships with the natural world, not only witnessing their own use of natural resources, but also having to self-sufficiently provide for all of their own livelihood needs, utilizing their knowledge of nature for survival. In other words, the environment is less about an outside natural world to be conserved and more about what goes in and out of kitchens and bodies everyday. The disparity between these perspectives highlights the need for conservation efforts to address subsistence and livelihood problems in communities.

However, even when projects are specifically designed to meet indigenous livelihood needs and secure land for them, these cultural differences make communication and understanding difficult. In an interview with a researcher at the IBC, she discussed the challenges of collaborating with indigenous communities that relate to differences in perspective on the natural environment. "They are two different visions. They have a different vision about what protected natural areas are, ${ }^{, 314}$ she said. She explained the 
process of coming to agreement about the communal reserve model with the communities involved, including the meetings and workshops that had been held. The ecological research resulted in management plans that include amplified community territories, areas for community timber extraction, and strict conservation areas limited to breeding grounds for sensitive fauna. She described how despite these efforts, communication is still a challenge:

But, there is a lot of misinformation about that in the [indigenous] organizations, and perhaps also ours. I think that we should- we have put a lot- invest a lot more time and work, whatever is necessary, to make our technical plan more visible. Because they do not understand it until now. So, that is a big problem that we have with them... and there the restricted areas, they don't want to know anything about them. But it's misinformation, basically. In other words, there are people who are really interested, they need to be informed. But it's also our mistake, us as well, to generate some type of information, perhaps, I don't know in what other form. ${ }^{315}$

Based on anthropological literature on these issues as well as the reality on the ground, indigenous perceptions of the natural world have not been sufficiently understood, so the gap between indigenous livelihood and Western environmental efforts has not been bridged. Ethnoscientific research is one way to improve this understanding. For example, ethnobotanical data provide pragmatic information about people's uses and preparations of plants and also reveal aspects of their conception of health and illness. In the same way, ethnoecology and other ethnosciences can be used to investigate not only individual natural resources, but also people's broader notions of the natural world. Still, even with better understanding of indigenous cultural paradigms of the environment, the process of translating, communicating, and working on natural resource projects poses many challenges. 
Cultural identity is a complex, dynamic phenomenon, and here I will briefly mention a few aspects that I noticed in the community that relate to the environment. As I described above, older people expressed pride in their Yagua culture and environmental knowledge, but people often blamed themselves for not passing on the Yagua language. In reality, the outside society and its values have over time exercised constraints and rewards on expression of indigenous identity, shaping people's sense of cultural pride and their behavior. The leaders, however, mentioned mestizo influence on language, and they often blamed the government and outsiders on many of their cultural and environmental problems.

The leaders of Comandancia also recognize that despite conflicts with mestizo society in Peru, indigenous identity provides them with "cultural capital" in the international community. They seemed to understand the "strategic essentialism" that Jim Igoe described (2005:283), applying it to not only environmental stewardship, but also to indigenous cultural identity. For example, during a recorded community meeting in which I was not present, in discussing their economic needs and their relationships with foreigners, the community president said: "We are more recognized than other rural communities. Tourists come mostly for indigenous peoples, for us. They like our customs. They like our clothes and everything that we have in our forest. And that is what they like."316

Community members did not distinguish between researchers, tourists, or any other type of foreigner. Peoples' dialogue about foreign visitors focused on community needs, and their rhetoric was always about hope for financial support or donations. The leader often talked about how they should be compensated for indigenous knowledge and 
environmental stewardship. In a focus group, he said that: "Travelers should not just come to take advantage of our resources, not just come to exchange our crafts, but also from their part, we need something." ${ }^{317}$ He described his viewpoint further in an interview: "For us it is also important to obtain some projects from foreigners because also it is they who come and want to know about our resources. Also, they want us to conserve our natural resources. ${ }^{318}$

In conclusion, this study's findings explain the many ways that culture, the environment, health, social change, and political and economic forces are complexly linked in this Yagua community. This case study fits well within a political ecology framework, and these findings and analyses contribute to environmental anthropology.

\section{Culture and Environment from Local to Global: Research}

\section{and Application}

\section{Community Needs and Suggestions for Research}

In this thesis, I have described many of the community's livelihood needs and have explained how these problems are tied to social, cultural and environmental change. These findings correspond with the social assessment report for the nearby reserve that summarizes the threats to indigenous communities in this area as:

incursion of outsiders to hunt, fish, or extract resources in indigenous territories; the erosion of indigenous culture; the lack of economic opportunities; the scarcity of fish and game; and the lack of social justice... lack of basic health and educational services in their communities, and discrimination against indigenous communities by government authorities. (Pitman, et al. 2004:174) 
The problems that the community of Comandancia reported include all of these as well as the issues with alcohol, cattle, politics and democracy, the Yagua language, male labor, organization and social capital, and apathy. This research also shows that the role of government and industry through natural resource policy and extractive activities adversely affect indigenous land rights and natural resource access. In several meetings and focus groups, I used the method of free-listing, categorizing, and prioritizing for the community members to articulate their specific material needs. These results are presented in Appendix 8.

During fieldwork, I collaborated with the teacher, one of the main participants in this project, and I sought his advice about what the community wanted to document and what methods should be used. Since he is a community member and dedicated to bilingual and bicultural education, his insights are valuable as an insider with the goal of documenting Yagua knowledge and now having experienced some research options to do so. Finding value in researching traditional knowledge, he said he would like the community to obtain more "support for this type of interview." 319 He said that the project "makes the community wake up. Because previously the community was with little knowledge. They were not interested in what so many things are used for. And now I see that they are getting to know..." ${ }^{320}$ The leaders also emphasized the importance of Yagua culture and encouraged sharing and recording it.

Following are some of the teacher's ideas and suggestions for future ethnobotanical and other anthropological research with the community. He thought that the focus group/meeting method worked well, and he wanted to conduct additional groups to investigate medicinal plants that were used in the past by asking questions about each 
plant and taking written notes on people's responses. He wanted focus groups to include discussions of traditions, customs, clothing, and other lifestyle information about the past to not forget these aspects of Yagua culture. Also, in terms of methods, he suggested conducting more couple interviews of older people to learn about personal histories. Identifying knowledgeable people who could be interviewed, he expressed great interest in tape recording more of their stories as well as medicinal plant uses and preparations in both Spanish and Yagua. A community member could be used as a translator, he said, to interview the older people who do not speak Spanish.

Recognizing the importance of connecting children and older people, he thought it would be good to bring them together so the adults could tell the children about past times, how they lived, and what their goals in life were. As mentioned earlier, the medicinal plant workshop was successful, and in future workshops children could be given a more active role. He wanted the children to learn about the clothing and the livelihood of their ancestors and the names of human body parts in Yagua. He also suggested that anthropologists or other researchers make multiple or longer trips to the community to be able to advance the research further.

Since community members are often not informed about decisions, he also thought that a more extensive consent process and community consensus before conducting future tape recordings would be helpful. He also said that more people would be willing to participate if they were paid, and that he had said to them: "That can't be. You want to sell your words- it's not like that." ${ }^{321}$ Finally, regarding products to create for cultural education, he liked the idea of a bilingual community book or laminated cards about medicinal plant uses and preparations and Yagua culture and history. 
Besides these suggestions for research on Yagua culture, history, and language mentioned by the teacher, I would recommend future research focusing on needs and natural resources, ethnobotany, and political ecology. Ecological and socioeconomic studies of forest product use could be undertaken as part of needs assessment and to collect baseline data, as has been done for other communities. Appropriate standards and indicators could be used to measure health, nutrition, and education. Studies assessing potential markets and sustainable harvesting of non-timber forest products are needed to explore economic options for the community. Further ethnobotanical research could investigate ecological and resource management knowledge, and the ecological status of the most important medicinals should be assessed.

More extensive research on the political ecology of land and natural resource use in the area is essential. Detailed analyses of the stakeholders and issues I have described above are necessary to better understand the complex interrelationships among the biological and social factors, the political and economic forces shaping environmental and cultural change, and the power distribution among the different actors. Although there is an abundance of literature on a wide variety of Amazonian environmental topics, little research has been conducted on the recent processes and effects of logging concessions and other aspects of forest privatization.

\section{Environment and Sustainable Livelihood in the Amazon}

This research on Comandancia is applicable to both local cultural and natural resource management and also to global cultural and biodiversity conservation efforts. The data indicate that the community has basic subsistence, health, and other livelihood 
needs as well as culture and language concerns. It seems that subsistence and health needs must be met before the community can begin to engage in addressing biocultural diversity conservation and other environmental and cultural issues. INEI data (2008) show that Peruvian jungle populations are increasing, and Loreto's population density is rising, so pressures on natural resouces supplies and environmental and social changes will continue to be challenges.

The recent growth of the non-profit sector has increased NGO activity in the Amazon. Ranging from environmental to community issues, NGOs have formed alliances amongst themselves and partnerships with local communities, indigenous federations, research institutions, governments, multilateral agencies, and other stakeholders. These new organizational arrangements connect local and global concerns and play a major role in the negotiations and activities involving Amazonian peoples and their ecosystems. Recognizing the ties between environmental conservation and rural livelihood, NGOS have been involved in a number of conservation and community initiatives including creating reserves and providing services and training. These organizations are of course limited by funding and other constraints, and the scope of problems is as large as the region, but their experiences provide a set of best practices and project ideas that can be built upon. Here I discuss potential solutions to Amazonian community and environmental problems from local NGOs and the literature, then in the next section, I offer suggestions based on this research.

Project Amazonas, for example, has been working with the Comandancia community as well as many other communities in the Loreto region for over ten years. As a small NGO, they have built trust with local communities using a bottom-up approach. They 
have been engaged in a variety of medical, educational, conservation, and research activities, collaborating with a number of different institutions. They have also explored options for environmentally and economically sustainable development based on their experiences with indigenous and other local communities and their knowledge about ecological and market feasibility of natural resource projects. Activities and projects that they have worked on that could be expanded include aquaculture for subsistence and ornamental fish production, management of forest animals, butterfly farming for export, small-scale timber, fruit, nut, and medicinal plant harvesting, woodwork, handicraft, and pottery production, and ecotourism.

A researcher at the $\mathrm{NGO}$ IBC explained to me in an interview that some communities have successfully managed sustainable logging projects, including certified wood. Since the market exists and no other forest product has provided an economic substitute, she said, logging has potential as a source of income for communities. She also said that ornamental fish farming could potentially generate income because there is a demand and little investment is required. Regarding NGOs implementing natural resource management projects with communities, she said that based on her experiences with a number of different organizations, a very long process of many years of invested effort is necessary to be successful. She explained that to operate projects with communities, organizations need to devote a lot of time to training and working with them. NGOs need to be present through difficulties, to address problems and goals at different levels, and to learn from their failures to finally achieve just the first step, she said. Community-level organization and institutions also play a major role, she said, in training people to conduct research and manage projects. She emphasized that NGOs cannot undertake all of these 
tasks alone and that much depends on the state, which has not had a good record for managing natural resources. The solutions are complex, she concluded, but they do exist.

Literature in environmental anthropology and other related fields describes examples of ecologically and culturally viable conservation and development projects with indigenous communities in the Amazon forest. For example, Vormisto (2002) describes the production and marketing of chambira fiber hammocks and bags among the Bora in the northeastern Peruvian Amazon, noting that the abundance of chambira in secondary forest indicates its potential for agroforestry. Pitman et al (2004) mention Peruvian Amazonian indigenous communities that harvest and sell irapay palm leaves used for building roofs, and Logback, et al (2002) discuss a grass-roots handicraft cooperative in the Ecuadorian Amazon.

Non-indigenous Amazonians such as rubber tappers and nut harvesters are also valuable sources of information about sustainable resource use (Carneiro da Cunha and de Almeida 2000; Redford 1991). Patricia Shanley of CIFOR has worked with communities in the Brazilian Amazon to produce natural resource data and materials that are useful to villagers and to provide training for communities through theatrical performances and workshops (Shanley 2006). They produced an illustrated manual of the ecology, economics, management, and cultural importance of key Amazonian forest species. This simple but informative book shows the effects of economic decisions and teaches the components of a management plan, highlighting the continuous returns on non-timber forest products as opposed to logging (Shanley and Medina 2005).

In Iquitos, the Instituto de Investigaciones en la Amazonia Peruana (Institute of Peruvian Amazon Research) (IIAP) manages a reserve where biologists are investigating 
Amazonian fruits that could be sustainably harvested for export. Challenges for nontimber forest products and these other potential projects include community organization and management as well as market demand and transport costs. Since logging continues to be prevalent and lucrative, reforestation and soil restoration activities are also essential.

Ecotourism has become a popular activity for conservation and community development and has been analyzed through anthropological and environmental research. Ben Blount (2001), for example, describes cases of tourism-related environmental destruction, sociocultural problems for local communities, and profits benefitting outsiders, and he advocates local involvement and bottom-up planning. Amanda Stronza (2005) discusses ecotourism, conservation, and anthropology in the context of the Peruvian Amazon, and she argues that anthropology should be applied to assess needs and impact and to facilitate mutual understanding. In a comparative study of three Yagua communities near Comandancia, Susan Lamont (1999) found that agriculture expansion into mature forest is actually greater in the community near an ecotourism operation and adjacent reserve. In all of these cases, as with the natural resource management ideas listed above, understanding the specific factors of the local site and ensuring that these cultural and environmental components are included in decision-making is essential for sustainable and culturally beneficial ecotourism. In Comandancia, I observed that tourism provides the community with economic and material benefits, but I also encountered many tourists in the area with unrealistic notions about indigenous communities, so it seems that visitors and community members could benefit from better cultural understanding. 


\section{$\underline{\text { Suggestions for Cultural and Biodiversity Conservation }}$}

Organizations, agencies, and other institutions working with indigenous Amazonian communities can utilize anthropological research to inform cultural and biodiversity conservation and other social and environmental goals. Here I offer a few ideas and suggestions based on my study of Comandancia. Overall, basic subsistence and health needs must be addressed at the same time as attention is given to education, preservation of the Yagua culture and language, and environmental conservation. Communityparticipatory and community-directed research and activities have the potential to empower people, and involving women and children in projects is also important. Ideally, projects could combine education with culture, health, and environmental sustainability goals. Projects with immediate and tangible community benefits are more likely to be successful, and long-term commitments are necessary.

Community members were interested and involved in documenting traditional knowledge through the participatory methods of this study, and it seems that ethnobotanical projects can benefit a community in a number of ways. Medicinal plant knowledge projects could be used to improve some aspects of health, and indigenous natural resource management could be investigated to incorporate into subsistence and conservation efforts. Sharing and documenting traditional botanical knowledge contributes to cultural preservation and education, and it appeared to increase people's self-esteem, pride in, and valuing of their Yagua culture. Communal medicinal plant gardens have been created in other communities and could be implemented for species conservation and educational purposes. Posters, cards, or books with pictures and usage information have also been successful in other places and could be created. 
I noticed two other issues that could be addressed through workshops or training. First, besides the problem of reading and math literacy, people seemed to have no conception of maps or understanding of how to read them. Second, despite numerous attempts through different methods, it was very difficult for people to discuss the future, solutions to problems, and decision-making. These skills are important for natural resource and other projects, and they could be taught using culturally appropriate and ethnoscientifically informed methods.

One of the greatest challenges in this community as well as many others is the issue of cooperation, collaboration, trust, and organization (what is sometimes referred to as social capital). Lamont's (1999) study of several nearby Yagua communities also found that lack of trust among community members in some of the villages was mentioned as an important factor in not having traditional communal work parties. Human and social capital and strong community institutions are emphasized in the literature as playing a major role in ecosystem management, conservation, and other community projects (Pretty and Smith 2004; Southgate 1998). In addition, Joseph Klesner (2007) demonstrates that greater involvement in non-political organizations and higher levels of interpersonal trust lead to more political participation, still lacking in Peru and elsewhere in Latin America. In Comandancia, social capital appeared to be very low, and with the existing leadership and political conflicts, civic capital also seemed to be absent. Since organization and cooperation are essential to natural resource management and other projects, strengthening community governance and organizations, building cohesion, distributing power, and other efforts will be necessary to ensure success. 
Linking individuals and communities to indigenous federations is important for cultural empowerment, strengthening these institutions, and training future leaders. Community members who are not leaders have little knowledge about their federations, yet the AIDESEP is well-developed and provides a plethora of useful, relevant information. Their website contains pictures, maps, and posters that could be printed and hung in the school classroom, for example. They have newsletters, children's books, and literature for adults about issues that indigenous communities face. Dissemination of this already existing information to community members and through the school would educate people and connect them to this larger community they are a part of.

I noticed that representatives of the indigenous federations as well as community members in general emphasized the importance of consultation, dialogue, and communication with organizations they collaborate with. The ORAI leaders expressed such appreciation that I went to their office to interview them that it seemed that my visit was of as much symbolic value as an exchange of information. It is necessary to have this dialogue, one of them said, and they would like NGOs to meet with them in their office to learn about their needs. Community members who are not among the leaders often said that they had never communicated with and so had no knowledge about partnerships and projects with outside organizations and that they would like to have meetings. Considering the issues with leadership and democracy described above as well as in other case studies in the literature, representation is also a concern.

Based on these data and observations, I would recommend that organizations working with communities attempt to hold meetings with all community members and to be aware of election cycles, changing leadership, and the democratic process. Since organizations 
have time and resource limitations, perhaps small gestures of symbolic value like visiting federations in their offices to hear about these concerns and goals could advance mutual understanding. It also seems that federation representatives and community members do not understand the broad scope of NGO activities and the number of communities served besides their own, so communication from organizations about the full extent of their projects and programs could provide community members with this perspective.

Although community-level projects and activities are important, since cultural and environmental changes in this Amazonian community and others result from outside social, political, and economic systems, these greater forces must be addressed. The national and global political and economic stakeholders who benefit from extraction of forest products for commercial purposes play a major role in community livelihood needs and environmental sustainability. Policies concerning natural resources, economic activities, indigenous peoples, and other relevant issues shape the use and distribution of resources, adversely affecting these forest communities. In this case study, I have described the effects of recent changes in Peruvian forestry laws that have granted logging concessions to companies. This is part of an overall trend of land privatization, which also includes concessions for petroleum and other mineral extraction. The market value of agricultural products and commercial fishing permits are other examples of state policy challenging indigenous livelihood in this area. Therefore, these environmental and indigenous issues must be addressed at the policy level, and NGOs and other international agencies should also focus on advocacy, lobbying, and political action.

In conclusion, this thesis aims to describe the community of Comandancia's culture and traditional plant knowledge, to investigate their needs and the environmental and 
social changes in the area, and through analysis of these data and the literature, to suggest how these problems might be addressed. This case study demonstrates how the community is linked to the larger social and environmental landscape through the livelihood and cultural issues they confront. As shown here, a complex mix of traditional and new factors affect the subsistence, health, and well-being of the Yagua people and their culture and ecosystems. Their ethnobotanical and other environmental knowledge is vast, and they desire to maintain their culture and language. The implications for cultural and biological diversity conservation are that local level human needs must be met and global level issues must be addressed.

Indigenous Amazonian communities continue to struggle for land and resource rights while extractive and other development activities as well as state and international economic policies threaten their survival. Indigenous federations are gaining strength, however, and indigenous peoples now have a forum in the $\mathrm{UN}$ and are receiving greater international support. Cultural and biological diversity continue to decline, though, and climate change will present additional challenges for indigenous livelihoods. There are no fast and easy answers to these problems, and holistic solutions are needed to meet indigenous livelihood needs and maintain their cultural knowledge. 


\section{NOTES}

1 “Culturalmente hablando, la sociedad Yagua está desapareciendo.”

2 "El conocimiento y la aplicación de plantas medicinales es dominio del saber colectivo. Todos los Yagua (hombres o mujeres) las conocen más o menos y pueden utilizarlas."

${ }^{3}$ Incidentally, FIU collaborates with the IBC on their ProPachitea aquatic biodiversity project.

${ }^{4}$ IBC operates the Sistema de Información sobre Comúnidades Nativas de la Amazonía Peruana (Information System on Native Communities of the Peruvian Amazon) (SICNA), a georeferenced database to assist with obtaining titles for community territories and to avoid superimposing concessions with native lands.

${ }^{5}$ Anthropac computes each individual free list using the following equation:

$s_{j}=1 \frac{r_{j} l}{n l}$

$s_{j}=\frac{n_{r_{j}}}{n 1}$

In this equation, $r_{j}=$ position of item $j$ in the list, and $\mathrm{n}=$ number of items in the list. The overall saliency index is computed by taking the average $s_{j}$ across all respondents.

6 “¿Cómo están?”

7 "Aquí estamos."

8 “¿Cuántos hijos tienen?”

9 "12 he tenido, pero de 12 viven solamente ocho. Seis mujeres y dos varones."

10 "Yo soy naturalmente de acá, de este Orosa."

11 "Aquí es todo una mezcladera- mestizos, Yaguas."

12 "La cultura es diferente. Ya vienen de razas diferentes, no son puros- hay cambio."

13 "Mis hijas, Christina, cómo lloraban, porque no veías nada."

14 “Mis hijas lloraban, decían, 'Vamos, mami, vamos a volver. ¿Qué vamos a hacer aquí?' Decían ellas, ‘iLos indios bravos nos van a acabar!' decían.”

15 "Era una espinada, Chrisina, Dios mio."

16 “Era monte!”

17 "Nosotros con mis hijas empezamos a meter con machetes." 
18 "Solamente los caminos para las puertas."

19 "Esta carretera hacían también para ir a la escuela los niños."

20 "Dejado todo libre. Hemos librado todo, ya, pues. Ha hecho acá un yucalon."

21 "Hemos sebrado todito, este era yuca."

22 "Plátano."

23 "No me querían dejar mis hijas."

24 "Y de esta manera estoy viviendo aquí. Esas son las cosas que han pasado antes."

25 "Queremos una historia, una historia de recuerdo, como han vivido antes, como vivían anteriormente...Queremos saber la formación de nuestro pueblo, como formó."

26 "Queremos hablar sobre la historia, de los pasados, de nuestros antepasados, por el fin de que nuestros niños, para los que quieren después, tengan este recuerdo: la historia que los pueblos Yaguas convivían."

27 “Antes, mi abuelita y mi abuelo, mi abuelita hacía su masato. Y mi abuelo se fue al monte y traía...y entregar a la mujer aquí en la cocina, y ella cocina. Y después de cocinar... visitantes, masato- pues toman, allí estaban juntos.”

28 "No les falta nada- comen, toman."

29 "Bailar, tomar, comer- no les falta nada."

30 "Bueno, verdaderamente así era antes. Cuando mi tío existía, el papá de mi cuñado. Cuando él venía a invitarle a mi papá, verdaderamente era así, ese historia. Que mi tío nunca nos invitaba por gusto- había masato, había carne ahumada, había patarashca de suri, aguaje- y verdaderamente nos invitaba a comer. Ellos no utilizaban antes como los platos de aquí- tenían su... de tierra. En la verdad, así, pues, nos invitaba mi tío antes, y comías bien, tomabas bien, y allí volvías bien comido. Y eso verdad era antes así. Y de esa manera, como dice mi hermano, así vivimos antes pues... Allí nos vamos, muchachos, con mi mamá a comer. Verdaderamente era así antes, pues. Comías bien, tomabas- no con hambre como ahora.”

31 "Y ya no hay los antiguos también. Todos están muertos ya."

32 "Anteriormente, mis abuelas- voy a contar una historia de como era antes. Ella nos contaba como hacer danzas, de donde y a donde vamos. Por el sol, y por la luna. Ella nos decía: la luna cuando nace, ya la luna se envejece y se pierde- es un mes, son 30 días.

33 “¡Cómo tenía su experiencia! No sabía, pero-”

34 "El sol no tiene así como la luna, el sol sale cada día. Se daban cuenta, mis paisanos, que hora es. Ya es tarde, ya cuando el sol está por acá. Y decían mis paisanos en idioma, 'Ya son las 3 de la tarde.' Se iban a algunas quebradas, y miraron el sol para ver a que hora van a volver. Y volvían para hacer comida en sus casas. Con toditos sus hijos, sus viejitos, esperaban... Daban a comer a sus hitos y nietos, y ya." 
“Anteriormente, no dormían en cama. En hamaca. Así como acá. Los antiguos. Anteriormente, me está haciendo recordar, que anteriormente, había un plato de tierra, se pone carbonos allí, y se pone embajo para espantar los zancudos. Le echa, allí esta humeando, calentando. Se pone embajo de la hamaca, y no arde."

35 "Los cambios que hemos visto en esta vida, de que durante nuestra vida hemos visto, que ya no usamos nuestro vestimento- todo es ropas. Ya no hablamos nuestra lengua. Ya no hacemos las dancas en cada fiesta que hacemos. Entonces ha cambiado mucho. Ya no utilizamos nuestas músicas típicas. Se utilizan equipos que ya no estan de acuerdo con nuestra realidad, y está cambiado bastante. Parece que el año 1955 ha cambiado y sigue cambiando hasta ahora. Ya muchos están olvidándose de la costumbre. Los mismos personas de edad ya no quieren demonstar a los niños la cultura, ya no quieren cantar, muchos ya no quieren hablar su lengua.

"Entonces, para nosotros ha sido un cambio, y de allí hasta hoy día; por esto pensamos nosotros nuevamente redactar y valorar nuestra propia cultura. Ese propio nosotros mismos tenemos que decir que sí: lo que hablamos todavía hoy es conversar con los niños, es hacerles entender a los niños que el Yagua es un país en Perú, es una lengua en Perú porque la Yagua existe en la región Loreto, no en todas partes del pais. Una parte en Brasil, y otra parte en Bolivia. Son lugares donde se encuentran nuestras poblaciones indígenas Yaguas."

36 “La gente vivía muy retirada del río, vivían en la montaña, y pocos usaban la medicina...lo que tenía era solamente la gripe. La tos ferina, que dicen, eso tenía miedo, la gente más antes. Pero como al llegar al tiempo, tenían que saber, vamos decir, del río, ¿no? Hacer sus pueblitos. Anterior, pues, era Comúnidad, ¿no? Donde habían hecho Comúnidad, donde viven puros. Pero como ahora ya pues no es como antes. Antes vivían solamente, una sola familia era una Comúnidad. Pero ahora ya no, hoy la Comúnidad se conforma de varios apellidos, ¿no? Hay diferentes, pues. Y de esa manera, yo, yo pienso que por medio de eso también, hay cambio de las ideas que uno usa- son diferentes."

37 “Quisiera contarle la historia de mi papa, el que fue antes, ¿no? Así antes, así como la compañera está hablando, no conocían nada, ¿no? Ellos vivían en la montaña. No querían vivir acá en el campo del río. Porque aquí dicen que hayan las enfermedades- la gripe... sarampión... Y no querían tomar agua de acá. Ellos preferían tomar agua de las quebradas, no de los ríos. Y cuando pasaba algún motor, preferían mis paisanos antes- ...allí está la enfermedad. Allí de poco a poco, hemos vivido mas civilizados..."

38 “...los antiguos no vivían ni siquiera cerca de los ríos. Antes vivían por allí, en el monte, en las quebraditas."

39 "Señorita, antes ellos tenían miedo a los mestizos. O sea, que ellos nunca han conocido mestizos... ‘Están viniendo ellos!' - eso decían los antiguos... No quieren ver gente de acá, de la Amazonas. Además, de acá lleva a las enfermedades, por ejemplo, gripe. Y de esa manera, no querían acercar pues... Pero ahora, ya sabemos hablar castellano. Y de esa manera estamos cerca de la orilla del río grande ya. No es como antes, no conversamos, ni castellano entendimos."

40 "No es como ahora los muchachos saben nadar en el río. ¡Quién va a saber nadar en quebraditas!... De las enfermedades tenían miedo, pues."

41 “As veces un mestizo tiene sarampión, tos ferida, esa es- por eso tenían miedo."

42 "Porque tenían miedo a los mestizos."

43 “Como no sabíamos castellano- nada, nada, ni unas palabras- en idioma se conversa... Pero más que todo por las enfermedades que ellos no querían acercar a los mestizos." 
44 "Señorita, cuando nosotras primera vez cuando se da nuestra regla, nosotras podemos avisar a nuestra mamá. Cuando nos da la primera regla. Nosotras no aparecíamos a mi papá y mis hermanos que son varones. Nos escondíamos. Entonces, cuando mi hermanito me buscó, le dice para mi mamá, que ya me da mi regla. Y entonces mi mamá le avisó a mi papá para hacer mi tambo. Un tambito. Una casita, así chiquita... Entonces mi papá hizo mi tambito donde voy a estar ya sola. Al terminar de hacer mi tambo, y mi papá ya viene de allí, mi mamá sabe donde estoy.

"Entonces mi mamá me dejó allá. Hasta una semana... Allí hacía mi candelita... Con comida allá. Nosotras comíamos escogida, no cualquier comida. Sin sal... Lleva para completar los cuatro días estaba allí en mi tambito, y como no estaba acostumbrada allí, entonces, yo le digo a mi mamá, 'mamí yo ya quiero salir, me aburro aquí."”

45 “¿Con quién vas a conversar? ¡Y tenía miedo con el tunchi! ¡Dormir solita!”

46 “Contaba a mi mamá, y le avisó a mi abuelito. 'Papí,' le dice, 'hay que ir a virotear a mi hija,' le dice. Bueno, el traía pucuna, pues, que estaba temprano. Entonces con una carapa de huacrapona, no poca, así grande, se la calienta en la candela. Son tres que van tapados. A de allí me virotió mi abuelito. Y eso así, todo, para ya estar al lado de la gente. Me hizo para tomar piripiri, me ha echado piripiri, todo ya para no pasar nada a mis hermanos y mi papá... Pero los mestizos son diferentes. Ellos han tomado pastillas para que no les baja mucha sangre. Y nosotras también tenemos pues nuestros remedios, así medicinales. Yo tengo esa piripiri que tengo para mujeres allí."

47 “Así como era antes... el marido era grande y la chica lloraba. No quería tener marido. Así le entregamos a la fuerza. 'Este es su marido.' Ya, pues, le entregaba al hombre. Entonces, cuando ya le entregaba, su mamá, de la chica, hacía su hamaca grande para que le pone su yerno allí, para entregar a la chica, su hija. Y así decía, 'bueno, esta es su mujer, vas a llevarla ya, pues, es su mujer.' Entonces, ella llora, porque no quería tener marido, pues. Una [chica] que no sabe nada todavía, que es un hombre. Y de esa manera, la chica lloraba."

48 "Y así yo mismo he visto mi hermana. Cuando le entregaba, mi hermana a su marido, a la fuerza porque ellos nunca se enamoraban. Y por eso yo lloraba yo también, pues de pena por mi hermana. Yo no sabía que es hombre. Y le entregó a mi hermana. Y mi mamá, de amarrar una hamaca, yo me recuerdo. Para que le pone mi hermana al lado de su marido. Entonces mi hermana lloraba, 'yo no quiero tener marido, mamí,' así. '¿Por qué? Este es tu marido ya, él es para ti;' así como era antes. Cuando decía pues su marido es para ti, que se entrega. Y de esa manera yo lloraba, por pena de mi hermana. Le va a llevar, ¿quién va a lavar mi ropa?"

49 "Han conversado padres entre padres, pero al joven, nunca le decía nada. Le miraba, pero nunca conversaba...Y yo no sabía nada que me iban a entregar... Allí no me decían nada. Mi ropa estaba en la bolsa con mi mamá."

50 “Cuando ella había reunido con su esposo, que su mamá y su papá no le quería. Porque dice era 'indio,' y 'no, ¿por qué te has reunido con ese indio?, nos va a comer,' dice. Así dice su papá."

51 "Y de esa manera, su papá y su mamá dicen, no le quería. 'Cuando tu vas a tener hijo, a tu hijo le vamos a botar en el agua para que come paña,' dice así su mamá... Y ella, le quería pues a su marido, ya no quería dejar, tú sabes, cuando tienes ya dos, tres hijos. ¿Qué vas a querer separar de su marido? ... Y de esa manera, dice su papá... y quería botar a sus hijos en el agua, para que coman los peces...”

"Entonces ella le dijo a su papá, ella le quiere a su marido, porque 'tu no vas a comprar mi ropa, no vas a comprar mi ropa interior.'... Un padre, pues, a veces no tiene posibilidad de comprar para uno, tu sabes... Y de esa manera, pues, ella no le quería dejar a su marido, pues, estaba acostumbrada. Porque le compraba sus ropas, porque, para servir, pues, a ella, su marido... Y de esa manera, pues, hasta ahorita, ha seguido 
viviendo con su marido, ella muy bien, viven tranquilos, con sus hijos. Ya como su papá ya no existe, se murió."

52 "Bueno, muchas veces el joven tiene que presentar ante el padre, ante la madre. Como decimos nosotros, la palabra común, es 'pedir la mano.'... Sí, ellos ya se conversan entre ellos. Era diferente, hoy conversan más."

53 "Hoy no se puede entregar así el papá a la chica ya; saben enamorar ya, pues."

54 "Yo pienso que anteriormente, una situación muy perjudicado... Pero ahora están diciendo francamente, ahora sí, la verdad nosotros tenemos que ver a nuestras hijas, que ellas deben querer, y claramente nuestras hijas tienen que presentar que la verdad quieren tener un esposo."

55 "Seguir, nomás!"

56 "Voy a contar en idioma primero."

57 "En la verdad, antes nosotros- mí papá, mí mamá- nosotros no conversamos castellano, purito idioma. Para, así, para una comida, nos llamamos- todo era en idioma, y mis abuelitos conversaban en idioma. Para nosotros no había castellano. Todo era purito idioma. Así era antes nosotros. Ahora, pues, nosotros los tres hermanos conversamos, pues, pero los hijos, muy poco, ya no saben."

58 "Bueno, yo también voy a contar que como cuando mis papás y yo éramos chiquitos, nosotros nunca hablamos castellano... Todavía mis papas nos conversamos en idioma antes... Con mis papas nunca conversé en castellano... Ahora la culpa tenemos uno mismo. Como madre, con los hijos, no conversamos en idioma. La culpa tenemos nosotros. Sabiendo hablar idioma, y no enseñar a los hijos. Mis hijos me dicen, 'Mamita, ¿porque no me enseñas idioma?'... Hay que hablar idioma con los hijos... La culpa tenemos uno. No hay que echar la culpa en otros, pues."

59 "Diferentes. Ahorita veo que- Para mí es una cosa diferente que no podemos nosotros conversar con mis paisanos en propia lengua."

60 "No podemos conversar porque no sabemos. Antes toditos sabían. No sabemos hablar nuestra idioma."

61 “¿Por qué somos Yagua pero los hijos no saben nada? ¿Quién tiene la culpa? Los padres y madres. Por no enseñar. Hasta yo tengo dos hijos. No saben. Entienden, pero no pueden hablar."

62 "Muy poco los niños, ya no saben hablar sus propios idiomas o lenguas por la razón que los mestizos nos han transformado en la lengua Español. Por la razón que siempre nos decía ellos que al hablar ustedes su idioma, 'Ustedes ya no son indios, ustedes ya son civilizados.' Pero esto para nosotros, hablando sobre la lengua Yagua y otras nacionalidades, otras lenguas- son igual como nosotros que también han valorado sus culturas como los pueblos Yaguas están valorando.”

63 "Hermanos, también quiero dejar este recuerdo. Que nunca dejen de hablar su propio idioma, nuestra propia lengua. Porque nosotros no podemos perder nuestras grandes historias Yaguas... Queremos enfrentar, diciendo que nosotros somos Yaguas, con nuestra lengua, reconociendo que somos Yaguas."

64 “Otra cosa, en cambio de el anterior, nosotros toditos hablábamos en la lengua materna, y ahorita se está perdiendo... De esta manera, el instituto lingüístico ha siempre preocupado un poco para buscar profesor 
bilingüe, y ahora nosotros estamos trabajando en esto, pero no tanto, no, no da. Entonces, aquí, lo que está pasando es que los padres de los niños están dejando de conversar con la misma lengua a sus hijos..."

"Y hay el cambio, en caso de la lengua materna, y ahorita algunos saben, algunos no hablan. Por ejemplo, yo mismo, me doy cuenta de mí. Yo soy profesor, ¿no? Mis hijos no saben hablar, nada de eso... y me parece que allí está- la culpa está en nosotros, los padres que no, no procuran de enseñar a sus hijos. Ahora yo me doy cuenta que mis hijos- porque no puedes llegar si alguna vez quieren ser algún profesional- pero tienen que hablar primero la lengua materna. Esa es ahorita la ley de la educación bilingüe. Eso es lo que estoy viendo los cambios, pues, Christina."

65 "La salud es la primordial."

66 "No puedes trabajar, no puedes hacer nada."

67 “Aquí más lo que hay, como de siempre, más de lo que sufren, es la diarrea, el vómito, el cólico, as veces hay la tos, tos seca, después hay la diarrea con sangre, que dicen 'pujo.' Eso es lo que sufre aquí más la populación... [A]s veces agaramos el bronquitis, la vista, la visión. Mucha gente está sufriendo de eso, de la vista. Pierde la visión. Es- no sé la base de que será este, Christina, no sé, yo también. Niños as veces, no se ven bien. Acá hay dos o tres personas que tienen vista así. Niños, no más, as veces pierden la vista."

68 "Bueno, yo pienso que de repente, por cambio de clima- as veces hay creciente, la creciente, el agua, o puede ser por el calor. Por eso, pues... [Antes] había calor, así como está de siempre, pero como, ha cambiado... y no sabemos cual es el problema, que pasa. Bueno, mucho dolor de ojo, que estaba diciendo... Por el motivo del sol. Parece que el sol da mucho calor, Christina."

"Y el agua, se va bañando en el agua, el agua contiene mucha suciedad. Y de repente como nosotros, no nos cuidamos de la vista, ¿no? Uno va a meterse en el aqua- lo peor es que los niños, se ensucian con el barro, y de allí propiene esa enfermedad. Yo pienso que es motivo del agua, y por el calor lo que da. Eso es el problema. La diarrea también viene por el agua. Aquí la populación no estamos acostumados de tomar agua hervida, pura cruda, como de antes, ¿no? Solamente estamos acostumbrados de recoger el agua... y bebemos."

“...Yo no sé cual será el cambio de la- de repente, por el cambio, de, de clima, como te vuelvo a repetir más.”

69 "Así es nuestra realidad."

70 “El problema que tenemos. ¿Por qué nosotros no podemos tener más educación? No todos tenemos plata a veces para comprar las necesidades.”

71 "Nosotros hacíamos fiestas... Invitábamos a nuestros compañeros. Teníamos la costumbre, tamborcitos, y uno con su música. Y de allí la gente, las viajas preparaban su comida en ollas grandes. ¿De qué es la olla? De tierra. Y de allí, pues, terminábamos la fiesta, ya todita la gente, cada uno volvía para su casa ya y llevaron sus tamborcitos por acá, por allá, otras. Sin ninguna pelea de ningún motivo con nadie... Así eran mis paisanos antes."

\footnotetext{
72 "Ya los viejos no viven."

73 "Esa era nuestra alegría."
}

74 “Antes tomaban mis abuelitos, mi papá, y mi mamá, ellos bailaban... Ellos dan vuelta en la casa y... yo era chiquita, yo miraba como bailaba mi mamá. Nosotras seguimos ese historia... Tomábamos con tamborcito, y nosotros bailábamos...” 
75 “Cuando la mamá bailaba, las hijas no bailaban. Y si las hijas ya bailaban, la mamá ya no bailaba.”

76 “Así era en ese tiempo cuando era chiquita y mis hermanos también... solamente mis papas se iban, puros viejos a la fiesta... Y cuando ya han sido mujeres, recién empiezan a participar en las fiestas.... bailaban, tomaban, pero con respecto en la casa de mi papá. No llegan borrachos. Así era, señorita, antes. Pero ahora no es así. Ahora, señorita, tu te vas a la fiesta, las hijas bailan... Nosotros nunca hemos tomado, solamente un trago con mi papá, y nunca hemos fumado cigarros. Los jóvenes en las fiestas con los mayores, tomando, fumando, no respectan a veces con la mama, con el papa.... A veces a uno, le duele el corazón."

77 "No somos mestizos, somos Yaguas."

78 “Ojala usted va a estar aquí para la fiesta que nosotros tenemos. Nosotros vamos a demonstar un poquitito de antes. La fiesta va a ser el 8 . Va a ver una presentación. Así vas a ver una parte de nosotros, los cantos, lo que era antes. Cinco personas están nombrados, y cinco mujeres para danca."

79 “Nosotros como parte de esta organización indígena mundial, tenemos que celebrarle, acordarnos de la grande historia de nuestros pueblos indígenas Amazónicas al nivel de Perú y al nivel mundial. Por eso, el orgullo de nosotros los pueblos Yaguas, estamos celebrando el día de nuestra lengua, idioma, de pueblos indígenas del país como también al nivel mundial. Por eso hemos preocupado mucho de valorar, redactar, para que nuestros pueblos, la juventud, y los que vienen después que nosotros acuerdan nuestra grande historia. ¿Cuál era el vestimiento de mis abuelos? ¿Cuál era la costumbre de mis abuelos? ¿Cuál era el canto de mis abuelos?... No solamente los pueblos indígenas Yaguas, sino al nivel de la región Loreto, al nivel mundial, existen indígenas de diferentes idiomáticos en nuestra tierra."

80 "Queremos saber las canciones tradicionales de nuestro pueblo... yo se que usted sabe de las canciones tradicionales anteriormente."

81 "Ustedes de allá tienen capacidad. Aquí lo que tenemos es masato."

82 "Para nosotros es malo, pues. Peleando entre familia."

83 "Ni un día sano... Toditos los días borracho."

84 “Está bien que toman, que no peleen."

85 "Mis hijos empezaron a tomar de 15 años, 15 años ya toman sus masatos."

86 "'Y de allí, señorita Christina, nunca más se volvía a enfrentar a su papá. Él se emborracha, se marea. Viene para descansar, y duerme... Y me dice, 'Mamita, ¿hay comida para comer? Estoy mareado,' y descansa. El buen borracho canta, llora- ese es un buen borracho, le digo yo... Tome tranquilo y se duerme. Ese es un buen borracho... Se arregló ya mi hijo... Duerme tranquilo cuando está mareado.”

87 "Bueno, de mí también son así. Mi hijo es borracho. Ese es un loco.”

88 "De borracho no le digas nada. Tú hablas, no le contesta nada."

89 "Ese es un loco, pues. Es un mal borracho, yo no digo que no. Malo borracho."

90 "Me pregunta si hay comida. Hay comida, a veces le doy. Y cuando no hay, ¿de dónde le vas a dar?" 
91 "Antes, los Yaguas no sabían leer y escribir, pero sin embargo, tenían sus historias, sus pasados, donde ellos podían vivir tranquilos en su tierra con sus recursos naturales. Y nunca ellos molestaban al Estado, no molestaban los autoridades, como ahora en estes años que estamos sufriendo."

92 "Lo que pasa, Christina, es que algunas organizaciones tienen sus propios fondos, tienen sus propios proyectos, ellos ya vienen trabajando como diez años, algunas federaciones, con sus propios recursos. Y la FEPYROA no tiene. No tiene absolutamente nada. Nosotros a veces tenemos que molestar a otras ONGs para que nos den siquiera 100 soles, 200 soles para poder hacer gestiones para las Comúnidades que pertenecen a nuestra organización...”

"Por eso es muy importante nosotros exijamos el conocimiento a muchos de los dirigentes regionales, que nos hagan algunos proyectos, para probar en una reunión en las Comúnidades. Para que esto- bueno, no sé si ellos podían hacer al nivel internacional, al nivel nacional. Porque al nivel del governo de Perú es difícil, difícil. No han querido reconocer nuestros proyectos, pero si en el tiempo de la política, todos quieren de los votos indígenas porque son cuantos millones que existen, y los votos de los pueblos indígenas para elegir el gobierno."

93 “¿Quién tiene la culpa?... El gobierno, ese es lo que manda toditos eses empresarios por aquí, porque él está recibiendo la plata por la madera, por territorio, lo que están vendiendo. El gobierno Peruano es muy malo. ¿Por qué? Porque no piensa por nosotros como indígenas... Al contrario, nos quieren matar de hambre."

94 "Y todos somos familia, yo no le podría discriminar a nadie. Todos sentimos igual de dolores, todos sentimos igual el hambre... todos pasamos los mismos problemas..."

95 "No. Ellos mismos se nombran. No hay elecciones. Hacen sus reuniones-"

96 "Se nombran, Christina. Preguntan quien va a ser el presidente Comúnal, y el pueblo ha dicho que va a ser [fulano]. Ellos piden entre ellos. Ellos dicen quien sea, y listo. Y los demás-"

97 "Entre ellos, entre ellos no más."

98 "Eso no sabemos, Christina."

99 "No sabemos."

100 "De repente, de cualquier ratito, la gente ya se va a dedicar a cambiarle."

101 "No hay en orden ahorita. A veces hay en algunos cuadernos, sus actas, donde están los nombres, pero ahora no están conforme."

102 "Por memoria. No se sabe."

103 "He visto el estatuto, y allí está toda la familia."

104 "Tiene dos caras."

105 “Él es el único ya, ya no hay nadie que puede decir nada."

106 "Esa es lo que a veces pasa aquí en nuestra Comúnidad. Manda una carta, sin saber, sin hacer ninguna reunión, sin conocimiento del pueblo... Eso me parece que está mal, Christina. Quieren hacer un informe, 
primero tienen que consultar con todos, para ver quienes están a favor y quienes están en contra. Pero aquí están acostumbrados los autoridades informar sin saber. O sea, el pueblo, no saben, no tienen conocimiento. Eso es un problema que tenemos aquí en la Comúnidad...”

"Esa familia que es siempre- sabemos, ¿no? Siempre contra los profesores. Y nunca quieren conversar frente a frente- es uno de los problemas, ¿no? Porque si yo tengo problema, puedo presentar, 'Yo tengo este problema con usted,' pero ellos nunca... Me parece que ahorita ya está conociendo que esa familia- Sin dar a conocer al pueblo- es un problema que hay... Eso es, no sabemos como solucionar, porque siempre van en contra de uno. Eso es lo que siempre está pasando.”

107 "No nos quieren avisar."

108 "Yo digo que no sería difícil, señorita, cuando el presidente Comúnal decide meter la cabeza. Para de juego."

109 “Ahora este también igualito se ve. Es lo que sufrimos ahora, pues. No puede ser difícil, depende de la autoridad, nada más. Nosotros también podemos acompañar cuando vienen personas de afuera, nosotros podemos acompañar para decir, 'Bueno, aquí no vas a pasar porque es prohibido.' Están terminando los peces, y los nietos, ¿qué van a comer? Eso es lo que debe hacer la autoridad, pues, lo que es de la Comúnidad. Pero como no nos dice nada, ¿cómo nosotros vamos a acompañar para apoyar?"

110 "Yo digo, pues, conversando, si ellos quieren, pues- si no, pues, ¿qué se puede hacer?"

111 "Para mí, Christina, estes problemas se podrían solucionar, tal vez cambiando los dirigentes. Tal vez de esa manera se puede arreglar. Yo pienso que sea otro dirigente. Porque allí es pura familia- no puede ver ninguna solución. Porque ellos no más- son ellos. Lo que ellos dicen, y allí muere. Y de esa manera, pues, no hay ninguna solución. Por eso yo pienso que tal vez cambiando la directiva. Qué sean otros... De tal manera así se puede arreglar porque de día a día la situación esta yendo peor."

112 "Y la juventud. Aquí en Comandancia, te voy a decir bien claro, que la juventud poca importancia da... se le invita a una asamblea y no se van... Ellos estuvieron mejor apresentarse en las asambleas para que puedan aprender todo de los acuerdos que uno se hace, para que vayan aprendiendo. Porque alguna vez nosotros muramos antes, vamos decir, ¿no? Nos vamos a desaparecer, y ¿quién va a quedar como autoridad? ¿Quién va a poder trabajar, vamos decir, en medio de la Comúnidad, dar ejemplo? No hay. Este es un problema que hay aquí en la Comúnidad...

Y poca importancia para la Comúnidad que desarrolle, ¿no?, O que haya una buena, una buena disciplina... para que estén conociendo, para que estén acordando... Hay una reunión- se van puros viejos, no los jóvenes, ¿no?... [A]lgun día las autoridades no van a vivir más como autoridad... Ellos también tienen que aprender, para que alguna vez también se responsibalizan como autoridad. Esa es que hay el cambio aquí yo estoy veyendo, Christina."

113 "Y esa es que por aquí, muchos se confundan de trabajos, las leyes que da el gobierno. Si no le estudiamos, si no le conocemos, si no le practicamos, si no tenemos reuniones así como estamos ahorita, muchos de los jóvenes no conocen, no conocen. Por eso, ¿por qué no estarían acá si hay una reunión acá? Porque no les interesa conocer, no les interesa aprender. Porque ellos creen de que con tiempo, van a vivir así como están ahorita. Va a ver de todo."

114 “Tu sabes, Christina, que cuando uno se habla, los demás no quieren hablar... A veces uno se reclamanuestro derecho, ¿no?... Entonces, yo digo que la sesión es para debatir las cosas... Ellos quedan callados, Christina, la mayoría no quieren decir nada... Si son pura familia, pues ¿qué se puede hacer? Si tú hablas, ellos quedan. Eso es lo que pasa aquí...”

"En vez de arreglarse, se empeora. Porque haciendo así, pues, se puede organizarse, como dicen ellos, hacer algo para estar bien el pueblo, pero no- en vez de arreglar, igual nomás se ve el pueblo.” 
115 “Hasta peor, peor. ¿No se da cuenta usted? Cuando hace una reunión, no aparece la gente.”

116 “Pero el trago hablando, eso sí. O si va a ver una donación para cualquier cosa, allí sí va la gente, Christina, está llenito. Pero para una reunión- no aparecen. ¿Te has dado cuenta?... Eso es lo que quiere uno: que se mejore el pueblo... Así te vuelvo a repetir, cuando hay alguna donación- a veces el alcalde dice 'voy a mandar tal cosa para el pueblo'- ese día ves a la gente. Está llenito. Pero para una reunión, aparecen dos, tres, cuatro es mucho. No les importa, creo, Christina, porque no quieren venir a las reuniones."

117 “Pero eso, como vuelvo a decir, Christina, ellos cuando están borrachos, pues, allí sí tienen boca, pero cuando están sanos, no dicen nada. A veces yo digo una cosa de mí. Cuando tengo una cosa de reclamar, ¿no?, yo tengo que conversar con esa persona, yo me voy a conversar con él. Pero ellos no. De borrachos se insultan, se gritan, lo que sea, pues... Eso no es la manera de conversar... Eso es lo que sufrimos aquí."

118 “Ahorita no recuerdo, pero está apuntado en el acto."

119 "Bueno, el presidente- para invitar a una asamblea al pueblo, para coordinar sus actividades que tienen dentro su organización en la Comúnidad."

120 "El policía de la Comúnidad actualmente son los vocales.”

121 “Como presidente Comúnal, él tiene su directiva, sus vocales, que son los policía que ellos avisan para las asambleas, ellos avisan que día podemos tener una reunión- eso es su función de ellos.”

122 "Bueno, el estatuto dice que cada cinco años presidente Comúnal. Agente municipal, cada periodo que se cambia el alcalde. Y es por tres años."

123 “... nos cobran 150 soles para preparar un estatuto de la Comúnidad. Y tiene que saber la historia de la Comúnidad, de sus leyes internos. Entonces todas esas cosas cuestan.”

124 “Bueno, como Comité de Salud, su responsabilidad es vigilar el pueblo y algunos enfermedades, en cuanto, cuando hay medicinas, del servicio del pueblo, si hay medicina."

125 "No sabe, no sabe."

126 “Bueno, la necesidad más grande aquí es que nosotros tenemos... por ejemplo a veces nos dan medicinas, ¿no? No tenemos quien puede administrar todas. Le da a una persona que no sabe administrar... De esa manera la Comúnidad sufre de las enfermedades más que todo...”

127 "Hay remedios, a veces había. Me recuerdo de una... de medicina que recibimos, una donación, y ahora no se sabe que es lo que hacen."

128 "Bueno, mayormente, cuando yo estoy acá, yo soy quien convoco todos, a que hora va a ser el cambio, como tienen que vender sus artesanías. Entonces, y más que todo, poner en orden cada uno sus cositas que tienen que vender, sus artesanías. Y también antes de eso, explicarles a ellos, no tocar de los pasajeros las muchillas... tener que cuidar más bien, no estar queriendo agarrar sus cosas."

129 "No teníamos representantes. Ya tenemos representantes y las organizaciones. Tenemos organizaciones al nivel de distrito, al nivel Comúnal, al nivel de la provincia, al nivel de la nación Peruana, al nivel internacional donde nosotros estamos organizados ahora para defender nuestras propias culturas y 
el derecho que tienen nuestros pueblos indígenas: más que todo por el territorio, por la vida y sus vidas los pueblos indígenas... ¿ ¿Tenemos que organizarnos por qué? Porque antes no nos exigía organizarnos porque había suficiente para vivir."

130 "Líder de mujeres en la federación. Cada vez nosotras nos vayamos a reuniones en Iquitos, nosotras pasemos la voz a las Comúnidades."

131 "Es una autodenominación porque... él es el fundador de esta organización, de los pueblos Yaguas. Y entonces, como en los pueblos indígenas, no había elecciones, era hereditaria, ¿no? Se transfería el poder... Ya con mucha anticipación se sabía quien iba a ser el próximo cacique una vez muerto, ya, ¿no? Entonces, de igual manera, siguen pensando, algunos hermanos, generalmente los mayores de edad, de que deben seguir estando en la organización."

"Pero, viene este nuevo sistema democrático, ¿no? Adaptamos también al sistema. Entonces, estés cambios, es como si el fundador o el depositario de conocimiento indígena, se sentía un poco afuera ya de la organización. Y también el tratamiento que daban los nuevos dirigentes a los ancianos, ¿no? Entonces aquí nosotros hemos pensado de que no se debe excluir a nadie, ¿no?”

"O sea, uno es el cargo, que se va turnando, que nosotros llamamos los dirigentes, y otros son los líderes. Y los líderes son aquellos que nos han dado los conocimientos de los antepasados y tienen un papel muy importante de la organización como consejeros en los momentos difíciles de la organización... En algunas Comúnidades, hay el consejo de ancianos. En algunas federaciones, justamente en los consejos de ancianos están aquellos hermanos que vienen directamente... de los hijos con parientes directos de quienes fueran los caciques, así hereditando y transfiriendo conocimiento, transfiriendo poder... [Y]o diría de que en vez de que se llame asesor, debería llamarse, pues, debería estar como consejero, como cacique."

${ }^{132}$ Although I think that measuring social and cultural qualities as forms of capital is problematic, the concepts themselves are useful, so I utilize this phrase for lack of a better term for community trust and cohesiveness.

133 “...por el Apayacu, tenemos unas reservas Comúnales y reserva como un parque de los pueblos indígenas."

134 "No va a ser parque: ha quedado como territorialidad indígena... Porque parque nacional tampoco no, a nosotros, no nos conviene, porque también está manejado por el Estado... Pero nosotros en congresos que hemos tenido en Lima, también hemos debatido sobre esto de territorialidad, y lo cual es que nos aceptaron que va a quedarse como territorialidad indígena... No va a ser parque, porque nos estaban queriendo dar como parque, parque nacional, o reserva, zona reservada, o mosaicos, pero ninguno de esas tres propuestas, a nosotros no nos convenía, pues... Cuando hablamos de los territorios indígenas, ya no solamente estamos hablando de territorio, lo que es encima, sino también estamos hablando de embajo, para tener derecho de reclamar contra el petróleo, otros minas que también traen."

135 "Entonces, cuando estamos superando esto los problemas territoriales hace 35 años atrás, vienen otros problemas más grandes, que es la exploración petrolera."

136 “Ahora estamos en otros tiempos, y estamos exigiendo más.”

137 "Es muy complicado, la conducta de los hermanos indígenas, si nos referimos al nivel individual. Al nivel colectivo, aquellos pueblos indígenas que mantienen la unidad son los que han demostrado la perseveranza en la lucha en la defensa de los pueblos indígenas."

138 “....a pesar de que los pueblos indígenas habían guerras interétnicas y principalmente por la defensa de nuestros territorios, y ese espíritu guerrero de los pueblos indígenas aun se mantiene.” 
139 "Pero sin embargo, no podemos negar que tenemos debilidades. Y debilidades no responden a una cuestión de herencia, ¿no?, sino, se responden a una cuestión de necesidad.”

140 “.... si pusieron en práctica la herencia de nuestros antepasados, no hubiera entrado ningún maderero. Entonces esto nosotros evaluamos como efecto de todos los procesos... a la fragmentación cultural... no solamente físicas, sino al nivel de autoestima, y la relación de los pueblos indígenas con el mercado, ¿no? Porque el mercado es donde se tienen que comprar, através de un medio de cambio, que es el dinero. Entonces, al no encontrar el dinero... para comprar otras necesidades que tenemos, y como no hay un plan del gobierno para aprovechar una manera sostenible... Allí está el problema: la dependencia. El mercado genera una serie de debilidades en nuestras Comúnidades."

141 “....diría que estamos progresando, estamos progresando. Hay un mayor tono de consciencia, cada vez mayor, y hay mayor responsabilidad para proteger nuestros recursos para futuros generaciones; nosotros pensamos de esa manera."

142 "Hay una serie de factores externos- culturales, económicos, sociales, gastronómicos - de otras partes, y como no tenemos los recursos para ir adecuándonos a los nuevos modelos, a los nuevos hábitos, caemos en una necesidad, y eso es lo que está pasando en las Comúnidades... Hemos debilitado nuestra seguridad alimentaria por querer copiar, se puede decir, las costumbres, que involuntariamente estamos asimilando con estes procesos. Entonces, hay también el problema de identidad, el problema cultural, y el problema educativo."

143 “Comúnicación es otro tema que estamos implementando. La Comúnicación en el sentido de que, a pesar de que viven muchos años aquí en la Amazonía, mucha gente no sabe, ni siquiera los que viven dentro del país, saben del valor cultural, el valor y el conocimiento tradicional de los pueblos indígenas."

144 “... las artesanías, y cuerpos desnudas de indígenas, así generalizando que solo sabemos danzar, tejer algunas artesanías, y andar desnudas. Pero la verdad, la sabiduría indígena, no.”

145 “...que vayan descubriendo el verdadero valor de los pueblos indígenas. Y el rol histórico que hemos cumplido para el equilibrio del ecosistema y como también para el equilibrio cultural."

146 “...que discutan la problemática de los pueblos indígenas en otros países, en otros continentes, con el fin de que, o sea, pueden seguir en la política del gobierno, porque el gobierno depende mucho también de la política global, de la política mundial de otras grandes instituciones, ¿no?’

147 “....porque estamos al nivel global, hay una serie de desequilibrios en el planeta, ¿no? ...una serie de problemas entre madereros, empresarios transnacionales y pueblos indígenas."

148 "Y ya no es como de antes. Antes, en la verdad, había bastante pescado-caimitano, paca, sunga- no es igual. Comía, y aparecía en la trampa ya bastante ya. Bueno, el tiempo no era una casería acá cuando mi papá existió- esa es, vivías como tres, cuatro casitas... Voy a contar esta historia, lo de mi papá cuando existía. En ese tiempo había bastantes animales, Christina. Había, verdad. Había aves, había huanganas, sajinos, venado, pescados, y sungas grandes, se veía, de este tamaño. Pero ahorita en este tiempo, pues, nosotros hemos hecho grandes, somos madres- mis hermanas, somos hombres también, tienen hijos- y ya no se ve animales. Se ve una cantidad de congeladores que han venido, quitando todos nuestros animales. Y de esa manera, pues, sufren ahora, este tiempo. Ya no comen como antes, nosotros comimos bien. Eso es que nosotros sufrimos en este tiempo."

149 "Por ejemplo, sufrimos, a veces por la comida, más los animales del bosque, y a los peces." 
150 “A veces, verdaderamente, no se come todos los días. Cuando se busca, también no hay en cantidad; a veces hay en la noche, para un desayuno, y para el mediodía ya no hay. En la tarde no hay nada ya, pues. Y de esa manera, los niños no tienen interés de estudiar- tu sabes, a veces en la mañana, no hay para el desayuno. Se va a tomar su chapita, no es suficiente para que ellos estudien. Y de esa manera los niños también se aburran en el colegio, 'Tengo hambre.' A veces en el recreo ya se largan varios, lo sienten en el estómago, tienen hambre. Y de esa manera, los hijos no aprenden leer- no quieren agarrar sus cuadernos, agarran sus trampitas y se van a la cocha para buscar algo para que comen... de esa manera los niños sufren aquí, esa necesidad."

"Y por eso, pues, hasta mis hijos... a veces no comen. 'Mamita, tengo hambre,' - no es suficiente un guineo que tenemos. Tenemos maduros, toman sus chapitas: no es como comer un pescado todos los días o tres veces al día. Eso es que sufren aquí pues los niños. No tienen interés de estudiar. A veces el mismo profesor no se ha comido nada. Claro, como él también va a enseñar, tiene que comer bien. Cuando tengamos plata, pues, un poquito, se va a comprar en la bodega para hacer un desayuno, pero uno solo. Y después no hay nada, se acaba."

151 “Así es, señorita, no hay.”

152 "Los muchachos comen y yo nada, a veces. Porque doy a comer a los muchachos."

153 "La vida en ese tiempo para mí era buena porque había, en ese tiempo- todo era fácil. Que todo había para comer, nada costaba. Ahora en este tiempo, las cosas cuestan, las cosas son caras... Por eso yo les digo a mis nietitos, 'Miren esas cosas, la situación que estamos sufriendo ahorita, y ustedes deben poner en práctica, y estudien... Antes era la baratura. Ahora sufrimos de la necesidad. Son caras las cosas.' Eso a veces yo digo, señorita. Por eso yo analizando bien las cosas, a veces conversando con mi señora, como son las cosas- las cosas bien caras. Pero tratando, uno mismo, analizar bien la situación, las cosas- es algo que pensar."

154 "A veces vendes un guineo; te pagan cuatro soles, tres soles. No da, señorita."

155 "Mucho han subido las cosas. Pero la vida de antes, era una vida regalada... Mis padres ni un día al colegio... Por eso yo les digo a mis nietos que aspiren en algo para ellos."

156 "Nuestros recursos naturales ya están perdiendo, señores padres de familia y moradores. Estamos viendo poco a poco que se van terminando, se van acabando, de que algún día no van a tener ni para nuestra canoa. Eso es lo que está pasando en nuestra Comúnidad. No solamente aquí, sino toda la zona de nuestra codirección. De eso hay que tener cuidado. Anteriormente, si nosotros hubiéramos el conocimiento, quizás no nos iban a aprovechar. Como han entrado las empresas más grandes, las empresas trabajan, las empresas madereras - vienen con la plata, hacen lo que quieren."

157 "Donde dice algunos recursos son aprovechamientos para la Comúnidad, pero otros recursos- el subsuelo, el petróleo, el oro, todo que es minas- nosotros no tenemos nada. Es un problema... Entonces no nos está favoreciendo la ley. Como le digo, una parte nos favorece, otra parte también nos traiciona."

158 "Le voy a hablar solamente sobre el territorio primero. Bueno, del territorio nosotros sufrimos aquí en Comandancia. Los empresarios ya nos quieren dejar sin territorio nosotros... Por ellos, nosotros ya no tenemos también alimentos porque los empresarios hacen con nuestros animales, los animales de acá de nuestro territorio."

"Ya no tenemos de donde hallar nuestro alimento...Ya no hay nada. No es como antes, antes nosotros no sufríamos hambre... Comíamos, no necesitábamos nada de cosas de mestizo. Nuestro alimento estaba a la mano, a la mano de nosotros... ¿Qué cosa vamos a comer? Los hijos ahora, los nietos ahora ya no van a conocer los animales. Y maderables... Nuestros nietos no van a conocer nada..." 
159 “Ahora, de los animales de huerta también, no se puede hacer porque a veces aquí nosotros mismos no nos organizamos... y una persona no le paga su día de trabajo, nadie quiere ayudar. Y tú sabes que para pagar a las personas, pues, quieren dinero, alimento, para hacer trabajar gente. Y entonces, como uno no tiene, pues no se puede hacer. Pero, como digo, organizándose también, sí, se puede hacer.

Pero acá, mayormente, pues, los hermanos de acá no están acostumbrados a trabajar de esa manera, organizados... Mayormente ya la gente está acostumbrado a trabajar por la plata. Mayormente están acostumbrados con los patrones... Patrones son los señores que ayudan a las personas de la Comúnidad para que van a trabajar en madera como mensualeros, trabajadores. Y también ayudan para cazar, caza de animales, y a ellos lo llaman patrones. O sea, les ayudan, les dan cosas, y ellos van a trabajar para que les ayuden. Y ese es el problema pues ahora, de que no podemos organizarnos... y nadie quiere trabajar, nadie te quiere ayudar así, por gusto. Eso es un poco falta de organización."

160 "Porque aquí es obligado, Christina, trabajar los jóvenes y novenas desde los 15 años... cuando llegaron a la edad de 15 años, me han dicho que deben de estar ya en el libro de actas reconocidos para los trabajos. Y empezaran a trabajar mis hijas de mí. Pedieron colaboraciones, y igual estaban con las colaboraciones. Pero Christina, aquí yo veo muy diferente. De mí, mis hijos colaboran. Pero veo otras madres que no colaboran sus hijos."

161 “Ahora se va. Al primero, no se iba. Aquí también, le invitaba su tía; ella le invitaba, no se iba. 'Para que voy a ir, mamita,' me dice, 'no es mi chacra para trabajar.' 'Pero no es así, mi hijito, hay que ayudar, porque nosotros también vamos a necesitar para hacer un trabajo.' No quería ir, pues. ¿Cómo voy a obligar si él no quiere ir? No se iba... Pero ahora tiene 16 ya, ya se va a la mecánica, toma su masatito."

162 "Pero más antes, trabajaban organizadamente, Christina... Por ejemplo, tengo mi chacra, van a trabajar hoy día- toditos nos vamos allá... ¿Por qué hemos dejado de trabajar ese grupado? Porque a veces no nos vamos todos: se queda uno, o dos se quedan, y los demás dicen, 'Bueno, en mi chacra no quieres trabajar, entonces yo no voy también a tu chacra.' No nos organizamos, pues. No trabajamos juntos.”

163 “Si hay un trabajo, vienen unos cuantos, y los demás no vienen. Y según dice pues, allí el fiscal, dice, dejar un pedazo para que trabajen los faltantes. Pero no se ve cuando cumplan los faltantes. Nosotros mismos vamos a trabajar. Así es aquí."

164 “Por eso dice allí la autoridad quienes hay que cumplir, y nunca se ve hasta ahorita. No se ve ningún cumplimiento de la autoridad.’

165 "En otras Comúnidades son más organizados... Si hay una minga, si va a poner una chacra- vamos decir, la chacra Comúnal- pues uno trabaja, todos unidos, y se ve lindo, Christina. Aquí, uno trabaja, no vienen los demás. No se ve lindo. Cuando estás en reunión, pues, con todos se da... Cuando están dos o tres, no acabas el trabajo..."

166 “Allí vas a hacer un trabajo- todos unidos. Entonces están organizados... Porque una invitación de trabajo, y están toditos allí. No hay quien que es faltante, nadie. Todos están- ese es su reunión. ¿Por qué aquí no? ¿Qué sería? Como se puede decir: son negligentes en el trabajo. Yo no sé que sería. Les invita a algún trabajo, obligado, y vas para avisarle, y no están por allí. Están en otra minga, ha ido a pescar, ha ido a montear. ¿Cómo?- ¿Por qué va a montear cuando ese día ha quedado para él trabajar? Y cuando trabajan, no es todo el día, es de dos horas, no es más.... En otras Comúnidades no es así. En otras Comúnidades hay cumplimiento. Una persona falta, no hace el trabajo, la policía viene a buscarle.”

167 “Había un trabajo público, y algunos padres no quieren venir ya. Van con su mujer o sus hijos: “¿Dónde está fulano?” "Enfermo está ya.” Y el teniente, ya, ¿Dónde está mi policía?” Y él va a ver si está 
enfermo en su casa. “¿Dónde está tu papá?” "Está en una minga, en tal parte.” Entonces no está enfermo, y “QQué piensan de eso?" Su multa es diez soles."

168 "Aquí son cinco soles es la multa, pero nunca se han realizado hasta ahorita. No veo nada de eso. ¿Por qué no quieren? ¿Qué sería? Unos hablamos para organizarnos- como que, les molesta. Les molesta, no quieren organizarse."

169 "Y algunos no tienen el dinero... es el primero problema. Tú sabes de que aquí en la Comúnidad pues el trabajo es un poco dificultoso. El único trabajo que hay aquí pues solamente es la madera. No hay la madera, y así va terminando, y va a llegar al tiempo que no vas a tener en que trabajar y ya no va a ver el dinero."

170 “Está bien que venden cosas de comer- arroz, tallarines, leche, azúcar, todavía. Pero el licor da muchos problemas."

171 "Pegando entre familias- esas cosas no me gustan ni un poquito. Yo he dicho, voy a poner mí..., no voy a poner trago. Porque trago- para mí no está bien, ni un poquito. No me gusta que están peleando. De repente mis dos hermanos están peleando por yo vender el trago- ¿Quién tiene la culpa? Yo mismo. No me gusta de licor. Poner otras cosas- gaseosas, cosas de comer, arroz, alimentos, para que compren el pueblo. Pero mayormente hay esa licor."

172 “Esa no falta, hasta en el monte hay. A ver, pregunta, ‘¿Hay arroz?'- No hay. A ver, pregunta, ¿'Trago?’- Hay. Eso no falta.”

173 "Pero ¿qué pasa en las concesiones, Christina? Las tierras vendidas en las concesiones por un sol cincuenta al metro- esto el Estado ha hecho por negociar a otros empresarios. Más bien, el gobierno agarra el dinero, no nosotros... La ley dice que los pueblos indígenas tienen territorios grandes, pero no le trabaja... el gobierno ha dicho ya. Esa gente- las Comúnidades indígenas, los ribereños- pero ellos no lo trabajan, ¿qué hacemos? Negociarla. A los que tienen plata, para el fondo del país. Así mayormente ha favorecido a gente que tiene plata..."

"Entonces, el gobierno Peruano, el mismo país Peruano, es así de está manera su política. Nunca llegan a hacer comprender a las realidades, como los pueblos indígenas pueden sustentar sus necesidades... No, lo que pasa es el gobierno ha hecho solo con sus congresistas, no con los autoridades regionales. Pero ¿cuándo han venido a consultar nosotros aquí?... Nunca han venido... No han consultado primero si nos va a perjudicar su decisión- allí está el problema. Y toda la venta es para otro país, no para nosotros. Y todavía nos están quitando más tierra. Están sacando nuestros recursos. Porque la ley facilita para sacar la madera. Entonces, ¿qué podemos hacer? Pero, organizada, la Comúnidad puede defender sus recursos, puede defender su territorio."

174 “Aquí en Santa Ursula hay una mina de petróleo, ya no faltará mucho que venga la compañía petrolera... Quiere decir que el gobierno ya no nos quiere ver vivo... ¿Qué agua tomaremos nosotros? Nada, moriremos de sed. Moriremos de hambre... Las plantas no pueden crecer, la yuca se pudre, el plátano se muere. Toda la tierra se hace negriño con el petróleo... Eso no queremos aceptar, nosotros como indígenas. Ellos con su plata, nosotros con nuestro derecho, nosotros como indígenas...”

175 "Debemos luchar para que no entre ese compañía."

176 "Bueno, cuando yo era chiquita con mi mamá, había bastante pescado."

177 "Yo me acuerdo de mí, de que todavía cuando yo era muchacho, todavía me iba a pescar con anzuelo. Me iba en mi canoa al estar yendo por la orilla del río pescando con anzuelo, con mi flecha... Eso pues es 
un cambio, es un cambio para nosotros. Ahora la única esperanza es la trampa. Si no es trampa, no te comes... Pero ahora, como va yendo los tiempos, ni con trampa se va a poder cazar peces."

178 "Ha entrado congeladores al río, a la cocha, y se va yendo el cambio. No era así antes, Christina- si tu ibas a agarrar con tu anzuelo, si tu ibas a la quebrada, traes pare que comas, pero ahora ya no... Si tú quieres pescar, no hay, no hay. Estamos sufriendo de una necesidad grande, grande."

179 “Bueno, el pescado, ya no tenemos en mayor cantidad. Ya se están terminando los pescados.

180 "Los pescados van en los congeladores, pues. Se vienen y agarran."

181 "Largan con los pescados."

182 "Y de esa manera, poco pescado hay. Los congeladores llevan para Iquitos. Todo acaba."

183 "Tienen bastante trampas, Christina. Una cantidad de trampas traen. De afuera son."

184 “Por eso muchos niños, y adultos, tienen diarrea- por tomar agua podrido, agua con veneno... Los pescados ya se están pudriendo ese río. ¿Cómo vamos a tomar ese agua?... Nunca vamos a solucionar, creo, nosotros, esas cosas."

185 "Me preocupo del pescado: que no hay, pues... A veces vas, señorita, tu, con anzuelo, con tu trampito y allí no agarras nada...No hay para comer tres veces al día."

186 "Nosotros como Comúneros de la Comúnidad, somos dueños de nuestra tierra.

Somos dueños de nuestros ríos... [E]l ministerio de pesquería también les da un permiso, un documento para que ellos puedan pescar por el río. Y eso es el problema a veces que nosotros también no se le puede cerrar el paso..."

"[C]omo ves, tu mismo, aquí en la Comúnidad, a veces las personas no son capaces de ir y decir de que está prohibido pescar aquí en nuestro lago porque es un territorio Comúnal, titulado, y la mayoría, pues, no quieren decir nada, solamente esperan de las autoridades. Pero veyendo la realidad, porque el servicio de los peces es de todos, y todos debemos de cuidar, y los montes, las maderas, por ejemplo..."

"[B]ueno, en estes tiempos, no se ve pescadores acá porque no casi yo les dejo... porque más antes, todita esta zona venían a pescar. En las cochas entraban congeladores. En un día, dos días, ya no había peces para comer. Pero ahora, por lo menos ya han evitado un poco. Pero ahora, como digo, pues, no es que no se puede cuidar, de todo es depende de nosotros. Sí también, la ley permite nosotros para defender nuestros territorios titulados."

187 "Y la misma cosa: se hace la reunión, tenía ese acuerdo, pero no veo ese acuerdo lo que hace. Y la gente no más pasa y pasa, los madereros, y ellos no dicen nada... Pasan con un montón de trampas. Y todos los días pasan, cinco, seis congeladores."

188 "Por ejemplo, antes pues nosotros usamos para matar los animales, no utilizamos una retrocarga; era una arma que la llamamos picuna. Tenía su virote, y van al montaña, le soplaban y mataban pues con veneno. Eso es bonito, ¿no? Esta era la tradición de ellos, así vivían... abuta macha, ese es el veneno. Y le raspaban y le prepararon con varias cosas, ¿no? Entonces allí sale el veneno... y le echaban en el virote, que dicen, ¿no?"

189 “Señorita, hoy es muy diferente... Todo era cerca. Tenía su arma, iba a matar cualquier cosa. Estaba cerca, no caminaban lejos para buscar algo para comer. Ahora, pues, no es así...Ahora ya no hay, ni aves, señorita." 
190 “Decían, en ese tiempo, 'Se ven aves, se ven todos animales, todo está cerca, pero con tiempo ya no van a ver. Ustedes están creciendo.' A los jóvenes decían, 'Crian los animales,' decían, 'gallinas, chanchos, para tener que comer. Porque en tiempo van a acabar los animales.' Ellos sabían, y eso es lo que pasó... Porque son de los tiempos antiguos, tenían experiencia."

191 "Porque, señorita, más antes, la gente no se metía."

192 “Antes, pues, no había madereros.”

193 "Ya no hay." "Pocos animales."

194 “También en la caza para el monte...Todavía matan aves, algunos monos. También es una costumbre, una vida para nosotros. Y antes había más... Pero ahora ya no hay, hay muy poco. Y más por adelante, no va a ver nada."

195 "Porque todo el mundo tenía su yuca al lado de su territorio... Toditos tenía a su lado plátanos. Ahora no ves nada... Por los animales, las vacas. Destruyan las plantas."

196 "Comían toditas las plantas."

197 “A veces llueve, no puedes ir a la chacra, está lejos. Cuando está cerca, sacas, pues, allí.”

198 “....[É]l no quiere encerrar los animales. Ya todo el mundo ya le ha dicho que quiere encerrado. En frente del colegio, como un portero de los animales; en el colegio, orina de las vacas, mierda que hay, y los muchachos están en eso. Para él no es nada. Él no quiere encerrar los animales. No se puede entenderle.”

199 "Los niños a veces tienen una picadura de alguna espina, o se cortan- dura, Christina. Demora para sanar."

200 “Tiene su pedazo queda alambrado, pero no quiere poner allí. No sé que será su problema ese.”

201 "Él dice que él es el dueño del terreno. De todo. Pero yo, Christina, he dejado ya-"

202 "Para evitar problemas. Lo hemos dicho, claro, sí, hemos ido a cobrar, que nos paguen los perjuicios. No quiso reconocer. Y como a mí no me gusta estar en problemas con él, entonces, lo dejemos, ¿no?”

203 "No es justo, pues. Pero como dije, a mí no me gusta estar entre vecinos peleando. Por eso lo he dejado este terreno. Lo he hecho en otra parte igual. Tengo chacra allá, pues."

204 "Ellos quieren lo que ellos dicen y así."

205 "Todo mundo tiene el derecho."

206 "Para criar, tenemos que tener, por ejemplo, chanchos. Tenemos que sembrar yuca en cantidad, y acá nosotros no podemos sembrar yuca cerca porque el animal grande puede dominar, porque no dejan- Hay lugares lejos, pero de allí para cargar para dar de comer a los animales es dificultoso... Porque el chancho es...puede ir, no se sabe a donde va- hay que criarlo encerrado. Igual a los animales grandes- deben de estar encerrados, y me parece que sería un buen manejo, ¿no? Ese es el manejo de un animal. Porque si los soltamos allí, a los vecinos les molesta." 
207 “Bastante tiempo. Más que 20 años porque yo, cuando vine aquí por primera vez a Comandancia en la 86, ya hubo madereros. Ya estaban. Pero todavía no en la Comúnidad, en otras partes."

208 "Bueno, los acuerdos de las autoridades. Pues, Christina, ha pasado la situación, en una conversación, en una reunión, ponemos en acuerdo, los Comúneros, de que cada Comúnero tiene que sacar de madera 30 trozas, no mas que 30 trozas. Y se avisa después de eso, ya no hay las 30 trozas. Y incluso, el mismo, vamos decir, el mismo asesoría, trabaja en la madera.

Y no hay quien cuida. Eso es el problema que hubo, pues. Y ahora, pues, no hay madera, ¿eh? Bueno, que se hace, ¿no? Quizás al primero, había bastante madera; ahora ya no hay. Esto es lo que a veces está pasando en la Comúnidad, Christina."

209 "Porque todita la gente trabaja en madera- trabaja, trabaja, pues, todo, todo quieren terminar. De aquí a poco, ya no va a ver esa madera que esta alto, y ¿en qué van a trabajar cuando falta la madera?... Aquí mismo, al rededor de nuestra purma, están sacando y están vendiendo... Hay que respectar nuestro territorio."

210 "Pero eso es uno de los grandes errores... Porque las Comúnidades, las poblaciones indígenas son la base de la producción de madera. O sea, son ellos los que sacan un 80 por ciento de la madera... O sea, son ellos los que trabajan para intermediarios y para madereros, como patrones. Pero son ellos los que sacan la madera... Con los pequeños productores nunca pensaron, y nunca pensaron en trabajar, mucho menos pensaron en organizaciones como Comúnales, o algún tipo de organización Comúnal que ellos hayan podido financiar para que ellos poder presentar en el concurso... Les faltó un mapa, algo para ver las cosas, todos los componentes de este sistema y tratar de trabajar con todos... La base, o sea, la gente que trabaja, la gente que extrae la madera acá no fue incluida en este proceso."

211 "Haciendo la reforestación."

212 "Sí, así hace."

213 "Con varios..."

214 "Al principio, todos... porque pone a todos, ese ley que hay que reforestar."

215 "Puro cedro. Nada más."

216 "Bueno, todavía no en esa siembra. Todavía- ellos cuando termina el contracto de esa madera, recién van a sembrar otra vez. Recién van, en todas las carreteras que han hecho, allá van sembrando. En todas las carreteras van sembrando para que nunca falta."

217 "Y igual manera a los recursos naturales, y todo que es maderable, también se está terminando. Y es un problema para nosotros. Y no vemos una forma de como solucionarlo porque las empresas siguen entrando, siguen trayendo todo lo que es la madera... Es un problema grande, grande para nosotros. Y además, para nuestros hijos, para nuestros nietos que van a venir, pues para ellos ya no va a ver- porque el único trabajo aquí es nada más la madera."

218 "No le siembran."

219 "Es porque mayormente, las personas que trabajan en la madera pues nada mas, están interesadas nada más por el bolsillo. No para el futuro. Solamente quieren destruir y no construir." 
220 "Bueno, en el momento, están sacando también dentro de Comandancia, y por fuera. Están sacando, pero no se le hace la reforestación."

221 "Así es. Se puede.”

222 "Bueno, para mí, claro, me gusta porque nos pagan. Es algo difícil porque hay una soledad, uno solito... No tengo con quien conversar, solito, pues... a veces seis meses..."

223 "No es una compañía. Vamos a decir, es un hombre habilitado que maneja gente."

224 "Bien nos trata. Todo mundo le aprecia porque trabaja con madera y paga la plata."

225 "Yo cocinaba para que comen, pero no ganaba. Eso era mi voluntad, que les apoyaba, pero también comía de allí. Así andaba."

226 “Bien. Yo he trabajado desde el '74, el año 1974, y pues trabajando en la madera he llegado acá, y hasta ahora sigo trabajando porque me tratan bien. Para mí no hay ningún problema con el trabajo. Pagan, me dan trabajo, así... Yo tengo 51 años, pero sigo trabajando con la madera."

227 "No queremos ser millonarios, simplemente para criar nuestros hijos. Aunque no bien pagado, pero a lo menos."

228 "Bueno, en mi trabajo, no. Todo ha salido bien. Bueno, yo siempre trabajo así de mensurero. Claro, hay responsibilidades en el trabajo."

229 "Mira, señorita, disculpa: yo he trabajado con la madera en Montawai, con 12 personas he trabajado... Me debía tres mil soles para pagar mi gente. No me ha pagado el patrón. No he podido pagar mi gente yo también... Esa es maderada... Me quieren matar a mí porque no les pago, por eso yo quiero reclamar de mi patrón.”

230 "No todos los madereados les pagan bien- a veces no sale bien, a veces no les pagan bien, demora el pago."

231 "No. Chacra, agricultura, maíz, así. Nunca me metí en la madera. No me gusta. Porque sabemos que son mal pagadores, los patrones. Nunca me metí en la madera."

232 "Ese señor no me quiere pagar de mi trabajo. Quiero hacerle una denuncia."

"Más de mil soles me debe."

233 "Bueno, se van a sacar también, ni siquiera viene a la autoridad, ese Comúnal. No se presentan, pues, cuando quieren sacar madera en el territorio de nosotros. Se van a sacar así nada mas, sin pedir permiso de nadie."

234 "Nosotros estamos de acuerdo- que nos apoyen, pues, ¿no? Que nos paguen, al menos el precio que ellos venden, que nos dejen con algo, fondos para la Comúnidad... Pero los que trabajan no vienen a presentarse a la Comúnidad, no sabemos quien está trabajando."

235 "Yo también quiero dar mi palabra, Christina, sobre eso, que están diciendo. En la verdad no se puede trabajar así como dice la mujer Comúnal, porque la mayor parte de los hijos se va a la madera... Se van meses allá, cuatro meses, as veces cinco meses se van....Y de esa manera, nosotros no podemos tener 
chacra suficiente. No podemos criar animales aquí porque las gallinas no se puede criar como guineotiene que sembrar maíz, tiene que sembrar arroz. Y de esa manera nosotros no podemos criar gallinas. Criamos, a veces, dos, tres gallinas, pero no es suficiente."

"¿Qué hacemos nosotras? Yo, como mamá solita, tengo menor hijos chiquititos, ¿qué voy a hacer con ellos? No pueden trabajar ellos, no da. Y los grandes, pues, se van al monte a trabajar con patrones, y de esa manera nosotros no podemos trabajar en nuestro trabajo, y todito esa juventud aquí, se van todos a la montaña... Por eso no criamos animales, no es suficiente, porque una solita no se puede trabajar en las chacras. Nosotras no podemos si los hombres no nos ayuden. Entonces esa es mi palabra.”

236 "Más es la borrachera... Anteriormente no era así, Christina... Hace como unos cinco años, que, desde que empezó la maderada... Le da a un, vamos decir, a un trabajador, resueldan 300, 400 soles. Porque tienen la plata, se van a la bodega y toman. Como tienen plata, tienen que vender, pues, el alcohol. Y toman. Eso, había bastante cambio en eso, hace cinco años atrás.”

237 "En la madera andábamos bien tranquilos- comiendo, tomando, igual. No teníamos problemas. A veces yo le digo a él- aquí estamos en nuestra casa pasando problemas, antes andabas por todos lados, no tenías problemas. No tenías problemas para nada, andabas feliz."

238 "En el centro haces tu campamento. Y cuando estaba allá, el primer hijito que ha nacido en Tamsheco... y de allí cuando tenía un mes-"

239 "Tres meses."

240 "Tres meses, hemos levado él al centro para trabajar en la madera... A la vez, pues, él ha crecido en el monte."

241 "Pero señorita, digo, que no sabíamos enfermar. No se enfermaban. Aquí tienen enfermedades, hasta tengo perdido dos hijos."

242 "No había nada de enfermedad. Pero cuando salieron ya, del pueblo, allá había la gripe. Y mayormente mis hijos han crecido en el monte, sin nada de ampollas, nada."

243 "De aquí a unos diez años, cinco años más, no van a ser las cosas iguales que están ahora. Todo va a cambiarse."

244 "Pero lo que pasa es que el pueblo no conoce, no quiere organizarse. Por motivo de los patrones van afuera de sus Comúnidades, muy disperso. Entonces, vienen después de medio año, seis, siete meses, y con estas personas no se puede trabajar para conseguir lo que estamos hablando aquí ahorita... porque ellos no van a aprender nada. Solamente aprenden, bueno, yo quiero trabajar con patrón, quiero ir a la madera, la pesca, la carne, pero ellos nunca van a hablar de... como valorar a mis tradiciones, mis costumbres."

245 "Hablando de proyectos y hablando de los problemas de la Comúnidad de Comandancia. Al respecto de los trabajos que a veces uno se quiere realizar, y tratando de hacer un proyecto- tu sabes que para preparar un proyecto, personas responsables, y pues, yo creo de que no es tanto como ponerle, como decimos, al nombre de la Comúnidad, todos los Comúneros. Es difícil. Yo más bien pensaba de que podríamos hacerle, de repente, un grupo de algunas personas que desean hacer este trabajo, de hacer un proyecto, para hacer crianzas de animales u otros trabajos, para así poder hacer, para tener un solo acuerdo. Porque hay muchas personas que no quieren: a veces tienen otros trabajos, y ... a veces no están de acuerdo.”

246 "Bueno, nosotras, como madres, nosotras nos preocupamos de enseñarles, pues, a los jóvenes. Algún día nos morimos, tienen que trabajar ellos también para sus hijos. Tienen que hacer chacra y comprar sus 
materiales- hacha, machete- por eso trabajamos nosotros. Y tienen que seguir al ejemplo que nosotros tenemos.... Yo les digo a mis hijos también... 'hay que trabajar, ya son hombrecitos, ¿qué cosa vamos a comer?'... Si uno no tiene chacra, ¿qué cosa vas a desayunar, pues?"

247 "Lo que sería como número uno, pues sería mayormente la crianza. Ya piscegranja y crianza de animales, porque son las dos cosas que a nosotros nos sirven todos los días para el alimento...No hay una piscegranja..."

248 "Por eso ahora digo, cuando tienes hijos- yo también tengo mis hijos, y les digo a ellos, a los jóvenes, para que tengan que comer, los animalitos. No solamente la mujer cría, el hombre también cría para que tengan que comer. Porque si no, ¿qué vas a comer? Te das cuenta que ahora no hay pescado como antes... Eso decía los antiguos, ¿no?... No es como antes ya. Todo cambia.”

249 “Bueno, ¿cuál será también el problema? De repente, poca crianza de animales aquí, de tratando de vivir una vida más o menos, ¿no? Criando gallinas se puede tener la plata, ¿no? Criando el chancho para poder tener la plata. Pero aquí pues, nadie, no crían pues, en cantidad..."

"Me parece que también hallan, la vean muy difícil. Porque, vamos decir, el chancho, el chancho come regular, el chancho come. Tiene una chacrita, y termina, y no hay para comer los animales. Es que la gallina, no- la gallina sí puedes criar. Siempre que tengas tu maíz, crías."

"Mas aquí yo creo que a veces también, la poca, la poca interés. De que es por decir: yo gano más ir a trabajar en la montaña, ¿no? Pero no es así. Me parece que criando... Trabajando aquí puedes tener plata... Por que hay algunas personas que se han ido muy bien. Trabajan, y tienen para que toman, tienen para que comen. Viven bien, no hay ningún problema... porque ellos se preocupan en la crianza... Aquí nadie cría, pues, piensa en la gallina... Esa es lo que hay, esa es el gran problema que hay aquí."

250 “Para los nietos, serviría, pues!”

251 "Entonces, aquí, justamente, la técnica: nosotros también somos técnicos de acuerdo a nuestros conocimientos acá. Ahora, en otra manera, si queremos sembrar en orden, es otra técnica, ¿no? Como podemos plantar cada árbol, un árbol acá, de otra clase, más allá de otra clase... Por allí, podemos, necesitamos ingenieros que nos puedan dar conocimiento, como podemos reforestar... un ingeniero de agricultura, de reforestación- eso nos podía servir."

“...según la cantidad de árboles que se siembra. De repente por persona, ya el Estado ya da un dinero para su mantenimiento... Entonces allí se necesita gente y se necesita dinero... O sea, el mismo producto da garantía, para que queda un respaldo, que con tiempo, nos va a servir para hacer palos."

252 "El gobierno no nos apoya. No nos da ninguna facilidad para trabajar. No tenemos, y no trabajamos con ningún proyecto. No hacemos ningún proyecto- ningunas instituciones, ONGs, no nos apoyan para nosotros poder trabajar y tener los recursos económicos. No tenemos ningún apoyo."

253 “¿Cuál es la dificultad? Porque no hay quien nos prepare el proyecto, para elaborar el proyecto. Sabemos que hay, hay para sacar, muchas cosas. Para piscegranja, para criandera, para reforestación... Todo eso hay. En otras partes, crían... todo están criando. Pero no es un pueblo, de los pueblos indígenas, son gentes extranjeros, que ellos han venido a preparar, y todo compran, y es un proyecto. Este tipo de proyecto es muy necesario que nosotros podríamos tener... proyectos sobre tres cosas: reforestación, piscegranja, todo lo que es crianza de animales... porque este es la única esperanza que podemos tener."

254 "Se podría. Organizar con todas las Comúnidades."

255 "Cuando las cosas cuestan, de ellos, y nuestros productos no cuestan- es lo peor. Solamente todavía de ellos, quieren subir, y de nosotros, nunca sube. Y otra cosa: nosotros queremos vender un animal- una gallina, un pato, un chancho. En vez de nosotros echamos el precio, ellos echan el precio... Ellos lo que 
dicen- 'voy a pagar tanto,' y listo. El productor, nada. A pesar que nosotros sufrimos para criar un animal... No se puede recuperar lo que ha gastado, lo que comió... Es el malo que hace el gobierno... Que vale, lo que pagan allí- un racimo de plátanos, tres soles, tres cincuenta el más grandazo.”

256 "Lo que no hay es donde vender productos, no hay quien compra. Si te compran, te compran poco... Pues si hubiera un, vamos decir, una parte donde vender en cantidad, sí. La producción de yuca, por ejemplo, de plátanos, la producción de otros productos, maíz- muy poco, muy poco compran... En la Amazonas, muy bien, ¿no? En la Amazonas, sí. Ellos viven allí, siembran a sus plátanos, llevan 50, 30 racimos, llevan a Iquitos. Aquí, dificultoso para llevar a Iquitos. ¿Por dónde, pues, llevar? Cargarlo no se puede."

257 "El nombre a veces cambia."

258 "Se le siembra, o crece a su gusto."

259 "Chacra es cosa de nosotros, agricultura. Hay que tener nuestra chacra para vivir."

260 "Bueno, nosotros... en la verdad, cuando tenemos platita, se compra arroz... para poder mejorar un poquito el desayuno también. Pero, la mayor parte nosotros comemos pangito, chiricano, mazamorra."

261 "Estaba diciendo, Christina, que antes, mis abuelos tenían aguaje para sus champas. Esa era sus pantalones antes. No utilizaban como nosotros... Usaban aguaje y chambira... Esa era su vestimento."

262 "El vestimento no le consigíamos en la ciudad, el vestimento le consigíamos en media monte. De allí salían... las champas, de allí salía todo el vestimento- nunca comprábamos vestidos. Pero ahora si es necesario de comprar, y no hay trabajo, no hay ayuda del Estado... Entonces, ese ha sido un cambio entre bien y mal."

263 "Esta hierba es para saludar."

264 "Este es albaca macho, perfume de los Yaguas. Es perfume de Yaguas, dicen."

265 "Ese perfume es nativo."

266 "Hay muchas plantas más que no se cree, que es una planta comestible, pero aparte la medicina sirve."

267 "Nosotros tenemos muchas aquí en la selva, plantas para medicinas."

268 "Por ejemplo, en la lista que está, todavía no está ni la mitad de lo que conocemos."

269 "Los antiguos, a veces, les dejan sus hijos con bronquios, gripe, y no saben con que van a sanar. No saben preparar, así como estamos hablando de vegetales de la selva. Están muriendo, y no saben como prepararlo a los enfermos."

"Y de esa manera, los antiguos- le tengo un enfermo, y no me importa nada. Va a morir, y lo dejan solito en su casa que se muere, y van a otras partes, hacer sus casas y chacra nueva, yuca, todo- y a ellos no les importa, hacen casa nueva en otra parte."

270 "Planta es, cuando aquí se enferma, señorita, es remedio. Antes, no sabían que cosa van a preparar. Aquí hay remedios, bastante hierbas. Aquí no muere como se morían antes. No sabían que planta preparar... Bastante remedios aquí, pero si no sabes nada... Pero sí ahora nosotros conocemos un poco... 
Antes morían los antiguos al lado de remedios, no sabían como preparar. Pero ahora no mueren, toditos sabemos eses remedios... Remocaspi es negra, es amargo, igualito a pastilla...Yo no voy a la bodega. Yo no voy a Iquitos. Aquí hay remedios. Antes, cuando se morían nuestros paisanos, nadie sabía que remedio... Hay remedios bastante. No sabían nada. Hay remedios ahorita, como estoy hablando con usted..."

271 "Cuando uno no conoce la planta, a veces uno se muere por no conocer. Las plantas medicinales, no todos conocemos."

272 “Ahora para los remedios, pues... nosotros tenemos eso aquí en la mano: plantas, conocimiento de como preparar y como usarlas. Si todos supieron como usarlas- tal planta, tal planta, ¿no? Entonces, si yo sé, por decir, he aprendido, entonces yo tengo que dar el ejemplo ahora."

"No necesitarías nada de remedio, pues, Christina, conociendo nosotros los remedios, y no queremos hacerla. Por ejemplo, el bronquitis... algunos con bronquitis se van a la posta médica- ¡acá nomás hay! El huevo de la gallina es bueno para la bronquitis. Siempre que tenga su mezcla, le hacen, y le pasa. Sin poner ampollas, nada, y me parece este es bueno, ¿no? Aprender y para no hacer mucho gasto... y no hay la plata. Yo se muy bien que puede haber remedios, ¿no? para el bronquitis, pero no hay la plata a veces. Y sabiendo que puede ser bueno, sabiendo preparar, se lo prepara."

273 "Respecto, digo, si algunos pueblos extranjeros, algunos vienen a hacer los estudios, por lo tanto, pues, debemos ser pagados. Pagados, porque este es lo mejor pulmón de Perú, donde existe los más vegetales que puede existir en todo Perú."

274 "Pero que pasa, que con tiempo, los que estamos acá, ya no utilizamos nuestros vegetales porque ya no queremos preparar. Porque vienen pastillas la misma cosa... O sea, nosotros dejamos de usar nuestra medicina por esperar un apoyo, por esperar una cápsula, por esperar un jarabe, de la misma vegetal que han sacado. Entonces nosotros, en vez de que nosotros beneficiar, nosotros más bien tenemos que comprar de ellos."

275 "Yo no conozco la montaña, vivo en mi casa, nada más."

276 "De la monte yo no conozco, porque nunca he ido al monte."

277 "La experiencia le enseña."

278 “Aquí hay remocaspi. Remocaspi y huanzamana para la malaria. Con eso curo yo. Eso crece en el monte. Su hoja. Cuando hay un enfermo, yo lo cocino. Yo sé preparar para curar mi gente cuando trabajo. Trabajo en maderada. Yo le curo a mi gente con eso. Yo soy médico de vegetales. Yo soy médico en verdad porque sé preparar remedios."

279 "Mientras que nosotros cuidamos nuestro territorio siempre vamos a tener medicinas vegetales. La tierra no sirve solamente para sacar madera, sirve para curar la vida, y las medicinas vegetales son las mas importantes."

280 "Uno se sabe de una preparación, de repente otro sabe de otra forma, de la misma planta. Nosotras sabíamos solamente para fresco... Ahora estoy aprendiendo yo también de ella."

281 "Valorar nuestra propia medicina... Los niños son los que van a necesitar estas vegetales."

282 "Que cada Comúnidad venga.. juntarles para dar el conocimiento mejor. Yo pienso que sería bonito.” 
283 "Hay otras Comúnidades que conocen más, conocen de otra forma de preparar la medicina."
284 "Ellos no saben, pues, que es tunchi, que es ese bijuntos- ¡no saben ellos!”
285 "En el cementerio vive, pero el espíritu anda por acá.”
286 “En mí casa!”
287 "El espíritu de uno, cuando tu te mueres.”
288 "Ya no es como cuando estás vivo... pues no hay calentura.”
289 "El tunchi era, pues.”
290 "Allí dicen que hay muertos, pues.”
291 "Ese es el tunchi, pues, señorita.”
292 “¡Allí duerme solita!”
293 "Bueno, como ya están acostumbrados, ya pues, los pasajeros llegan, y no saben que es tunchi, nada de eso, bueno, el tunchi también se acostumbra junto con la gente."

294 “Por eso, digo, sirve esa piripiri... Para que no entre la sombra, se dice, la mujer al hombre... Por eso tomamos esa piripiri pues."

295 "Se muere."

296 "Se hincha la barriga. No puede ya respirar... Por eso nosotras usamos esa piripiri...Nosotras tomamos eso para que a ellos no les pasa nada."

297 “Tío, yo sé que usted es medicinista y conoce la tradición de nuestra idiomática.”

298 "Hay muchas. Hay planta medicina ayahuasca primera. Después hay planta toé. Medicina hay bastante. Planta de ajo sacha hay mucha."

299 “Toé... Ese toma el médico, para que aprenda, para que mate a la gente.”

300 "Los curiosos."

301 "aprender la ciencia oculta"

302 "Y como ustedes acaban de explicar, este tabaco también es una medicina. Nuestros abuelos curaban con eso. Habían las creencias, los médicos vegetalistas, algunos le toman para concentrarse de la enfermedad, que tiene la criatura. Primero la mareación, se curaba con esa medicina. O sea, también es una medicina, no es solamente un vicio. También apoyo para nosotros ha sido como medicina. Eso tampoco, no es malo." 
${ }^{303}$ Although discussing the bioactivity and efficacy of each of the medicinal plants listed in these sections is beyond the scope of this thesis, Duke and Vasquez (1994), Desmarchelier and Witting Schaus (2000), and other Amazonian ethnobotanical dictionaries and field guides reference literature that describes results from laboratory studies for many of these plants.

304 "No comemos como en la ciudad."

305 "Es una planta que tiene un olor fuerte, y eso bota la enfermedad."

306 "La mucura: para fresco, para gripe, para todo."

307 "Cuando tiene una enfermedad, yo tengo que sacar ajo sacha para fresco contra el gripe y el fiebre... Uno mismo se puede curar con eso también, con ajo sacha. Si tienes fiebre alta, raspas la raíz, y se toma."

308 "Es lo mejor contra fiebre." "Con eso se sana, es una medicina buena." "Es para toda enfermedad."

309 "Yo tengo la lancetilla que está allí; sirve para un fresco para la fiebre."

310 "Tenemos una seguridad en esta planta porque nos ha curado. Al darle a un niño, ya no tiene este enfermedad más. Se sana por completo.”

311 "Porque eso sana a los niños." "Porque hice la prueba cuando mi hijo tuvo choque de mal aire y funcionó."

312 "Se les sana a las personas."

313 "Porque lo hemos comprobado y es bueno." "Porque es mejor que lo del botiquín."

314 “.... son dos visiones diferentes. Ellos tienen una visión diferente sobre lo que son áreas naturales protegidas."

315 "Pero, hay mucha desinformación en eso en las organizaciones, y quizás también nuestra. Creo que deberíamos- hemos puesto mucho- invertir mucho más tiempo y trabajo, lo que es que se necesite, en hacer que nuestro planeamiento técnico sea más visible. Porque ellos no le entienden hasta ahorita. Entonces, ese es el gran problema que tenemos con ellos... y allí las áreas restringidas, de que no quieren saber nada. Pero es desinformación, básicamente. O sea, hay gente interesadísima, hay que informarles. Pero es también nuestro error, por nosotros también, de generar algún tipo de información, quizás, no sé de que forma más.”

316 “Nosotros somos más reconocidos que otras Comúnidades campesinas. Los turistas vienen mayormente por los pueblos indígenas, por nosotros. A ellos les gustan nuestras costumbres. Les gustan nuestro vestimiento y todo lo que nosotros tenemos en nuestra selva. Y eso es lo que a ellos les gusta."

317 "No solamente los pasajeros deben venir a aprovechar nuestros recursos, no solamente venir a cambiar nuestras artesanías, sino también de su parte de ellos, necesitamos algo.”

318 "Para nosotros también es importante de conseguir algunos proyectos de extranjeros porque también son ellos que vienen y quieren conocer nuestros recursos. También, ellos quieren que nosotros conservemos nuestros recursos naturales." 
319 "apoyo para esta clase de entrevista."

320 “...hacer despertar a la Comúnidad. Porque anteriormente la Comúnidad estaba con bajo conocimiento. A ellos no les interesaba para que sirve tanta cosa. Y ahora veo que van conociendo..."

321 "No puede ser. Ustedes quieren vender sus palabras- no es así." 


\section{REFERENCES CITED}

Agrawal, Arun

2005 Environmentality: Technologies of Government and the Making of Subjects. New Delhi: Oxford University Press.

AIDESEP

2009 Jesús Manacés elegido como coordinador de la "Comisión Especial para investigar y analizar los sucesos de Bagua" [Jesús Manacés chosen as coordinator of the "special commission to investigate and analyze the Bagua events."]. Lima, Peru: AIDESEP.

Alexiades, Miguel N.

1996 Selected Guidelines for Ethnobotanical Research: A Field Manual. New York: The New York Botanical Garden.

Alexiades, Miguel N., and Didier Lacaze D.

1995 FENAMAD's Program in Traditional Medicine: An Integrated Approach to Health Care in the Peruvian Amazon. In Medicinal Resources of the Tropical Forest. M.J. Balick, ed. New York: Columbia University Press.

Balée, William

1989 The Culture of Amazonian Forests. In Resource Management in Amazonia: Indigenous and Folk Strategies. D.A. Posey and W. Balée, eds. Pp. 1-21. Advances in Economic Botany, Vol. 7. New York: New York Botanical Garden.

Balée, William L.

2001 Environment, Culture, and Sirionó Plant Names. In On Biocultural Diversity: Linking Language, Knowledge, and the Environment. L. Maffi, ed. Pp. 298-310. Washington: Smithsonian Institution Press.

Balick, Michael J.

1996 Transforming Ethnobotany for the New Millennium. Annals of the Missouri Botanical Garden 83:58-66.

Beebe, James

1995 Basic Concepts and Techniques of Rapid Appraisal. Human Organization 54(1):42- 51.

Bennett, Bradley C.

1992 Plants and People of the Amazonian Rainforests: The Role of Ethnobotany in Sustainable Development. BioScience 42(8):599-608.

2002 Forest Products and Traditional Peoples: Economic, Biological, and Cultural Considerations. Natural Resources Forum 26:293-301. 
Berkes, Fikret

2004 Rethinking Community-Based Conservation. Conservation Biology 18(3):621-30.

Berlin, Brent

1992 Ethnobiological Classification: Principles of Categorization of Plants and Animals in Traditional Societies. Princeton, N.J.: Princeton University Press.

Bernard, H. Russell

2002 Research Methods in Anthropology: Qualitative and Quantitative Approaches. Walnut Creek: AltaMira Press.

Blount, Ben G.

2001 Indigenous Peoples and the Uses and Abuses of Ecotourism. In On Biocultural Diversity: Linking Language, Knowledge, and the Environment. L. Maffi, ed. Pp. 503-516. Washington: Smithsonian Institution Press.

Boom, Brian M.

1987 Ethnobotany of the Chácobo Indians, Beni, Bolivia. Advances in Economic Botany 4:1-68.

Borgatti, S.P.

1996 ANTHROPAC 4.0. Natick, MA: Analytic Technologies.

Brosius, J. Peter

1999 Analyses and Interventions: Anthropological Engagements with Environmentalism. Current Anthropology 40(3):277- 309.

Brown, Michael F.

2003 Who Owns Native Culture? Cambridge, Massachusetts: Harvard University Press.

Brush, Stephen B.

1993 Indigenous Knowledge of Biological Resources and Intellectual Property Rights: The Role of Anthropology. American Anthropologist 95(3):653-686.

2001 Protectors, Prospectors, and Pirates of Biological Resources. In On Biocultural Diversity: Linking Language, Knowledge, and the Enivronment. L. Maffi, ed. Pp. 517-530. Washington: Smithsonian Institution Press.

Bryant, Raymond L. , and Sinead Bailey

1997 Third World Political Ecology. London: Routledge.

Budwoski, Gerald

1990 Home Gardens in Tropical America: A Review. In Tropical Home Gardens. K. Landauer and M. Brazil, eds. Pp. 3- 8. Tokyo: United Nations University Press. 
Carlson, Thomas J.

2001 Language, Ethnobotanical Knowledge, and Tropical Public Health. In On Biocultural Diversity: Linking Language, Knowledge, and the Environment. L. Maffi, ed. Pp. 489-502. Washington: Smithsonian Institution Press.

Carneiro da Cunha, Manuela, and Mauro W.B. de Almeida

2000 Indigenous People, Traditional People, and Conservation in the Amazon. Daedalus 129(2):315+.

Chapin, Mac

2004 A Challenge to Conservationists. World Watch 17(6):17-31.

Chaumeil, Jean Pierre

1981 Historia y Migraciones de los Yagua de Finales del Siglo XVII Hasta Nuestros Dias [History and migrations of the Yagua from the end of the XVII century until the present]. Volume 3. Lima: Centro Amazonico de Antropologia y Aplicación Práctica.

1984 Entre el Zoo y la Esclavitud: los Yagua del Oriente Peruano en su Situación Actual [Between the zoo and slavery: the Yagua of eastern Peru in their current situation]. In IWGIA report, Vol. 3. Copenhagen.

1987 Nihamwo: Los Yagua del Nor-Oriente Peruano [Nihamwo: the Yagua of northeastern Peru]. Lima: Centro Amazonico de Antropologia y Aplicacion Practica.

1998 Ver, Saber, Poder: El Chamanismo de los Yagua de la Amazonia Peruana [Seeing, Knowing, Power: Shamanism of the Yagua of the Peruvian Amazon].

2001 The Blowpipe Indians: Variations on the Theme of Blowpipe and Tube among the Yagua Indians of the Peruvian Amazon. In Beyond the Visible and the Material: The Amerindianization of Society in the Work of Peter Riviere. L. Rival and N. Whitehead, eds. Oxford: Oxford University Press.

Conklin, Beth A.

2002 Shamans versus Pirates in the Amazonian Treasure Chest. American Anthropologist 104(4):1050-1061.

Conklin, Beth A., and Laura R. Graham

1995 The Shifting Middle Ground: Amazonian Indians and Eco-Politics. American Anthropologist 97(4):695-710.

Cotton, C.M.

1996 Ethnobotany: Principles and Applications. Chichester: John Wiley \& Sons. 
De Lima, R.X., et al.

2002 An Ethnobiological Survey of the Environmental Protection Area of Guaraquecaba-Paraná, Brazil. In Ethnobiology and Biocultural Diversity: Proceedings of the Seventh International Congress of Ethnobiology. J.R. Stepp, F.S. Wyndham, and R.K. Zarger, eds. Pp. 61-71. Athens, Georgia: International Society of Ethnobiology.

Desmarchelier, Cristian, and Fernando Witting Schaus

2000 Sesenta Plantas Medicinales de la Amazonía Peruana: Ecología, Etnomedicina y Bioactividad [Sixty medicinal plants of the Peruvian Amazon: ecology, ethnomedicine, and bioactivity]. Peru.

Duke, James Alan, and Rodolfo Vasquez

1994 Amazonian Ethnobotanical Dictionary. Boca Raton, FL: CRC Press, Inc.

Ervin, Alexander M.

2005 Applied Anthropology: Tools and Perspectives for Contemporary Practice. Boston: Pearson Education.

Escobar, Arturo

1996 Elements for a Post-Structuralist Political Ecology. Futures 28(4):325-343.

1999 After Nature: Steps to an Antiessentialist Political Ecology. Current Anthropology 40(1):1- 30 .

Espinoza Llanos, Roberto

2004 Forest Privatization and Indigenous Rights and Knowledge in Peru: United Nations Forestry Forum (UNFF).

Fejos, Paul

1943 Ethnography of the Yagua. New York: The Viking Fund, Inc.

Fernandes, E. C. M. , and P. K. R. Nair

1990 An Evaluation of the Structure and Function of Tropical Home Gardens. In

Tropical Home Gardens. K. Landauer and M. Brazil, eds. Pp. 105-114. Tokyo: United Nations University Press.

Finerman, Ruthbeth , and Ross Sackett

2003 Using Home Gardens to Decipher Health and Healing in the Andes. Medical Anthropology Quarterly 17(4):459-482.

Foster, Robin, et al.

Rapid Color Guide \# 119, version 1.0: Palms of Allpahuayo-Mishana. Zona Reservada Allpahuayo-Mishana, Iquitos, Loreto, Peru. In Environmental and Conservation Programs. Chicago, IL: The Field Museum. 
Galarza, Elsa, and Karlos La Serna

2005a Las Concesiones Forestales en el Perú: ¿Cómo Hacerlas Sostenibles? [Forestry Concessions in Peru: How to Make Them Sustainable?]. In La Política Forestal en la Amazonía Andina. Estudio de Casos: Bolivia, Ecuador y Perú. R. Barrantes, ed. Pp. 445-600. Serie Diagnóstico y Propuesta Lima: Consorcio de Investigación Económica y Social (CIES).

Galarza, Elsa, and Karlos La Serna

2005b ¿Son Sostenibles las Concesiones Forestales en el Perú? [Are Forestry

Concessions in Peru Sustainable?]. Economía y Sociedad 56.

Gibson, Clark C., Margaret A. McKean, and Elinor Ostrom, eds.

2000 People and Forests: Communities, Institutions, and Governance. Cambridge, Massachusetts: The MIT Press.

Gray, Andrew

1997 Indigenous Rights and Development: Self-Determination in an Amazonian Community. 3 vols. Volume 3. Oxford: Berghahn Books.

Griffiths, Tom

2004 Indigenous Peoples in the Peruvian Amazon Call for Forest Policy Reform and Major Changes in Implementation of the Forest Law Forest Peoples Programme (FPP).

Hecht, Susanna, and Alexander Cockburn

1989 The Fate of the Forest: Developers, Destroyers, and Defenders of the Amazon. London: Verso.

Heckler, Serena L.

2007 Herbalism, Home Gardens, and Hybridization: Wõthihã Medicina and Cultural Change. Medical Anthropology Quarterly 21(1):41-63.

Igoe, Jim

2005 Global Indigenism and Spaceship Earth: Convergence, Space, and Re-entry Friction. Globalizations 2(3):377-90.

INEI, El Instituto Nacional de Estadística e Informática

2007 Sistema de Consulta de Principales Indicadores Demográficos, Sociales y

Económicos [Database of primary demographic, social, and economic indicators]. In Perú: Census Nacionales 2007: XI de Poblacion Y VI de Vivienda: INEI- el órgano rector de los Sistemas Nacionales de Estadística e Informática en el Perú.

2008 Perú: Crecimiento y Distribución de la Población, 2007 [Peru: population growth and distribution, 2007] In Perú: Census Nacionales 2007: XI de Poblacion Y VI de Vivienda. Lima, Peru: INEI, El Instituto Nacional de Estadística e Informática. 
Instituto del Bien Comun

2008 Information System on Native Communities of the Peruvian Amazon (SICNA). Lima, Peru: Instituto del Bien Comun.

Killick, Evan

2008 Creating Community: Land Titling, Education, and Settlement Formation Among the Ashéninka of Peruvian Amazonia. Journal of Latin American and Caribbean Anthropology 13(1):22-47.

Klesner, Joseph L.

2007 Social Capital and Political Participation in Latin America: Evidence from Argentina, Chile, Mexico, and Peru. Latin American Research Review 42(2).

Kottak, Conrad P.

1999 The New Ecological Anthropology. American Anthropologist 101(1):23-35.

Lamont, Susan R.

1999 The Effects of Ecotourism on Plant Resource Use and Management in Amazonian Peru. Dissertation, Miami University.

Lizarralde, Manuel

2001 Biodiversity and Loss of Indigenous Languages and Knowledge in South America. In On Biocultural Diversity: Linking Language, Knowledge, and the Environment. L. Maffi, ed. Pp. 265-281. Washington: Smithsonian Institution Press.

Logback, J., et al.

2002 Economic Alternatives Protect the Amazon Rainforest in Ecuador. In Ethnobiology and Biocultural Diversity: Proceedings of the Seventh International Congress of Ethnobiology. J.R. Stepp, F.S. Wyndham, and R.K. Zarger, eds. Pp. 61-71. Athens, Georgia: International Society of Ethnobiology.

MacLean Stearman, Allyn

1994 Revisiting the Myth of the Ecologically Nobel Savage in Amazonia: Implications for Indigenous Land Rights. Culture and Agriculture 49:2-6.

Maffi, Luisa

2001a Language, Knowledge, and Indigenous Heritage Rights. In On Biocultural Diversity: Linking Language, Knowledge, and the Environment. L. Maffi, ed. Pp. 412-432. Washington: Smithsonian Institution Press.

2001b On the Interdependence of Biological and Cultural Diversity. In On Biocultural Diversity: Linking Language, Knowledge, and the Environment. L. Maffi, ed. Pp. 1-50. Washington: Smithsonian Institution Press. 
Mendez, V.E., R. Lok, and E. Somarriba

2001 Interdisciplinary Analysis of Homegardens in Nicaragua: Micro-zonation, Plant Use and Socioeconomic Importance. Agroforestry Systems 51:85-96.

Nabhan, G.P., P. Pynes, and T. Joe

2002 Where Biological and Cultural Diversity Converge: Safeguarding Endemic Species and Languages on the Colorado Plateau. In Ethnobiology and Biocultural Diversity: Proceedings of the Seventh International Congress of Ethnobiology. J.R. Stepp, F.S. Wyndham, and R.K. Zarger, eds. Pp. 61-71. Athens, Georgia: International Society of Ethnobiology.

Nair, P.K.R.

2001 Do Tropical Homegardens Elude Science, or Is It the Other Way Around? Agroforestry Systems 53:239-245.

Neumann, Roderick

2005 Making Political Ecology. New York: Oxford University Press.

Niñez, Vera

1987 Household Gardens: Theoretical and Policy Considerations. Agricultural Systems $23: 167-186$

1990 Garden Production in Tropical America. In Tropical Home Gardens. K. Landauer and M. Brazil, eds. Pp. 186-192. Tokyo: United Nations University Press.

ORAI

2006a Pronunciamiento de Rechazo a las Actividades Petroleras y en Defensa de la Vida y Diversidad Biológica de la Amazonía Peruana [Statement denouncing petroleum activities and in defense of life and biological diversity of the Peruvain Amazon]. Iquitos, Peru: Organización Regional AIDESEP Iquitos (ORAI).

2006b iQueremos paz y no muerte! [We want peace and not death!]. Iquitos, Peru: Organización Regional AIDESEP Iquitos (ORAI)

Orlove, Benjamine S. , and Stephen B. Brush

1996 Anthropology and the Conservation of Biodiversity. Annual Review of Anthropology 25:329-52.

Padoch, Christine

1988 The Economic Importance and Marketing of Forest and Fallow Products in the Iquitos Region. In Swidden-Fallow Agroforestry in the Peruvian Amazon. W.M. Denevan and C. Padoch, eds. Advances in Economic Botany, Vol. 5. New York: The New York Botanical Garden. 
Padoch, Christine, and Wil de Jong

1991 The House Gardens of Santa Rosa: Diversity and Variability in an Amazonian Agricultural System. Economic Botany 45(2):166- 175.

Painter, Michael

1995 Anthropology in Pursuit of Conservation and Development. National Association for the Practice of Anthropology Bulletin 15(1):33-45.

Parker, Eugene

1993 Fact and Fiction in Amazonia: The Case of the Apete. American Anthropologist 95(3):715-723.

Peet, Richard, and Michael Watts, eds.

1996 Liberation Ecologies: Environment, Development, Social Movements. London: Routledge.

Pérez, Diana

2002 Etnobotánica Medicinal y Biocidas para Malaria en la Región Ucayali [Medicinal ethnobotany and biocides for malaria in the Ucayali region]. Folia Amazónica 13(1-2):87-108.

Pitman, Nigel, et al., eds.

2004 Peru: Ampiyacu, Apayacu, Yaguas, Medio Putumayo. Volume 12. Chicago: The Field Museum.

Pitman, Nigel, Corine Vriesendorp, and Debra Moskovits, eds.

2003 Peru: Yavari. Volume 11. Chicago: The Field Museum.

Posey, Darrell A.

1982 The Keepers of the Forest. Garden 6(1):18-24.

2001 Biological and Cultural Diversity: The Inextricable, Linked by Language and Politics. In On Biocultural Diversity: Linking Language, Knowledge, and the Environment. L. Maffi, ed. Pp. 379-396. Washington: Smithsonian Institution Press.

Pretty, Jules, and David Smith

2004 Social Capital and Biodiversity Conservation and Management. Conservation Biology 18(3):631-638.

Project Amazonas

2000 Medcap Introductory Manual: Upper Amazon River Region, Department of Loreto, Peru: Project Amazonas, Inc.

Quinlan, Marsha B., and Robert J. Quinlan

2007 Modernization and Medicinal Plant Knowledge in a Caribbean Horticultural Village. Medical Anthropology Quarterly 21(2):169-192. 
Redford, Kent H.

1991 The Ecologically Nobel Savage. Cultural Survival Quarterly 15(1):46- 48.

Redford, Kent H., and Allyn MacLean Stearman

1993 Forest-Dwelling Native Amazonians and the Conservation of Biodiversity: Interests in Common or in Collision? Conservation Biology 7(2):248-255.

Rénique, Gerardo

2009 Against the Law of the Jungle: Peru's Amazonian Uprising. NACLA Report on the Americas 42(1):5-8.

Robbins, Paul

2004 Political Ecology: A Critical Introduction. Malden, MA: Blackwell Publishing.

Rocheleau, Dianne, and David Edmunds

1997 Women, Men and Trees: Gender, Power and Property in Forest and Agrarian Landscapes. World Development 25(8):1351-1371.

Schmink, Marianne , and Charles H. Wood

1987 The 'Political Ecology' of Amazonia. In Lands at Risk in the Third World: Local Level Perspectives. P.D. Little and M. Horowitz, eds. Boulder: Westview Press.

Serje, Margarita

2003 Malocas and Barracones. Tradition, Biodiversity, and Participation in the Columbian Amazon. International Social Science Journal 178:561-572.

Shanley, Patricia

2006 Science for the Poor: How One Woman Challenged Researchers, Ranchers, and Loggers in Amazonia. Ecology and Society 11(2):28+.

Shanley, Patricia, and Gabriel Medina, eds.

2005 Frutíferas e Plantas Úteis na Vida Amazônica [Fruit trees and useful plants in Amazon life]. Belém, Brazil: CIFOR Imazon.

Shepard, G.H., Jr

2002 Nature's Madison Avenue: Sensory Cues as Mnemonic Devices in the Transmission of Medicinal Plant Knowledge among the Matisgenka and Yora of Peru. In Ethnobiology and Biocultural Diversity: Proceedings of the Seventh International Congress of Ethnobiology. J.R. Stepp, F.S. Wyndham, and R.K. Zarger, eds. Pp. 61-71. Athens, Georgia: International Society of Ethnobiology.

Sillitoe, Paul

1998 The Development of Indigenous Knowledge: A New Applied Anthropology. Current Anthropology 39(2):223-252. 
Singer, Merrill, and Hans A. Baer

2007 Introducing Medical Anthropology: A Discipline in Action. Lanham, MD: AltaMira Press.

Smith, Nigel J.H.

1999 The Amazon River Forest: A Natural History of Plants, Animals, and People. New York: Oxford University Press.

Southgate, Douglass

1998 Tropical Forest Conservation: An Economic Assessment of the Alternatives in Latin America. New York: Oxford University Press.

Sponsel, Leslie E

1995 Introduction. In Indigenous Peoples and the Future of Amazonia: An Ecological Anthropology of an Endangered World. L.E. Sponsel, ed. Tucson: The University of Arizona Press.

Stronza, Amanda

2005 Hosts and Hosts: The Anthropology of Community-Based Ecotourism in the Peruvian Amazon. NAPA Bulletin 23:170-190.

Ticktin, T., et al.

2002 Participatory Ethnoecological Research for Conservation: Lessons from Case Studies in Mesoamerica. In Ethnobiology and Biocultural Diversity: Proceedings of the Seventh International Congress of Ethnobiology. J.R. Stepp, F.S. Wyndham, and R.K. Zarger, eds. Pp. 61-71. Athens, Georgia: International Society of Ethnobiology.

Toledo, V.M., et al.

2002 Mesoamerican Ethnoecology: A Review of the State of the Art. In Ethnobiology and Biocultural Diversity: Proceedings of the Seventh International Congress of Ethnobiology. J.R. Stepp, F.S. Wyndham, and R.K. Zarger, eds. Pp. 61-71. Athens, Georgia: International Society of Ethnobiology.

Vayda, Andrew P., and Bradley B. Walters

1999 Against Political Ecology. Human Ecology 27(1):167-179.

Vickers, W.T, and T. Plowman

1984 Useful Plants of the Siona and Secoya Indians of Eastern Ecuador. Fieldiana, Botany New Series 15:1-61.

Vormisto, Jaana

2002 Making and Marketing Chambira Hammocks and Bags in the Village of Brillo Nuevo, Northeastern Peru. Economic Botany 56(1):27-40. 
Walker, Peter A.

2005 Political Ecology: Where is the Ecology? Progress in Human Geography 29(1):73-82.

Warren, D. Michael

2001 The Role of the Global Network of Indigenous Knowledge Resource Centers in the Conservation of Cultural and Biological Diversity. In On Biocultural Diversity: Linking Language, Knowledge, and the Environment. L. Maffi, ed. Pp. 446-461. Washington: Smithsonian Institution Press.

Wezel, A. , and S. Bender

2003 Plant Species Diversity of Homegardens of Cuba and Its Significance for Household Food Supply. Agroforestry Systems 57:39-49.

Wilbert, W.

2002 The Transfer of Traditional Phytomedical Knowledge among the Warao of Northeastern Venezuela. In Ethnobiology and Biocultural Diversity: Proceedings of the Seventh International Congress of Ethnobiology. J.R. Stepp, F.S. Wyndham, and R.K. Zarger, eds. Pp. 61-71. Athens, Georgia: International Society of Ethnobiology.

Wojtkowski, P.A.

1993 Toward an Understanding of Tropical Home Gardens. Agroforestry Systems 24:215-222.

Wolff, Phillip, and Douglas L. Medin

2001 Measuring the Evolution and Devolution of Folk-Biological Knowledge. In On Biocultural Diversity: Linking Language, Knowledge, and the Environment. L. Maffi, ed. Pp. 212-227. Washington: Smithsonian Institution Press.

Zarger, R.K.

2002 Acquisition and Transmission of Subsistence Knowledge by Q'eqchi' Maya in Belize. In Ethnobiology and Biocultural Diversity: Proceedings of the Seventh International Congress of Ethnobiology. J.R. Stepp, F.S. Wyndham, and R.K. Zarger, eds. Pp. 61-71. Athens, Georgia: International Society of Ethnobiology.

Zent, Stanford

2001 Acculturation and Ethnobotanical Knowledge Loss among the Piaroa of Venezuela: Demonstration of a Quantitative Method for the Empirical Study of Traditional Environmental Knowledge Change. In On Biocultural Diversity: Linking Language, Knowledge, and the Environment. L. Maffi, ed. Pp. 190-211. Washington: Smithsonian Institution Press. 


\section{APPENDICES}

\section{Appendix 1: Field Data Collected}

All data collected July 4 - August 12, 2005 in Comandancia, Loreto, Peru and with members of Comandancia unless noted otherwise.

\section{$\underline{\text { Interviews }}$}

\section{Structured (questionnaires completed)}

- 13 houses (sample: probability, population: 33 houses)

Interviewees: male and/or female head of household, 20 total people

(6 individual and 7 couple interviews)

Literate children administered the questionnaires

Questions include: Household census: name, relationship, birth year, and birth place of all household members

○ 10 most important medicinal plants used and location, part, use, and preparation for each

- Supernatural/ritual plants and location, part, use, and preparation for each

- Plants used in the past, use, and why not in present

○ Children learned about medicinal plants and which

- All household members' memberships and leadership roles past and present in community governance, community organizations, and indigenous federations

- Employment, past and present, of all household members

- Speak Yagua at home with children

\section{Semi-structured (tape recorded)}

- Director of school and teacher (key participant)

$$
<1 \text { hour } 27 \text { July }
$$

Plants, community, education, problems, vision

- Biologist (Stanford; not in Comandancia, at P.A. station) $<1$ hour 27 July Local environment, conservation, logging, community needs, Peruvian issues

- Indigenous leaders (couple interview) $<1$ hour 2 August Community governance and organizations, indigenous federations, roles, positions, years, Yagua language

- Community members (couple interview) <2 hours 6 August Community problems, life histories, marital problems, generational differences, alcohol, other communities,

- Instituto del Bien Común staff (2 representatives; not in Comandancia, in Iquitos branch office) $<1$ hour 12 August Proposed protected area, indigenous communities, conservation efforts, challenges, natural resources, etc. 
- ORAI representatives (2 representatives, 1 from Comandanica; not in Comandancia, in Iquitos office) $<1$ hour 12 August Indigenous issues, bilingual education, challenges with government and extractive industries, historical examples, current struggles, natural resource management, etc.

\section{Unstructured}

Conducted with many community members, data in handwritten notebooks and typed field notes

\section{Focus Groups (tape recorded)}

- Community members (large group) $<3$ hours 30 July Slideshow to discuss plants, list of needs, community problems, Yagua culture

- Community members (small group) $<3$ hours 1 August Medicinal plants, community problems (lack of food, alcohol, etc.), solutions, stories from the past, Yagua language

- Women $<2$ hours 3 August Stories from the past (how met husbands, old and new courtship), list of needs, medicinal and other plants, community problems

- Leaders $<2$ hours 3 August Community problems, national and international NGOs, protected areas, indigenous issues, Yagua culture

- Community members $<1$ hour 5 August Stories from the past, medicinal plants, life histories

Workshops and Meetings (tape recorded; community planned/collaborated)

- Medicinal Plant Workshop $<1$ hour 14 July People brought medicinal plants to show and tell children about use and preparation

- Medicinal Plant Meeting

$<1$ hour 28 July Teacher leads discussion with community members about medicinal plants

- Meeting $<1$ hour 8 August Show slideshow and discuss plants

- Meeting $<1$ hour 10 August

Show slide show

\section{Other (tape recorded)}

- Annual Yagua Celebration $<1$ hour 8 August 
Speeches by leaders of Comandanica and other communities, dancing, drumming, and singing in Yagua, party, man complains about logging company

- Dancing and singing in Yagua (with visiting family) $<1$ hour 9 August

\section{Field Notes}

- 65 typed pages and 2 handwritten notebooks including about 30 days of: participant-observation notes from time spent daily in community, unstructured and informal interviews with community leaders and other members, researchers at the station, meetings with leaders and key participants, detailed plant use and preparation for medicinals, excursions to parts in and near the community, research progress, working with the children, etc.

Each day divided into: time of day/activities, methods employed today, and reflections on the day and thinking about methods.

\section{Digital Photos}

- About 1300 digital photos of people, plants, the community, cultural artifacts, etc. taken.

\section{Community Created}

\section{(in addition to collaboration/participatory methods above)}

- Wrote detailed plant use and preparation for 16 medicinal plants in Spanish and Yagua. Key participants were some of the most Spanish and Yagua literate in the community, and a few other community members collaborated orally.

- Compiled a plant list with about 460 Spanish names of many of the plants in the community. The base list was compiled as a large group effort by the children, then additions were made by adults. Key participant noted use for some of them.

- Took about 50 regular photos (2 rolls) of people, the community, etc. Both adults and children took these photos when I was not present with a camera I lent them. 


\section{Appendix 2: Structured Interview Questionnaire}

\section{Demographics}

1.) ¿Cuántas familias viven en esta casa? ${ }^{322}$

2.) ¿Cuáles son las relaciones entre las familias en esta casa con otras familias en Comandancia?

3.) ¿Cómo se llama usted?

¿Y usted? (if the interview is with both mother and father head of household)

OR ¿Y su esposo/a? (if the interview is with either mother or father head of household)

4.) ¿En qué año nació usted?

¿Y usted? (if the interview is with both mother and father head of household)

OR ¿Y su esposo/a? (if the interview is with either mother or father head of household)

5.) ¿Dónde nació?

$¿ Y$ usted? (if the interview is with both mother and father head of household)

OR ¿Y su esposo/a? (if the interview is with either mother or father head of household)

6.) ¿Cuántos hijos tiene(n) en total?

7.) ¿Cuántos de sus hijos viven en la casa ahora?

8.) ¿Cómo se llama el primer hijo?

9.) ¿En qué año nació?

10.) ¿Dónde nació?

Repeat 8-10 for all of the children of the interviewees, then the other mothers, fathers, and children in the household.

\section{Medicinal Plants}

Ahora vamos a hablar sobre las plantas medicinales que usan.

11.) ¿Cuáles son las 10 plantas medicinales mas importantes para usted(es) y su familia? Ask the following about each of the 10 plants mentioned:

12.) ¿Y dónde se consigue la ?

(garden around the house, agricultural field (specify which family), forest, someone else)

13.) ¿Para qué sirve?

14.) ¿Cuál parte se usa?

15.) ¿Cómo se prepara?

16.) ¿Por qué la ___ es una de las 10 plantas medicinales más importantes para ustedes?

\section{Spiritual/Ritual Plants}

La mucura sirve para alejar a los malos espíritus. El tabaco sirve para aprender la ciencia oculta y para concentrarse para ver las enfermedades de una persona. ${ }^{323}$

17.) ¿Cuáles otras plantas sirven para malos espíritus, ver las enfermedades, o otros usos así?

For each plant listed, ask the following:

18.) ¿Y dónde se consigue?

(garden around the house, agricultural field (of which family), forest, someone else)

19.) ¿Para qué sirve?

20.) ¿Cuál parte se usa?

21.) ¿Cómo se prepara? 
22.) ¿Se usa en esta casa?

\section{Children Learn Medicinal Plants}

23.) ¿Sus hijos han aprendido de ustedes sobre las plantas medicinales- para que sirven y como se preparan?

24.) ¿Cúales plantas y sus usos han aprendido?

\section{Past Plants}

25.) ¿Hay plantas que antes usaban pero ya no?

26.) ¿Y por qué ya no se usa?

\section{Involvement in Community Governance, Community Organizations and Indigenous}

\section{Organizations}

27.) ¿Alguien en esta casa es o era presidente, vicepresident, agente municipal, tesorero, secretario, o algún otro cargo de la Comúnidad de Comandancia?

¿Me podría decir quiénes en esta casa pertenecen o tienen algún cargo como presidente, vicepresidente, secretario, tesorero, o vocales en las siguientes organizaciones:

28.) APAFA - la Asociación de Padres de Familia?

29.) La Directiva de Artesanias?

30.) Vaso de Leche?

31.) Promotor de Salud?

32.) ¿Alguien en esta casa ha tenido cargo o ha sido parte de la FEPYROA, la ORAI, o otra federación indígena?

\section{Employment}

33.) ¿Quiénes en esta casa han tenido otros trabajos aparte de la chacra?

34.) ¿Cuáles son los otros trabajos?

35.) ¿Quiénes han trabajado para una persona o una compañía maderera?

\section{Yagua Language}

36.) ¿Ustedes hablan idioma Yagua en casa con sus hijos?

If yes:

¿Todos los días, as veces, o de vez en cuando?

322 "Family" was defined by community members as once a couple lives together or once a woman has a child, although there were a few adults with no partner or children who were considered independent or a separate "family" for the purposes of this interview.

${ }^{323}$ In the attempt to elicit plants in whatever they would consider this category to be, these descriptions came from the text of the medicinal plant book that community members wrote. 


\section{Appendix 3: Structured Interview Entity-Relationship Model}

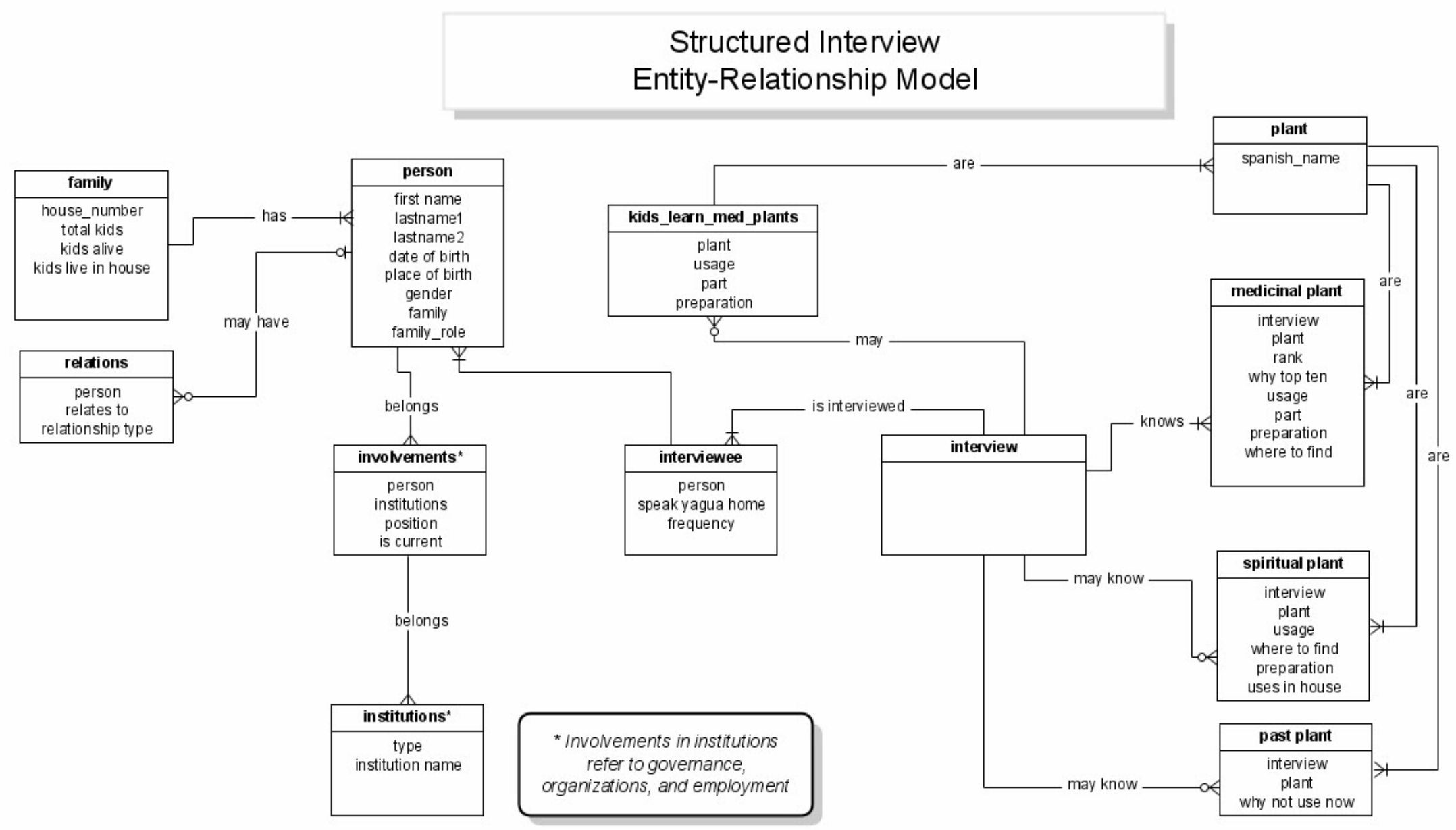




\section{Appendix 4: Community Plant List}

\begin{tabular}{|c|c|c|c|c|}
\hline$\#$ & Spanish & Scientific & Family & English \\
\hline 1 & Abuta & Abuta sp. & Menispermaceae & \\
\hline 2 & Abuta macho & Abuta solimosensis & Menispermaceae & \\
\hline 3 & Abuta sacha & $\begin{array}{l}\text { Anomospermum } \\
\text { chloranthum }\end{array}$ & Menispermaceae & \\
\hline 4 & $\begin{array}{l}\text { Achiote, } \\
\text { Achote }\end{array}$ & Bixa orellana & Bixaceae & Annatto \\
\hline 5 & $\begin{array}{l}\text { Achiotillo, } \\
\text { Achote } \\
\text { amarillo }\end{array}$ & Bixa sp. & Bixaceae & Annatto \\
\hline 6 & Achira & Canna sp. & Cannaceae & \\
\hline 7 & $\begin{array}{l}\text { Afasi caspi, } \\
\text { Afasi huayo }\end{array}$ & Bothriospora corymbosa & Rubiaceae & \\
\hline 8 & Aguacate, Palta & Persea americana & Lauraceae & Avocado \\
\hline 9 & Aguaje & Mauritia flexuosa & Arecaceae & \\
\hline 10 & $\begin{array}{l}\text { Ajengibre, } \\
\text { Jengibre }\end{array}$ & Zingiber officinale & Zingiberaceae & Ginger \\
\hline 11 & $\begin{array}{l}\text { Aji charapita, } \\
\text { Charapilla }\end{array}$ & Capsicum frutescens & Solanaceae & $\begin{array}{l}\text { Chili } \\
\text { pepper }\end{array}$ \\
\hline 12 & Aji dulce & Capsicum sp. & Solanaceae & $\begin{array}{l}\text { Chili } \\
\text { pepper }\end{array}$ \\
\hline 13 & Aji macusario & Capsicum sp. & Solanaceae & $\begin{array}{l}\text { Chili } \\
\text { pepper }\end{array}$ \\
\hline 14 & Aji mirasol & Capsicum sp. & Solanaceae & $\begin{array}{l}\text { Chili } \\
\text { pepper }\end{array}$ \\
\hline 15 & $\begin{array}{l}\text { Aji ojo de } \\
\text { mono }\end{array}$ & Capsicum sp. & Solanaceae & $\begin{array}{l}\text { Chili } \\
\text { pepper }\end{array}$ \\
\hline 16 & Aji picante & Capsicum sp. & Solanaceae & $\begin{array}{l}\text { Chili } \\
\text { pepper }\end{array}$ \\
\hline 17 & $\begin{array}{l}\text { Aji rudo de } \\
\text { pescado }\end{array}$ & Capsicum sp. & Solanaceae & $\begin{array}{l}\text { Chili } \\
\text { pepper }\end{array}$ \\
\hline 18 & Ajo & Allium sativum & Liliaceae & Garlic \\
\hline 19 & $\begin{array}{l}\text { Ajo sacha, } \\
\text { Sacha ajo }\end{array}$ & Mansoa alliaceae & Bignoniaceae & Wild garlic \\
\hline 20 & Alambre tamshi & Heteropsis $s p$. & Araceae & \\
\hline 21 & $\begin{array}{l}\text { Albaca, } \\
\text { Albahaca }\end{array}$ & Ocimum $s p$. & Lamiaceae & Basil \\
\hline 22 & Algodón & Gossypium sp. & Malvaceae & Cotton \\
\hline 23 & Algodón blanco & Gossypium sp. & Malvaceae & $\begin{array}{l}\text { White } \\
\text { cotton }\end{array}$ \\
\hline
\end{tabular}




\begin{tabular}{|c|c|c|c|c|}
\hline$\#$ & Spanish & Scientific & Family & English \\
\hline 24 & Almendro & Terminalia catappa & Combretaceae & $\begin{array}{l}\text { Indian } \\
\text { almond }\end{array}$ \\
\hline 25 & Altahin & & & \\
\hline 26 & Amasisa & Erythrina sp. & Fabaceae & \\
\hline 27 & Amor seco & Desmodium $s p$. & Fabaceae & Dry love \\
\hline 28 & Ana caspi & Apuleia leiocarpa & Fabaceae & \\
\hline 29 & $\begin{array}{l}\text { Anahuayo, } \\
\text { Anihuayo }\end{array}$ & Calyptranthus $s p$. & Myrtaceae & \\
\hline 30 & Añallo caspi & Cordia sp. & Boraginaceae & \\
\hline 31 & Andiroba & Carapa guianensis & Meliaceae & $\begin{array}{l}\text { Brazilian } \\
\text { mahogany }\end{array}$ \\
\hline 32 & Annonilla & $\begin{array}{l}\text { Rollinia sp.OR Guatteria } \\
\text { sp. }\end{array}$ & Annonaceae & \\
\hline 33 & Anona & Annona sp.OR Rollinia sp. & Annonaceae & Annona \\
\hline 34 & Añushi moena & Anaueria brasiliensis & Lauraceae & \\
\hline 35 & Apacharama & Licania $s p$. & Chrysobalanaceae & \\
\hline 36 & Aranilla & & & \\
\hline 37 & Arco sacha & Ludwigla nervosa & Onagraceae & \\
\hline 38 & Aripari & $\begin{array}{l}\text { Macrolobium } \\
\text { acaciaefolium }\end{array}$ & Fabaceae & \\
\hline 39 & Arroz & Oryza sativa & Poaceae & Rice \\
\hline 40 & Arroz aguja & Oryza sativa & Poaceae & Rice \\
\hline 41 & $\begin{array}{l}\text { Arroz } \\
\text { charapilla }\end{array}$ & Oryza sativa & Poaceae & Rice \\
\hline 42 & Arroz enano & Oryza sativa & Poaceae & Rice \\
\hline 43 & Arroz gigante & Oryza sativa & Poaceae & Rice \\
\hline 44 & Arroz gusanillo & Oryza sativa & Poaceae & Rice \\
\hline 45 & Arroz inti & Oryza sativa & Poaceae & Rice \\
\hline 46 & Arroz muyuuy & Oryza sativa & Poaceae & Rice \\
\hline 47 & $\begin{array}{l}\text { Arroz tres } \\
\text { mesinos }\end{array}$ & Oryza sativa & Poaceae & Rice \\
\hline 48 & Atadijo & Trema micrantha & Ulmaceae & Bay Cedar \\
\hline 49 & Ayahuasca & Banisteriopsis spp. & Malpigiaceae & \\
\hline 50 & Ayauma & Couroupita guianensis & Lecythidaceae & \\
\hline 51 & Azúcar huayo & Hymenaea sp. & Fabaceae & \\
\hline 52 & $\begin{array}{l}\text { Bacaba, } \\
\text { Cinamillo }\end{array}$ & Oenocarpus sp. & Arecaceae & \\
\hline 53 & Bacapaca & & & \\
\hline 54 & Bala huayo & Gnetum sp. & Gnetaceae & \\
\hline
\end{tabular}




\begin{tabular}{|c|c|c|c|c|}
\hline$\#$ & Spanish & Scientific & Family & English \\
\hline 55 & Balata huayo & $\begin{array}{l}\text { Ecclinusa sp. OR } \\
\text { Micropholis sp. }\end{array}$ & Sapotaceae & \\
\hline 56 & $\begin{array}{l}\text { Bambu, } \\
\text { Marona } \\
\text { amarillo }\end{array}$ & Guadua sp. & Poaceae & \\
\hline 57 & Barbasco & Clibadium $s p$. & Asteraceae & \\
\hline 58 & Barbasco sacha & $\begin{array}{l}\text { Deguelia utilis } O R \\
\text { Lonchocarpus } s p \text {. }\end{array}$ & Fabaceae & \\
\hline 59 & Begonia & Begonia sp. & Begoniaceae & \\
\hline 60 & $\begin{array}{l}\text { Bellaco caspi, } \\
\text { Socoba }\end{array}$ & Himatanthus sucuuba & Apocynaceae & \\
\hline 61 & Bijao & Calathea lutea & Marantaceae & \\
\hline 62 & $\begin{array}{l}\text { Bijao } \\
\text { chancaquero }\end{array}$ & Calathea insignis & Marantaceae & \\
\hline 63 & Binuayo & Coccoloba sp. & Polygonaceae & \\
\hline 64 & Boa caspi & Haploclathra sp. & Clusiaceae & \\
\hline 65 & Bolaina & Muntingia calabura & Elaeocarpaceae & \\
\hline 66 & Bolaina blanca & Guazuma crinita & Sterculiaceae & \\
\hline 67 & Bolsa mullaca & Physalis angulata & Solanaceae & \\
\hline 68 & Bolsa patiquina & & & \\
\hline 69 & Bombonaje & Carludovica palmata & Cyclanthaceae & $\begin{array}{l}\text { Panama hat } \\
\text { palm }\end{array}$ \\
\hline 70 & Brashico & & & \\
\hline 71 & Brea caspi & $\begin{array}{l}\text { Protium grandifolium } O R \\
\text { Tetragastris panamensis }\end{array}$ & Burseraceae & \\
\hline 72 & Buseta & Colocasla sp. & Acaceae & \\
\hline 73 & $\begin{array}{l}\text { Caballo } \\
\text { sanango }\end{array}$ & Faramea multiflora & Rubiaceae & \\
\hline 74 & Cacahuillo & Carpotroche longifolia & Flacourtiaceae & \\
\hline 75 & Cacao & Theobroma cacao & Sterculiaceae & Cocoa \\
\hline 76 & Cacao pelejo & & & \\
\hline 77 & Cacao verde & & & \\
\hline 78 & Café & Coffea arabica & Rubiaceae & Coffee \\
\hline 79 & Caguena & Ayapana pilluanenis & Asteraceae & \\
\hline 80 & $\begin{array}{l}\text { Cahuara } \\
\text { ishanga }\end{array}$ & Urera $s p$. & Urticaceae & \\
\hline 81 & Caimitillo & $\begin{array}{l}\text { Chrysophyllum sp. OR } \\
\text { Pouteria sp. }\end{array}$ & Sapotaceae & \\
\hline 82 & Caimito & Pouteria caimito & Sapotaceae & \\
\hline
\end{tabular}




\begin{tabular}{|c|c|c|c|c|}
\hline \# & Spanish & Scientific & Family & English \\
\hline 83 & Caimito tocino & & & \\
\hline 84 & Calabaza & Lagenaria siceraria & Cucurbitaceae & $\begin{array}{l}\text { Squash, } \\
\text { Gourd }\end{array}$ \\
\hline 85 & Calzón panga & Cyclanthus bipartitus & Cyclanthaceae & \\
\hline 86 & Camalonga & Thevetia peruvana & Apocynaceae & \\
\hline 87 & Camote & Ipomoea batatus & Convolvuaceae & $\begin{array}{l}\text { Sweet } \\
\text { potato }\end{array}$ \\
\hline 88 & $\begin{array}{l}\text { Caña amarilla, } \\
\text { Caña de azúcar, } \\
\text { Caña dulce }\end{array}$ & Saccharum $x$ officinarum & Poaceae & Sugar cane \\
\hline 89 & Caña brava & Gynerium sagittatum & Poaceae & Giant cane \\
\hline 90 & Caña negra & & & Black cane \\
\hline 91 & Cañagre & Costus sp. & Costaceae & \\
\hline 92 & Capinuri & Maquira coriacea & Moraceae & \\
\hline 93 & $\begin{array}{l}\text { Capinuri de } \\
\text { altura }\end{array}$ & $\begin{array}{l}\text { Clarisia biflora OR } \\
\text { Naucleopsis concinna }\end{array}$ & Moraceae & \\
\hline 94 & Capirona & Calycophyllum sp. & Rubiaceae & \\
\hline 95 & $\begin{array}{l}\text { Capirona del } \\
\text { altura }\end{array}$ & Capirona decorticans & Rubiaceae & \\
\hline 96 & $\begin{array}{l}\text { Capirona del } \\
\text { bajo }\end{array}$ & & & \\
\hline 97 & Carahuasca & $\begin{array}{l}\text { Anaxagorea brevipes OR } \\
\text { Guatteria sp. OR } \\
\text { Tetrameranthus } \\
\text { pachycarpus }\end{array}$ & Annonaceae & \\
\hline 98 & $\begin{array}{l}\text { Carahuasca } \\
\text { blanca }\end{array}$ & Guatteria sp.? & & \\
\hline 99 & $\begin{array}{l}\text { Carahuasca } \\
\text { negra }\end{array}$ & Guatteria sp.? & & \\
\hline 100 & Carambola & Averrhoa carambola & Oxalidaceae & Starfruit \\
\hline 101 & Caraná & Bursera graveolens & Burseraceae & \\
\hline 102 & Carricillo & $\begin{array}{l}\text { Arthrostylidium sp.OR } \\
\text { Olyra latifolia }\end{array}$ & Poaceae & \\
\hline 103 & Cashapona & Socratea exorrhiza & Arecaceae & \\
\hline 104 & Cashipana & Chamaedorea pinnatifrons & Arecaceae & \\
\hline 105 & Cashu & Anacardium occidentale & Anacardiaceae & Cashew \\
\hline 106 & $\begin{array}{l}\text { Catahua } \\
\text { amarilla }\end{array}$ & Hura crepitans & Euphorbiaceae & \\
\hline 107 & Catahua blanca & Hura crepitans & Euphorbiaceae & \\
\hline 108 & Catahua negra & Hura crepitans? & Euphorbiaceae & \\
\hline
\end{tabular}




\begin{tabular}{|c|c|c|c|c|}
\hline$\#$ & Spanish & Scientific & Family & English \\
\hline 109 & Caucho & Castilla ulei & Moraceae & \\
\hline 110 & Cayhua & & & \\
\hline 111 & Cebolla & Allium sp. & Liliaceae & Onion \\
\hline 112 & Ceda & & & \\
\hline 113 & Cedro blanco & Cedrela sp. & Meliaceae & White cedar \\
\hline 114 & Cedro masha & Cedreling a cataneiformis & Fabaceae & \\
\hline 115 & $\begin{array}{l}\text { Cedro, Cedro } \\
\text { Rojo }\end{array}$ & Cedrela odorata & Meliaceae & $\begin{array}{l}\text { Tropical } \\
\text { cedar, } \\
\text { Spanish } \\
\text { Cedar }\end{array}$ \\
\hline 116 & Cetico & Cecropia sp. & Cecropiaceae & \\
\hline 117 & Cetico blanco & Cecropia sp. & Cecropiaceae & \\
\hline 118 & Cetico colorado & Cecropria sp. & Cecropiaceae & \\
\hline 119 & Chambira & Astrocaryum chambira & Arecaceae & \\
\hline 120 & Chanca piedra & Phyllanthus sp. & Euphorbiaceae & $\begin{array}{l}\text { Stone } \\
\text { breaker }\end{array}$ \\
\hline 121 & Charichuelo & Rheedia gardneriana & Clusiaceae & \\
\hline 122 & $\begin{array}{l}\text { Charichuelo } \\
\text { chico }\end{array}$ & Garcinia madruno & Clusiaceae & \\
\hline 123 & $\begin{array}{l}\text { Charichuelo } \\
\text { grande }\end{array}$ & Garcinia macrophylla & Clusiaceae & \\
\hline 124 & Chiclayo & Vigna unguiculata & Fabaceae & Cowpea \\
\hline 125 & Chicle huayo & Lacmellea sp. & Apocynaceae & Chicle \\
\hline 126 & Chimicua & $\begin{array}{l}\text { Brosimum parinarioides } \\
\text { OR Perebea sp. OR } \\
\text { Pseudolmedia sp. }\end{array}$ & Moraceae & \\
\hline 127 & Chiric sanango & Brunfelsia grandiflora & Solanaceae & \\
\hline 128 & Chirimoya & Annona sp. & Annonaceae & Soursop \\
\hline 129 & Chonta quiro & Diplotropis sp. & Fabaceae & \\
\hline 130 & $\begin{array}{l}\text { Chonta, } \\
\text { Huasahí }\end{array}$ & Euterpe precatoria & Arecaceae & Heart palm \\
\hline 131 & Chontilla & Aiphanes weberbaueri & Arecaceae & \\
\hline 132 & Chopé & Gustavia sp. & Lecythidaceae & \\
\hline 133 & $\begin{array}{l}\text { Chuchuasha, } \\
\text { Chuchuhuasi }\end{array}$ & Maytenus sp. & Celastraceae & \\
\hline 134 & $\begin{array}{l}\text { Cilantro, } \\
\text { Culantro }\end{array}$ & Eryngium foetidum & Apiaceae & Coriander \\
\hline 135 & $\begin{array}{l}\text { Ciruela, } \\
\text { Ciruelo }\end{array}$ & Bunchosia armeniaca & Malpighiaceae & Cherry \\
\hline
\end{tabular}




\begin{tabular}{|c|c|c|c|c|}
\hline \# & Spanish & Scientific & Family & English \\
\hline 136 & Coco & Cocos nucifera & Arecaceae & Coconut \\
\hline 137 & Cocona & Solanum sessiliflorum & Solanaceae & \\
\hline 138 & Coconilla & Solanum sp. & Solanaceae & \\
\hline 139 & Conta & Attalea tesmannii & Arecaceae & \\
\hline 140 & Copaiba & Copaifera sp. & Fabaceae & \\
\hline 141 & Copal & Protium sp. & Burseraceae & Copal \\
\hline 142 & Copalillo & & & \\
\hline 143 & Cortadera & Scleria sp. & Cyperaceae & Cutgrass \\
\hline 144 & Coto guineo & & & \\
\hline 145 & Coto shimbillo & Inga sp. & Fabaceae & \\
\hline 146 & Cresta de gallo & $\begin{array}{l}\text { Celosia argentea var. } \\
\text { Cristata }\end{array}$ & Amaranthaceae & $\begin{array}{l}\text { Cock's } \\
\text { comb }\end{array}$ \\
\hline 147 & Cuchillo batna & & & \\
\hline 148 & Cumala & Virola $s p$. & Myristicaceae & \\
\hline 149 & Cumala blanco & $\begin{array}{l}\text { Virola sp. OR } \\
\text { Osteophloeum sp. }\end{array}$ & Myristicaceae & \\
\hline 150 & $\begin{array}{l}\text { Cumala } \\
\text { colorada }\end{array}$ & Iryanthera sp. & Myristicaceae & \\
\hline 151 & Cumala negro & Virola sp. & Myristicaceae & \\
\hline 152 & Cumalilla & & Myristicaceae & \\
\hline 153 & Cumaseba & Swartzia polyphylla & Fabaceae & \\
\hline 154 & Cunchi moena & Endlicheria krukovii & Lauraceae & \\
\hline 155 & Daledale & Calathea allouia & Marantaceae & \\
\hline 156 & Doctor caspi & & & \\
\hline 157 & $\begin{array}{l}\text { Escalera de } \\
\text { mono }\end{array}$ & Bauhinia guianensis & Fabaceae & $\begin{array}{l}\text { Monkey } \\
\text { ladder }\end{array}$ \\
\hline 158 & Espintana & Xylopia $s p$. & Annonaceae & \\
\hline 159 & $\begin{array}{l}\text { Filipina, } \\
\text { Filipino }\end{array}$ & & & \\
\hline 160 & $\begin{array}{l}\text { Flor de } \\
\text { cementario }\end{array}$ & Dracaena fragrans & Liliaceae & $\begin{array}{l}\text { Cemetery } \\
\text { flower }\end{array}$ \\
\hline 161 & Flor de muerto & Hedychium coronarium & Zingiberaceae & $\begin{array}{l}\text { Dead } \\
\text { person } \\
\text { flower }\end{array}$ \\
\hline 162 & $\begin{array}{l}\text { Gallinazo } \\
\text { mullaca }\end{array}$ & & & \\
\hline 163 & $\begin{array}{l}\text { Gallinazo } \\
\text { panga }\end{array}$ & Cyphomandra hartwegii & Solanaceae & Tree tomato \\
\hline 164 & Garbanzo & Cicer urletinum & Fabaceae & Chick pea \\
\hline
\end{tabular}




\begin{tabular}{|c|c|c|c|c|}
\hline \# & Spanish & Scientific & Family & English \\
\hline 165 & Grama & & Poaceae & Grass \\
\hline 166 & Grama nudillo & Panicum laxum & Poaceae & \\
\hline 167 & Gramalote & Paspalum repens & Poaceae & \\
\hline 168 & $\begin{array}{l}\text { Granadilla, } \\
\text { Tumbo }\end{array}$ & Passiflora sp. & Passifloraceae & \\
\hline 169 & Guaba & Inga edulis & Fabaceae & \\
\hline 170 & Guabilla & Inga $s p$. & Fabaceae & \\
\hline 171 & Guanábana & Annona sp. & Annonaceae & Soursop \\
\hline 172 & $\begin{array}{l}\text { Guanábana } \\
\text { sacha }\end{array}$ & Annona spp. & Annonaceae & \\
\hline 173 & Guayaba & Psidium guajava & Myrtaceae & Guava \\
\hline 174 & $\begin{array}{l}\text { Guayaba } \\
\text { Brasilera }\end{array}$ & Eugenia stipitata & Myrtaceae & $\begin{array}{l}\text { Brazilian } \\
\text { Guava }\end{array}$ \\
\hline 175 & Guayaba rojo & & & $\begin{array}{l}\text { Colored } \\
\text { Guava }\end{array}$ \\
\hline 176 & Guayabilla & Myrcia sp. & Myrtaceae & \\
\hline 177 & Guisador & Curcuma longa & Zingiberaceae & Turmeric \\
\hline 178 & Hierba santa & Cestrum sp. & Solanaceae & \\
\hline 179 & Hoja amarga & & & \\
\hline 180 & Huaca & Clibadium sp. & Asteraceae & \\
\hline 181 & $\begin{array}{l}\text { Huacamayo } \\
\text { piña, Piña } \\
\text { negra }\end{array}$ & Ananas comosus & Bromeliaceae & Pineapple \\
\hline 182 & Huacapurana & Campsiandra sp. & Fabaceae & \\
\hline 183 & $\begin{array}{l}\text { Huacrapona, } \\
\text { Pona }\end{array}$ & Iriartea deltoidea & Arecaceae & Stilt palm \\
\hline 184 & Huamanzamana & Jacaranda copaia & Bignoniaceae & \\
\hline 185 & Huancai papa & & & \\
\hline 186 & Huascatopa & Coussapoua sp. & Cecropiaceae & \\
\hline 187 & Huayra caspi & $\begin{array}{l}\text { Brosimum guianense } \\
\text { (Moraceae) OR } \\
\text { Cedrelinga cataneiformis } \\
\text { (Fabaceae) }\end{array}$ & & \\
\hline 188 & Huayruro & Ormosia sp. & Fabaceae & \\
\hline 189 & $\begin{array}{l}\text { Huayruro } \\
\text { colorado }\end{array}$ & Ormosia coccinea & Fabaceae & \\
\hline 190 & Huevo de gato & & & \\
\hline 191 & Huicungo & Astrocaryum murumuru & Arecaceae & \\
\hline 192 & Huimba & Ceiba samauma & Bombacacae & \\
\hline
\end{tabular}




\begin{tabular}{|c|c|c|c|c|}
\hline \# & Spanish & Scientific & Family & English \\
\hline 193 & Huingo & Crescentia cujete & Bignoniaceae & \\
\hline 194 & Huiririma & Astrocaryum jauari & Arecaceae & \\
\hline 195 & Huitillo & Alibertia edulis & Rubiaceae & \\
\hline 196 & Huitina & Xanthosoma sp. & Araceae & \\
\hline 197 & Huito & Genipa americana & Rubaiceae & \\
\hline 198 & Inayuga & Attalea sp. & Arecaceae & \\
\hline 199 & $\begin{array}{l}\text { Insira, Insira } \\
\text { amarilla }\end{array}$ & Maclura tinctoria & Moraceae & \\
\hline 200 & Iporuro & Alchornea castaneifolia & Euphorbiaceae & \\
\hline 201 & Irapay & Lepidocaryum tessmannii & Arecaceae & $\begin{array}{l}\text { Thatch } \\
\text { palm }\end{array}$ \\
\hline 202 & Ishanga & Urera sp. & Urticaceae & \\
\hline 203 & Ishanga blanca & Laportea aestuans & Urticaceae & White nettle \\
\hline 204 & $\begin{array}{l}\text { Ishanga } \\
\text { colorada }\end{array}$ & & & \\
\hline 205 & Isleñia & & & \\
\hline 206 & Isula huayo & Siparuna guianensis & Monimiaceae & \\
\hline 207 & Isula tamshi & & & \\
\hline 208 & $\begin{array}{l}\text { Jarabe huayo, } \\
\text { Loro micuna }\end{array}$ & Macoubea guianensis & Apocynaceae & \\
\hline 209 & Jergón quiro & $\begin{array}{l}\text { Anthurium fosteri } O R \\
\text { Anthurium loretense }\end{array}$ & Araceae & \\
\hline 210 & Jergón sacha & Dracontium loretense & Araceae & Wild Snake \\
\hline 211 & Lagarto caspi & Calophyllum brasiliense & Clusiaceae & \\
\hline 212 & Lanas tamishi & & & \\
\hline 213 & Lancetilla & Peperomia rubea & Piperaceae & \\
\hline 214 & $\begin{array}{l}\text { Leche caspi, } \\
\text { Leche huayo }\end{array}$ & Couma macrocarpa & Apocynaceae & Milk tree \\
\hline 215 & $\begin{array}{l}\text { Lengua de } \\
\text { perro }\end{array}$ & Caladium sp. & Araceae & $\begin{array}{l}\text { Dog's } \\
\text { toungue }\end{array}$ \\
\hline 216 & $\begin{array}{l}\text { Lima de } \\
\text { yashingo }\end{array}$ & & & \\
\hline 217 & Limón & Citrus aurantiifolia & Rutaceae & Lime \\
\hline 218 & Limón ácido & Citrus limon & Rutaceae & Lemon \\
\hline 219 & Limón casha & & Rutaceae & \\
\hline 220 & Limón cidra & Citrus medica & Rutaceae & \\
\hline
\end{tabular}




\begin{tabular}{|c|c|c|c|c|}
\hline$\#$ & Spanish & Scientific & Family & English \\
\hline 221 & Limón dulce & Citrus sp. & Rutaceae & $\begin{array}{l}\text { Sweet } \\
\text { lemon }\end{array}$ \\
\hline 222 & $\begin{array}{l}\text { Llanchama } \\
\text { caspi }\end{array}$ & & & \\
\hline 223 & Llanllama & & & \\
\hline 224 & Llantén & Plantago major & Plantaginaceae & Plantain \\
\hline 225 & Llausa cetico & & & \\
\hline 226 & Lobo sanago & $\begin{array}{l}\text { Stenosolen eggersii } O R \\
\text { Tabernaemontana } s p .\end{array}$ & Apocynaceae & \\
\hline 227 & Lupuna & Ceiba pentandra & Bombacaceae & \\
\hline 228 & Macambo & Theobroma bicolor & Sterculiaceae & \\
\hline 229 & $\begin{array}{l}\text { Machimango } \\
\text { blanco }\end{array}$ & Eschweilera spp. & Lecythidaceae & \\
\hline 230 & $\begin{array}{l}\text { Machimango } \\
\text { colorado }\end{array}$ & $\begin{array}{l}\text { Lecythis spp.OR } \\
\text { Eschweilera spp. }\end{array}$ & Lecythidaceae & \\
\hline 231 & $\begin{array}{l}\text { Machimango } \\
\text { negro }\end{array}$ & Eschweilera spp. & Lecythidaceae & \\
\hline 232 & Maíz duro & Zea mays & Poaceae & Corn \\
\hline 233 & Maíz enano & Zea sp. & Poaceae & Corn \\
\hline 234 & Maíz pocopoco & Zea sp. & Poaceae & Corn \\
\hline 235 & Maíz suave & Zea sp. & Poaceae & Corn \\
\hline 236 & Malbilla & & & \\
\hline 237 & Malva & Malachra sp. & Malvaceae & \\
\hline 238 & Mandarina & Citrus sp. & Rutaceae & Tangerine \\
\hline 239 & Mandi & & & \\
\hline 240 & Mangua dulce & Mangifera indica & Anacardiaceae & Mango \\
\hline 241 & Maní & Arachis hypogaea & Fabaceae & Peanut \\
\hline 242 & Manzana & Musasp. & Musaceae & $\begin{array}{l}\text { Little } \\
\text { banana }\end{array}$ \\
\hline 243 & $\begin{array}{l}\text { Maquizapa } \\
\text { ñaccha }\end{array}$ & $\begin{array}{l}\text { Apeiba aspera ssp. } \\
\text { membranacea }\end{array}$ & Tiliaceae & \\
\hline 244 & $\begin{array}{l}\text { Maquizapa } \\
\text { ñaccha blanco }\end{array}$ & Apeiba tibourbou & Tiliaceae & \\
\hline 245 & $\begin{array}{l}\text { Maramara } \\
\text { ishanga }\end{array}$ & Urera $s p$. & Urticaceae & \\
\hline 246 & Maria buena & $\begin{array}{l}\text { Clitoria arborea OR } \\
\text { Pterocarpus sp. }\end{array}$ & Fabaceae & Good Maria \\
\hline 247 & Marona & Guadua weberbaueri & Poaceae & \\
\hline
\end{tabular}




\begin{tabular}{|c|c|c|c|c|}
\hline$\#$ & Spanish & Scientific & Family & English \\
\hline 248 & Marupá & Simarouba amara & Simaroubaceae & \\
\hline 249 & Masaranduva & Manilkara sp. & Sapotaceae & \\
\hline 250 & Matacaracha & Picramnia sp. & Sapindaceae & Itchkill \\
\hline 251 & $\begin{array}{l}\text { Matacaracha } \\
\text { del bajo }\end{array}$ & Picramnia sp. & Sapindaceae & $\begin{array}{l}\text { Lower } \\
\text { itchkill }\end{array}$ \\
\hline 252 & Matapalo & Clusia spp. & Clusiaceae & Treekiller \\
\hline 253 & Matapasto & $\begin{array}{l}\text { Eclypta sp. OR } \\
\text { Pseudelephantopus sp. }\end{array}$ & Asteraceae & Grasskiller \\
\hline 254 & Melon & Cucumis melo & Cucurbitaceae & Melon \\
\hline 255 & Menta & Menthasp. & Lamiaceae & Mint \\
\hline 256 & Meto huayo & Caryodendron orinocense & Euphorbiaceae & \\
\hline 257 & Mishimuillo & Abelmoschus moxchatus & Malvaceae & \\
\hline 258 & Mishqui panga & Renealmia alpina & Zingiberaceae & \\
\hline 259 & Moena & $\begin{array}{l}\text { Nectandra spp. OR Ocotea } \\
\text { spp. }\end{array}$ & Lauraceae & \\
\hline 260 & Moena amarilla & $\begin{array}{l}\text { Nectandra globosa OR } \\
\text { Ocotea petalanthera }\end{array}$ & Lauraceae & \\
\hline 261 & Moena negra & Ocotea spp. & Lauraceae & \\
\hline 262 & Mojarra caspi & $\begin{array}{l}\text { Alchornea triplinervia OR } \\
\text { Hieronima sp. }\end{array}$ & Euphorbiaceae & \\
\hline 263 & Motelo sanango & Abuta grandifolia & Menispermaceae & \\
\hline 264 & Mucura & Petiveria alliacea & Phytolaccaceae & \\
\hline 265 & Mullaca & Physalis angulata & Solanaceae & \\
\hline 266 & $\begin{array}{l}\text { Mullaca } \\
\text { morada }\end{array}$ & Clidemia hirta & Melastomataceae & \\
\hline 267 & Naranja & Citrus sinensis & Rutaceae & Orange \\
\hline 268 & $\begin{array}{l}\text { Naranjo } \\
\text { podrido }\end{array}$ & Parahancornia peruviana & Apocynaceae & $\begin{array}{l}\text { Rotten } \\
\text { orange }\end{array}$ \\
\hline 269 & Ñejilla & Bactris spp. & Arecaceae & \\
\hline 270 & Nina caspi & $\begin{array}{l}\text { Leonia glycicarpa } \\
\text { (Violaceae) OR Licania } \\
\text { britteniana } \\
\text { (Chrysobalanaceae) }\end{array}$ & & \\
\hline 271 & Nispero & Loreya umbellata & Melastomataceae & \\
\hline 272 & Ñucñu pichana & Scoparia dulcis & Scrophulariaceae & \\
\hline
\end{tabular}




\begin{tabular}{|c|c|c|c|c|}
\hline \# & Spanish & Scientific & Family & English \\
\hline 273 & Nudillo & $\begin{array}{l}\text { Brachiaria mutica OR } \\
\text { Ichnanthus pallens OR } \\
\text { Leptochloa spp. OR } \\
\text { Axonopus compressus }\end{array}$ & Poaceae & \\
\hline 274 & Ocuera negra & Pollalesta discolor & Asteraceae & \\
\hline 275 & Ocuero & Vernonia baccharoides & Asteraceae & \\
\hline 276 & Ojé & Ficus insipida & Moraceae & \\
\hline 277 & $\begin{array}{l}\text { Ojé de hoja } \\
\text { menuda }\end{array}$ & Ficus yoponensis & Moraceae & \\
\hline 278 & Ojo de vaca & Mucuna sp. & Fabaceae & Cow's eye \\
\hline 279 & Orégano & Origanum vulgare & Lamiaceae & Oregano \\
\hline 280 & Orquídia & & Orchidaceae & Orchid \\
\hline 281 & Paichecara & Kalanchoe pinnata & Crassulaceae & \\
\hline 282 & Paico & $\begin{array}{l}\text { Chenopodium } \\
\text { ambrosioides }\end{array}$ & Amaranthaceae & \\
\hline 283 & Palillo & Campomanesia lineatifolia & Myrtaceae & \\
\hline 284 & Palisangre & Brosimum rubescens & Moraceae & \\
\hline 285 & Palma aceitera & Elaeis guineensis & Arecaceae & $\begin{array}{l}\text { African } \\
\text { oilpalm }\end{array}$ \\
\hline 286 & Palmicha & Geonoma spp. & Arecaceae & \\
\hline 287 & $\begin{array}{l}\text { Palmicha } \\
\text { macho }\end{array}$ & Geonoma spp. & Arecaceae & \\
\hline 288 & Palo de sangre & $\begin{array}{l}\text { Hieronima alchornoides } \\
\text { OR Dialium guianensis }\end{array}$ & Euphorbiaceae & \\
\hline 289 & Palometa caspi & & & \\
\hline 290 & Palometa huayo & Alchornea discolor & Euphorbiaceae & \\
\hline 291 & Pampa orégano & Lippia alba & Verbenaceae & \\
\hline 292 & $\begin{array}{l}\text { Pampa } \\
\text { remocaspi }\end{array}$ & Chimarrhis glabriflora & Rubiaceae & \\
\hline 293 & $\begin{array}{l}\text { Pan del arbol, } \\
\text { Pandisho }\end{array}$ & Artocarpus altilis & Moraceae & Breadfruit \\
\hline 294 & Papailla & Momordica charantia & Cucurbitaceae & \\
\hline 295 & Papaya & Carica papaya & Caricaceae & Papaya \\
\hline 296 & Papaya caspi & Jacaratia digitada & Caricaceae & Tree papaya \\
\hline 297 & Parinari & $\begin{array}{l}\text { Couepia spp. OR Licania } \\
\text { spp. }\end{array}$ & Chrysobalanaceae & \\
\hline 298 & $\begin{array}{l}\text { Parinari } \\
\text { colorado }\end{array}$ & Licania unguiculata & Chrysobalanaceae & \\
\hline 299 & Parinarillo & Humiria balsamifera & Humiriaceae & \\
\hline
\end{tabular}




\begin{tabular}{|c|c|c|c|c|}
\hline \# & Spanish & Scientific & Family & English \\
\hline 300 & Pashaco & $\begin{array}{l}\text { Parkia spp. OR Piptadenia } \\
\text { suaveolens OR } \\
\text { Schizolobium spp. }\end{array}$ & Fabaceae & \\
\hline 301 & Pashaquilla & $\begin{array}{l}\text { Leucaena leucocephala } \\
\text { OR Macrolobium } \\
\text { acaciaefolium }\end{array}$ & Fabaceae & \\
\hline 302 & $\begin{array}{l}\text { Pashaquilla } \\
\text { colorada }\end{array}$ & Jacqueshuberia loretensis & Fabaceae & \\
\hline 303 & Patiquina & Dieffenbachia spp. & Araceae & \\
\hline 304 & Patiquina negro & & & \\
\hline 305 & Paujil chaqui & $\begin{array}{l}\text { Davilla kunthii OR } \\
\text { Tetracera volubilis }\end{array}$ & Dilleniaceae & Watervine \\
\hline 306 & Pega-pega & $\begin{array}{l}\text { Boerhavia caribaea } \\
\text { (Nyctaginaceae) OR } \\
\text { Desmodium axillare } \\
\text { (Fabaceae) OR Pavonia } \\
\text { spp. (Malvaceae) OR } \\
\text { Triumfetta semitriloba } \\
\text { (Tiliaceae) }\end{array}$ & & \\
\hline 307 & Pepino & Cucumis sativus & Cucurbitaceae & Cucumber \\
\hline 308 & $\begin{array}{l}\text { Pichirina hoja } \\
\text { ancha }\end{array}$ & Vismia $s p$. & Hypericaceae & \\
\hline 309 & $\begin{array}{l}\text { Pichirina hoja } \\
\text { mediana }\end{array}$ & Vismia sp. & Hypericaceae & \\
\hline 310 & $\begin{array}{l}\text { Pichirina hoja } \\
\text { menuda }\end{array}$ & Vismia minutiflora & Hypericaceae & \\
\hline 311 & Picho huayo & Siparuna guianensis & Monimiaceae & \\
\hline 312 & Pijuayo & Bactris gasipaes & Arecaceae & Peach palm \\
\hline 313 & Piñon & Jatropha curcas & Euphorbiaceae & Physic nut \\
\hline 314 & $\begin{array}{l}\text { Piñon colorado, } \\
\text { Piñon rojo }\end{array}$ & Jatropha sp. & Euphorbiaceae & \\
\hline 315 & Piñon negro & Jatropha gossypifolia & Euphorbiaceae & $\begin{array}{l}\text { Black } \\
\text { physic nut }\end{array}$ \\
\hline 316 & Pinsha caspi & Aspidosperma nitidum & Apocynaceae & \\
\hline 317 & Pintachanbira & & & \\
\hline 318 & Piripiri & Cyperus spp. & Cyperaceae & \\
\hline 319 & $\begin{array}{l}\text { Piripiri de } \\
\text { demanda }\end{array}$ & Cyperus sp. & Cyperaceae & \\
\hline 320 & $\begin{array}{l}\text { Piripiri de } \\
\text { víbora }\end{array}$ & Cyperus articulatus & Cyperaceae & \\
\hline
\end{tabular}




\begin{tabular}{|c|c|c|c|c|}
\hline \# & Spanish & Scientific & Family & English \\
\hline 321 & Piripiri rojo & Cyperus sp. & Cyperaceae & \\
\hline 322 & $\begin{array}{l}\text { Pishco isma, } \\
\text { Suelda con } \\
\text { suelda }\end{array}$ & $\begin{array}{l}\text { Oryctanthus spp. OR } \\
\text { Phoradendron spp. OR } \\
\text { Phthirusa spp. }\end{array}$ & Loranthaceae & \\
\hline 323 & Plátano bellaco & Musa sp. & Musaceae & Plantain \\
\hline 324 & Plátano blanco & Musa sp. & Musaceae & Plantain \\
\hline 325 & $\begin{array}{l}\text { Plátano } \\
\text { colorado }\end{array}$ & Musasp. & Musaceae & Plantain \\
\hline 326 & Plátano negro & Musa sp. & Musaceae & Plantain \\
\hline 327 & Plátano sarnoso & Musa sp. & Musaceae & Plantain \\
\hline 328 & $\begin{array}{l}\text { Plátano } \\
\text { tosquino }\end{array}$ & Musa sp. & Musaceae & Plantain \\
\hline 329 & $\begin{array}{l}\text { Plátano, } \\
\text { Guineo }\end{array}$ & Musa $\times$ paradisiaca & Musaceae & Plantain \\
\hline 330 & Pomarrosa & Syzygium jambos & Myrtaceae & Rose apple \\
\hline 331 & Ponilla & Iriartella stenocarpa & Arecaceae & \\
\hline 332 & Porotillo & Swartzia simplex & Fabaceae & \\
\hline 333 & Prata & & & \\
\hline 334 & Puca lupuna & Cavanillesia umbellata & Bombacaceae & \\
\hline 335 & Puca quiro & Simira spp. & Rubiaceae & \\
\hline 336 & Pucacuro & & & \\
\hline 337 & Puma caspi & Roucheria punctata & Linaceae & \\
\hline 338 & Punga & Pseudobombax munguba & Bombacaceae & \\
\hline 339 & Punga de altura & Pachira insignis & Bombacaceae & \\
\hline 340 & Purma cetico & Cecropia sciadophylla & Cecropiaceae & \\
\hline 341 & $\begin{array}{l}\text { Purma } \\
\text { shimbillo }\end{array}$ & & & \\
\hline 342 & Putu-putu & Eichhornia spp. & Pontederiaceae & $\begin{array}{l}\text { Water } \\
\text { hyacinth }\end{array}$ \\
\hline 343 & Quillo sisa & $\begin{array}{l}\text { Erisma spp. OR Qualea } \\
\text { paraensis OR Ruitzerania } \\
\text { trichanthera OR Vochysia } \\
\text { spp. }\end{array}$ & Vochysiaceae & \\
\hline 344 & Quinilla & $\begin{array}{l}\text { Chrysophyllum } \\
\text { nanaosense OR Manilkara } \\
\text { bidentata OR Micropholis } \\
\text { spp. }\end{array}$ & Sapotaceae & \\
\hline 345 & Quinilla blanca & Pouteria simulans & Sapotaceae & \\
\hline
\end{tabular}




\begin{tabular}{|c|c|c|c|c|}
\hline \# & Spanish & Scientific & Family & English \\
\hline 346 & $\begin{array}{l}\text { Quinilla } \\
\text { colorada }\end{array}$ & Chrysophyllum prieurii & Sapotaceae & \\
\hline 347 & Quinilla negra & $\begin{array}{l}\text { Micropholis egensis OR } \\
\text { Pouteria neglecta }\end{array}$ & Sapotaceae & \\
\hline 348 & Raya caspi & Banara guianensis & Flacourtiaceae & \\
\hline 349 & Remo caspi & Aspidosperma spp. & Apocynaceae & \\
\hline 350 & Renaco & Ficus spp. & Moraceae & \\
\hline 351 & Renaquilla & Clusia rosea & Clusiaceae & Star fruit \\
\hline 352 & Requia & Guarea spp. & Meliaceae & \\
\hline 353 & Requia blanca & & & \\
\hline 354 & Requia roja & & & \\
\hline 355 & Retama & Cassia spp. & Fabaceae & \\
\hline 356 & Retama negra & & & \\
\hline 357 & Rifari & Miconia spp. & Melastomataceae & \\
\hline 358 & Riñon papa & & & $\begin{array}{l}\text { Kidney } \\
\text { potato }\end{array}$ \\
\hline 359 & Rosario & & & Rosary \\
\hline 360 & Rosasisa & Tagetes erecta & Asteraceae & \\
\hline 361 & Ruda & Ruta chalepensis & Rutaceae & Rue \\
\hline 362 & Rumo caspi & Byrsonima sp. & Malpighiaceae & \\
\hline 363 & Sabalo huayo & Coccolobasp. & Polygonaceae & \\
\hline 364 & Sábila & Aloe vera & Liliaceae & Aloe vera \\
\hline 365 & Sacha achote & Bixa orellana & Bixaceae & Wild annato \\
\hline 366 & Sacha caimito & Chrysophyllum ulei & Sapotaceae & wild \\
\hline 367 & $\begin{array}{l}\text { Sacha cashu, } \\
\text { Sacha casho }\end{array}$ & $\begin{array}{l}\text { Anacardium giganteum } \\
\text { (Anacardiaceae) OR } \\
\text { Vochysia lomatophylla } \\
\text { (Vochysiaceae) }\end{array}$ & & $\begin{array}{l}\text { Wild } \\
\text { cashew }\end{array}$ \\
\hline 368 & Sacha culantro & Eryngium foetidum & Apiaceae & $\begin{array}{l}\text { Wild } \\
\text { coriander }\end{array}$ \\
\hline 369 & Sacha guayaba & $\begin{array}{l}\text { Eugenia patrisi } \\
\text { (Myrtaceae) OR } \\
\text { Lacunaria sp. } \\
\text { (Quiinaceae) }\end{array}$ & & Wild guava \\
\hline 370 & Sacha mangua & Grias spp. & Lecythidaceae & wild \\
\hline 371 & Sacha papa & Dioscorea trifida & Dioscoreaceae & Wild potato \\
\hline 372 & Sacha papaya & Jacaratia $s p$. & Caricaceae & $\begin{array}{l}\text { Wild } \\
\text { papaya }\end{array}$ \\
\hline
\end{tabular}




\begin{tabular}{|c|c|c|c|c|}
\hline \# & Spanish & Scientific & Family & English \\
\hline 373 & Sacha piña & Aechmea spp. & Bromeliaceae & $\begin{array}{l}\text { Wild } \\
\text { pineapple }\end{array}$ \\
\hline 374 & Sacha uvilla & Pourouma cecropiafolia & Moraceae & Wild grape \\
\hline 375 & Sanango & $\begin{array}{l}\text { Bonafousia spp. } \\
\text { (Apocynaceae) OR } \\
\text { Faramea anisocalyx } \\
\text { (Rubiaceae) OR Rauwolfia } \\
\text { spp. (Apocynaceae) OR } \\
\text { Tabernaemontana spp. } \\
\text { (Apocynaceae) }\end{array}$ & & \\
\hline 376 & Sandia & Citrullus lanatus & Cucurbitaceae & Watermelon \\
\hline 377 & $\begin{array}{l}\text { Sangre de } \\
\text { grado }\end{array}$ & Croton spp. & Euphorbiaceae & \\
\hline 378 & Santa Maria & Piper peltatum & Piperaceae & Saint Maria \\
\hline 379 & Santo & & & Saint \\
\hline 380 & Sapo huasca & $\begin{array}{l}\text { Odontadenia macrantha } \\
\text { (Apocynaceae) OR } \\
\text { Paullinia pinnata } \\
\text { (Sapindaceae) }\end{array}$ & & Toad vine \\
\hline 381 & Sapo huayo & & & \\
\hline 382 & Sapote & Quararibea cordata & Bombacaceae & \\
\hline 383 & $\begin{array}{l}\text { Sapotillo del } \\
\text { bajo }\end{array}$ & & & \\
\hline 384 & Sapucho & & & \\
\hline 385 & Sapucho blanco & & & \\
\hline 386 & Sarsaparilla & & & \\
\hline 387 & Sauco & Salix martiana & Salicaceae & \\
\hline 388 & $\begin{array}{l}\text { Shapaja, } \\
\text { Shebón }\end{array}$ & Attalea sp. & Arecaceae & \\
\hline 389 & Sharamasho & Ocimum campechianum & Lamiaceae & \\
\hline 390 & Shimbillo & Inga $s p$. & Fabaceae & \\
\hline 391 & $\begin{array}{l}\text { Shimbillo de } \\
\text { vugeo }\end{array}$ & Inga $s p$. & Fabaceae & \\
\hline 392 & $\begin{array}{l}\text { Shimbillo } \\
\text { rufinde }\end{array}$ & Inga sp. & Fabaceae & \\
\hline 393 & $\begin{array}{l}\text { Shimbillo } \\
\text { rugino }\end{array}$ & Inga $s p$. & Fabaceae & \\
\hline 394 & Shiringa & Hevea spp. & Euphorbiaceae & Rubber \\
\hline 395 & Shiringuilla & Mabea nitida & Euphorbiaceae & \\
\hline 396 & Situlli & Heliconia spp. & Heliconiaceae & \\
\hline
\end{tabular}




\begin{tabular}{|c|c|c|c|c|}
\hline \# & Spanish & Scientific & Family & English \\
\hline 397 & Siucahuito & Solanum wrightii & Solanaceae & \\
\hline 398 & Tabaco & Nicotiana tabacum & Solanaceae & Tobacco \\
\hline 399 & Tahuar piripiri & & & \\
\hline 400 & Tahuarí & Tabebuia chrysantha & Bignoniaceae & \\
\hline 401 & $\begin{array}{l}\text { Tahuarí } \\
\text { amarillo }\end{array}$ & Tabebuia serratifolia & Bignoniaceae & \\
\hline 402 & Tamamuri & Brosimum spp. & Moraceae & \\
\hline 403 & Tamara & Leonia glycicarpa & Violaceae & \\
\hline 404 & Tamara blanca & Crataeva tapia & Capparidaceae & \\
\hline 405 & Tamshi & Heteropsis spp. & Araceae & \\
\hline 406 & Tamshi delgado & Heteropsis jenmanii & Araceae & \\
\hline 407 & Tanbishi & & & \\
\hline 408 & Tangarana & Triplaris $s p$. & Fabaceae & \\
\hline 409 & Taperiba & Spondias cytherea & Anacardiaceae & \\
\hline 410 & Toé & Brugmansia spp. & Solanaceae & $\begin{array}{l}\text { Angel's } \\
\text { trumpet }\end{array}$ \\
\hline 411 & Toé blanco & & & \\
\hline 412 & Toé negro & Teliostachya lanceolata & Acanthaceae & \\
\hline 413 & Toé rojo & & & \\
\hline 414 & Tomate & Lycopersicum esculentum & Solanaceae & Tomato \\
\hline 415 & Topa & Ochroma pyrimidale & Bombacaceae & Balsa \\
\hline 416 & Tornillo & Cedreling a cataneiformis & Fabaceae & \\
\hline 417 & Toronja & Citrus paradisi & Rutaceae & Grapefruit \\
\hline 418 & Tortuga caspi & Duguetia spp. & Annonaceae & \\
\hline 419 & Torurco & $\begin{array}{l}\text { Digitaria insularis OR } \\
\text { Homolepis aturensis OR } \\
\text { Panicum pilosum OR } \\
\text { Paspalum conjugatum }\end{array}$ & Poaceae & \\
\hline 420 & $\begin{array}{l}\text { Trigo, Lagrima } \\
\text { de Job }\end{array}$ & Coix lacryma-jobi & Poaceae & Job's tear \\
\hline 421 & $\begin{array}{l}\text { Trompetero } \\
\text { sacha }\end{array}$ & Abuta spp. & Menispermaceae & \\
\hline 422 & Trujillo & Impatiens balsamina & Balsaminaceae & \\
\hline 423 & Ubilla & Pourouma cecropiaefolia & Moraceae & Grape tree \\
\hline 424 & Ubos & Spondias spp. & Anacardiaceae & \\
\hline 425 & Umarí & Pouraqueiba spp. & Icacinaceae & \\
\hline 426 & Umarí amarillo & Pouraqueiba spp. & Icacinaceae & \\
\hline
\end{tabular}




\begin{tabular}{|c|c|c|c|c|}
\hline \# & Spanish & Scientific & Family & English \\
\hline 427 & $\begin{array}{l}\text { Umari del } \\
\text { monte }\end{array}$ & Paypayrola grandiflora & Violaceae & \\
\hline 428 & Umarí negro & & & \\
\hline 429 & Uña de gato & Uncaria spp. & Rubiaceae & Cat's claw \\
\hline 430 & Ungurahui & Jessenia bataua & Arecaceae & \\
\hline 431 & Vaca shimbillo & & & \\
\hline 432 & Vanilla & Vanilla spp. & Orchidaceae & Vanilla \\
\hline 433 & Vara casha & Desmoncus spp. & Arecaceae & Rattan palm \\
\hline 434 & Verbena & Verbena littoralis & Verbenaceae & Verbena \\
\hline 435 & Verbena negra & & & \\
\hline 436 & Verdolaga & Portulaca oleracea & Portulacacae & Purslane \\
\hline 437 & Viejilla & & & \\
\hline 438 & Vino huayo & Coccoloba spp. & Polygonaceae & \\
\hline 439 & Waca & Clibadium surinamense & Asteraceae & \\
\hline 440 & Waquilla & & & \\
\hline 441 & Wira bijao & Calathea inocephala & Marantaceae & \\
\hline 442 & Yacuruna huito & Genipa spruceana & Rubiaceae & \\
\hline 443 & $\begin{array}{l}\text { Yacuruna } \\
\text { tamshi }\end{array}$ & & & \\
\hline 444 & Yacushapana & $\begin{array}{l}\text { Buchenavia fanshawei OR } \\
\text { Terminalia spp. }\end{array}$ & Combretaceae & \\
\hline 445 & Yagé & Psychotria spp. & Rubiaceae & \\
\hline 446 & Yagua piripiri & & & \\
\hline 447 & Yahuar piri piri & Eleutherine bulbosa & Iridaceae & \\
\hline 448 & Yana vara & $\begin{array}{l}\text { Aparisthmium cordatum } \\
\text { (Euphorbiaceae) OR } \\
\text { Pollalesta discolor } \\
\text { (Asteraceae) }\end{array}$ & & \\
\hline 449 & Yarina & Phytelephas macrocarpa & Arecaceae & Ivory palm \\
\hline 450 & $\begin{array}{l}\text { Yerba Luisa, } \\
\text { Zacate de limón }\end{array}$ & Cymbopogon citratus & Poaceae & $\begin{array}{l}\text { Lemon } \\
\text { grass }\end{array}$ \\
\hline 451 & Yerba santa & & & Saint herb \\
\hline 452 & Yuca & Manihot esculenta & Euphorbiaceae & Manioc \\
\hline 453 & $\begin{array}{l}\text { Yuca amarillo } \\
\text { (variety) }\end{array}$ & & & Manioc \\
\hline 454 & $\begin{array}{l}\text { Yuca blanco } \\
\text { (variety) }\end{array}$ & & & Manioc \\
\hline
\end{tabular}




\begin{tabular}{|c|l|l|l|l|}
\hline$\#$ & \multicolumn{1}{|c|}{ Spanish } & \multicolumn{1}{|c|}{ Scientific } & \multicolumn{1}{c|}{ Family } & English \\
\hline 455 & Yute & $\begin{array}{l}\text { Urena lobata } \text { var. } \\
\text { Reticulata }\end{array}$ & Malvaceae & Jute \\
\hline 456 & Yutubanco & $\begin{array}{l}\text { Heisteria } \text { iquitensis } \\
\text { (Olaceaceae) OR Rinorea } \\
\text { racemosa (Violaceae) }\end{array}$ & Cucurbitaceae & \\
\hline 457 & Zapallito & Gurania spinulosa & Cucurbitaceae & $\begin{array}{l}\text { Pumpkin, } \\
\text { Squash }\end{array}$ \\
\hline 458 & Zapallo & Cucurbita spp. & & \\
\hline & \multicolumn{4}{|l}{$\begin{array}{l}\text { *All scientific names on this list are approximations since plants } \\
\text { were not identified using voucher specimens. }\end{array}$} \\
\hline
\end{tabular}




\section{Appendix 5: Ranked List of All Community Top Ten Medicinal Plants}

\begin{tabular}{|c|c|c|}
\hline Rank & Plant & $\begin{array}{l}\text { Chaumeil Listed } \\
\text { as Medicinal }\end{array}$ \\
\hline 1 & Mucura & $\mathrm{x}$ \\
\hline 2 & Ajo Sacha/Sacha Ajo & $\mathrm{x}$ \\
\hline 3 & Lancetilla & $\mathrm{x}$ \\
\hline 4 & Algodón & \\
\hline 5 & Huito & \\
\hline 6 & Rosasisa & \\
\hline 7 & Malva & $\mathrm{x}$ \\
\hline 8 & Toronja & \\
\hline 9 & Ajengibre/Jengibre & \\
\hline 10 & Orégano & \\
\hline 11 & Piripiri & $\mathrm{x}$ \\
\hline 12 & Guayaba & $\mathrm{x}$ \\
\hline 13 & Yahuar Piri Piri & \\
\hline 14 & Toé & $\mathrm{x}$ \\
\hline 15 & Chuchuasha/Chuchuhuasi & \\
\hline 16 & Albaca/Albahaca & \\
\hline 17 & Limón & $\mathrm{x}$ \\
\hline 18 & Achote/Achiote & \\
\hline 19 & Ubos & \\
\hline 20 & Guava & \\
\hline 21 & Ungurahui & \\
\hline 22 & Chiric Sanango & \\
\hline 23 & Azúcar Huayo & \\
\hline 24 & Culantro/Cilantro & $\mathrm{x}$ \\
\hline 25 & Cañagre & \\
\hline 26 & Piñon & \\
\hline 27 & Sanango & $\mathrm{x}$ \\
\hline 28 & Llantén & \\
\hline 29 & Gallinazo Panga & \\
\hline 30 & Colmeno & \\
\hline 31 & Motelo Sanango & \\
\hline 32 & Cacao & \\
\hline 33 & Aranilla & \\
\hline 34 & Mullaca & \\
\hline 35 & Manzana & \\
\hline 36 & Trompetero & \\
\hline 37 & Abuta & \\
\hline
\end{tabular}




\begin{tabular}{|l|l|c|}
\hline Rank & \multicolumn{1}{|c|}{ Plant } & $\begin{array}{c}\text { Chaumeil Listed } \\
\text { as Medicinal }\end{array}$ \\
\hline 38 & Doctor Caspi & \\
\hline 39 & Amor Seco & \\
\hline 40 & Jergon Sacha & \\
\hline 41 & Matacaracha & \\
\hline 42 & Remo Caspi & \\
\hline 43 & Caimito & \\
\hline 44 & Granadilla/Tumbo \\
\hline 45 & Tabaco & \\
\hline 46 & Huingo & \\
\hline 47 & Suelda con Suelda/Pishco \\
\hline 48 & Isma & \\
\hline 49 & Huacapurana & \\
\hline 50 & Santa Maria & \\
\hline 51 & Jetico & \\
\hline 52 & Coco & \\
\hline 53 & Cumala & \\
\hline 54 & Piñon Rojo & \\
\hline 55 & Paichecara & \\
\hline 56 & Sauco & \\
\hline 57 & Verdolaga & \\
\hline 58 & Cedro & \\
\hline 59 & Piñon Colorado & \\
\hline Total & $\mathbf{5 9}$ & \\
\hline & & \\
\hline
\end{tabular}




\section{Appendix 6: Uses for Medicinal Plants: All Symptoms, Plants, and Mentions}

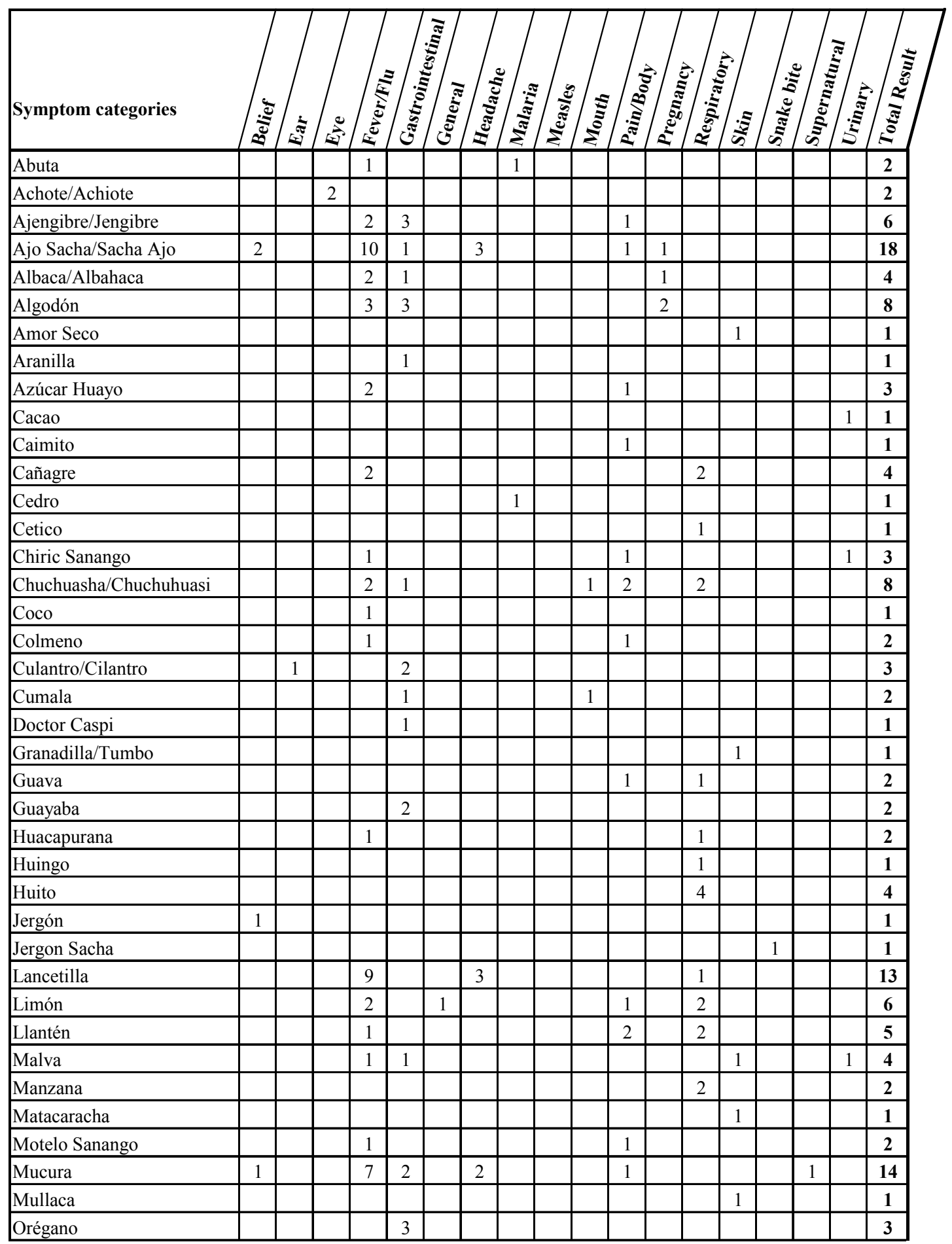




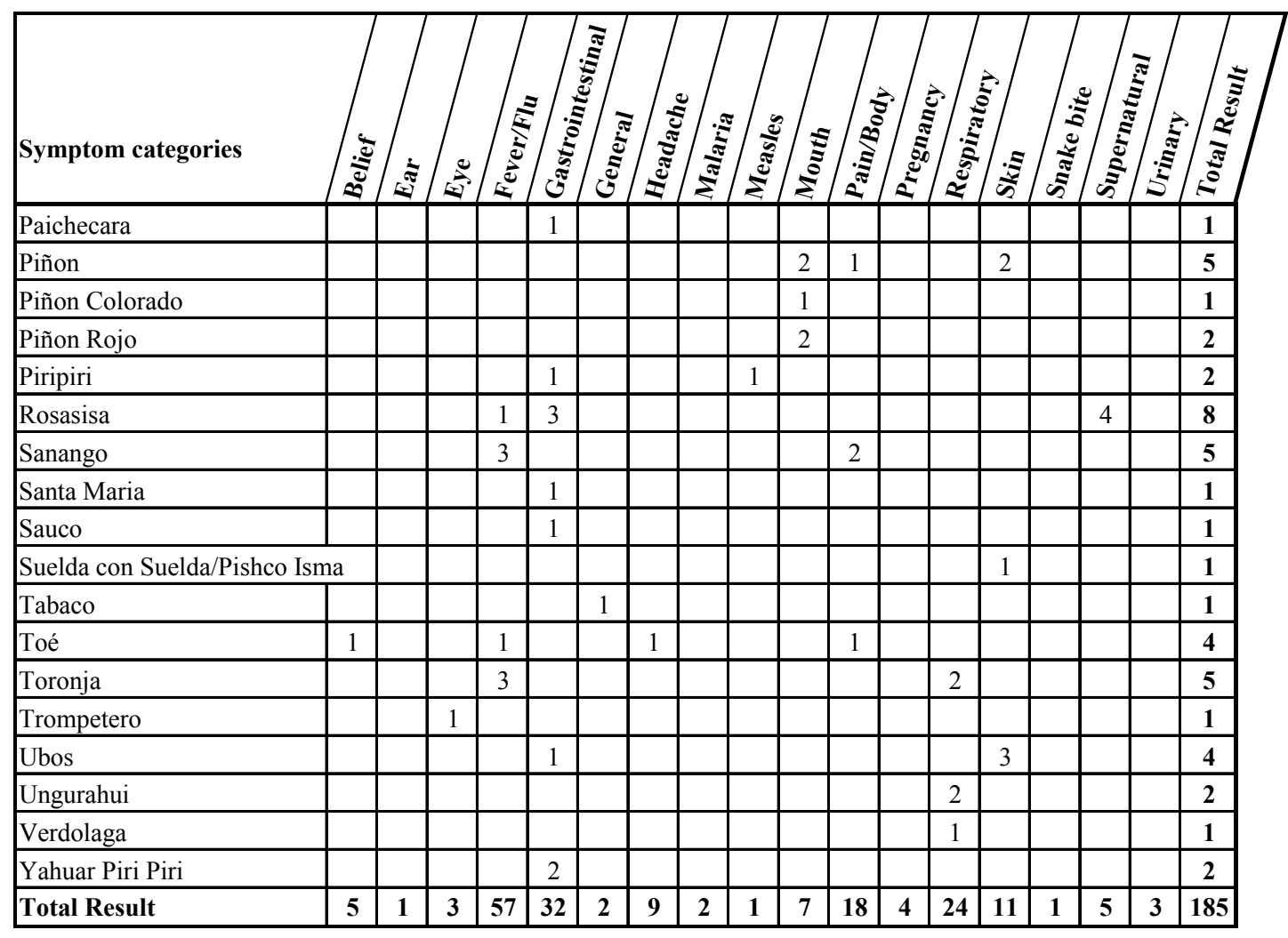




\section{Appendix 7: Symptom Categories}

\begin{tabular}{|l|l|}
\hline \multicolumn{1}{|c|}{ Belief } \\
\hline Botar la saladera & To get rid of bad luck \\
\hline $\begin{array}{l}\text { Para que los bijuntos y el } \\
\text { tunchi no acercen }\end{array}$ & $\begin{array}{l}\text { To keep ghosts and spirits } \\
\text { away }\end{array}$ \\
\hline $\begin{array}{l}\text { Para ver ladrones } \\
\text { thief was }\end{array}$ \\
\hline $\begin{array}{l}\text { Para que la culebra no } \\
\text { muerde }\end{array}$ & To avoid snakebite \\
\hline
\end{tabular}

\begin{tabular}{|l|l|}
\hline \multicolumn{2}{|c|}{ Fever/Flu } \\
\hline Gripe & Flu \\
\hline Botar el frío & Get rid of cold \\
\hline Fiebre & Fever \\
\hline Resfrío & Have a cold \\
\hline Frío & To be cold \\
\hline Fresco & To refresh \\
\hline
\end{tabular}

\begin{tabular}{|l|l|}
\hline \multicolumn{2}{|c|}{ General } \\
\hline Cualquier & Any [illness $]$ \\
\hline
\end{tabular}

\begin{tabular}{|c|c|}
\hline \multicolumn{2}{|c|}{ Headache } \\
\hline Dolor de cabeza (fuerte & Headache (strong) \\
\hline
\end{tabular}

\begin{tabular}{|l|l|}
\hline \multicolumn{1}{|c|}{ Measles } \\
\hline Sarampión & Measles \\
\hline
\end{tabular}

\begin{tabular}{|l|l|}
\hline \multicolumn{2}{|c|}{ Pain/Body } \\
\hline Artritis & Arthritis \\
\hline Reumatismo & Reumatism \\
\hline Dolor de hueso & Bone pain \\
\hline Dolor de cuerpo & Body pain \\
\hline Herridas adentro & Inside wounds \\
\hline Dolor & Pain \\
\hline Calmar el cuerpo & To calm the body \\
\hline
\end{tabular}

\begin{tabular}{|l|l|}
\hline \multicolumn{2}{|c|}{ Respiratory } \\
\hline Bronquitis & Bronquitis \\
\hline Pulmon & Lung \\
\hline Bronquios & Broncios \\
\hline Tos & Cough \\
\hline
\end{tabular}

\begin{tabular}{|l|c|}
\hline \multicolumn{2}{|c|}{ Supernatural Causes } \\
\hline Choque de aire & $\begin{array}{c}\text { Vomiting and illness in } \\
\text { children caused by an } \\
\text { encounter with a ghost or } \\
\text { Mal aire }\end{array}$ \\
\cline { 1 - 2 } Choque de mal aire & spirit \\
\hline
\end{tabular}

\begin{tabular}{|l|l|}
\hline & Urinary \\
\hline Infección úrinario & Urinary infection \\
\hline Riñones & Kidneys \\
\hline
\end{tabular}

\begin{tabular}{|c|c|}
\hline \multicolumn{2}{|c|}{$\underline{\text { Ear }}$} \\
\hline Dolor de oido & Ear ache \\
\hline \multicolumn{2}{|c|}{ Eye } \\
\hline Dolor de ojo & Eye pain \\
\hline
\end{tabular}

\begin{tabular}{|l|l|}
\hline \multicolumn{2}{|c|}{ Gastrointestinal } \\
\hline Vómito & Vomiting \\
\hline Diarrea & Diarrhea \\
\hline Dolor de estómago & Stomachache \\
\hline Malestar de estómago & Ill feeling in the stomach \\
\hline Barriga hinchada & Swollen stomach \\
\hline Para limpiar el estómago & To clean the stomach \\
\hline Infección intestinal & Intestinal infection \\
\hline Pujo (sangre en la caca) & Blood in stool \\
\hline Cólico & Colic \\
\hline Cholera & Cholera \\
\hline
\end{tabular}

\begin{tabular}{|l|l|}
\hline \multicolumn{2}{|c|}{ Malaria } \\
\hline Malaria & Malaria \\
\hline \multicolumn{2}{|l|}{} \\
\hline \multicolumn{2}{|c|}{ Mouth } \\
\hline Pático & Sores in mouth \\
\hline Pático blanco & White sores in mouth \\
\hline Pático rojo & Red sores in mouth \\
\hline Boca & Mouth \\
\hline
\end{tabular}

\begin{tabular}{|l|l|}
\hline \multicolumn{2}{|c|}{ Pregnancy/Childbirth } \\
\hline Durante el embarazo & During pregnancy \\
\hline Dolor antes de dar la luz & Pain before giving birth \\
\hline Para dar luz & To give birth \\
\hline Parto & Childbirth \\
\hline
\end{tabular}

\begin{tabular}{|l|l|}
\hline \multicolumn{2}{|c|}{ Snakebite } \\
\hline Mordida de culebra & Snakebite \\
\hline
\end{tabular}

\begin{tabular}{|l|l|}
\hline \multicolumn{2}{|c|}{ Skin } \\
\hline Corte & Cut \\
\hline Cortado & Cut \\
\hline Herrida & Wound \\
\hline Infección & Infection \\
\hline Irritación & Irritation \\
\hline Parte hinchada & Swollen area \\
\hline
\end{tabular}




\section{Appendix 8: Specific Material Needs}

After some tourists had brought gifts and things to trade, some of which were perhaps more useful and relevant to their lives than others, I asked people if they wanted to create a list of things that they need in order of priority. The president said: "We as a community, as owners of our village, we should make a list to give to them, because they

don't know the problems that we have. They don't know what we need."324 In a meeting open to the community, I guided them in free-listing things that they need. Then they put all those items into categories by type, and then prioritized those categories. Here are the results of that method:

1. clothing for children, women, and men (shirts (including long sleeved), pants, underwear, skirts, caps), boots, shoes, toys for kids, and mosquito nets

2. knives, spoons, forks, plates, and bowls

3. batteries, fishing line, and hooks

4. brushes, scissors for hair and cloth

5. different sized saws for cutting wood and crafts, hammers, machetes

The teachers created a prioritized list for the school as well:

1. medical kit

2. pencils, erasers, crayons, pens, markers, paper, notebooks (lines and graphic), construction paper, chalk, large board, pencil sharpeners

3. books in Spanish (sciences, history, etc.), encyclopedia, teacher's books

4. soccer ball and volley ball

I repeated the method of free-listing material needs in a women's focus group. These results are not grouped or prioritized because the focus group took place in a home with no blackboard. The women mentioned: clothing for children, women, and men; school supplies including notebooks, pencils, paper, and erasers; spoons, plates, serving spoons, pots, cups, pitchers; kids soccer shoes; hooks and line; soccer and volley balls; toothbrushes; large bedsheets; saws, hammers, knives, machetes; craft supplies, carving 
tools; pills for fever and pain; bath towels; conjunctivitis eye drops; scissors for hair and cloth; sandals and flip-flops; socks and underwear; laundry soap and ivory soap (floats); batteries; and matches. They also mentioned that clothing brought for them is often too large, and that donations should be distributed equally throughout the community.

These results identify their specific material needs, and these methods could be repeated to quantify economic needs if needed for a future project. In addition to the materials needed to build fish ponds and to raise animals, in a focus group discussing projects and needs, the president said he would like cultivating equipment for the community. The teacher said that tourists should help to fund school breakfasts, and that it would be nice to have a sign for the front of the school with its name on it.

324 "Nosotros como comúnidad, como dueños de nuestro pueblo, debemos hacer una lista para entregarle a ellos, porque ellos no saben la problemática que nosotros pasamos. No saben lo que nosotros necesitamos." 